\author{
UNIVERSIDADE DE SÃO PAULO \\ FACULDADE DE CIÊNCIAS FARMACÊUTICAS \\ Programa de Pós-Graduação em Fármaco e Medicamentos \\ Área de Produção e Controle Farmacêuticos
}

\title{
Desenvolvimento e estudo de eficácia clínica por métodos instrumentais de bases de uso tópico contendo extrato de soja fermentado
}

\author{
Rafael Pinto Vieira
}

Dissertação para obtenção do grau de MESTRE Orientadora:

Prof $^{a}$. Dr ${ }^{a}$. M. Valéria Robles Velasco

São Paulo

2008 
Rafael Pinto Vieira

Desenvolvimento e estudo de eficácia clínica por métodos instrumentais de bases de uso tópico contendo extrato de soja fermentado

\author{
Comissão Julgadora \\ da \\ Dissertação para obtenção do grau de Mestre
}

Prof. ${ }^{\stackrel{a}{ }}$ Dr. ${ }^{\underline{a}}$ Maria Valéria Robles Velasco

orientador/presidente

Prof. ${ }^{\text {a }}$ Dr. ${ }^{\underline{a}}$ Patrícia Maria Berardo Maia Campos

$1^{\circ}$ examinador

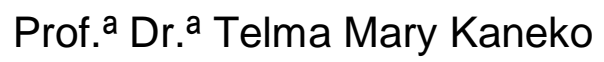

2e examinador

São Paulo, 28 de outubro de 2008 


\section{RESUMO}

Máscaras faciais são preparações cosméticas utilizadas desde a Antigüidade e, atualmente, têm seu uso difundido em função de suas características multifuncionais. Dentre os efeitos atribuídos a estas preparações, temos: limpeza profunda; ações tonificante, adstringente, hidratante e tensora na pele e sensação de bem-estar. Podem ser classificadas conforme sua aplicação, componentes ou grau de risco. As máscaras peel off à base de álcool polivinílico são formulações que, após a aplicação e secagem, formam um filme oclusivo sobre a face e, após sua remoção, conferem maciez, limpeza e ação tensora à pele, retirando células mortas do estrato córneo, resíduos e outros materiais depositados. O extrato de soja obtido pela fermentação do leite de soja pelo Bifidobacterium animale possui açúcares, aminoácidos, peptídeos, proteínas e alto teor de isoflavonas na forma livre, quando comparado ao leite não fermentado. Seu uso em formulações cosméticas visa combater os efeitos do envelhecimento cutâneo, propiciando hidratação, efeito tensor e emoliência à pele. Bases cosméticas de máscaras faciais peel off e emulsão óleo em água, acrescidas ou não de extrato de soja fermentado $5 \% \mathrm{p} / \mathrm{p}$ foram avaliadas em estudos de estabilidade física e físico-química em diversas condições de temperatura e períodos de avaliação, visando obter as de melhor desempenho para estudos clínicos. Os resultados indicaram que as preparações aditivadas com o extrato mantiveram-se estáveis quanto às suas características nos testes de estabilidade, não apresentando variações significativas. As preparações foram submetidas aos estudos clínicos em voluntários com o objetivo de avaliar seus efeitos tensor, na hidratação e na perda de água transepidérmica. Os resultados comprovaram que, em um estudo cinético, a base cosmética de máscara facial peel off, contendo ou não o extrato de soja fermentado, não apresentou diferença estatisticamente significativa para as formulações de emulsão quantos à promoção de elasticidade e firmeza à pele e diminuição da perda de água transepidérmica, mas promoveu maior hidratação das camadas superficiais da pele que as preparações de emulsão óleo em água.

Palavras-chave: máscara facial; álcool polivinílico; extrato de soja; hidratação 


\section{ABSTRACT}

\section{Development and clinical studies using instrumental methods of topical formulations containing fermented soybean extract}

Facial masks are used since antiquity and, currently, its use has spread according to their multifunctional characteristics. Among the effects attributed to these preparations there are deep cleaning; invigorating, stringent, moisturizing and tensor actions and well-being sense. They can be classified according to their application, components or risk degree. Peel off facial masks based on polyvinyl alcohol are formulations that form a film on the face after application and drying. After their removal, they cause tenderness, cleaning and tensor action on the skin, removing dead cells of the stratum corneum other materials deposited. Soybean extract obtained from soymilk fermentation by Bifidobacterium animale has sugars, amino acids, peptides, proteins and high levels of free isoflavones, when compared to nonfermented milk. Its use in cosmetic formulations aims to avoid aging effects on skin, providing moisturizing, softness and tensor effect. Peel off facial masks and emulsions oil in water preparations, containing or not fermented soymilk $5 \% \mathrm{w} / \mathrm{w}$ were evaluated in physical and physical-chemistry stability studies in various temperature and time conditions, targeting the best formulations for clinical tests. Results indicated that preparations containing extract remained stable about their characteristics, showed no significant variations. Preparations were submitted to clinical studies in volunteers to evaluate tensor, moisturizing and transepidermal water loss effects. In a short-term study, results confirmed that peel off facial masks formulations, containing or not soybean fermented extract, showed no statistically significant difference in comparison to emulsion formulations on elasticity and firmness promotion and decreasing on transepidermal water loss. However, peel off facial masks provided greater hydration on skin surface layers than the oil in water emulsion preparations.

Keywords: peel off facial mask; polyvinyl alcohol; soybean fermented extract; moisturizing 


\section{Agradecimento especial}

Agradeço à minha orientadora, Prof. ${ }^{a}$ Dr. ${ }^{\text {a }}$ Maria Valéria Robles Velasco, pelo empenho e auxílio na realização de todos os trabalhos que desenvolvi ao longo deste projeto 


\section{AGRADECIMENTOS}

Agradeço e dedico aos meus pais, Francisco Dornas Vieira e Maria da Conceição Pinto Vieira, pela dedicação e exemplos de honestidade, amor e amizade.

Aos meus irmãos Eliane, Heloisa, Maria Inês, Márcia, Francisco e aos meus sobrinhos Nathália, Gabriel, Augusto e Marina. Formamos uma família grande e uma grande família.

Aos meus grandes amigos Bernardo, Bruno, Marcelo, Leonardo, Luis Osório, Pablo e Wendel. Sempre alimentamos amizades saudáveis. E sempre soubemos aproveitar os bons momentos de festa e nos apoiarmos nos momentos difíceis.

A todos os colegas do laboratório e do Mestrado, que tornaram o trabalho durante 0 projeto mais prazeroso e contribuíram para o meu crescimento profissional.

À Claudinéia Pinto, técnica do laboratório de Farmacotécnica, pelo suas enormes qualidades, que influenciam direta e positivamente na qualidade do trabalho de todos no Laboratório de Farmacotécnica. Sua paciência, competência, compreensão e dedicação são singulares.

À Vivian Zague, colega no Mestrado. Trata-se de uma grande profissional cujo conhecimento contribuiu em várias etapas deste trabalho, além de seu bom humor e amizade inigualáveis.

Às estagiárias Alessandra, Débora, Fernanda e Lívia, sem as quais a conclusão deste trabalho seria inviável.

A todos os funcionários e professores da USP cujas atividades influenciaram direta ou indiretamente este projeto. Graças a eles, pude vivenciar com intensidade a USP, como grande instituição que é.

À EVIC Brasil e todos os seus funcionários, principalmente à Sra. Idalina Maria Nunes Salgado Reis dos Santos, Dra. Carla Goulart Perón e Juliana Salles 
Moscardi, que propiciaram a realização deste trabalho e com quem trabalhei e pude vivenciar excelentes experiências profissionais e pessoais.

À Statistika Consultoria e seus funcionários que, com competência, possibilitaram a realização da análise estatística dos resultados deste trabalho.

Ao Cristália Produtos Químicos Farmacêuticos e a todos os amigos e profissionais que lá conheci. Foi esta empresa que me trouxe a São Paulo e com a qual pude aprender a trabalhar.

A São Paulo, uma cidade que nos seduz. As pessoas e lugares que conheci e às experiências que vivi nesta cidade única no Brasil e do mundo, que hoje compõem uma importante parte do mosaico que sou. 


\section{SUMÁRIO}

LISTA DE FIGURAS

Página

LISTAS DE QUADROS

LISTA DE TABELAS

17

I - INTRODUÇÃO

18

II - REVISÃO DA LITERATURA 25

1 PELE 26

1.1 Constituição 26

1.2 Hidratação da pele $\quad 29$

$\begin{array}{ll}1.3 \text { Elasticidade da pele } & 30\end{array}$

2 MÁSCARAS FACIAIS 31

2.1 História 31

2.2 Mercado atual 31

2.3 Usos e classificação $\quad 34$

2.4 Máscaras faciais peel off $\quad 37$

2.5 Substâncias ativas utilizadas nas máscaras faciais 38

3 ÁLCOOL POLIVINÍLICO (PVA) 39

4 EXTRATO DE SOJA

5 ESTABILIDADE DE PRODUTOS COSMÉTICOS 42

6 AVALIAÇÃO INSTRUMENTAL 44

6.1 Corneometria $\quad 45$

6.2 Determinação da perda de água transepidérmica 47

$\begin{array}{ll}6.3 \text { Cutometria } & 48\end{array}$

III - OBJETIVOS 52

IV - MATERIAL E MÉTODOS

1 MATERIAL $\quad 55$

1.1 Reagentes (grau de pureza analítico, P.A.) 55

1.2 Matérias-primas (grau de pureza farmacêutico) 55

1.3 Equipamentos $\quad 66$

$\begin{array}{ll}1.4 \text { Outros materiais } & 66\end{array}$ 
1.5 Descrição quali e quantitativa das bases de máscara facial peel

off e pré formulações de emulsão

2 MÉTODOS

74

2.1 Preparo das bases de máscaras faciais peel off 74

2.2 Preparo da base e da formulação de emulsão 74

2.3 Estudo de Estabilidade Preliminar (EP) 75

2.3.1 Condições para Avaliação - Estudo de Estabilidade

Preliminar

2.3.1.1 Centrifugação 76

2.3.1.2 Estresse térmico $\quad 76$

2.3.1.3 Estufa a $50^{\circ} \mathrm{C} / 72$ horas $\quad 76$

2.3.2 Variáveis analisadas $\quad 76$

2.3.2.1 Características organolépticas $\quad 76$

2.3.2.2 Valor de $\mathrm{pH} \quad 78$

2.3.2.3 Teste de secagem e formação de filme 78

2.4 Estudo de Estabilidade Preliminar (EP) - formulações de máscaras faciais

78

2.5 Estudo de Estabilidade Acelerada (EA) 81

2.5.1 Condições do teste 81

2.5.1.1 Geladeira $(5,0 \pm 1,0 \stackrel{\circ}{-})$

2.5.1.2 Freezer $\left(-10 \pm 1,0^{\circ} \mathrm{C}\right)$

2.5.1.3 Temperatura ambiente $\left(22,0 \pm 2,0^{\circ} \mathrm{C}\right)$

2.5.1.4 Estufa $(45,0 \pm 2,0 \stackrel{\circ}{\circ})$

2.5.1.5 Ciclos gela e degela $\left(45,0 \pm 2,0^{\circ} \mathrm{C} /-5,0 \pm 2,0^{\circ} \mathrm{C}\right)$

2.5.2 Variáveis analisadas $\quad 82$

2.5.2.1 Características organolépticas 82

2.5.2.2 Valor de $\mathrm{pH} \quad 83$

2.5.2.3 Viscosidade aparente 83

2.5.2.4 Tempo de secagem e formação de filme 83

2.6 Testes Clínicos - Sujeitos $\quad 84$

2.6.1 Desenho do estudo $\quad 84$

2.6.2 Tipo do estudo $\quad 84$

2.6.3 Centro de investigação $\quad 84$ 
2.6.4 Cronograma de realização do estudo 84

2.6.5 Ética em pesquisa $\quad 85$

2.6.6 Amostra $\quad 85$

2.6.6.1 Critérios específicos de inclusão dos voluntários no estudo

85

2.6.6.2 Critérios específicos de não-inclusão dos voluntários no estudo

86

2.6.6.3 Riscos mínimos previstos para o estudo $\quad 87$

2.6.7 Aplicação das formulações $\quad 87$

2.6.8 Avaliação instrumental $\quad 91$

2.6.8.1 Efeito de hidratação das camadas superiores da pele

91

2.6.8.2 Efeito da perda de água transepidérmica 92

2.6.8.3 Efeito na elasticidade e na firmeza da pele $\quad 92$

2.6.9 Análise estatística dos dados 92

V - RESULTADOS E DISCUSSÃO 94

1 Teste de Estabilidade Preliminar (EP) 95

1.1 Bases de máscaras faciais peel off 95

1.1.1 Características organolépticas e valor de $\mathrm{pH} \quad 95$

1.1.2 Tempo de secagem e formação de filme 103

1.2 Adequação da base F35 e Estudo de Estabilidade Preliminar $\quad 104$

1.2.1 Características organolépticas e valor de pH 104

1.2.2 Tempo de secagem e formação de filme 107

1.3 Base da emulsão óleo em água 108

2 Estudo de Estabilidade Acelerada $\quad 110$

2.1 Variáveis analisadas nas formulações F35/17G e F35/18 110

2.2 Variáveis analisadas na formulação de emulsão óleo em água contendo extrato de soja fermentado

3 Testes clínicos

3.1 Dados obtidos nas medidas instrumentais $\quad 131$

3.2 Análise estatística dos dados 143

3.2.1 Efeito na firmeza e elasticidade da pele 143

3.2.2 Efeito na perda de água transepidérmica 149 
3.2.3 Efeito no aumento da hidratação da pele

VI - CONCLUSÕES

VII - REFERÊNCIAS BIBLIOGRÁFICAS

VIII - ANEXOS

1 Carta do Comitê de Ética

2 Termo de Consentimento Livre e Esclarecido - Voluntários 


\section{LISTA DE FIGURAS}

Figura 1. Estrutura esquemática dos principais componentes da pele. Página 27.

Figura 2. Estrutura esquemática das principais camadas (estratos) da epiderme. Página 28.

Figura 3. Remoção mecânica de máscaras faciais peel off, após secagem. Página 38.

Figura 4. Fórmula estrutural do álcool polivinílico (PVA), onde $n$ varia de 500 a 5000 (grau de polimerização). Página 40.

Figura 5. Deformação da pele avaliado por Cutometer $^{\circledR}$ SEM 575 (Courage and Khazaka). Página 50.

Figura 6. Locais de aplicação das formulações nos voluntários. Página 89.

Figura 7. Tempo de secagem ( $\mathrm{min}$ ) das bases 1 a 36 (média da triplicata) em estufa $\left(36,5 \pm 1,0^{\circ} \mathrm{C}\right)$. Página 103.

Figura 8. Tempo de secagem ( $\mathrm{min}$ ) das formulações obtidas a partir das modificações na de máscara facial peel off F35 (média da triplicata), na condição de estufa $\left(36,5 \pm 1,0^{\circ} \mathrm{C}\right)$. Página 107.

Figura 9. Variação percentual do valor de $\mathrm{pH}$ para as formulações $F 35 / 18$ e F35/17G na condição de armazenamento em estufa (45,0 $\pm 2,0 \stackrel{\circ}{\circ} \mathrm{C})$, durante $\mathrm{O}$ Estudo de Estabilidade Acelerada. Página 112.

Figura 10. Variação percentual do valor de $\mathrm{pH}$ para as formulações $F 35 / 18$ e F35/17G nas condições de armazenamento em Geladeira ( $\mathrm{Ge}-5,0 \pm 1,0{ }^{\circ} \mathrm{C}$ ), Freezer $\left(\mathrm{F}--10,0 \pm 1,0^{\circ} \mathrm{C}\right)$ e Temperatura Ambiente $\left(\mathrm{TA}-22,0 \pm 2,0^{\circ} \mathrm{C}\right)$ no Estudo de Estabilidade Acelerada. Página 113. 
Figura 11. Variação percentual do valor de $\mathrm{pH}$ para as formulações-teste F35/18 e F35/17G na condição de armazenamento Ciclos gela e degela $\left(45,0 \pm 2,0{ }^{\circ} \mathrm{C} /-10,0\right.$ $\left.\pm 1,0^{\circ} \mathrm{C}\right)$ no Estudo de Estabilidade Acelerada. Página 114.

Figura 12. Variação percentual do valor de viscosidade para as formulações $F 35 / 18$ e F35/17G na condição de armazenamento em estufa $(45,0 \pm 2,0 \stackrel{\circ}{\circ}$ ) no Estudo de Estabilidade Acelerada. Página 115.

Figura 13. Variação percentual do valor de viscosidade para as formulações $F 35 / 18$ e F35/17G nas condições de armazenamento em Geladeira ( $\mathrm{Ge}-5,0 \pm 1,0{ }^{\circ} \mathrm{C}$ ), Freezer $\left(\mathrm{F}--10,0 \pm 1,0{ }^{\circ} \mathrm{C}\right)$ e Temperatura Ambiente (TA $-22,0 \pm 2,0{ }^{\circ} \mathrm{C}$ ) no Estudo de Estabilidade Acelerada. Página 116.

Figura 14. Variação percentual do valor de viscosidade para as formulações $F 35 / 18$ e F35/17G na condição de armazenamento Ciclos gela e degela $\left(45,0 \pm 2,0{ }^{\circ} \mathrm{C} /\right.$ $10,0 \pm 1,0 \stackrel{\circ}{\mathrm{C}}$ ) no Estudo de Estabilidade Acelerada. Pagina 114.

Figura 15. Variação percentual do tempo de secagem para as formulações-teste $\mathrm{F} 35 / 18$ e $\mathrm{F} 35 / 17 \mathrm{G}$ na condição de armazenamento estufa $\left(45,0 \pm 2,0{ }^{\circ} \mathrm{C}\right)$, geladeira $\left(\mathrm{Ge}-5,0 \pm 1,0{ }^{\circ} \mathrm{C}\right)$, freezer $\left(\mathrm{F}--10,0 \pm 1,0^{\circ} \mathrm{C}\right)$ e temperatura ambiente $(\mathrm{TA}-22,0 \pm$ 2,0 ${ }^{\circ} \mathrm{C}$ ) no Estudo de Estabilidade Acelerada. As variações são decorrentes da diferença obtida do $15^{\circ}$ dia para t0, em todas as condições. Página 118.

Figura 16. Variação percentual do valor de $\mathrm{pH}$ para a formulação de emulsão contendo extrato de soja fermentado por Bifidobacterium animale na condição de armazenamento em estufa $(45,0 \pm 2,0 \stackrel{\circ}{\circ})$, durante o Estudo de Estabilidade Acelerada. Página 124.

Figura 17. Variação percentual do valor de pH para a formulação de emulsão contendo extrato de soja fermentado por Bifidobacterium animale nas condições de armazenamento em Geladeira $\left(\mathrm{Ge}-5,0 \pm 1,0{ }^{\circ} \mathrm{C}\right)$, Freezer $\left(\mathrm{F}--10,0 \pm 1,0{ }^{\circ} \mathrm{C}\right)$ e 
Temperatura Ambiente (TA $-22,0 \pm 2,0{ }^{\circ} \mathrm{C}$ ) no Estudo de Estabilidade Acelerada. Página 125.

Figura 18. Variação percentual do valor de $\mathrm{pH}$ para a formulação de emulsão contendo extrato de soja fermentado por Bifidobacterium animale na condição de armazenamento Ciclos gela e degela $(45,0 \pm 2,0 \stackrel{\circ}{\circ} /-10,0 \pm 1,0 \stackrel{\circ}{C})$ no Estudo de Estabilidade Acelerada. Página 118.

Figura 19. Variação percentual do valor de viscosidade para a formulação de emulsão contendo extrato de soja fermentado por Bifidobacterium animale na condição de armazenamento em estufa $\left(45,0 \pm 2,0{ }^{\circ} \mathrm{C}\right)$ no Estudo de Estabilidade Acelerada. Página 127.

Figura 20. Variação percentual do valor de viscosidade para a formulação de emulsão contendo extrato de soja fermentado por Bifidobacterium animale nas condições de armazenamento em Geladeira $\left(G e-5,0 \pm 1,0^{\circ} \mathrm{C}\right)$, Freezer $(F--10,0 \pm$ $1,0{ }^{\circ} \mathrm{C}$ ) e Temperatura Ambiente $\left(\mathrm{TA}-22,0 \pm 2,0^{\circ} \mathrm{C}\right.$ ) no Estudo de Estabilidade Acelerada. Página 128.

Figura 21. Variação percentual do valor de viscosidade para a formulação de emulsão contendo extrato de soja fermentado por Bifidobacterium animale na condição de armazenamento Ciclos gela e degela $\left(45,0 \pm 2,0{ }^{\circ} \mathrm{C} /-10,0 \pm 1,0{ }^{\circ} \mathrm{C}\right)$ no Estudo de Estabilidade Acelerada. Página 129.

Figura 22. Fotografias das manifestações (dermatite atópica) dos voluntários após aplicação e retirada da formulação de máscara facial peel off sem extrato de soja fermentado por Bifidobacterium animale. Os pontos azuis delimitam a área de aplicação do produto. Página 141.

Figura 23. Fotografias das manifestações (dermatite atópica) dos voluntários após aplicação e retirada da formulação de máscara facial peel off com extrato de soja fermentado por Bifidobacterium animale. Os pontos azuis delimitam a área de aplicação do produto. Página 142. 
Figura 24. Variação da estimativa - após tratamento estatístico dos dados brutos do valor de M1 (deformação final ou extensibilidade máxima) em relação ao tempo para as formulações de emulsão, contendo ou não extrato de soja fermentado por Bifidobacterium animale (com e sem, respectivamente). Página 145.

Figura 25. Variação da estimativa - após tratamento estatístico dos dados brutos do valor de M1 (deformação final ou extensibilidade máxima) em relação ao tempo para as formulações de máscara facial contendo ou não extrato de soja fermentado por Bifidobacterium animale (com e sem, respectivamente). Página 146.

Figura 26. Variação da estimativa - após tratamento estatístico dos dados brutos do valor de M2 (deformação resultante em comparação com o valor inicial) em relação ao tempo para as formulações de emulsão contendo ou não extrato de soja fermentado por Bifidobacterium animale (com e sem, respectivamente). Página 147.

Figura 27. Variação da estimativa - após tratamento estatístico dos dados brutos do valor de M2 (deformação resultante em comparação com o valor inicial) em relação ao tempo para as formulações de máscara facial contendo ou não extrato de soja fermentado por Bifidobacterium animale (com e sem, respectivamente). Página 148.

Figura 28. Variação da estimativa - após tratamento estatístico dos dados brutos do valor de TEWL (perda de água transepidérmica) em relação ao tempo para as formulações de emulsão contendo ou não extrato de soja fermentado por Bifidobacterium animale (com e sem, respectivamente). Página 151.

Figura 29. Variação da estimativa - após tratamento estatístico dos dados brutos do valor de TEWL (perda de água transepidérmica) em relação ao tempo para as formulações de máscara facial contendo ou não extrato de soja fermentado por Bifidobacterium animale (com e sem, respectivamente). Página 152.

Figura 30. Variação da estimativa - após tratamento estatístico dos dados brutos do valor de CW (hidratação das camadas superiores da pele) em relação ao tempo 
para as formulações de emulsão contendo ou não extrato de soja fermentado por Bifidobacterium animale (com e sem, respectivamente). Página 155.

Figura 31. Variação da estimativa - após tratamento estatístico dos dados brutos do valor de CW (hidratação das camadas superiores da pele) em relação ao tempo para as formulações de máscara facial contendo ou não extrato de soja fermentado por Bifidobacterium animale (com e sem, respectivamente). Página 155. 


\section{LISTA DE QUADROS}

Quadro 1. Composição geral de máscara facial usualmente comercializada no mercado europeu. Página 33.

Quadro 2. Classificação das máscaras faciais conforme sua aplicação. Página 35.

Quadro 3. Classificação das máscaras faciais conforme sua composição. Página 36.

Quadro 4. Composição do extrato (leite) de soja antes e após fermentação por Bifidobacterium animale. Página 61.

Quadro 5. Fototipos, sua descrição e respectiva sensibilidade ao sol. Página 86. 


\section{LISTA DE TABELAS}

Tabela 1. Bases de máscara facial peel off ( 1 a 11$)$ submetidas ao Estudo de Estabilidade Preliminar (EP), com as concentrações dos componentes variáveis em negrito. Página 69.

Tabela 2. Bases de máscara facial peel off (12 a 22) submetidas ao Estudo de Estabilidade Preliminar (EP), com as concentrações dos componentes variáveis em negrito. Página 70.

Tabela 3. Bases de máscara facial peel off ( 23 a 33) submetidas ao Estudo de Estabilidade Preliminar (EP), com as concentrações dos componentes variáveis em negrito. Página 71.

Tabela 4. Bases de máscara facial peel off (34 a 36) submetidas ao Estudo de Estabilidade Preliminar (EP), com as concentrações dos componentes variáveis em negrito. Página 72.

Tabela 5. Base cosmética (ES) e formulação de emulsão contendo extrato de soja fermentado por Bifidobacterium animale (EC) submetidas ao Estudo de Estabilidade Preliminar (EP) e testes de eficácia clínica, e com as concentrações dos componentes variáveis em negrito. Página 73.

Tabela 6. Formulações de máscara facial peel off (adaptações da base F35 de máscara facial peel off) submetidas ao Estudo de Estabilidade Preliminar (EP), com as concentrações dos componentes variáveis em negrito. Todas as formulações contêm o extrato de soja fermentado. Página 80.

Tabela 7. Codificação da base e da formulação de máscaras facial peel off e da base e da formulação de emulsão óleo em água utilizadas nos ensaios clínicos. Página 88. 
Tabela 8. Descrição da quantidade e modo de aplicação das preparações utilizadas no teste clínico. Página 90.

Tabela 9. Descrição das preparações de acordo com os respectivos locais de aplicação, conforme aleatorização. Página 91.

Tabela 10. Avaliação das características organolépticas e valor de $\mathrm{pH}$ das bases de máscara facial peel off (1 a 8) durante o Estudo de Estabilidade Preliminar. Página 96.

Tabela 11. Avaliação das características organolépticas e valor de pH das bases de máscara facial peel off (9 a 16) durante o Estudo de Estabilidade Preliminar. Página 97.

Tabela 12. Avaliação das características organolépticas e valor de $\mathrm{pH}$ das bases de máscara facial peel off (17 a 24) durante o Estudo de Estabilidade Preliminar. Página 98.

Tabela 13. Avaliação das características organolépticas e valor de pH das bases de máscara facial peel off (25 a 32) durante o Estudo de Estabilidade Preliminar. Página 99.

Tabela 14. Avaliação das características organolépticas e valor de pH das bases de máscara facial peel off (33 a 36) durante o Estudo de Estabilidade Preliminar. Página 100.

Tabela 15. Avaliação das características organolépticas e valor de $\mathrm{pH}$ das formulações de máscara facial peel off (modificações da base F35) no Estudo de Estabilidade Preliminar. Página 105.

Tabela 16. Avaliação das características organolépticas e valor de $\mathrm{pH}$ das preparações de emulsão O/A sem extrato de soja fermentado (ES, base) e contendo extrato de soja fermentado (EC, formulação) durante o Estudo de Estabilidade Preliminar. Página 109. 
Tabela 17. Avaliação das características organolépticas, $\mathrm{pH}$ e viscosidade aparente das formulações 35/17G e 35/18, no Estudo de Estabilidade Acelerada. Página 111.

Tabela 18. Avaliação das características organolépticas, $\mathrm{pH}$ e viscosidade aparente da formulação de emulsão contendo extrato de soja fermentado, no Estudo de Estabilidade Acelerada. Página 123.

Tabela 19. Avaliação clínica da hidratação $(\mathrm{CW})$ e perda de água transepidérmica (TEWL) para a amostra MS - base cosmética de máscara facial peel off (sem extrato de soja fermentado por Bifidobacterium animale). Página 132.

Tabela 20. Avaliação clínica da hidratação $(\mathrm{CW})$ e perda de água transepidérmica (TEWL) para a amostra MC - base cosmética de máscara facial peel off (com extrato de soja fermentado por Bifidobacterium animale). Página 133.

Tabela 21. Avaliação clínica da hidratação $(\mathrm{CW})$ e perda de água transepidérmica (TEWL) para a amostra ES - emulsão sem extrato de soja fermentado por Bifidobacterium animale. Página 134.

Tabela 22. Avaliação clínica da hidratação $(\mathrm{CW})$ e perda de água transepidérmica (TEWL) para a amostra EC - emulsão com extrato de soja fermentado por Bifidobacterium animale. Página 135.

Tabela 23. Avaliação clínica da elasticidade e firmeza da pele (CUTO) para a amostra MS - base cosmética de máscara facial peel off (sem extrato de soja fermentado por Bifidobacterium animale). Página 136.

Tabela 24. Avaliação clínica da elasticidade e firmeza da pele (CUTO) para a amostra MC - base cosmética de máscara facial peel off (com extrato de soja fermentado por Bifidobacterium animale). Página 137. 
Tabela 25. Avaliação clínica da elasticidade e firmeza da pele (CUTO) para a amostra ES - emulsão sem extrato de soja fermentado por Bifidobacterium animale. Página 138

Tabela 26. Avaliação clínica da elasticidade e firmeza da pele (CUTO) para a amostra EC - emulsão com extrato de soja fermentado por Bifidobacterium animale. Página 139.

Tabela 27. Tratamento estatístico obtido dos valores mensurados para M1 (deformação final ou extensibilidade máxima). Página 144.

Tabela 28. Comparação entre os tempos de aplicação e avaliação das preparações produtos para M1, com os respectivos níveis de significância (deformação final ou extensibilidade máxima). Página 146

Tabela 29. Tratamento estatístico obtido dos valores mensurados para M2 (deformação resultante em comparação com o valor inicial). Págian 146

Tabela 30. Tratamento estatístico obtido dos valores mensurados para TEWL (perda de água transepidérmica). Página 149.

Tabela 31. Comparação entre os tempos de aplicação e avaliação dos produtos para TEWL (perda de água transepidérmica), com os respectivos níveis de significância. Página 151.

Tabela 32. Tratamento estatístico obtido dos valores mensurados para CW (hidratação das camadas superiores da pele). Página 153.

Tabela 33. Comparação entre os tempos de aplicação e avaliação dos produtos para CW (hidratação das camadas superiores da pele), com os respectivos níveis de significância. Página 154.

Tabela 34. Comparação entre os tempos de aplicação e avaliação dos produtos para CW (hidratação das camadas superiores da pele). Página 154. 
I INTRODUÇÃO 
O uso de máscaras faciais remonta da Antigüidade, quando se atribuíam propriedades milagrosas a alguns tipos de argila (WILKINSON \& MOORE, 1982). Atualmente, o interesse por estas formulações de uso tópico foi retomado pela Cosmetologia, devido à atribuição de vários efeitos, como limpeza profunda, estimulante, tonificante, adstringente, hidratante e tensora (BONADEO, 1982; DRAELOS, 1999; MARTINE et al., 1995; POUCHER, 1991).

Máscaras faciais peel off são constituídas por álcool polivinílico (PVA) ou acetato de polivinila, utilizados como formadores de filme (WILKINSON \& MOORE, 1982; ARANHA \& LUCAS, 2001). As máscaras peel off produzem oclusão e ação tensora após a secagem, tornando a pele mais suave ao toque e, caso alguma substância ativa seja adicionada à formulação, esta ação se acentua (BABY et al., 2004; DeNAVERRE, 1975). A principal vantagem deste tipo de formulação está relacionada com a facilidade de sua remoção completa após a formação do filme, sem deixar resíduos (DeNAVERRE, 1975). São adequadas para peles sensíveis, desidratadas e envelhecidas (POUCHER, 1991). Estas formulações geralmente contêm plastificantes, umectantes, conservantes, tensoativos, fragrâncias, corantes e, conforme o propósito, substâncias ativas.

Uma etapa determinante no desenvolvimento de uma formulação cosmética é o estudo de estabilidade, requisito fundamental à qualidade da preparação, relacionada à manutenção dos seus atributos físicos, químicos, microbiológicos e toxicológicos durante todo o seu prazo de validade, e que reflete no desempenho, segurança, eficácia, além da sua aceitação pelo consumidor. Considerando as máscaras faciais peel off, é importante a avaliação das características como aspecto, cor, odor e o desempenho do produto na pele, bem como o tempo de formação de filme (AGÊNCIA NACIONAL DE VIGILÂNCIA SANITÁRIA, 2004).

O extrato de soja, utilizado em formulações de uso tópico, é obtido pela fermentação do extrato (leite) de soja por Bifidobacterium animale. O leite fermentado apresenta açúcares, aminoácidos, peptídeos, proteínas e alto teor de isoflavonas na forma livre, quando comparado ao leite não fermentado. Sua alta concentração de isoflavonas livres é atribuída à atividade da $\beta$-glucosidase do microorganismo, enzima que hidrolisa os glicosídeos a agliconas, entre elas a genisteína e a daidzeína (OTIENO, 2006). Estudos recentes têm demonstrado a atividade antioxidante das agliconas presentes em extratos de soja fermentado, 
prevenindo fotocarcinogênese e fotoenvelhecimento. Além disso, são atribuídas propriedades hidratantes dos produtos cosméticos incorporados deste extrato, em função da sua rica composição (BAUMANN, 2001). Para a comprovação da ações atribuídas ao extrato, é importante que se realizem estudos envolvendo a avaliação da hidratação, efeito tensor e emoliência.

A aplicação de um produto cosmético na pele contendo substâncias ativas pode interferir no metabolismo cutâneo. Assim, devem ser realizados estudos clínicos de produtos cosméticos que envolvam a avaliação da eficácia das formulações, por meio de análises subjetivas, como as avaliações de desempenho e objetivas, utilizando instrumentos de avaliação das propriedades biomecânicas da pele (SOUZA, 2000).

As máscaras faciais peel off podem ser utilizadas como veículo para aplicação do extrato de soja fermentado, permitindo que ocorram as ações da preparação, além de possibilitar a avaliação dos efeitos tensor, hidratante e de perda de água transepidérmica. A avaliação da estabilidade das formulações de máscaras faciais peel off e emulsão óleo em água contendo o extrato fermentado, em conjunto com estudos clínicos dos efeitos propiciados à pele, fornecem informações importantes ao meio científico, que carece de estudos deste tipo de formulação cosmética, bem como do extrato de soja fermentado incorporado em formulações de uso tópico. 
II REVISÃO DA LITERATURA 


\section{PELE}

\subsection{Constituição}

A pele é um órgão que ocupa, em média, uma superfície equivalente a $2 \mathrm{~m}^{2} \mathrm{e}$ é tão complexo quanto o cérebro, com relação à variedade de tipos celulares que a compõe. Ela é o contato direto do nosso organismo com o meio exterior e desempenha funções vitais, como a de prevenir a perda de água e proteger contra agressão de agentes externos (HADGRAFT, 2001). É responsável pela termorregulação do organismo, devido às glândulas, aos vasos sangüíneos e ao tecido adiposo que a compõem; recebe informações do meio ambiente, devido às suas terminações nervosas sensitivas e protege o organismo contra os raios ultravioleta, devido à produção do pigmento melanina. Na pele, também é formada a vitamina $D_{3}$, pela ação da radiação ultravioleta sobre os precursores encontrados no organismo e os adquiridos, principalmente, na dieta alimentar (JUNQUEIRA \& CARNEIRO, 2004; SHAH \& MAIBACH, 1993).

Este órgão pode ser considerado como uma membrana heterogênea, uma vez que possui várias camadas, cada uma com tipos particulares de células e, conseqüentemente, funções diferentes (HADGRAFT, 2001). Possui uma camada de origem ectodérmica, a epiderme, e outra de origem mesodérmica, a derme. Dependendo da espessura da epiderme, distingue-se a pele espessa, encontrada na palma da mão e planta dos pés, e a pele fina, que recobre o restante do corpo. A pele apresenta ainda algumas estruturas anexas, que são os pêlos, unhas, glândulas sudoríparas e sebáceas (GARTNER \& HIATT, 1999; JUNQUEIRA \& CARNEIRO, 2004). A Figura 1 apresenta as principais estruturas da pele (BRASIL, 2008).

A derme é formada pelo tecido conjuntivo e une a pele ao tecido celular subcutâneo. Na derme, encontram-se os nervos e os vasos sangüíneos e linfáticos. Apresenta fibrilas de colágeno e fibras elásticas, responsáveis em parte pela elasticidade da pele. Possui duas camadas, a papilar, mais superficial, e a reticular, mais profunda. A camada papilar é constituída por tecido conjuntivo frouxo que forma as papilas dérmicas, que são reentrâncias da derme na epiderme. A camada 


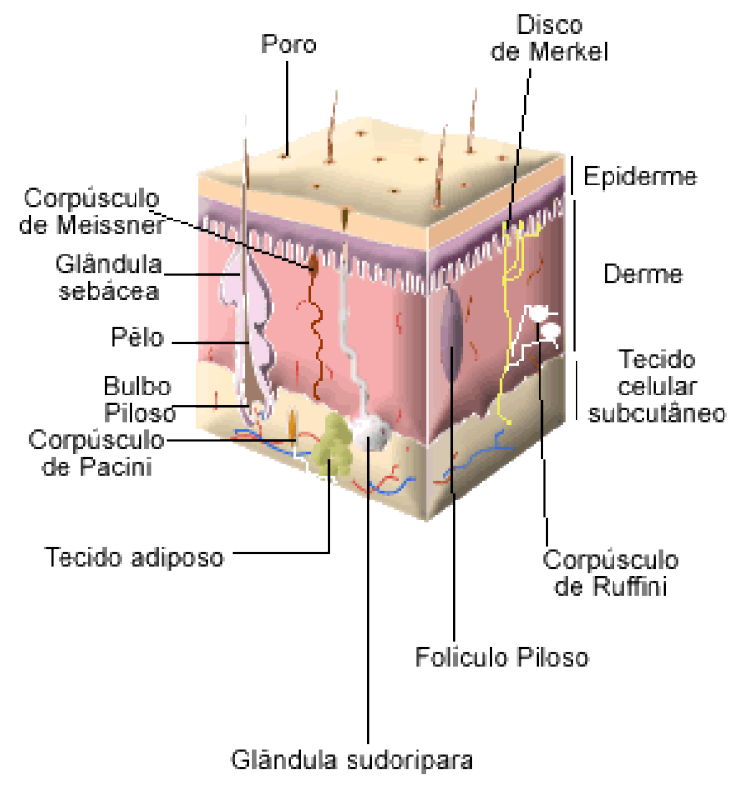

Figura 1. Estrutura esquemática dos principais componentes da pele (BRASIL, 2008).

reticular é constituída por tecido conjuntivo denso e é mais espessa (JUNQUEIRA \& CARNEIRO, 2004).

A epiderme é constituída por epitélio pavimentoso estratificado. Apresenta quatro tipos de células: os queratinócitos, os melanócitos, as células de Langerhans e as de Merckel, sendo os queratinócitos as células mais numerosas (GARTNER \& HIATT, 1999; JUNQUEIRA \& CARNEIRO, 2004).

Os melanócitos se encontram entre os queratinócitos da camada basal e são responsáveis pela síntese da melanina, pigmento que resulta na cor da pele. As células de Langerhans localizam-se em toda extensão da epiderme e têm origem na medula óssea, transportadas até a pele pela circulação sangüínea. São capazes de captar antígenos, processá-los e apresentá-los aos linfócitos T, sendo, portanto, importantes para as reações imunes cutâneas. As células de Merckel existem em maior quantidade na pele espessa, localizam-se na parte profunda da epiderme, apoiadas na membrana basal e presas aos queratinócitos por desmossomos. Funcionam como mecano-receptores, enviando informações sensitivas para o sistema nervoso central (BAREL et al., 2001; JUNQUEIRA \& CARNEIRO, 2004)

A espessura da epiderme varia, podendo chegar a 1,5 $\mathrm{mm}$ na pele espessa. A epiderme possui cinco camadas (ou estratos), sendo que na pele fina as camadas 
granulosa e lúcida podem estar ausentes. A camada basal é rica em células-tronco, também chamada de camada germinativa. É responsável, juntamente com a camada espinhosa, pela constante renovação da epiderme. A camada espinhosa apresenta células-tronco e células cubóides ligeiramente achatadas com filamentos de queratina unidas por desmossomos, importantes na coesão entre as células, fornecendo resistência ao atrito. $\mathrm{Na}$ camada granulosa, as células passam ao formato poligonal achatado e apresentam grânulos lamelares, que, juntamente com o conteúdo lipídico, contribui para a formação de uma barreira contra a penetração de substâncias e torna a pele impermeável à água, impedindo a desidratação. $A$ camada lúcida, por sua vez, é formada por células mais achatadas, com numerosos filamentos de queratina, e é mais evidente na pele espessa. Finalmente, a camada córnea possui espessura variável, formada por células mortas, achatadas e sem núcleo, com citoplasma repleto de queratina (BAREL et al., 2001; JUNQUEIRA \& CARNEIRO, 2004). A Figura 2 apresenta as camadas da epiderme (UNIVERSIDADE DE SÃO PAULO, 2007).

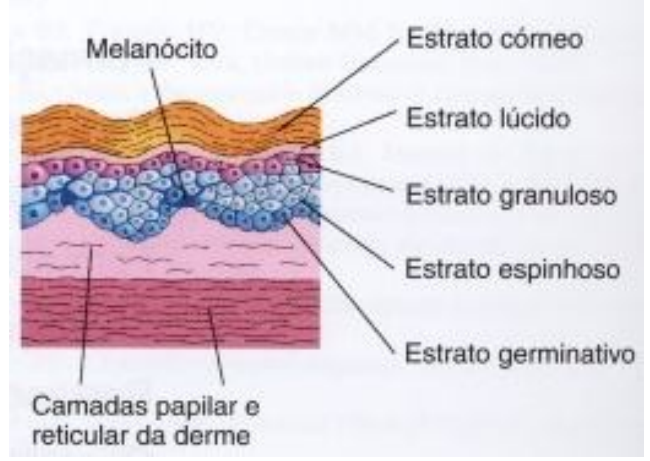

Figura 2. Estrutura esquemática das principais camadas (estratos) da epiderme (UNIVERSIDADE DE SÃO PAULO, 2007)

Destas camadas, destaca-se o estrato córneo, camada mais externa, diretamente relacionada à função de barreira à penetração de agentes externos no organismo. Os trabalhos relacionados à penetração de substâncias no organismo através da pele têm como foco principal a investigação das propriedades do estrato córneo (HADGRAFT, 2001, BAREL et al., 2001).

$\mathrm{Na}$ camada córnea, a pele possui fatores de hidratação natural (NMF) que participam do manto hidrolipídico e possuem caráter higroscópico. Dentre esses, 
temos aminoácidos e seus derivados, ácido láctico, uréia e açúcares. Estes compostos atuam na umectação e hidratação da camada córnea, pois absorvem a umidade presente na atmosfera e dissolvem a própria água de hidratação, produzida na pele (RAWLINGS, 2004).

\subsection{Hidratação da pele}

A água é um dos principais constituintes da epiderme. A hidratação da epiderme está diretamente relacionada à flexibilidade da pele e aos processos de renovação (descamação). Portanto, a hidratação é um fator determinante na aparência saudável da pele (BAREL et al., 2001).

A epiderme é constantemente suprida de água pela camadas inferiores, ao mesmo tempo em que este fornecimento é gradualmente perdido para atmosfera, por evapo-transpiração. Além da água, outro importante componente da epiderme é uma mistura de substâncias higroscópicas denominadas NMF (Natural Moisturizing Factor - fator de hidratação natural), que constituem até $10 \%$ do peso seco dos corneócitos e se apresenta como um filme fino, de espessura variada. Entre os componentes no NMF, destacam-se aminoácidos, ácidos carboxílicos (PCAs), lactatos, carboidratos e uréia. O NMF é formado a partir de proteínas de camadas inferiores da pele e sua produção é regulada conforme a hidratação do estrato córneo. A função básica do NMF é elevar o conteúdo de água na epiderme e retardar sua perda para o ambiente (BAREL et al., 2001; MAGALHÃES, 2000).

Os produtos cosméticos que visam aumentar a hidratação superficial da pele, potencializando a ação promovida pelo NMF, empregam umectantes, emolientes e oclusivos na formulação e atuam exclusivamente no estrato córneo. As substâncias umectantes promovem retenção de água pela camada córnea, atuando superficialmente, enquanto as oclusivas diminuem a perda de água para o ambiente. As emolientes possuem ação oclusiva complementar, contribuindo também para a hidratação da camada córnea. Devemos considerar também as substâncias de ação hidratante profunda, que atuam de dentro para fora, com ação complementar aos umectantes. Qualquer que seja a natureza da pele, é recomendável a aplicação dos agentes promotores de hidratação ao menos duas vezes ao dia (POUCHER, 1991; RAWLINGS \& HARDING, 2004). 
Dentre as substâncias umectantes, os mais utilizados são os glicóis, como glicerina, propilenoglicol e butilenoglicol; as proteínas, os aminoácidos, peptídeos e polissacarídeos. Como hidratantes, pode-se citar a uréia, lactatos, fatores de hidratação natural e hialuronatos. Os agentes oclusivos, como a vaselina, formam uma camada sobre a superfície da pele e retardam a perda de água. Os emolientes são óleos e lípides que espalham facilmente na pele e provocam oclusão parcial e uma melhor aparência da pele, com sensação de maciez. Os mais utilizados são os estearatos e a lanolina (RAWLINGS \& HARDING, 2004).

As tecnologias cosméticas para hidratação variam os tipos $e$ as concentrações dos agentes umectantes, hidratantes, emolientes e oclusivos e assim diferem nos seus efeitos. (RAWLINGS \& HARDING, 2004).

\subsection{Elasticidade da pele}

A pele é freqüentemente submetida a agressões do ambiente externo como choques, trações e esmagamentos. Ela deve aliviar esses efeitos, preservando sua integridade e dos demais tecidos (PEYREFITTE et al., 1998).

Todas as camadas da pele, inclusive o tecido subcutâneo e a derme, têm funções e componentes que conferem a sua resistência à tração (PEYREFITTE et al., 1998). A elastina é um componente natural da derme responsável por promover o retorno da pele à sua configuração inicial após a tração (DRAELOS, 1999).

No entanto, é na epiderme que a pele possui a principal estrutura de resistência às agressões mecânicas do ambiente - a camada córnea. Quanto mais esta é distendida, maior é a resistência da pele. No entanto, caso a extensão ultrapasse a ordem de $5 \%$, a elasticidade começa a desaparecer e as marcas da agressão passam a ser definitivas ou, até mesmo, atingem um ponto de ruptura (PEYREFITTE et al., 1998).

Vários fatores interferem na perda elasticidade da pele. À medida que a idade avança, a rede formada pelas fibras de elastina da derme torna-se mais compacta, diminuindo a capacidade de extensão da pele (SCOTTI e VELASCO, 2003). Além disso, a hidratação é determinante na extensibilidade da epiderme, sendo que ela se torna 10 vezes mais extensível quando a hidratação ultrapassa valores $40 \%$ superiores aos valores usuais (PEYREFITTE et al., 1998). 
Portanto, formulações que promovem hidratação por meio da oclusão, quando ocorre a formação de barreira sobre a pele para impedir a perda e água transepidérmica; umectação, que absorvem água do ambiente, ou hidratação ativa, quando as substâncias são absorvidas pela pele e promovem hidratação intrínseca, tendem a promover melhora na elasticidade do tecido cutâneo (SCOTTI e VELASCO, 2003).

\section{MÁSCARAS FACIAIS}

\subsection{História}

Desde a Antiguidade existem relatos do uso de máscaras faciais como formulações de uso tópico, em função da propriedades atribuídas a alguns tipos de argila (WILKINSON \& MOORE, 1982).

No Egito Antigo, as mulheres utilizavam estas preparações e as gregas empregavam a argila da ilha de Lemnos em sua higienização rotineira. No início da era Cristã, o poeta Ovídio descreve na sua obra "Arte de Amar" o emprego de diferentes preparações de lamas impregnadas de mel, ovos e bulbos de plantas em procedimentos de beleza. No período do Renascimento italiano, as mulheres aplicavam o liccio no rosto, máscara à base de sais de mercúrio, com o intuito de promover o clareamento da pele. Finalmente, no século XIX, surgiram as primeiras formulações de acordo com o conceito atual, ou seja, utilizando matérias-primas como caolim, argilas e as demais, ainda presentes nos produtos atuais (MARTINE et al., 1995).

O atual interesse no desenvolvimento de formulações de máscaras faciais é atribuído aos vários efeitos propostos pelos produtos, como limpeza profunda, estimulante, tonificante, adstringente, hidratante e tensora (POUCHER, 1991).

\subsection{Mercado atual}

Existem poucos dados do mercado sobre as máscaras faciais. Estas formulações são amplamente empregadas nas clínicas de estética em etapas finais dos tratamentos de beleza, mas seu emprego no cotidiano tem aumentado gradativamente devido os efeitos benéficos do produto. As informações disponíveis 
demonstram a utilização destas preparações por uma porcentagem significativa da população feminina, com números variando de 14 a 25\%. Estes dados indicam também o crescimento na utilização de máscaras em gel contendo álcool e polióis, além da crescente utilização das fórmulas promotoras de peeling, envolvendo a descamação das camadas superficiais da pele (DeNAVERRE, 1975).

A COLIPA, associação européia que representa os interesses da indústria cosmética e de perfumaria na União Européia, estabeleceu no Cosmetic Frame Formulations Guideline (Guia de fórmulas estruturais dos cosméticos) informações a respeito dos componentes e suas concentrações máximas presentes nas formulações dos cosméticos comercializados no continente atualmente. O objetivo principal foi fornecer informações que seriam úteis aos centros de atendimento médico, em caso de emergências relacionadas à intoxicação pelo uso dos cosméticos, direcionando o tratamento. A relação compreende os vários tipos de produtos, entre eles os destinados ao tratamento da pele, cabelos, barba, perfumaria, maquiagem e produtos infantis. Estas fórmulas, além da aplicação nos tratamentos por intoxicação e reações de hipersensibilidade, podem ser utilizadas como informativo sobre a composição das preparações comercializadas no mercado europeu, na atualidade. O Quadro 1 apresenta a composição geral de uma máscara facial, com o limite máximo de seus componentes na fórmula, comercializada atualmente no mercado europeu (COLIPA, 2008). 


\begin{tabular}{|c|c|}
\hline \multicolumn{2}{|l|}{ FÓRMULA GERAL DE MÁSCARA FACIAL } \\
\hline COMPONENTES & $\begin{array}{l}\text { CONCENTRAÇÃO } \\
\text { MÁXIMA (\% p/p) }\end{array}$ \\
\hline Ceras (ex. cera branca), óleos (minerais e vegetais) e gorduras & 90 \\
\hline $\begin{array}{l}\text { Agentes controladores da viscosidade (ex. bentonita, carbômero, } \\
\text { celulose) }\end{array}$ & 60 \\
\hline Umectantes (ex: glicerina, propilenoglicol) & 40 \\
\hline Agentes suspensores (ex: amido, óxido e zinco, caolim) & 30 \\
\hline $\begin{array}{l}\text { Tensoativos e emulsificantes (ex: estearato de glicerila, lauril sulfato } \\
\text { de sódio) }\end{array}$ & 25 \\
\hline Etanol (ex: álcool, álcool desnaturado) & 20 \\
\hline $\begin{array}{l}\text { Componentes adicionais (ex: extratos de plantas, filtros UV, } \\
\text { antioxidantes) }\end{array}$ & 5 \\
\hline Emolientes (ex: miristato de isopropila) & 5 \\
\hline Conservantes & 2 \\
\hline Essência & 1 \\
\hline Corantes & 1 \\
\hline Agentes quelantes & 0,5 \\
\hline Água & q.s.p. 100 \\
\hline
\end{tabular}

Quadro 1. Composição geral de máscara facial usualmente comercializada no mercado europeu (COLIPA, 2008). 


\subsection{Usos e classificação}

As formulações de máscaras faciais, para que possuam desempenho adequado e aceitabilidade no mercado, devem atender aos seguintes requisitos: suavidade na aplicação (sem grumos ou partículas); secagem rápida (entre 10 e 30 minutos) e formação de película aderente sobre a pele; remoção fácil, sem causar dor ou desconforto; sensação de maciez e limpeza sobre a pele; e não devem provocar reação sensibilizante (BONADEO, 1982; CHARLET, 1996; MARTINE et al., 1995; WILKINSON \& MOORE, 1982). São cosméticos aos quais são atribuídos efeitos similares às emulsões hidratantes, mas apresentam o efeito de forma mais pronunciada e em menos tempo (BONADEO, 1982). Devido a este efeito intenso, as máscaras faciais não devem ser utilizadas diariamente, como as demais formulações promotoras de hidratação, entre elas géis e emulsões, que devem ter aplicação diária (CHARLET, 1996).

As máscaras faciais podem ser classificadas conforme sua aplicação ou composição, que se completam quanto às informações (DRAELOS, 1999; MARTINE et al., 1995). A classificação das máscaras faciais conforme sua aplicação está descrita no Quadro 2 (BONADEO, 1982; CHARLET, 1996; MARTINE et al., 1995) e de acordo com sua composição está descrita no Quadro 3 (DRAELOS, 1999). 


\begin{tabular}{|c|c|c|c|c|c|c|c|}
\hline \multirow{3}{*}{ Características } & \multicolumn{7}{|c|}{ Tipos de máscaras faciais } \\
\hline & \multicolumn{5}{|c|}{ Máscaras de aplicação a frio } & \multirow{2}{*}{$\begin{array}{c}\begin{array}{c}\text { Máscaras } \\
\text { autotérmicas }\end{array} \\
\text { Gesso }\end{array}$} & \multirow{2}{*}{$\begin{array}{c}\text { Máscaras } \\
\text { formadoras de } \\
\text { filme de aplicação } \\
\text { a quente } \\
\text { Látex }\end{array}$} \\
\hline & Cremes & Argilosas & Gel & $\begin{array}{c}\text { Formadoras de filme } \\
\text { (peel off) }\end{array}$ & Gelificantes a frio & & \\
\hline 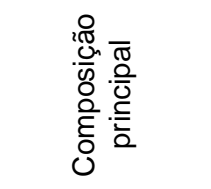 & $\begin{array}{l}\text { Alginatos, acrilatos, } \\
\text { umectantes, extratos } \\
\text { vegetais }\end{array}$ & $\begin{array}{l}\text { Bentonita, caolim, } \\
\text { silicatos, lamas } \\
\text { termais ou marinhas, } \\
\text { adstringentes, } \\
\text { umectantes }\end{array}$ & $\begin{array}{l}\text { Gelatina, gomas, } \\
\text { resinas acrílicas }\end{array}$ & $\begin{array}{l}\text { Polímeros formadores } \\
\text { de filme (álcool } \\
\text { polivinílico, gomas, } \\
\text { látex), substâncias } \\
\text { ativas, plastificantes }\end{array}$ & $\begin{array}{l}\text { Gelatina, gomas, } \\
\text { resinas acrílicas (a } \\
\text { gelificação é feita no } \\
\text { momento da } \\
\text { aplicação) }\end{array}$ & Sulfato de cálcio & $\begin{array}{l}\text { Látex, cera de } \\
\text { abelhas, óxido de } \\
\text { titânio e de zinco }\end{array}$ \\
\hline 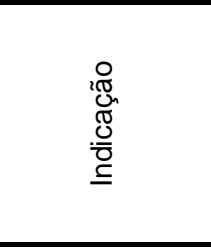 & todos os tipos de pele & $\begin{array}{l}\text { Principalmente para } \\
\text { peles oleosas }\end{array}$ & $\begin{array}{c}\text { todos os tipos de } \\
\text { pele, principalmente } \\
\text { desidratadas, devido } \\
\text { à oclusão }\end{array}$ & $\begin{array}{c}\text { Peles desidratadas } \\
\text { (ação oclusiva) e } \\
\text { envelhecidas (efeito } \\
\text { tensor) }\end{array}$ & $\begin{array}{c}\text { todos os tipos de } \\
\text { pele, principalmente } \\
\text { desidratadas, devido } \\
\text { à oclusão }\end{array}$ & $\begin{array}{c}\text { A mistura } \\
\text { gesso/água } \\
\text { promove aumento } \\
\text { de temperatura, } \\
\text { facilita absorção de } \\
\text { substâncias. } \\
\text { Oclusiva }\end{array}$ & $\begin{array}{l}\text { Todos os tipos de } \\
\text { pele, exceto } \\
\text { indivíduos com } \\
\text { problemas } \\
\text { vasculares }\end{array}$ \\
\hline 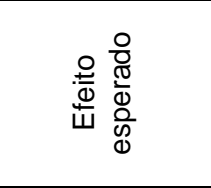 & $\begin{array}{l}\text { Hidratação ou } \\
\text { conforme substância } \\
\text { adicionada (anti- } \\
\text { rugas, clareador, etc) }\end{array}$ & Adstringência & $\begin{array}{l}\text { Hidratação ou } \\
\text { conforme substância } \\
\text { adicionada (anti- } \\
\text { rugas, clareador, etc) }\end{array}$ & $\begin{array}{l}\text { Hidratação, efeito } \\
\text { tensor ou conforme } \\
\text { substância ativa } \\
\text { adicionada. }\end{array}$ & $\begin{array}{l}\text { Hidratação ou } \\
\text { conforme substância } \\
\text { adicionada (anti- } \\
\text { rugas, clareador, etc) }\end{array}$ & $\begin{array}{l}\text { Hidratação ou } \\
\text { conforme } \\
\text { substância ativa } \\
\text { adicionada }\end{array}$ & $\begin{array}{c}\text { Vasodilatador } \\
\text { (facilita absorção } \\
\text { de substâncias) e } \\
\text { oclusivo } \\
\text { (hidratação) }\end{array}$ \\
\hline 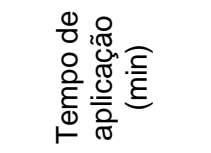 & 10 a 15 & 10 a 20 & 10 a 20 & 10 a 20 & 10 a 20 & 20 a 30 & 10 a 20 \\
\hline 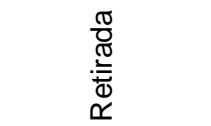 & $\begin{array}{l}\text { Utilizando lenços } \\
\text { umedecidos ou } \\
\text { esponjas }\end{array}$ & $\begin{array}{l}\text { Utilizando lenços } \\
\text { umedecidos ou } \\
\text { esponjas }\end{array}$ & $\begin{array}{l}\text { Utilizando lenços } \\
\text { umedecidos ou } \\
\text { esponjas }\end{array}$ & $\begin{array}{l}\text { Remoção mecânica, } \\
\text { sem resíduos }\end{array}$ & $\begin{array}{l}\text { Utilizando lenços } \\
\text { umedecidos ou } \\
\text { esponjas }\end{array}$ & $\begin{array}{l}\text { Remoção } \\
\text { mecânica, sem } \\
\text { resíduos }\end{array}$ & $\begin{array}{l}\text { Remoção } \\
\text { mecânica, sem } \\
\text { resíduos }\end{array}$ \\
\hline
\end{tabular}

Quadro 2. Classificação das máscaras faciais conforme sua aplicação (BONADEO, 1982; CHARLET, 1996; MARTINE et al., 1995). 


\begin{tabular}{|c|c|c|c|c|}
\hline \multirow{2}{*}{ Características } & \multicolumn{4}{|c|}{ Classificação das máscaras faciais conforme composição } \\
\hline & À base de cera & $\begin{array}{l}\text { À base de vinil ou } \\
\text { borracha }\end{array}$ & Hidrocolóides & À base de argila \\
\hline Composição principal & Cera de abelha ou parafina & $\begin{array}{l}\text { Látex, álcool polivinílico ou } \\
\text { acetato de polivinila }\end{array}$ & $\begin{array}{l}\text { Gomas, umectantes, aveia } \\
\quad \text { (fornecidas a seco) }\end{array}$ & $\begin{array}{l}\text { Bentonita, caulim, óxido de } \\
\text { zinco, ácido salicílico }\end{array}$ \\
\hline Indicação & Peles secas & Todos os tipos de pele & Todos os tipos de pele & Pele oleosa \\
\hline Efeitos esperados & $\begin{array}{l}\text { Relaxante e hidratação } \\
\text { (oclusão) }\end{array}$ & $\begin{array}{l}\text { Refrescante (evaporação } \\
\text { do veículo), tensor e } \\
\text { hidratante (oclusão) }\end{array}$ & $\begin{array}{l}\text { Tensor e hidratante } \\
\text { (oclusão) }\end{array}$ & Adstringente \\
\hline
\end{tabular}

Quadro 3. Classificação das máscaras faciais conforme sua composição (DRAELOS, 1999). 


\subsection{Máscaras faciais peel off}

As preparações compostas em resinas vinílicas (máscaras peel off) são constituídas por álcool polivinílico (PVA) ou acetato de polivinila, utilizados como formadores de filme (WILKINSON \& MOORE, 1982). Além disso, estas formulações geralmente contêm plastificantes, umectantes, conservantes, tensoativos, fragrâncias, corantes e, conforme o propósito, substâncias ativas.

Os plastificantes mais utilizados nas formulações de máscaras faciais peel off são os glicóis, destacando-se a glicerina, o propilenoglicol e o butilenoglicol. Esses componentes atuam conjuntamente com os formadores de película (álcool polivinílico), evitando a formação de um filme quebradiço, o que dificultaria sua retirada (FAZENDA, 1993). Além disso, atuam como umectantes da formulação, evitando a perda de água para o ambiente. Ao butilenoglicol são também atribuídas funções de retardar a perda da fragrância e atuar como conservante, evitando contaminação microbiana (BAREL et al., 2001).

O uso de tensoativos neste tipo de formulação tem a função de dispersar as essências e outros componentes lipofílicos, uma vez que a base da máscara facial peel off é hidrofílica. A utilização de um tensoativo também evita possíveis irritações na retirada da máscara, promovendo a retirada suave após a secagem do produto na face, requisito fundamental para a adesão dos usuários ao tratamento (WILKINSON \& MOORE, 1982). Os demais componentes exercem as mesmas funções consagradas em outras preparações cosméticas.

A máscara peel off ocasiona oclusão e ação tensora após a secagem. A pele torna-se mais suave ao toque e, caso alguma substância ativa seja adicionada à formulação, esta ação pode ser acentuada (BABY et al., 2004; DeNAVERRE, 1975). A principal vantagem deste tipo de formulação está relacionada com a facilidade de sua remoção completa após a formação do filme, sem deixar resíduos na pele (DeNAVERRE, 1975). Esta característica torna a máscara facial peel off uma das preparações mais indicadas para uso doméstico (DRAELOS, 1999). São também adequadas para peles sensíveis, desidratadas e envelhecidas (POUCHER, 1991). Embora não existam estudos disponíveis, são importantes os trabalhos para confirmar a ação hidratante por meio de oclusão das máscaras peel off, ou mesmo o efeito tensor, atribuído ao uso destas formulações. 
A Figura 3 apresenta as fotografias de máscaras faciais peel off após secagem, no momento da remoção mecânica da formulação da face (PARIS. CLUB DES CRATEURS DE BEAUTÉ, 2008).
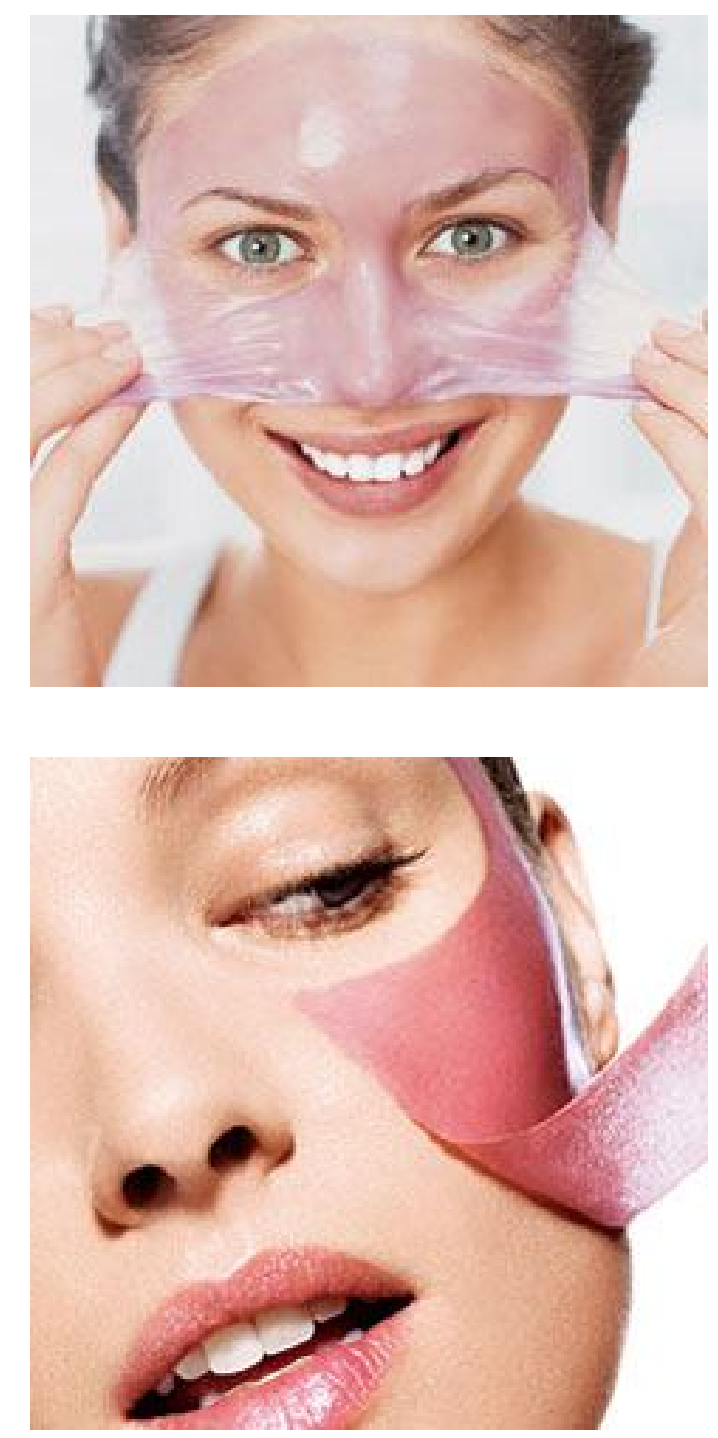

Figura 3. Remoção mecânica de máscaras faciais peel off, após secagem (PARIS. CLUB DES CRATEURS DE BEAUTÉ, 2008).

\subsection{Substâncias ativas utilizadas nas máscaras faciais}

Substâncias ativas são componentes encontrados em diversas formulações de máscaras faciais disponíveis no mercado (DeNAVERRE, 1975). 
A ação destas substâncias ocorre no período de tempo de secagem do produto e sua utilização apresenta uso definido conforme os tipos de pele. Para formulações destinadas à pele acnéica, são adicionados peróxido de benzoíla (5 a $10 \%$ ), extrato de hamamélis, extrato de própolis, extrato de camomila, enxofre, mentol e cânfora. Para pele oleosa, são incorporadas às máscaras faciais substâncias como hamamélis, cloridróxido de alumínio e mentol. Para peles secas, são utilizados uréia e alantoína. Outras substâncias são amplamente utilizadas e, dentre elas, destacam-se azuleno, triclosano, sais de amônio quaternário, enzimas proteolíticas, aminoácidos, calamina, sais adstringentes, vitaminas do complexo $\mathrm{B}$ e vitamina E (DeNAVERRE, 1975; MAGALHÃES, 2000).

É importante ressaltar que não há estudos disponíveis na literatura a respeito da eficácia de substâncias ativas adicionadas às formulações de máscaras faciais.

\section{3 ÁLCOOL POLIVINÍLICO (PVA)}

O álcool polivinílico (PVA) é a resina sintética produzida em maior volume no mundo, na ordem centenas de toneladas ao ano. Existem cerca de 10 marcas registradas de PVA produzidas por empresas químicas situadas na Alemanha, Espanha, Eslováquia, Itália, Estados Unidos, Japão e China (CHIELLINI et al., 2003).

A obtenção do PVA é dada a partir de uma reação radicalar, promovendo a polimerização do acetato de vinila em acetato de polivinila, com posterior hidrólise induzida por metanol - metanólise (ARANHA \& LUCAS, 2001; CHIELLINI et al., 2003). O peso molecular da cadeia polimérica é controlado pelo tempo de permanência do polímero no reator, taxa de alimentação de acetato de polivinila, quantidade de solvente (metanol), concentração do radical iniciador da reação e temperatura em que a reação ocorre. O grau de hidrólise do PVA também é controlado pelo tempo de permanência no reator, concentração do catalisador e temperatura (CHIELLINI et al., 2003).

As propriedades básicas do PVA dependem dos graus de polimerização e hidrólise (ARANHA \& LUCAS, 2001). O PVA é estável a temperaturas de até $150^{\circ} \mathrm{C}$ (CHIELLINI et al., 2003). A Figura 4 representa a fórmula estrutural do polímero, onde o valor de $n$ (unidades vinílicas) pode variar de 500 a 5000 (MANTINDALE, 1989). 


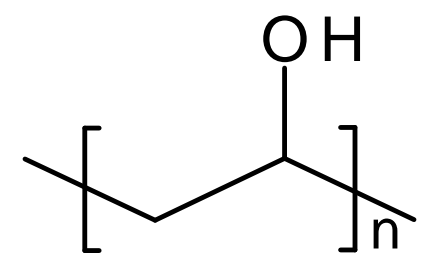

Figura 4. Fórmula estrutural do álcool polivinílico (PVA), onde $n$ varia de 500 a 5000 (grau de polimerização) (MARTINDALE, 1989).

O PVA apresenta-se como pó branco-amarelado ou em grânulos translúcidos, solúvel em água, atóxico para os seres humanos, e biodegradável, sendo largamente utilizado na indústria como estabilizante, formador de filmes, adesivo e tensoativo não-iônico (KUMAR et al., 2007; LYOO et al., 2002). Na área de biomédica, é utilizado na fabricação de lentes e no desenvolvimento de sistemas de liberação prolongada de fármacos e bio/nano-materiais (ARANHA \& LUCAS, 2001; KUMAR et al., 2007; LYOO et al., 2002). Na área cosmética, polímeros como o álcool polivinílico são utilizados como agentes de dispersão, agentes formadores de filme ou espessantes (LIU \& HOFFMANN, 2004).

Utilizado como agente de permeação cutânea, a eficácia do PVA está relacionada à ligação cruzada do polímero com outros agentes, como o cloreto de succinila, formando hidrogéis que podem ser utilizados como veículos para princípios ativos. O PVA pode aumentar a solubilidade de substâncias ativas de natureza hidrofílica e aumentar a sua permeação, provavelmente pela interação do polímero com o estrato córneo na pele (ORIENTI et al., 2000).

NOKHODCHI et al. (2006) produziram micropartículas de etilcelulose contendo peróxido de benzoíla, utilizando o álcool polivinílico como agente emulsificante, com o objetivo de diminuir a irritação causada pelo fármaco no tratamento de patologias cutâneas, como a acne, através da liberação prolongada da substância. Observou-se que a presença do agente emulsificante é determinante na formação das microesponjas, designações aos poros na superfície das micropartículas, formadas devido à difusão do solvente. A formação de microesponjas interfere no perfil de liberação do princípio ativo.

Desta forma, além das suas funções usuais como componente de formulações de uso tópico, o PVA surge como uma substância potencial para uso 
como carreador de princípios ativos em produtos cosméticos, uma vez que pode interferir na liberação destes compostos para a epiderme.

\section{EXTRATO DE SOJA}

A partir dos anos 80, a crescente demanda do mercado cosmético por produtos mais efetivos impulsionou a indústria na busca de novas substâncias ativas. Neste contexto, o extrato de soja, rico em componentes como isoflavonas e proteínas, surgiu como candidato a componente de formulações que promovem ação antioxidante e/ou hidratante (BAUMANN \& LAZARUS, 2001; LUPO, 2001).

A soja é um grão que possui $40 \%$ de proteínas, $20 \%$ de lipídios (óleo), $5 \%$ de minerais e $34 \%$ de carboidratos (glicose, frutose e sacarose, fibras e oligosacarídeos - rafinose e estaquiose). Cada $100 \mathrm{ml}$ de extrato de soja, também conhecido como leite de soja, contém $2,5 \%$ de carboidratos, 3,4\% de proteínas, 2,3\% de lipídios, $40 \mathrm{mg}$ de cálcio, $105 \mathrm{mg}$ de potássio e 1,2 mg de ferro, $40 \mathrm{mg}$ de vitamina $\mathrm{B}_{1}$ e 120 mg de vitamina $B_{2}$ (EMBRAPA SOJA, 2007).

As isoflavonas são fitoestrógenos e podem ser encontrados em concentrações elevadas na soja. Os fitoestrógenos são conhecidos por suas atividades estrogênica, anticarcinogênica, antiviral, antifúngica, antiosteoporose e antioxidante. As isoflavonas exercem efeito antioxidante por possuírem a capacidade de doar um hidrogênio aos radicais livres derivados do oxigênio, pela complexação com metais, que possuem atividade de oxidação e redução, e pela inibição das lipooxigenases. A soja e produtos derivados são fontes importantes de isoflavonas, sendo as principais a gliciteína, genisteína e daidzeína, que exercem ação antioxidante (PRAKASH et al., 2007).

As isoflavonas estão presentes na soja em quatro formas químicas. As estruturas agliconas da daidzeína, gliciteína e genisteína podem ser conjugadas para formar derivados malonil-, acetil- e $\beta$-glicosídeo. As diferenças estruturais entre as formas das isoflavonas resultam em biodisponibilidade variável em sistemas biológicos. Além disso, as isoflavonas agliconas é que são biologicamente ativas, pois atuam em receptores estrogênicos e são mais facilmente absorvidas que as formas glicosídicas em humanos (CHIEN et al., 2006). As isoflavonas agliconas de soja, principalmente a genisteína e a daidzeína, representam 2 a 3\% do total de 
isoflavonas contidas na soja. A maior parte se encontra na forma de glicosídeos (MIYAZAKI et al., 2002).

A conversão das formas glicosídicas para as formas de agliconas pode ser dada por duas vias. Ao ingerir a soja, as formas glicosídicas podem ser convertidas a agliconas pela ação da enzima $\beta$-glucosidase, presente no intestino (MIYAZAKI et al., 2002). Da mesma forma, o leite de soja submetido ao processo de fermentação por Bifidobacterium animale possui maior concentração de isoflavonas na forma de agliconas (OTIENO et al., 2006). Isso ocorre devido à atividade $\beta$-glucosidase do microorganismo no substrato, provocando a conversão das formas isoflavonóides malonil, acetil e glicosídeo em aglicona (CHIEN, 2006).

MIYAZAKI et al. (2002) verificaram a influência da genisteína, daidzeína e suas formas glicosídeas na produção de ácido hialurônico (HA) em culturas de queratinócitos humanos e em camundongos sem pêlo. Somente as formas agliconas apresentaram efeito significativo no estímulo da síntese de HA, tanto in vitro quanto in vivo.

O crescente interesse da incorporação do extrato de soja fermentado em formulações de uso tópico é baseado nos vários estudos relacionados à atividade antioxidante das isoflavonas que compõem o extrato (WEI, 1998). No entanto, estudos que comprovam a eficácia do extrato de soja fermentado como hidratante são escassos. Atualmente, muitas empresas de produtos cosméticos incorporam o extrato em formulações hidratantes de preço elevado. Apesar de se tratar de uma grande promessa como agente promotor de hidratação da pele, isso torna necessário o estudo dos efeitos do extrato na epiderme (BAUMANN \& LAZARUS, 2001).

\section{ESTABILIDADE DE PRODUTOS COSMÉTICOS}

Os estudos de estabilidade de uma formulação cosmética tem o objetivo de predizer as possíveis alterações físicas, físico-químicas, químicas e microbiológicas que podem ocorrer com a preparação desde sua fabricação até o término do seu prazo de validade. Estas alterações podem ser provocadas por fatores extrínsecos e intrínsecos. Os primeiros envolvem temperatura, luz, oxigênio, umidade, reações com material de acondicionamento primário, degradação por microrganismos e vibrações ocasionadas por transporte inadequado. Dentre os fatores intrínsecos, 
ocasionados pela própria incompatibilidade dos componentes entre si ou com as características físicas da preparação e/ou do material de acondicionamento, destacam-se a variação do valor de $\mathrm{pH}$, a incompatibilidade física, reações de óxidoredução e reações de hidrólise (AGÊNCIA NACIONAL DE VIGILÂNCIA SANITÁRIA, 2004).

Além de permitir a avaliação do desempenho, segurança e eficácia do produto cosmético, o estudo de estabilidade orienta o desenvolvimento das formulações cosméticas, direcionando aos materiais de acondicionamento mais apropriados à formulação e fornecendo informações para aperfeiçoamento das formulações em casos de manifestações de instabilidade e/ou incompatibilidade entre componentes (AGÊNCIA NACIONAL DE VIGILÂNCIA SANITÁRIA, 2004).

Para que o teste de estabilidade seja significativo, é importante estabelecer as variáveis que serão avaliadas, definindo os critérios de aceitação e/ou os métodos aptos a mensurar as variações destes atributos ao longo do tempo. A definição dos testes a serem avaliados são de responsabilidade e critério do analista, uma vez que cada formulação possui suas características particulares. Estes critérios devem levar em consideração, também, as principais características do produto analisado, pois são estes atributos que devem permanecer inalterados - ou alterados de forma que não comprometam o desempenho e a apresentação das preparações (BAREL et al., 2001).

A realização do estudo de estabilidade é importante desde o desenvolvimento das formulações, em laboratório, até a fabricação dos lotes-piloto e dos primeiros lotes industriais. Além disso, o estudo deve ser novamente conduzido em caso de alterações nos componentes da formulação, material de acondicionamento, processos de fabricação e equipamentos, uma vez que tais alterações podem modificar completamente as características da formulação (AGÊNCIA NACIONAL DE VIGILÂNCIA SANITÁRIA, 2004).

Os estudos de estabilidade devem ser conduzidos no menor tempo possível, em condições que acelerem a manifestação dos processos de instabilidade, mas que não sejam tão extremas ao ponto que provoquem reações que não ocorreriam nem mesmo no tempo de prateleira do produto. Esta sistemática permite conclusões sobre a estabilidade do produto e uma avaliação gradativa dos processos de instabilidade. Assim, recomenda-se, seqüencialmente, a condução dos Testes de Estabilidade Preliminar, caracterizada por uma triagem das formulações básicas, em 
condições mais adversas que os demais testes, o que permite a seleção das formulações de melhor desempenho; os Testes de Estabilidade Acelerada, que permitem uma previsão das possíveis manifestações de instabilidade da formulação no mercado e a determinação do provável prazo de validade do produto; e, finalmente, os Testes de Estabilidade Normal, Longa Duração ou Shelf-life (tempo de prateleira), que permitem avaliar as variações nas características da formulação em condições normais do mercado durante todo o prazo de validade do produto, validando-o (AGÊNCIA NACIONAL DE VIGILÂNCIA SANITÁRIA, 2004).

As variações e as manifestações observadas durante um estudo de estabilidade podem não ocorrer com os produtos em condições de uso (shelf life). Neste sentido, o estudo de estabilidade é uma ferramenta para triagem do todas as possíveis manifestações de estabilidade de uma formulação, mesmo que elas nunca ocorram nas condições de uso do produto, prevenindo os analistas das manifestações possíveis e garantindo uma triagem minuciosa das características e possíveis alterações a que o produto está sujeito antes que seja liberado para o consumidor (BAREL et al., 2001; AGÊNCIA NACIONAL DE VIGILÂNCIA SANITÁRIA, 2004).

\section{AVALIAÇÃO INSTRUMENTAL}

A aplicação de um produto cosmético sobre a pele pode promover efeitos negativos ou positivos. Desta maneira, é importante definir procedimentos e métodos experimentais que sejam capazes de determinar a extensão destas alterações.

A avaliação da eficácia de produtos cosméticos pode ser realizada in vitro (fase pré-clínica), como os estudos em membranas celulares isoladas. Estudos de absorção percutânea e de toxicidade estão entre os mais comuns testes in vitro. Apesar de serem estudos mais dinâmicos, pois permitem a triagem de várias substâncias simultaneamente, eles não avaliam o impacto das substâncias no organismo como um todo, sendo necessário, em algumas ocasiões, mais de um teste pré-clínico para que seja realizada a equivalência dos resultados com o estudo in vivo (AUBIN, 1994; MAJMUDAR \& SMITH, 1998).

A fase clínica, que envolve a avaliação em seres humanos, fornece resultados mais conclusivos a respeito do desempenho do produto, mas só pode ser realizada caso sejam seguidas as normas estabelecidas pelos comitês de ética 
em pesquisa. A partir daí, a comprovação da eficácia pode ser determinada por análises subjetivas (como as avaliações sensoriais) ou objetivas, utilizando instrumentos e equipamentos específicos (SOUZA, 2000).

Existem muitos métodos para avaliar eficácia de produtos cosméticos. Parâmetros relevantes incluem aspectos sensoriais, efeito percebido, aparência visual e integridade da pele. O método a ser utilizado depende dos objetivos da avaliação e geralmente os ensaios clínicos utilizam várias metodologias simultaneamente. Na eficácia percebida, muito utilizada quando existem muitos sujeitos de estudo ( $n>100)$, geralmente o consumidor aplica o produto em casa com freqüência e período de tempo determinados e preenche questionários periodicamente. A avaliação pessoal é importante também para correlacionar os benefícios percebidos com aqueles mensuráveis por equipamentos específicos (RAWLINGS \& HARDING, 2004).

As técnicas para avaliar a eficácia podem ser visuais, como na fotografia, na videomicroscopia, na observação visual por especialista ou na auto-avaliação subjetiva. Podem ser mais específicas como na avaliação da hidratação por higrômetros (medidas de capacitância e condutância) e por espectroscopia (acústica, infra-vermelho, ressonância magnética nuclear). Para avaliar a função de barreira da pele, pode-se medir a perda de água transepidérmica (TEWL) e para avaliar a elasticidade, existem algumas técnicas biomecânicas, como o ballistometer, o dermal torque meter e o pinch recoil (RAWLINGS \& HARDING, 2004).

A duração dos testes de eficácia pode variar desde um dia, caracterizando os estudos de cinética de avaliação, com aplicação única do produto, até várias semanas, com várias aplicações em tempos determinados (RAWLINGS \& HARDING, 2004).

\subsection{Corneometria}

É importante a presença de água no estrato córneo para conferir maciez, flexibilidade e aspecto saudável à pele. Portanto, a determinação in vivo do grau de hidratação do estrato córneo está relacionada não somente com a aparência estética da epiderme, mas também com a identificação de patologias, grau de envelhecimento da pele e, principalmente, a verificação da eficácia de formulações com ação hidratante (BAREL \& CLARYS, 1995). 
A corneometria baseia-se no princípio de um capacitor comum, que consiste em duas placas metálicas eletricamente isoladas por vácuo, ar, vidro ou plástico (dielétrico). Quando uma carga uniforme é conduzida em um capacitor ideal, existe excesso de elétrons na placa negativa e, conseqüentemente, pequena quantidade na placa positiva, condição que deve permanecer inalterada quando a fonte for removida. Capacitância é a capacidade de armazenar carga elétrica. Como a carga negativa atrai a positiva e vice-versa, cria-se um campo elétrico entre as cargas, o que afeta as moléculas do dielétrico. A placa positiva atrai os elétrons e a negativa, os núcleos atômicos. Ocorre a polarização de moléculas inicialmente neutras, que passam para pólos opostos, positivos e negativos, o que permite ao capacitor armazenar mais carga, aumentando sua capacidade. As características de cada dielétrico influenciam o aumento de capacitância pelo capacitor. A maior parte dos materiais aumenta a capacitância de um capacitor por um fator menor que 7, quando comparado ao vácuo. Um fator de aumento de cerca de 81 é observado quando o dielétrico for a água. Isso significa que a quantidade de água na pele é proporcional à capacitância (BERARDESCA et al., 1995).

O Corneometer ${ }^{\circledR}$ é um equipamento que determina a variação do conteúdo de água no estrato córneo por meio de capacitância em uma grande variedade de condições patológicas, fisiológicas e/ou experimentais. Suas vantagens envolvem a determinação da quantidade de água com alta reprodutibilidade, em um curto período de tempo - cerca de $1 \mathrm{~s}$. Além disso, é um equipamento econômico e de fácil manuseio (BERARDESCA, 1995).

SERUP \& O'GOSHI (2005) realizaram as medidas de capacitância na pele sob condições normais utilizando três equipamentos Corneometer ${ }^{\circledR}$, utilizando duas unidades do modelo of CM820 e uma do modelo CM810. O objetivo foi verificar a reprodutibilidade dos resultados obtidos entre os três instrumentos. Os resultados indicaram que as três unidades apresentavam valores de capacitância similares, apresentando boa correlação entre si.

COUTEAU et al. (2006) analisaram diferentes formulações produtos hidratantes contendo uréia. O objetivo foi comparar, realizando medidas de capacitância por meio do Corneometer $^{\circledR}$ CM825 em indivíduos saudáveis, a influência do efeito hidratante da uréia, quando veiculada por diferentes formas cosméticas, como géis e emulsões óleo em água. As medidas obtidas indicaram que géis de poliacrilamida associados a polissorbato 85 apresentaram capacidade 
hidratante mais elevada que algumas emulsões, enquanto géis de carboximetilcelulose apresentaram a menor capacidade de hidratação da pele dentre as preparações avaliadas.

SHIMIZU et al. (2005) avaliaram a hidratação, flexibilidade, espessura e perda de água transepidérmica em pacientes com ictiose congênita, distúrbio que causa desordens no processo de queratinização, comprometendo a integridade do estrato córneo. As medidas de hidratação do estrato córneo foram realizadas com o Corneometer $^{\circledR}$ ASA-M2. Verificou-se que os voluntários analisados apresentavam hidratação reduzida do estrato córneo. Pôde-se afirmar que, em conjunto com as demais medidas, a determinação da hidratação do estrato córneo é um fator importante na determinação da severidade de ictiose congênita.

Portanto, a determinação da capacitância da pele utilizando-se a corneometria é uma importante ferramenta na determinação de patologias do tegumento bem como da eficácia de formulações cosméticas hidratantes.

\subsection{Determinação da perda de água transepidérmica}

Uma das funções da pele é evitar a perda de água do organismo para o ambiente. Assim, a medida da perda de água transepidérmica é importante na avaliação de patologias, fenômenos fisiológicos e eficácia de tratamentos dermatológicos e cosméticos (BERARDESCA et al., 1995). A perda de água transepidérmica é dependente da umidade relativa do ar, da integridade da barreira cutânea, da temperatura e, inversamente, da espessura do estrato córneo. Há três técnicas para determinação da perda de água transepidérmica (transepidérmica water loss - TEWL):

- Método da câmara fechada: avaliação da pele que não permite uma avaliação contínua pois, uma vez que é realizado em ambiente fechado, a saturação do ar faz com que a perda de água pela pele seja interrompida.

- Método da câmara ventilada: a mistura de um gás com quantidade definida de água passa pela pele, em câmara fechada. A água é interceptada por um higrômetro. Permite mensurações contínuas, mas 
um gás muito seco pode induzir evaporação anormal da pele, causando interferência.

- Método da câmara aberta: método realizado em aberto, sendo um princípio largamente utilizado em equipamentos. Deve-se atentar para o movimento do ar e umidade, que são interferentes do método (BERARDESCA et al., 1995).

O Tewameter $^{\circledR}$ TM 210 tem seu princípio baseado no método da câmera aberta. O equipamento possui um probe (dispositivo) que é colocado sobre a pele do voluntário. O local de contato do probe com a pele é um cilindro $(10 \mathrm{~mm}$ de diâmetro e $20 \mathrm{~mm}$ de altura), dentro do qual estão o sensores de temperatura e umidade. A configuração do probe, em formato cilíndrico, tem o objetivo de impedir a interferência do ar e umidade atmosféricos e ele é conectado a um equipamento que decodifica os dados obtidos, convertendo-os em unidades arbitrárias de medida de umidade (BERARDESCA et al., 1995).

FLUHR et al. (2005) avaliaram a alteração da permeabilidade da barreira cutânea por meio da exposição de voluntários à irritação por lauril sulfato de sódio, em concentrações variando de 0 a $5 \%$, na tentativa de simular injúrias provocadas por xenobióticos no ambiente de trabalho. A permeabilidade da barreira cutânea foi avaliada pela medida da perda de água transepidérmica, utilizando o Tewameter $^{\circledR}$ TM 210. Verificou-se, pelos resultados obtidos com o equipamento, o aumento estatisticamente significativo da perda de água transepidérmica cinco dias após a exposição ao agente, indicando alterações nas propriedades da barreira do tegumento.

Desta forma, a utilização do método de determinação da perda de água transepidérmica em câmara aberta é útil no entendimento de processos fisiopatológicos e na avaliação de desempenho de formulações cosméticas.

\subsection{Cutometria}

A avaliação da elasticidade da pele é importante na determinação de doenças ou manifestações relacionadas a processos como no envelhecimento cutâneo. Assim, a avaliação mecânica da elasticidade proporciona correlações com 
processos bioquímicos e fisiológicos que ocorrem na pele e em todo o organismo (BERARDESCA et al., 1995).

Dados biomecânicos da pele são relativos à tensão que é exercida sobre o órgão e como ele reage. Esta reação é dada pelo estiramento. Após o estiramento, a pele não retorna imediatamente à sua conformação original, mantendo-se ligeiramente deformada, um fenômeno denominado histerese (BERARDESCA et al., 1995). À medida que a idade avança, a rede formada pelas fibras de elastina da derme torna-se mais compacta, diminuindo a capacidade de extensão da pele, e conseqüentemente, sua capacidade de retorno à configuração inicial após ser submetida a uma deformação (SCOTTI e VELASCO, 2003).

Os instrumentos utilizados em bioengenharia para determinação das propriedades mecânicas da pele diferem bastante quanto à forma como provocam a deformação na pele. Conforme o dispositivo, é empregada torção, elevação, impressão, sucção e/ou vibração. As vantagens e desvantagens de cada processo são variadas (BERARDESCA et al., 1995).

Equipamentos baseados em extensão têm seus resultados diretamente relacionados ao ângulo aplicado no local de teste. Eles promovem torção e abrangem uma extensa área de teste, o que exclui locais de avaliação como a face, dedos ou genitálias. Instrumentos baseados em elevação, sucção ou vibração não possuem muitos impedimentos, mas são dependentes de estruturas próprias. (BERARDESCA et al., 1995).

Nas avaliações da elasticidade da pele, fatores biológicos e comportamentais como idade, fototipo, sexo, área do corpo, espessura da pele, distúrbios internos ou da pele, cicatrização ou cura de feridas, uso de medicamentos e cosméticos devem ser levados em consideração na avaliação ou podem ser objetos da avaliação, uma vez que estão relacionados aos processos bioquímicos e fisiológicos da pele (BERARDESCA et al., 1995).

O Cutometer ${ }^{\circledR}$ é um equipamento que, por meio de um probe (dispositivo), aplica uma sucção perpendicular na pele, empregando vácuo. Não existem danos, pois a área aplicação do vácuo é de cerca de $3 \mathrm{~mm}^{2}$. A Figura 5 apresenta uma curva deformação $(E)$ - tempo, obtida com o equipamento. 


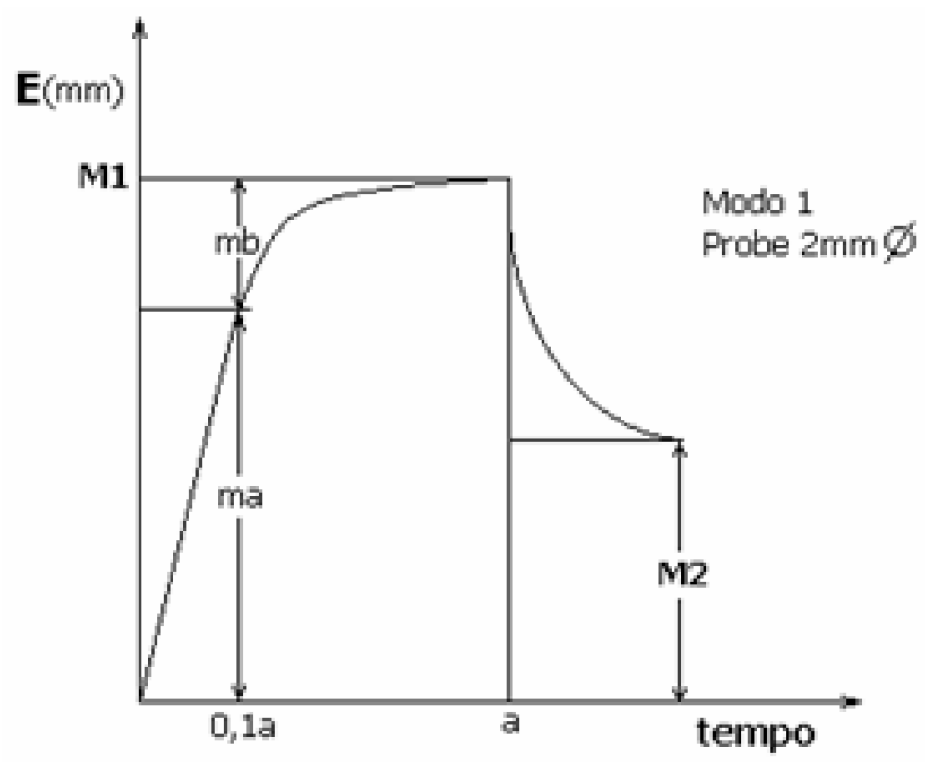

Figura 5. Deformação da pele avaliado por Cutometer ${ }^{\circledR}$ SEM 575 (Courage and Khazaka) (BERARDESCA et al., 1995, adaptada).

A Figura 5 representa a deformação da pele em resposta à sucção. A curva é composta de uma rápida deformação, seguida de uma parte de retração do tecido, retornando à configuração inicial.

O valor de ma é definido como a deformação imediata da pele ou extensibilidade, mb como distensão retardada, M1 como deformação final ou extensibilidade máxima e (M1 - M2) é a retração imediata. O valor de M2 é considerado a deformação resultante em comparação com o valor inicial. O programa do equipamento capta todos estes dados e os armazena em arquivo eletrônico. A razão entre os valores provê significativos resultados biológicos. A razão (M1-M2)/M1 é a taxa de retração imediata à deformação total, denominada elasticidade biológica. Além disso, considera-se que, se M1 decresce, a firmeza cutânea aumenta, e vice-versa. De forma semelhante, se M2 decresce, a elasticidade cutânea aumenta, e vice-versa (BERARDESCA et al., 1995, adaptada).

CUA el al (1990) avaliaram as alterações das propriedades mecânicas em função do envelhecimento em 11 regiões anatômicas de 33 voluntários. Foram aplicadas três diferentes pressões nos locais de avaliação. Verificou-se que a elasticidade diminuía com a idade, sem a observação de nenhuma diferença relativa ao sexo entre as respostas biomecânicas.

$\mathrm{OH}$ et al (2002) avaliaram a variação na elasticidade da pele da face em decorrência de Diabetes mellitus em 96 pacientes com aparência normal. O grupo de pacientes apresentou diminuição significativa da elasticidade da pele, quando 
comparado ao grupo controle. Estes resultados reforçam a teoria que os resultados das avaliações da pele estão diretamente relacionados às patologias do organismo.

Da mesma forma que as demais avaliações instrumentais realizadas em Bioengenharia, a Cutometria pode ser utilizada como ferramenta para elucidar manifestações do organismo ou comprovar a eficácia de substâncias e formulações cosméticas na promoção de melhoria da elasticidade da pele. 
III OBJETIVOS 
O objetivo geral deste trabalho foi:

- Desenvolver formulações de máscaras faciais peel off e emulsões óleo em água contendo extrato de soja fermentado pelo Bifidobacterium animale, avaliando a estabilidade acelerada e o efeito hidratante, tensor e na perda de água transepidérmica.

Os objetivos específicos deste trabalho foram:

- Desenvolver e padronizar o método de determinação do tempo de secagem in vitro de máscaras faciais peel off;

- Realizar os Estudos de Estabilidade Preliminar e Estabilidade Acelerada das bases cosméticas e formulações e selecionar a de melhor desempenho;

- Avaliar o efeito hidratante, tensor e na perda de água transepidérmica das bases de máscara facial peel off e emulsão óleo em água sem adição do extrato de soja fermentado e adicionado deste componente ativo. 
IV MATERIAL E MÉTODOS 


\section{MATERIAL}

\subsection{Reagentes (grau de pureza analítico, P.A.)}

- Ácido clorídrico fumegante $37 \%$, Merck;

- Hidróxido de sódio, Merck.

\subsection{Matérias-primas (grau de pureza farmacêutico)}

- Acriloildimetiltaurato de amônio/Copolímero VP;

- Adipato de dibutila;

- Álcool cetílico etoxilado e propoxilado;

- Álcool de cereais;

- Álcool polivinílico;

- Base autoemulsionante;

- Butilenoglicol;

- Cera autoemulsificante não-iônica;

- Complexos conservantes

- Dimetil dimetil hidantoína / lodo propinil butil carbamato;

- Fenoxietanol/ parabenos;

- Corante azul;

- EDTA tetrassódico diidratado;

- Essência Givaudan ${ }^{\circledR}$;

- Extrato de soja contendo isoflavonas;

- Glicerídeos etoxilados derivados do leite;

- Glicerina;

- Goma Guar;

- Lactato de miristila;

- Metilparabeno;

- Oleato de decila;

- Óleo mineral;

- Palmitato de isopropila;

- Propilenoglicol; 
- Silicone de copolímero glicol;

- Silicone poliéter.

A seguir, tem-se a descrição detalhada das matérias-primas acima citadas.

\section{ACRILOILDIMETILTAURATO DE AMÔNIO/ COPOLÍMERO VP}

- Aspecto: pó branco a $20^{\circ} \mathrm{C}$

- $\mathrm{pH}$ (1\% em água destilada): 4,0 - 6,0

- Viscosidade (1\% em água destilada): 48000 - $80000 \mathrm{mPas}$

- Estudo crítico: copolímero de ácido sulfônico usado como modificador reológico em sistemas aquosos e como espessantes/estabilizantes de emulsão em emulsões óleo/água.

- Nome comercial: Aristoflex ${ }^{\circledR}$ AVC

- Concentrações de uso: 0,5 a 1,0\%

- Pode ser usado numa faixa de pH de 4,0 a 9,0 (CLARIANT, 2007)

\section{ADIPATO DE DIBUTILA}

- $C A S N^{0}: 105-99-7$

- Nome INCI: DIBUTYL ADIPATE

- Aspecto: óleo de baixo peso molecular, incolor, inodoro.

- Nome comercial: Cetiol $B^{\circledR}$

- Estudo crítico: plastificante, solvente, melhora a espalhabilidade da formulação (BRANDÃO, 2000; SPECIAL CHEM, 2007)

\section{ÁLCOOL CETÍLICO ETOXILADO E PROPOXILADO}

- CAS N ${ }^{0} .9087-53-0$

- Nome comercial: Procetyl ${ }^{\circledR}$ AWS

- Aspecto: líquido claro a levemente turvo 
- Estudo crítico: solúvel em água, é um tensoativo emoliente e solubilizante de essências lipofílicas. Utilizado em formulações de xampus, géis de banho e desodorantes

- Concentrações de uso: 0,5 a 5,0\% (CRODA, 2006)

\section{ÁLCOOL DE CEREAIS}

- Fórmula molecular: $\mathrm{C}_{2} \mathrm{H}_{6} \mathrm{O}$

- Definição: etanol desodorizado

- Estudo crítico: solvente, conservante, agente secante (BRANDÃO, 2000)

\section{ÁLCOOL POLIVINÍLICO}

- Definição: polímero derivado do acetato de polivinila

- Nome comercial: Poval ${ }^{\circledR} 224$

- Fórmula mínima: $\left(-\mathrm{C}_{2} \mathrm{H}_{4} \mathrm{O}\right)_{n}$

- Fórmula estrutural:

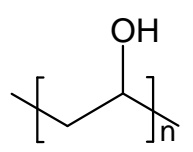

- Aspecto: pó branco a amarelado

- Ponto de fusão: aproximadamente $190^{\circ} \mathrm{C}$

- Solubilidade em água: $10 \mathrm{~g} / 100 \mathrm{~mL}$

- Estudo crítico: Agente emulsificante e de polimerização; dispersante; formador de filme (ARANHA \& LUCAS, 2001; IPIRANGA QUÍMICA, 2006)

\section{BASE AUTOEMULSIONANTE}

- Composição: associação balanceada de doadores de viscosidade, emulsionantes, ésteres fosfóricos e emolientes não comedogênicos. Atua como tensoarivo aniônico

- Nome comercial: Hostacerin ${ }^{\circledR} \mathrm{NCB}$

- Estabilidade: estável na faixa de pH de 4,0 a 9,0 
- Estudo crítico: utilizada em formulações de emulsões O/A (óleo/água) não comedogênicas estáveis, que têm como principais características uma fácil espalhabilidade e um toque agradável à pele, não promovendo sensação pegajosa e deixando sobre a pele um toque de suavidade. Tem caráter aniônico e é compatível com diversos aditivos como extratos vegetais, Aloe vera, alguns solventes orgânicos, como etanol, e também princípios ativos farmacêuticos incluindo aqueles que requerem valores de $\mathrm{pH}$ mais baixos, como os AHA`s (CLARIANT, 2006)

\section{BUTILENOGLICOL}

- $C A S N^{0}: 107-88-0$

- Sinonímia: 1,3-butilenoglicol

- Aspecto: líquido viscoso, incolor, odor característico

- Solubilidade: miscível em água e álcoois

- Estudo crítico: agente regulador da viscosidade, umectante, solvente (BRANDÃO, 2000)

\section{CERA AUTOEMULSIONANTE NÃO-IÔNICA}

- Nome INCI: EMULSIFYING WAX NF

- Nome comercial: Uniox $C^{\circledR}$

- Definição: cera auto-emulsionante de caráter não iônico, estável com a maioria dos princípios ativos cosméticos e farmacêuticos.

- Estudo crítico: agente de consistência

- Concentração usual: de 5 a 15\% (CHEMYUNION, 2007) 


\section{COMPLEXOS CONSERVANTES}

\section{DMDMH / IPBC - DIMETIL DIMETIL HIDANTOÍNA / IODO PROPINIL BUTIL CARBAMATO}

- Composição: combinação dos ativos dimetil dimetil hidantoína (DMDMH) com o iodo propinil butil carbamato (IPBC)

- Nome comercial: Glydant plus ${ }^{\circledR}$

- Aplicação: conservante, bacteriostático e fungicida.

- Fórmula estrutural:
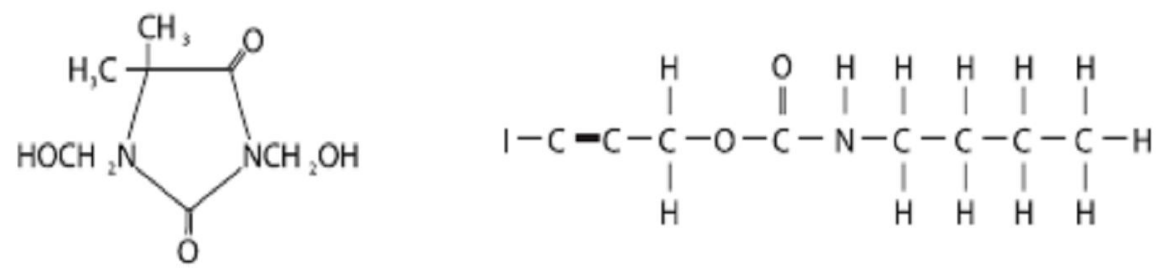

- Aparência física: líquido límpido incolor

- $\mathrm{pH}: 6,5-7,5$

- Solubilidade: solúvel em água, surfactantes catiônicos, aniônicos e não aniônicos

- Concentração de IPBC no Glydant Plus: 2,8\% (máxima)

- Concentração de DMDMH no Glydant Plus: 70\% (LONZA, 2006)

\section{FENOXIETANOL / PARABENOS}

- CAS N ${ }^{0}: 122-99-6 ; 99-76-3 ; 120-47-8 ; 94-26-8 ; 94-13-3 ; 4247-02-3$

- Nome comercial: Phenova ${ }^{\circledR}$

- Nome INCl: Phenoxyethanol \& Methylparaben \& Ethylparaben \& Butylparaben \& Propylparaben \& Isobutylparaben

- Aspecto: líquido incolor a levemente amarelado

- Estudo crítico: antimicrobiano de amplo espectro (CRODA, 2007) 


\section{CORANTE AZUL}

- CAS No. 3844-45-9

- Color Index: 42090

- Nome comercial: Corante Bleu Soluble ${ }^{\circledR}$ W6002

- Definição: triarilmetano (corante azul)

- Aspecto: pó azul

- Solubilidade em água $\left(20^{\circ} \mathrm{C}\right): 100 \mathrm{~g} / \mathrm{L}$

- $\mathrm{pH}$ (1\% em água destilada): 6,5 a 7,5

- Estudo crítico: corretivo da cor permitido para todos os tipos de produtos (LCW, 2006; BRASIL, 2000)

\section{EDTA TETRASSÓDICO DIIDRATADO}

- CAS N ${ }^{0} .10378-23-1$

- Fórmula molecular: $\mathrm{C}_{10} \mathrm{H}_{12} \mathrm{~N}_{2} \mathrm{Na}_{4} \mathrm{O}_{8} \cdot 2 \mathrm{H}_{2} \mathrm{O}$

- Aspecto: pó branco cristalino

- Solubilidade: levemente solúvel em solventes orgânicos, como etanol e facilmente solúvel em água

- Estudo crítico: quelante de íons metálicos, atuando como antioxidante preventivo (BRANDÃO, 2000)

\section{ESSÊNCIA GIVAUDAN ${ }^{\circledR}$}

- Composição: essência floral doce de caráter lipofílico

- Estudo crítico: aromatizante

\section{EXTRATO DE SOJA CONTENDO ISOFLAVONAS, YAKULT COSMETICS}

- Composição: solução aquosa obtida da fermentação do leite de soja por Bifidobacterium animalis (OTIENO et al., 2006). A composição média quantitativa e qualitativa do leite de soja e o conteúdo de agliconas 
(isoflavonas livres) no extrato fermentado estão descritas no Quadro 4 (YAKULT COSMETICS, 2007).

Quadro 4. Composição do extrato (leite) de soja antes e após fermentação por Bifidobacterium animale (YAKULT COSMETICS, 2007).

\begin{tabular}{c|c}
\hline \multicolumn{2}{c}{ Extrato (leite) de soja } \\
\hline Componentes (antes da fermentação) & Quantidade/ 100 $\mathbf{~ L L}$ \\
\hline Carboidratos & $2,5 \%$ \\
\hline Proteínas & $3,4 \%$ \\
\hline Lipídeos & $2,3 \%$ \\
\hline Cálcio & $40 \mathrm{mg}$ \\
\hline Potássio & $105 \mathrm{mg}$ \\
\hline Ferro & $1,2 \mathrm{mg}$ \\
\hline Vitamina B1 & $40 \mathrm{mg}$ \\
\hline Vitamina B2 & $120 \mathrm{mg}$ \\
\hline Isoflavonas totais & $3,6 \mathrm{mg}$ \\
\hline Isoflavonas livres & Não detectável \\
\hline \multicolumn{2}{c|}{ Extrato (leite) de soja } \\
\hline Componentes (após a fermentação) & Quantidade/ 100 $\mathbf{m L}$ \\
\hline Isoflavonas livres & $3,5 \mathrm{mg}$ \\
\hline
\end{tabular}

- Estudo crítico: provável efeito hidratante na pele e prevenção do envelhecimento cutâneo, através da ação antioxidante das isoflavonas de soja presentes no leite (BAUMANN \& LAZARUS, 2001).

\section{GLICERÍDEOS ETOXILADOS DERIVADOS DO LEITE}

- Nome INCI: HYDROXILATED MILK GLYCERIDES

- Nome comercial: Cremerol $\mathrm{HMG}^{\circledR}$

- Estudo crítico: agente condicionador da pele, conferindo hidratação superficial e maciez (BRANDÃO, 2000) 


\section{GLICERINA}

- CAS N $N^{0} .56-81-5$

- Sinonímias: glicerol, 1,2,3 - propanotriol e 1,2,3-triidroxipropano

- Fórmula molecular: $\mathrm{C}_{3} \mathrm{H}_{8} \mathrm{O}_{3}$

- Aspecto: líquido viscoso, incolor e inodoro

- Solubilidade: completamente miscível em água e álcoois

- Estudo crítico: hidratante e umectante em formulações de produtos cosméticos (BRANDÃO, 2000)

\section{GOMA GUAR}

- Aspecto: pó amarelado de livre escoamento.

- Nome comercial: Jaguar ${ }^{\circledR}$

- Peso molecular: por volta de 220.000

- Origem: endosperma de Cyamopsis tetragonolobus (L.) - Leguminosae cultivada na Índia. A porção hidrossolúvel (85\%) é chamada guaran e consiste em cadeias lineares de $(1 \rightarrow 4)-\beta$-D-manopiranosil com $\alpha$-D-galactopiranosil ligadas por ligações $(1 \rightarrow 6)$. A razão entre $D$-galactose e $D$-manose é 1:2

- Solubilidade: completamente solúvel em água fria ou quente; praticamente insolúvel em óleos, gorduras, hidrocarbonetos, cetonas, éteres

- Aspecto: solução aquosa é insípida, inodora, não-tóxica, de coloração cinza translúcida, neutra e estável ao calor

- Outras informações: possui de 5 a 8 vezes o poder espessante do amido. Soluções aquosas podem ser convertidas em gel com pequena quantidade de bórax

- Estudo crítico: colóide protetor, estabilizante, espessante e agente formador de filme em suspensões, emulsões, loções, cremes e pastas de dentes (MERCK, 1996) 


\section{LACTATO DE MIRISTILA}

- CAS No: 1323-03-1

- Nome INCI: MYRISTYL LACTATE

- Nomes comerciais: Uniester ${ }^{\circledR}$ LM

- Estudo crítico: agente condicionador da pele

- Definição: éster derivado de alfa hidróxi-ácidos com propriedade umectante.

Promove brilho e toque suave e sedoso

- Concentração usual: 1 a 5\% (CHEMYUNION, 2007)

\section{METILPARABENO}

- CAS No: 99-76-3

- Definição: Ácido 4-hidroxibenzóico metil ester; metil p-hidroxibenzoato

- Nome comercial: Nipagin ${ }^{\circledR}$

- Fórmula molecular: $\mathrm{C}_{8} \mathrm{H}_{8} \mathrm{O}_{3}$

- Fórmula estrutural:<smiles>COC(=O)c1ccc(O)cc1</smiles>

- Ponto de fusão: $131^{\circ} \mathrm{C}$

- Ponto de ebulição: $270-280^{\circ} \mathrm{C}$

- Solubilidade: $1 \mathrm{~g}$ dissolve em $400 \mathrm{~mL}$ água, $40 \mathrm{~mL}$ de óleo aquecido, $70 \mathrm{~mL}$ de glicerol aquecido. Solúvel em álcool, acetona e éter

- Análise crítica: antimicrobiano utilizado como conservante em cosméticos, exercendo ação contra bolores e fungos (MERCK, 1996).

\section{OLEATO DE DECILA}

- CAS No: 3687-46-5

- Nome INCI: DECYL OLEATE

- Nome comercial: Cetiol $\mathrm{V}^{\circledR}$ 
- Definição:- éster do álcool decílico com ácido oléico

- Aspecto: líquido transparente, branco a amarelo pálido.

- Densidade: $0,86 \mathrm{~g} / \mathrm{L}$ a $20^{\circ} \mathrm{C}$

- Solubilidade: Insolúvel em água

- Nomes comerciais: Cetiol ${ }^{\circledR}$, Ceraphyl $140^{\circledR}$

- Estudo crítico: agente condicionador da pele e emoliente (BRANDÃO, 2000)

- Fórmula estrutural (ÁBACO VITAL, 2007):

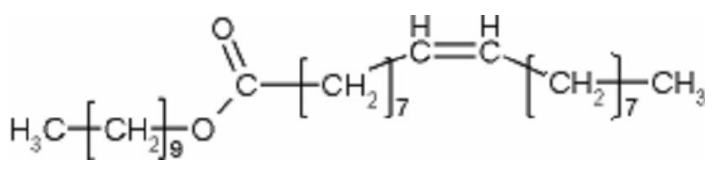

\section{ÓLEO MINERAL}

- CAS No: 8012-95-1

- Definição: petrolato líquido, parafina líquida; óleo mineral branco;

- Nomes comerciais: Vaselina Líquida ${ }^{\circledR}$

- Características: incolor, óleo líquido, praticamente inodoro e insípido mesmo quando aquecido

- Solubilidade: Insolúvel em água e etanol. Solúvel em benzeno, clorofórmio, éter, dissulfeto de carbono, éter de petróleo e óleos

- Estudo crítico: lubrificante, emoliente, agente condicionador e protetor da pele, agente condicionador dos cabelos (BRANDÃO, 2000; MERCK, 1996).

\section{PALMITATO DE ISOPROPILA}

- CAS N $\mathrm{N}^{0}: 142-91-6$

- Estudo crítico: agente condicionador da pele, emoliente, promove aumento de consistência da formulação (BRANDÃO, 2000)

- Fórmula molecular: $\mathrm{CH}_{3}\left(\mathrm{CH}_{2}\right)_{14} \mathrm{COOCH}\left(\mathrm{CH}_{3}\right)_{2}$

- Origem: sintética, podendo ser produzido a partir do ácido graxo animal ou de origem vegetal - a partir da reação de esterificação do ácido palmítico e o álcool isopropílico (ABOISSA, 2007). 


\section{PROPILENOGLICOL}

- CAS N $N^{0}$ 57-55-6

- Sinonímias: 1,2-propanodiol; metiletileno glicol; propilenoglicol; 1,2 diidroxipropano

- Fórmula molecular: $\mathrm{C}_{3} \mathrm{H}_{8} \mathrm{O}_{2}$

- Aspecto: líquido viscoso, incolor e inodoro.

- Solubilidade: miscível em água, acetona e clorofórmio, mas imiscível com óleos

- Características: líquido higroscópico, estável, mas incompatível com cloretos ácidos, anidridos ácidos, agentes oxidante e redutores

- Estudo crítico: umectante, hidratante para a pele, solvente e agente redutor da viscosidade (BRANDÃO, 2000).

\section{SILICONE DE COPOLÍMERO GLICOL}

- Descrição INCI: PEG-12 Dimeticona

- Definição: silicone de copolímero glicol solúvel em água, álcool e sistemas hidroalcoólicos; é hidroliticamente estável

- Nome comercial: Silicone ${ }^{\circledR}$ DC 193 Fluid

- Estudo crítico: agente aplicado na diminuição da tensão superficial, agente umectante, emulsificante e formador de espuma em uma grande variedade de cosméticos e produtos de cuidado pessoal

- Viscosidade $\left(25^{\circ} \mathrm{C}\right): 425 \mathrm{~mm}^{2} . \mathrm{s}^{-1}$

- Quantidade utilizada em loções para pele para proporcionar emoliência, lubrificação e umidade: 0,1 a 2,0\% (DOW CORNING, 2006)

\section{SILICONE POLIÉTER}

- Nome INCI: CYCLOPENTASILOXANE E PEG/PPG-18/18 DIMETHICONE

- Definição: dispersão a $10 \%$ de silicone poliéter de alto peso molecular em ciclopentasiloxano fluido

- Nome comercial: Dow Corning ${ }^{\circledR} 5225 \mathrm{C}$ 
- Aspecto: líquido translúcido a pouco turvo, acinzentado; possível ocorrer pouca sedimentação

- Estudo crítico: agente aplicado na diminuição da tensão superficial, agente umectante, emulsificante e formador de espuma em uma grande variedade de cosméticos e produtos de cuidado pessoal (DOW CORNING, 2007)

\subsection{Equipamentos}

- Agitador mecânico em hélice - IKA ${ }^{\circledR}$, modelo RW 20.n.;

- Agitador tipo mixer Walita ${ }^{\circledR}$ mode RI 312;

- Balança analítica - Sartorius ${ }^{\circledR}$, modelo BL21OS;

- Balança semi-analítica eletrônica Explorer, com precisão de 0,01 mg, modelo OHAUS ${ }^{\circledR}$;

- Banho-maria digital $\left(0\right.$ a $\left.100^{\circ} \mathrm{C}\right)$ - Nova Ética ${ }^{\circledR}$, modelo 500D;

- Centrífuga - Donner ${ }^{\circledR}$, modelo CD100;

- Corneometer ${ }^{\circledR}$ CM 825 ou Combi 3 SM CM PH (Courage \& Khazaka);

- Cutometer $^{\circledR}$ SEM 575 (Courage\&Khazaka);

- Destilador de água - Fabbe ${ }^{\circledR}$, modelo 106;

- Estufa - Fanem ${ }^{\circledR}$, modelo $902 \mathrm{CB}$;

- Freezer Consul ${ }^{\circledR}$ Slim 200;

- Geladeira Bosch ${ }^{\circledR} 370$ Eco Plus;

- Peagômetro (pHmetro) - Digimed $^{\circledR}$, DM 20;

- Termômetro com graduação de 0 a $100 \stackrel{\circ}{\circ}$;

- Tewameter $^{\circledR}$ TM 210 ou Combi 3 SM CM PH (Courage\&Khazaka);

- Viscosímetro - Fungilab ${ }^{\circledR}$ S.A. modelo Visco Star-R, agulhas TR 10 e TR 11.

\subsection{Outros materiais}

- Dedeira de látex natural, Mucambo;

- Espátula plástica;

- Frascos de polietileno branco opaco, capacidade de $50 \mathrm{~g}$;

- Frascos de vidro transparente, inerte, com capacidade de $60 \mathrm{~g}$; 
- Gabarito de plástico, $5 \mathrm{~cm} \times 5 \mathrm{~cm}$;

- Maca ambulatorial, Ramsor;

- Marcador cirúrgico Codman, J\&J Professional, INC - EUA;

- Pincel tigre $n^{\circ} 4$;

- Placa de vidro - $4 \mathrm{~mm}$ de espessura, $30 \mathrm{~cm}$ de comprimento, $30 \mathrm{~cm}$ de largura;

- Seringas descartáveis, sem agulha, com capacidade de $1 \mathrm{~mL}$; estéril, atóxica e apirogênica, Ingex;

\subsection{Descrição quali e quantitativa das bases de máscara facial peel off e pré- formulações de emulsão}

Foram elaboradas bases cosméticas utilizando o álcool polivinílico (máscaras faciais peel off) e emulsões óleo em água (O/A).

A elaboração de ambas preparações objetivou comparar seu desempenho nos testes de eficácia clínica, descritos posteriormente, considerando que possuem perfis de aplicação distintos, com e sem remoção do produto após a aplicação, respectivamente. Adicionalmente, foi acrescentado às bases cosméticas o extrato de soja fermentado por Bifidobacterium animale a $5 \%$ p/p. A partir deste momento, as bases passaram a ser denominadas formulações.

A máscara facial peel off é removida da superfície da pele minutos após sua aplicação. Foram avaliados os efeitos tensor e hidratante com e sem o extrato de soja fermentado pelo Bifidobacterium animale, tanto nas bases quanto nas formulações, verificando se ocorreria a potencialização destes efeitos pela adição do extrato. Possuindo um perfil de aplicação diferente, a emulsão é uma formulação cosmética que permanece na pele, após sua aplicação. A utilização da base da emulsão nos testes clínicos foi útil para a comparação dos efeitos tensor e hidratante de formas cosméticas com perfil de aplicação distinto da máscara facial peel off, que é removida após secagem. Além disso, a utilização do extrato de soja fermentado incorporado à base da emulsão permitiu definir se a base interferiu nos efeitos do extrato, tanto durante o estudo de estabilidade como na avaliação clínica.

A seleção da máscara facial peel off ideal para os testes clínicos foi iniciada com a elaboração de 36 bases cosméticas, com a posterior realização do Estudo de Estabilidade Preliminar e seleção da base de melhor desempenho. A esta base, foi 
adicionado o extrato de soja fermentado e foram feitas adaptações na composição dos excipientes, visando aprimorar o tempo de secagem e diminuir as possíveis manifestações de instabilidade da formulação. Dentre as oito formulações resultantes das adaptações, foi selecionada a de melhor desempenho, após Estudos de Estabilidade Preliminar e Acelerada, para realização dos testes clínicos. A seguir, estão descritas as etapas citadas anteriormente.

As Tabelas 1 a 4 descrevem 36 bases de máscaras faciais peel-off, sem 0 emprego do extrato de soja fermentado, inicialmente elaboradas para o Estudo de Estabilidade Preliminar (BABY, 2005; AGÊNCIA NACIONAL DE VIGILÂNCIA SANITÁRIA, 2004; PINTO, 2005; TRAVERSA, 2003; ZAGUE, 2007).

A Tabela 5 descreve a base da emulsão óleo em água (ES) e a base acrescida do extrato de soja fermentado (EC), denominada formulação. Ambas foram submetidas ao Estudo de Estabilidade Preliminar e ao Estudo de Eficácia Clínica.

A escolha da base da emulsão foi fundamentada em estudos realizados previamente por PINTO (2005), que a submeteu aos estudos de Estabilidade Preliminar, Acelerada e Normal. Os estudos de Estabilidade Preliminar foram refeitos com a base da emulsão e a formulação, contendo o extrato de soja fermentado por Bifidobacterium animale. A concentração utilizada do extrato de soja foi $5 \% \mathrm{p} / \mathrm{p}$, a mesma utilizada para a máscara facial peel off. Esta concentração, por sua vez, foi definida a partir de concentrações usualmente utilizadas para substâncias ativas em máscaras disponíveis no mercado (COLIPA, 2008). 
Tabela 1. Bases de máscara facial peel off (1 a 11) submetidas ao Estudo de Estabilidade Preliminar (EP), com as concentrações dos componentes variáveis em negrito.

\begin{tabular}{|c|c|c|c|c|c|c|c|c|c|c|c|}
\hline \multicolumn{12}{|c|}{ Pré-Formulação (\% p/p) } \\
\hline COMPONENTES & 1 & 2 & 3 & 4 & 5 & 6 & 7 & 8 & 9 & 10 & 11 \\
\hline \multicolumn{12}{|l|}{ Fase aquosa } \\
\hline $\begin{array}{l}\text { Álcool Polivinílico } \\
\text { (PVA) }\end{array}$ & 12,0 & 12,0 & 12,0 & 12,0 & 12,0 & 12,0 & 12,0 & 12,0 & 12,0 & 15,0 & 15,0 \\
\hline Propilenoglicol & 8,0 & 8,0 & - & - & - & - & 8,0 & - & - & 8,0 & 8,0 \\
\hline Glicerina & - & - & 8,0 & 8,0 & - & - & - & 8,0 & - & - & - \\
\hline Butilenoglicol & - & - & - & - & 8,0 & 8,0 & - & - & 8,0 & - & - \\
\hline Água destilada q.s.p. & 100,0 & 100,0 & 100,0 & 100,0 & 100,0 & 100,0 & 100,0 & 100,0 & 100,0 & 100,0 & 100,0 \\
\hline \multicolumn{12}{|l|}{ Fase complementar } \\
\hline DMDMH / IPBC & 0,5 & 0,5 & 0,5 & 0,5 & 0,5 & 0,5 & 0,5 & 0,5 & 0,5 & 0,5 & 0,5 \\
\hline $\begin{array}{l}\text { Silicone de Copolímero } \\
\text { glicol }\end{array}$ & 2,0 & 1,0 & 2,0 & 1,0 & 2,0 & 1,0 & - & - & - & 2,0 & 1,0 \\
\hline Base autoemulsionante & 2,0 & 1,0 & 2,0 & 1,0 & 2,0 & 1,0 & - & - & - & 2,0 & 1,0 \\
\hline $\begin{array}{l}\text { Álcool cetílico } \\
\text { etoxilado e propoxilado }\end{array}$ & - & - & - & - & - & - & 2,0 & 2,0 & 2,0 & - & - \\
\hline Corante azul & 0,1 & 0,1 & 0,1 & 0,1 & 0,1 & 0,1 & 0,1 & 0,1 & 0,1 & 0,1 & 0,1 \\
\hline Essência Givaudan ${ }^{\circledR}$ & 0,05 & 0,05 & 0,05 & 0,05 & 0,05 & 0,05 & 0,05 & 0,05 & 0,05 & 0,05 & 0,05 \\
\hline Álcool de cereais & 8,0 & 8,0 & 8,0 & 8,0 & 8,0 & 8,0 & 8,0 & 8,0 & 8,0 & 8,0 & 8,0 \\
\hline EDTA tetrassódico & 0,1 & 0,1 & 0,1 & 0,1 & 0,1 & 0,1 & 0,1 & 0,1 & 0,1 & 0,1 & 0,1 \\
\hline
\end{tabular}


Tabela 2. Bases de máscara facial peel off (12 a 22) submetidas ao Estudo de Estabilidade Preliminar (EP), com as concentrações dos componentes variáveis em negrito.

\begin{tabular}{|c|c|c|c|c|c|c|c|c|c|c|c|}
\hline \multicolumn{12}{|c|}{ Pré-Formulação (\% p/p) } \\
\hline COMPONENTES & 12 & 13 & 14 & 15 & 16 & 17 & 18 & 19 & 20 & 21 & 22 \\
\hline \multicolumn{12}{|l|}{ Fase aquosa } \\
\hline $\begin{array}{l}\text { Álcool Polivinílico } \\
\text { (PVA) }\end{array}$ & 15,0 & 15,0 & 15,0 & 15,0 & 15,0 & 15,0 & 15,0 & 12,0 & 12,0 & 12,0 & 12,0 \\
\hline Propilenoglicol & - & - & - & - & 8,0 & - & - & 6,0 & 6,0 & - & - \\
\hline Glicerina & 8,0 & 8,0 & - & - & - & 8,0 & - & - & - & 6,0 & 6,0 \\
\hline Butilenoglicol & - & - & 8,0 & 8,0 & - & - & 8,0 & - & - & - & - \\
\hline Água destilada q.s.p. & 100,0 & 100,0 & 100,0 & 100,0 & 100,0 & 100,0 & 100,0 & 100,0 & 100,0 & 100,0 & 100,0 \\
\hline \multicolumn{12}{|l|}{ Fase complementar } \\
\hline DMDMH / IPBC & 0,5 & 0,5 & 0,5 & 0,5 & 0,5 & 0,5 & 0,5 & 0,5 & 0,5 & 0,5 & 0,5 \\
\hline $\begin{array}{l}\text { Silicone de Copolímero } \\
\text { glicol }\end{array}$ & 2,0 & 1,0 & 2,0 & 1,0 & - & - & - & 2,0 & 1,0 & 2,0 & 1,0 \\
\hline Base autoemulsionante & 2,0 & 1,0 & 2,0 & 1,0 & - & - & - & 2,0 & 1,0 & 2,0 & 1,0 \\
\hline $\begin{array}{l}\text { Álcool cetílico } \\
\text { etoxilado e propoxilado }\end{array}$ & - & - & - & - & 2,0 & 2,0 & 2,0 & - & - & - & - \\
\hline Corante azul & 0,1 & 0,1 & 0,1 & 0,1 & 0,1 & 0,1 & 0,1 & 0,1 & 0,1 & 0,1 & 0,1 \\
\hline Essência Givaudan ${ }^{\circledR}$ & 0,05 & 0,05 & 0,05 & 0,05 & 0,05 & 0,05 & 0,05 & 0,05 & 0,05 & 0,05 & 0,05 \\
\hline Álcool de cereais & 8,0 & 8,0 & 8,0 & 8,0 & 8,0 & 8,0 & 8,0 & 8,0 & 8,0 & 8,0 & 8,0 \\
\hline EDTA tetrassódico & 0,1 & 0,1 & 0,1 & 0,1 & 0,1 & 0,1 & 0,1 & 0,1 & 0,1 & 0,1 & 0,1 \\
\hline
\end{tabular}


Tabela 3. Bases de máscara facial peel off (23 a 33) submetidas ao Estudo de Estabilidade Preliminar (EP), com as concentrações dos componentes variáveis em negrito.

\begin{tabular}{|c|c|c|c|c|c|c|c|c|c|c|c|}
\hline \multicolumn{12}{|c|}{ Pré-Formulação (\% p/p) } \\
\hline COMPONENTES & 23 & 24 & 25 & 26 & 27 & 28 & 29 & 30 & 31 & 32 & 33 \\
\hline \multicolumn{12}{|l|}{ Fase aquosa } \\
\hline $\begin{array}{l}\text { Álcool Polivinílico } \\
\text { (PVA) }\end{array}$ & 12,0 & 12,0 & 12,0 & 12,0 & 12,0 & 15,0 & 15,0 & 15,0 & 15,0 & 15,0 & 15,0 \\
\hline Propilenoglicol & - & - & 6,0 & - & - & 6,0 & 6,0 & - & - & - & - \\
\hline Glicerina & - & - & - & 6,0 & - & - & - & 6,0 & 6,0 & - & - \\
\hline Butilenoglicol & 6,0 & 6,0 & - & - & 6,0 & - & - & - & - & 6,0 & 6,0 \\
\hline Água destilada q.s.p. & 100,0 & 100,0 & 100,0 & 100,0 & 100,0 & 100,0 & 100,0 & 100,0 & 100,0 & 100,0 & 100,0 \\
\hline \multicolumn{12}{|l|}{ Fase complementar } \\
\hline DMDMH / IPBC & 0,5 & 0,5 & 0,5 & 0,5 & 0,5 & 0,5 & 0,5 & 0,5 & 0,5 & 0,5 & 0,5 \\
\hline $\begin{array}{l}\text { Silicone de Copolímero } \\
\text { glicol }\end{array}$ & 2,0 & 1,0 & - & - & - & 2,0 & 1,0 & 2,0 & 1,0 & 2,0 & 1,0 \\
\hline Base autoemulsionante & 2,0 & 1,0 & - & - & - & 2,0 & 1,0 & 2,0 & 1,0 & 2,0 & 1,0 \\
\hline $\begin{array}{l}\text { Álcool cetílico } \\
\text { etoxilado e propoxilado }\end{array}$ & - & - & 2,0 & 2,0 & 2,0 & - & - & - & - & - & - \\
\hline Corante azul & 0,1 & 0,1 & 0,1 & 0,1 & 0,1 & 0,1 & 0,1 & 0,1 & 0,1 & 0,1 & 0,1 \\
\hline Essência Givaudan ${ }^{\circledR}$ & 0,05 & 0,05 & 0,05 & 0,05 & 0,05 & 0,05 & 0,05 & 0,05 & 0,05 & 0,05 & 0,05 \\
\hline Álcool de cereais & 8,0 & 8,0 & 8,0 & 8,0 & 8,0 & 8,0 & 8,0 & 8,0 & 8,0 & 8,0 & 8,0 \\
\hline EDTA tetrassódico & 0,1 & 0,1 & 0,1 & 0,1 & 0,1 & 0,1 & 0,1 & 0,1 & 0,1 & 0,1 & 0,1 \\
\hline
\end{tabular}


Tabela 4. Bases de máscara facial peel off (34 a 36) submetidas ao Estudo de Estabilidade Preliminar (EP), com as concentrações dos componentes variáveis em negrito.

\begin{tabular}{|c|c|c|c|}
\hline \multicolumn{4}{|c|}{ Pré-Formulação (\% p/p) } \\
\hline COMPONENTES & 34 & 35 & 36 \\
\hline \multicolumn{4}{|l|}{ Fase aquosa } \\
\hline $\begin{array}{l}\text { Álcool Polivinílico } \\
\text { (PVA) }\end{array}$ & 15,0 & 15,0 & 15,0 \\
\hline Propilenoglicol & 6,0 & - & - \\
\hline Glicerina & - & 6,0 & - \\
\hline Butilenoglicol & - & - & 6,0 \\
\hline Água destilada q.s.p. & 100,0 & 100,0 & 100,0 \\
\hline \multicolumn{4}{|l|}{ Fase complementar } \\
\hline DMDMH / IPBC & 0,5 & 0,5 & 0,5 \\
\hline $\begin{array}{l}\text { Silicone de Copolímero } \\
\text { glicol }\end{array}$ & - & - & - \\
\hline Base autoemulsionante & - & - & - \\
\hline $\begin{array}{l}\text { Álcool cetílico } \\
\text { etoxilado e propoxilado }\end{array}$ & 2,0 & 2,0 & 2,0 \\
\hline Corante azul & 0,1 & 0,1 & 0,1 \\
\hline Essência Givaudan ${ }^{\circledR}$ & 0,05 & 0,05 & 0,05 \\
\hline Álcool de cereais & 8,0 & 8,0 & 8,0 \\
\hline EDTA tetrassódico & 0,1 & 0,1 & 0,1 \\
\hline
\end{tabular}


Tabela 5. Base cosmética (ES) e formulação de emulsão contendo extrato de soja fermentado por Bifidobacterium animale (EC) submetidas ao Estudo de Estabilidade Preliminar (EP) e testes de eficácia clínica, e com as concentrações dos componentes variáveis em negrito (PINTO, 2005).

\begin{tabular}{|c|c|c|}
\hline \multirow{2}{*}{ COMPONENTES } & $\begin{array}{c}\text { Emulsão } \\
\text { (ES) }\end{array}$ & $\begin{array}{c}\text { Emulsão + } \\
\text { Extrato (EC) }\end{array}$ \\
\hline & \multicolumn{2}{|c|}{$\%(p / p)$} \\
\hline \multicolumn{3}{|l|}{ Fase oleosa } \\
\hline Cera autoemulsionante não-iônica & 1,5 & 1,5 \\
\hline Óleo mineral & 0,5 & 0,5 \\
\hline Lactato de miristila & 1,0 & 1,0 \\
\hline Palmitato de isopropila & 2,0 & 2,0 \\
\hline Oleato de decila & 2,0 & 2,0 \\
\hline Glicerídeos etoxilados derivados do leite & 0,5 & 0,5 \\
\hline Adipato de butila & 1,0 & 1,0 \\
\hline Acriloildimetiltaurato de amônio/ Copolímero VP & 1,5 & 1,5 \\
\hline \multicolumn{3}{|l|}{ Fase aquosa } \\
\hline Propilenoglicol & 2,5 & 2,5 \\
\hline Água destilada q.s.p. & 100,0 & 100,0 \\
\hline \multicolumn{3}{|l|}{ Fase complementar } \\
\hline Metilparabeno & 0,6 & 0,6 \\
\hline Fenoxietanol/parabenos & 0,25 & 0,25 \\
\hline Silicone poliéter & 2,5 & 2,5 \\
\hline Essência & 0,05 & 0,05 \\
\hline EDTA tetrassódico & 0,08 & 0,08 \\
\hline Extrato de soja fermentado & - & 5,0 \\
\hline
\end{tabular}




\section{MÉTODOS}

\subsection{Preparo das bases de máscaras faciais peel off}

Foram elaboradas 36 bases cosméticas. As composições destas formulações estão descritas nas Tabelas 1 a 4. Variaram-se a concentração do álcool polivinílico, o tipo e a concentração dos umectantes (butilenoglicol, glicerina, propilenoglicol), e dos tensoativos (álcool cetílico etoxilado e propoxilado e a base autoemulsionante) e a presença ou ausência do silicone de copolímero glicol. Os demais componentes permaneceram sem alteração em todas as formulações. Foram elaborados $100 \mathrm{~g}$ de cada pré-formulação, conforme método padronizado, que consiste na dispersão do PVA previamente incorporado ao umectante em água destilada, a uma temperatura de $80-90^{\circ} \mathrm{C}$ e agitação constante (ARANHA \& LUCAS, 2001; CHIELLINI et al., 2003). Após o resfriamento da preparação até a temperatura inferior a $40^{\circ} \mathrm{C}$, adicionaram-se, em seqüência e separadamente, o etanol, o conservante (DMDMH / IPBC), o EDTA tetrassódico, o silicone de copolímero glicol e a essência, incorporados aos tensoativos e, finalmente, o corante azul.

Após um período de 48 horas de repouso, atingiu-se o tempo inicial (t0), para a estabilização das formulações, sendo envasadas em frascos de polietileno branco, opaco e com capacidade para $50 \mathrm{~g}$, e realizadas as avaliações das características organolépticas e de desempenho e os testes do Estudo de Estabilidade Preliminar (EP) (BABY, 2005; AGÊNCIA NACIONAL DE VIGILÂNCIA SANITÁRIA, 2004; PINTO, 2005; TRAVERSA, 2003; ZAGUE, 2007).

\subsection{Preparo da base e da formulação de emulsão}

Foram elaborados $100 \mathrm{~g}$ de cada uma das preparações de base e formulação de emulsão, descritas na Tabela 5. Iniciou-se o preparo das formulações aquecendo os componentes da fase aquosa e da fase oleosa separadamente, em recipientes de inox em fogo brando, até a temperatura de $70^{\circ} \mathrm{C}$. Verteu-se a fase aquosa sobre a fase oleosa, sob a forma de fio e agitação constante, utilizando-se o Mixer. Após completa homogeneização das fases e resfriamento da mistura, adicionou-se, separadamente, o complexo fenoxietanol/parabenos, o metilparabeno, o silicone e a essência, sob a agitação manual a cada adição. Finalmente, adicionou-se o EDTA 
tetrassódico previamente solubilizado em água destilada suficiente e, em seguida, incorporou-se o extrato de soja (apenas na formulação denominada EC), ambos sob agitação manual constante, utilizando espátula plástica (ANSEL et al., 2000; PINTO, 2005; PRISTA et al., 1992).

O envase e os testes do Estudo de Estabilidade Preliminar foram realizados $48 \mathrm{~h}$ após o preparo das formulações (CONTRERAS et al., 2001).

\subsection{Estudo de Estabilidade Preliminar (EP)}

As 36 bases das máscaras faciais peel off sem adição do extrato de soja fermentado por Bifidobacterium animale descritas nas Tabelas 1 a 4 foram submetidas, a partir do to, período denominado após $48 \mathrm{~h}$ do preparo considerado como referência para comparação das variáveis analisadas (CONTRERAS et al., 2001) -, às avaliações das características organolépticas (aspecto, cor, odor e aplicação/toque); determinação do valor de $\mathrm{pH}$ antes e após a estabilidade em estufa a 50,0 $\pm 2,0{ }^{\circ} \mathrm{C}$ e estresse térmico; e avaliação do desempenho (tempo de secagem e formação de filme em estufa, nas condições do teste). As bases que obtiveram resultados satisfatórios nesta etapa foram selecionadas conforme os critérios de aceitação e passaram a receber a denominação de formulações, após a adição do extrato de soja às bases das máscaras faciais peel off, sendo posteriormente submetidas ao Estudo de Estabilidade Acelerada.

A base da emulsão (ES) e da formulação da emulsão acrescida do extrato de soja fermentado (EC), citadas na Tabela 5 , foram submetidas à avaliação das características organolépticas, centrifugação e determinação valor de $\mathrm{pH}$ antes e após a condição em estufa a 50,0 $\pm 2,0 \stackrel{\circ}{ } \mathrm{C}$ e estresse térmico, durante o Estudo de Estabilidade Preliminar (BABY, 2005; AGÊNCIA NACIONAL DE VIGILÂNCIA SANITÁRIA, 2004; PINTO, 2005; TRAVERSA, 2003; ZAGUE, 2007). 


\subsubsection{Condições para Avaliação - Estudo de Estabilidade Preliminar}

\subsubsection{Centrifugação}

Pesaram-se cerca de 5,0 g de cada base cosmética de máscara facial peel off e da emulsão (ES) e da formulação de emulsão (EC). Estas preparações foram submetidas a ciclos de centrifugação de 1000, 2000 e 3000 rpm em centrífuga, durante 15 min para cada velocidade.

\subsubsection{Estresse térmico}

Pesaram-se cerca de 10,0 g de cada base cosmética de máscara facial peel off e da emulsão (ES) e da formulação de emulsão (EC). Estas preparações foram transferidas para tubos de ensaio, encaminhados para banho-maria no intervalo de temperatura entre 40 e $80^{\circ} \mathrm{C}$. O valor da temperatura foi elevado de $10 \mathrm{em} 10{ }^{\circ} \mathrm{C}$, mantendo-a por trinta minutos em cada valor.

\subsubsection{Estufa a $50{ }^{\circ} \mathrm{C} / 72$ horas}

Pesaram-se cerca de 10,0 g de cada base cosmética de máscara facial peel off e da emulsão (ES) e da formulação de emulsão (EC). Estas preparações foram acondicionadas em frascos de polietileno branco e de boca larga, com capacidade nominal de 50 gramas. Estes foram transferidos para estufa, previamente estabilizada em 50,0 $\pm 2,0^{\circ} \mathrm{C}$, por $1 \mathrm{~h}$. As amostras permaneceram $72 \mathrm{~h}$ nesta condição, sendo transferidas posteriormente para temperatura ambiente $(22 \pm 2 \stackrel{\circ}{\circ})$.

\subsubsection{Variáveis analisadas}

\subsubsection{Características organolépticas}

Esta etapa do teste envolveu a avaliação das características das bases cosméticas de máscara facial peel off e da emulsão (ES) e da formulação de emulsão (EC) a fim de identificar processos de instabilidade, como separação de fases; alterações de cor, odor e do toque durante a aplicação. Os critérios para 
avaliação foram estabelecidos pelo próprio analista e estão descritos a seguir. Estas avaliações foram realizadas 48 horas após o preparo (t0) e após cada condição no respectivo tempo dentro do Estudo de Estabilidade Preliminar, a fim de verificar possíveis processos de instabilidade, comparando-os com os resultados iniciais (BABY, 2005; AGÊNCIA NACIONAL DE VIGILÂNCIA SANITÁRIA, 2004; PINTO, 2005; TRAVERSA, 2003; ZAGUE, 2007).

\section{a) COR}

$\mathbf{N}$ - Normal, sem alterações da cor original (azul)

M - Modificada (nuances do azul original)

IM - Intensamente modificada (outras cores)

\section{b) ODOR}

N - Normal, sem alterações (odor da essência)

M - Modificado (odor da essência ou de outro componente intensificado ou suavizado e/ou odor de etanol intensificado)

IM - Intensamente modificado (perda da essência e odor intenso de etanol e/ou de outro componente)

\section{c) ASPECTO}

$\mathbf{N}$ - Normal, sem alterações (homogêneo)

M - Modificado (indicação de separação de fases)

IM - Intensamente modificado (separação completa de fases)

\section{d) CARACTERÍSTICAS DE APLICAÇÃO (espalhabilidade e toque)}

A - toque agradável, com facilidade de aplicação na pele (espalhabilidade)

D - toque desagradável, pegajosidade, com relativa dificuldade de aplicação na pele (espalhabilidade)

MD - toque muito desagradável, alta pegajosidade, comprometendo aplicação na pele. 


\subsubsection{Valor de $\mathrm{pH}$}

Os valores de $\mathrm{pH}$ foram aferidos a $25,0 \pm 1,0^{\circ} \mathrm{C}$, diluindo-se as amostras das bases cosméticas e formulações em água recém-destilada e previamente neutralizada, na proporção 1:10. A leituras foram feitas com as amostras antes e após o estresse térmico e aquelas submetidas à estabilidade a $50,0 \pm 1,0^{\circ} \mathrm{C} / 72 \mathrm{~h}$ (DAVIS, 1977). Como critério de aceitação, foram reprovadas as formulações que apresentaram variações do valor de $\mathrm{pH}$ superiores a $15 \%$, para mais ou para menos, em relação ao valor inicial, uma vez que o ponto isoelétrico das proteínas da soja encontra-se no valor de pH igual a 4,5, e valores além da faixa de valor de pH 2 a 10 causam degradação das proteínas presentes no extrato de soja fermentado (GENOVESE et al., 2006).

\subsubsection{Teste de secagem e formação de filme}

A metodologia deste teste foi desenvolvida e padronizada conforme descrito a seguir, baseado no uso do produto comercial. $O$ teste foi realizado para as bases cosméticas das máscaras faciais peel off descritas nas Tabelas 1 a 4, 48 h após o preparo (t0).

Amostras em triplicata com cerca de $0,7 \mathrm{~g}$ de cada base foram pesadas e distribuídas, com o auxílio de pincel, sobre área de 5,0 × 2,5 cm de uma lâmina de vidro, formando uma camada fina e uniforme de cerca de $1 \mathrm{~mm}$, a fim de mimetizar o filme formado em uma aplicação facial de uma máscara peel off disponível no mercado. A placa foi colocada em estufa, previamente estabilizada à temperatura de $36,5 \pm 2,0{ }^{\circ} \mathrm{C}$ por $1 \mathrm{~h}$, simulando a temperatura corpórea. A secagem das formulações foi monitorada a cada $10 \mathrm{~min}$, até ocorrer a secagem e remoção integral do filme formado da lâmina.

\subsection{Estudo de Estabilidade Preliminar (EP) - formulações de máscaras faciais}

A partir dos resultados do Estudo de Estabilidade Preliminar das bases de máscaras peel off sem adição do extrato de soja fermentado por Bifidobacterium animale, observou-se a necessidade de realizar adaptações nestas bases com o objetivo de eliminar indícios de processos de instabilidade e, simultaneamente, 
melhorar seu desempenho no teste de secagem e formação de filme (BRASIL, 2004).

Foram realizadas alterações nas concentrações de PVA e foi adicionando um agente espessante - Goma Guar - à base F35, que apresentou o melhor desempenho. Além das alterações dos excipientes, foi adicionada a fração do extrato de soja fermentado às novas preparações, que passaram a ser denominadas formulações.

A Tabela 6 apresenta a composição das formulações, após as modificações descritas anteriormente. 
Tabela 6. Formulações de máscara facial peel off (adaptações da base F35 de máscara facial peel off) submetidas ao Estudo de Estabilidade Preliminar (EP), com as concentrações dos componentes variáveis em negrito. Todas as formulações contêm o extrato de soja fermentado.

\begin{tabular}{|c|c|c|c|c|c|c|c|c|}
\hline \multicolumn{9}{|c|}{ Variações na Formulação F35 (\%p/p) } \\
\hline COMPONENTES & $35 / 15$ & 35/15G & $35 / 17$ & 35/17G & $35 / 18$ & 35/18G & $35 / 20$ & 35/20G \\
\hline \multicolumn{9}{|l|}{ Fase aquosa } \\
\hline $\begin{array}{l}\text { Álcool Polivinílico } \\
\text { (PVA) }\end{array}$ & 15,0 & 15,0 & 17,0 & 17,0 & 18,0 & 18,0 & 20,0 & 20,0 \\
\hline Glicerina & 6,0 & 6,0 & 6,0 & 6,0 & 6,0 & 6,0 & 6,0 & 6,0 \\
\hline Goma Guar & - & 0,5 & - & 0,5 & - & 0,5 & - & 0,5 \\
\hline Água destilada qsp & 100,0 & 100,0 & 100,0 & 100,0 & 100,0 & 100,0 & 100,0 & 100,0 \\
\hline \multicolumn{9}{|l|}{ Fase complementar } \\
\hline DMDMH / IPBC & 0,5 & 0,5 & 0,5 & 0,5 & 0,5 & 0,5 & 0,5 & 0,5 \\
\hline $\begin{array}{l}\text { Álcool cetílico etoxilado e } \\
\text { propoxilado }\end{array}$ & 2,0 & 2,0 & 2,0 & 2,0 & 2,0 & 2,0 & 2,0 & 2,0 \\
\hline Corante azul & 0,1 & 0,1 & 0,1 & 0,1 & 0,1 & 0,1 & 0,1 & 0,1 \\
\hline $\begin{array}{l}\text { Extrato de soja } \\
\text { fermentado }\end{array}$ & 5,0 & 5,0 & 5,0 & 5,0 & 5,0 & 5,0 & 5,0 & 5,0 \\
\hline Essência Givaudan ${ }^{\circledR}$ & 0,05 & 0,05 & 0,05 & 0,05 & 0,05 & 0,05 & 0,05 & 0,05 \\
\hline Álcool de cereais & 8,0 & 8,0 & 8,0 & 8,0 & 8,0 & 8,0 & 8,0 & 8,0 \\
\hline EDTA tetrassódico & 0,1 & 0,1 & 0,1 & 0,1 & 0,1 & 0,1 & 0,1 & 0,1 \\
\hline
\end{tabular}

Legenda:

Codificação das formulações - 35/15G - o primeiro número (35) significa a formulação usada como referência para reformulação;

O segundo número (15) indica a quantidade, em \% p/p, de álcool polivinílico utilizada nas formulações; a presença da letra $\mathbf{G}$ indica utilização de Goma Guar como espessante; a ausência da letra $\mathbf{G}$ indica ausência de Goma Guar na formulação. 
As preparações resultantes das adaptações feitas a partir da base de máscara facial peel off pré-formulação F35 foram submetidas ao Estudo de Estabilidade Preliminar, compreendendo a realização dos testes e análise das variáveis conforme descrito no item 2.3.

\subsection{Estudo de Estabilidade Acelerada (EA)}

As formulações de máscara facial peel off acrescidas do extrato de soja fermentado (Tabela 6) que apresentaram desempenho satisfatório após as adaptações, considerando-se inicialmente o tempo de secagem e, posteriormente, as características organolépticas e a determinação do valor de $\mathrm{pH}$ durante o Estudo de Estabilidade Preliminar, foram submetidas ao Estudo de Estabilidade Acelerada (BABY, 2005; AGÊNCIA NACIONAL DE VIGILÂNCIA SANITÁRIA, 2004; PINTO, 2005; TRAVERSA, 2003; ZAGUE, 2007). Foram elaboradas amostras em duplicata das formulações para as avaliações nos testes, considerando cada condição e tempo de análise, conforme a descrição a seguir.

A formulação de emulsão acrescida do extrato de soja fermentado (Tabela 5) após realização do estudo de Estudo de Estabilidade Preliminar, foi submetida ao Estudo de Estabilidade Acelerada para verificação do impacto da adição do extrato à base nas variáveis analisadas (BABY, 2005; AGÊNCIA NACIONAL DE VIGILÂNCIA SANITÁRIA, 2004; PINTO, 2005; TRAVERSA, 2003; ZAGUE, 2007). Foram elaboradas amostras em duplicata das formulações para as avaliações nos testes, considerando cada condição e tempo de análise, conforme a descrição a seguir.

\subsubsection{Condições do teste}

As preparações foram inicialmente avaliadas após to, considerando as respostas obtidas como referência comparativa para as demais respostas encontradas ao longo do estudo. As variáveis estão descritas a seguir (CONTRERAS et al., 2001). 


\subsubsection{Geladeira $(5,0 \pm 1,0 \stackrel{\circ}{\circ})$}

As amostras foram mantidas em geladeira durante 15 dias e avaliadas nos $3^{\circ}$, $7^{\circ}$ e $15^{\circ}$ dias.

\subsubsection{Freezer $(-10,0 \pm 1,0 \stackrel{\circ}{C})$}

As amostras foram mantidas em freezer durante 15 dias e avaliadas nos $3^{\circ}$, $7^{\circ}$ e $15^{\circ}$ dias.

\subsubsection{Temperatura ambiente $(22,0 \pm 2,0 \stackrel{\circ}{\circ})$}

As amostras foram mantidas em temperatura ambiente durante 15 dias e avaliadas nos $3^{\circ}, 7^{\circ}$ e $15^{\circ}$ dias.

\subsubsection{Estufa $\left(45,0 \pm 2,0^{\circ} \mathrm{C}\right)$}

As amostras foram mantidas em estufa durante 15 dias e avaliadas no $1^{\circ}, 3^{\circ}$, $7^{\circ}$ e $15^{\circ}$ dias.

\subsubsection{Ciclos gela e degela $(45,0 \pm 2,0 \stackrel{\circ}{\circ} /-5,0 \pm 2,0 \stackrel{\circ}{ } \mathrm{C})$}

As formulações foram submetidas aos períodos de congelamento $(-10,0 \pm$ $\left.1,0{ }^{\circ} \mathrm{C}\right)$ por $24 \mathrm{~h}$ em freezer, seguido de descongelamento em estufa $\left(45,0 \pm 2,0{ }^{\circ} \mathrm{C}\right)$ por $24 \mathrm{~h}$. Isto completa um ciclo. Foram realizados seis ciclos, sendo as amostras avaliadas no $3^{\circ}\left(6^{\circ} \mathrm{dia}\right)$ e $6^{\circ}$ ciclos $\left(12^{\circ} \mathrm{dia}\right)$.

\subsubsection{Variáveis analisadas}

\subsubsection{Características organolépticas}

As observações das características organolépticas tinham como objetivo verificar as alterações no odor, cor e aspecto das formulações de máscaras faciais peel off acrescidas do extrato de soja fermentado. Foram adotados os critérios de 
avaliação e procedimentos descritos no item 2.3.2.1. Os resultados obtidos na avaliação inicial (t0) foram considerados os valores de referência comparativa para as respostas obtidas ao longo do estudo.

\subsubsection{Valor de $\mathrm{pH}$}

Os valores de $\mathrm{pH}$ foram aferidos conforme os procedimentos e os critérios de aceitação descritos no item 2.3.2.2. As avaliações foram realizadas em todas as condições e dias determinados para avaliação. Os resultados obtidos na avaliação inicial (t0) foram considerados como referência (100\%), para o cálculo das variações observadas em relação ao valor inicial.

\subsubsection{Viscosidade aparente}

Pesaram-se cerca de $15 \mathrm{~g}$ de cada amostra das formulações de máscara facial peel-off, de todos os tempos de avaliação, e foram analisadas em viscosímetro, à temperatura ambiente, utilizando-se a agulha TR11, à velocidade de 6 rpm. Para todas as amostras, as leituras foram efetuadas após 2 min de estabilização das preparações. Os resultados obtidos na avaliação inicial (t0) foram considerados os valores de referência (100\%) para o cálculo das variações observadas (MAIA, 2002).

\subsubsection{Tempo de secagem e formação de filme}

Os valores de tempo de secagem foram determinados apenas para as preparações de máscara facial peel off, como descrito no item 2.3.2.3. Estes valores foram determinados para as formulações ao término do período de acondicionamento das condições acima citadas, comparando-se com aqueles obtidos inicialmente (t0). 


\subsection{Testes Clínicos - Sujeitos}

\subsubsection{Desenho do estudo}

Foram realizadas medidas instrumentais em seres humanos a fim de avaliar objetivamente a eficácia da máscara facial peel off, selecionada no Estudos de Estabilidade Acelerada, e da emulsão. Avaliaram-se as bases cosméticas das formulações aditivadas ou não do extrato de soja fermentado na melhora da elasticidade, da firmeza, da barreira cutânea e da hidratação da pele sob condições normais de uso, a fim de comprovar os efeitos tensor e hidratante da máscara, além dos efeitos de hidratação atribuídos ao extrato de soja fermentado, comprovando também qual a formulação ideal para incorporação das substâncias ativas (BAUMANN \& LAZARUS, 2001).

\subsubsection{Tipo do Estudo}

O estudo foi classificado como monocêntrico e realizado em aberto, de acordo com as "Condições Gerais para a realização de um teste em humanos", por meio dos termos de consentimento livre e esclarecido dos voluntários, apresentado em ANEXOS (AGÊNCIA NACIONAL DE VIGILÂNCIA SANITÁRIA, 1996).

\subsubsection{Centro de Investigação}

EVIC Brasil

Av. Indianópolis, 1455 - Planalto Paulista

04063-002 - São Paulo - SP - Brasil

Fone: $55115581-4949$

\subsubsection{Cronograma de realização do estudo}

O estudo teve a duração de dois dias, no Centro de Investigação. 


\subsection{5 Ética em pesquisa}

O estudo foi realizado de acordo com a Legislação Brasileira, baseada na "Resolução Normativa 196/96, CNS/MS", normas da International Conference Harmonization (ICH), Good Clinical Practices (GCP) e a Declaração de Helsinque, após a obtenção da aprovação do Comitê de Ética em Pesquisa (CEP), regulamentado pelo Conselho Nacional de Ética em Pesquisa (CONEP). A aprovação do estudo pelo CEP é apresentada no parecer, em ANEXOS (AGÊNCIA NACIONAL DE VIGILÂNCIA SANITÁRIA, 1996).

Os testes somente foram iniciados após a informação e esclarecimento dos voluntários quantos aos riscos e benefícios do teste, sendo seu consentimento informado e registrado por meio do Termo de Consentimento Livre e Esclarecido, documento que permanece arquivado no Centro de Investigação.

O anonimato do voluntário e sua saída voluntária do estudo foram garantias apresentadas durante todo o estudo.

\subsubsection{Amostra}

Conforme desenho experimental estabelecido em conjunto com a Empresa Statistika Consultoria, o estudo caracterizou-se pela aleatorização dos locais de aplicação dos produtos-teste em dez voluntários. Foram selecionados doze voluntários, para evitar interrupção do estudo em caso de desistência.

\subsubsection{Critérios específicos de inclusão dos voluntários no estudo}

Os critérios específicos de inclusão, definidos neste protocolo pelo médico responsável, foram os seguintes:

- idade: 18 a 60 anos;

- sexo: feminino;

- pele normal a seca.

- pele correspondente aos fototipos I a IV, conforme Quadro 5 (FITZPATRICK et al., 1974). 
Quadro 5. Fototipos, sua descrição e respectiva sensibilidade ao sol (FITZPATRICK et al., 1974).

\begin{tabular}{c|cc}
\hline Fototipos & Descrição & Sensibilidade ao Sol \\
\hline I - Branca & $\begin{array}{c}\text { Queima com facilidade, } \\
\text { nunca bronzeia }\end{array}$ & Muito sensível \\
\hline II - Branca & $\begin{array}{c}\text { Queima com facilidade, } \\
\text { bronzeia muito pouco }\end{array}$ & Sensível \\
\hline III - Morena Clara & $\begin{array}{c}\text { Queima moderadamente, } \\
\text { bronzeia moderadamente }\end{array}$ & Normal \\
\hline IV - Morena Moderada & $\begin{array}{c}\text { Queima pouco, bronzeia } \\
\text { com facilidade }\end{array}$ & Pouco sensível \\
\hline V - Morena Escura & $\begin{array}{c}\text { Queima raramente, } \\
\text { bronzeia bastante }\end{array}$ & Insensível \\
\hline VI - Negra & $\begin{array}{c}\text { Nunca queima, totalmente } \\
\text { pigmentada }\end{array}$ &
\end{tabular}

\subsubsection{Critérios específicos de não-inclusão dos voluntários no estudo}

Os critérios específicos de não-inclusão, definidos pelo co-investigador (médico responsável) no protocolo, foram os seguintes:

- marcas cutâneas na área experimental que poderiam interferir na avaliação das reações da pele, como problemas de pigmentação, elementos de cicatrizes, desenvolvimento de pilosidade exagerado, efélides e nevus em grande quantidade, bronzeamento;

- patologias cutâneas ativas (locais ou disseminadas) que poderiam interferir nos resultados do estudo;

- alergia ou reatividade para a categoria de produtos testados;

- exposição intensiva ao sol até 15 dias antes da avaliação;

- uso de vitamina A ácida e derivados nos 3 meses antecedentes ao estudo;

- tratamento com corticóides tópicos na área de aplicação do teste até 8 dias antes do estudo;

- uso de drogas antiinflamatórias ou imunossupressoras;

- antecedentes atópicos/ alérgicos;

- tratamento com radiação UVA ou UVB até um mês antes do início do estudo;

- mulheres grávidas ou em amamentação. 


\subsubsection{Riscos mínimos previstos para o estudo}

Os riscos mínimos previstos para este tipo de estudo, definidos pelo coinvestigador (médico responsável) e informados aos voluntários antes da realização do mesmo, foram possíveis manifestações de reações de hipersensibilidade a um ou mais produtos cosméticos testados ou a um ou mais componentes das formulações. Além disso, foi exposto como reação provável o aparecimento de irritação no local de aplicação, na forma de vermelhidão da pele ou prurido, e ocorrência de aquecimento, formigamento, repuxamento, queimação, inchaço, vesícula, bolha, crosta, pápula, ressecamento ou alteração de cor da pele nos locais de aplicação. Nos casos de ocorrência destes eventos, a aplicação do produto foi suspensa, sendo colocada à disposição do voluntário toda a assistência necessária.

\subsubsection{Aplicação das formulações}

Foi selecionada uma formulação de máscara facial peel off com extrato de soja fermentado que apresentou o melhor desempenho (MC) nos Estudos de Estabilidade Preliminar e de Estabilidade Acelerada, conforme critérios e procedimentos definidos nos itens 2.3 e $\mathbf{2 . 5}$.

Para realização dos Testes Clínicos, foram elaborados o placebo da formulação de máscara facial peel off selecionada (MS) e uma formulação de emulsão contendo extrato de soja com isoflavonas (EC) e seu respectivo placebo (ES), como descrito no item 2.2. A identificação dos produtos-teste está descrita na

\section{Tabela 7.}


Tabela 7: Codificação da base e da formulação de máscaras facial peel off e da base e da formulação de emulsão óleo em água utilizadas nos ensaios clínicos.

\begin{tabular}{l|c}
\multicolumn{1}{c|}{ DENOMINAÇÃO DO PRODUTO TESTE } & CÓDIGO \\
\hline \hline Máscara facial peel off contendo extrato de soja fermentado & MC \\
\hline $\begin{array}{l}\text { Base da máscara facial peel off - sem extrato de soja } \\
\text { fermentado }\end{array}$ & MS \\
\hline $\begin{array}{l}\text { Emulsão óleo em água contendo o extrato de soja } \\
\text { fermentado }\end{array}$ & EC \\
\hline $\begin{array}{l}\text { Base da emulsão óleo em água - sem extrato de soja } \\
\text { fermentado }\end{array}$ & ES \\
\hline \hline
\end{tabular}

As aplicações das formulações e as leituras obtidas nos equipamentos foram efetuadas em locais de aplicação definidos nos antebraços, no total de seis locais por voluntário (S1 a S6). As áreas de cada local foram demarcadas utilizando-se

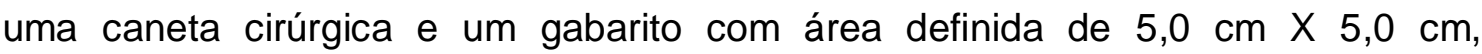
totalizando $25,0 \mathrm{~cm}^{2}$. A numeração e localização as aplicações foi a mesma para todos os voluntários avaliados, conforme a descrição da Figura 6.

Antes da aplicação e realização das medidas, os voluntários foram submetidos a condições padronizadas de temperatura $\left(20,0 \pm 2,0^{\circ} \mathrm{C}\right)$ e de umidade relativa $(50,0 \pm 5,0 \%)$, durante o período de tempo mínimo de trinta minutos antes da aplicação e realização das medidas. O procedimento de climatização visou diminuir as variações e as interferências nas medidas instrumentais (BERARDESCA et al., 1995). 


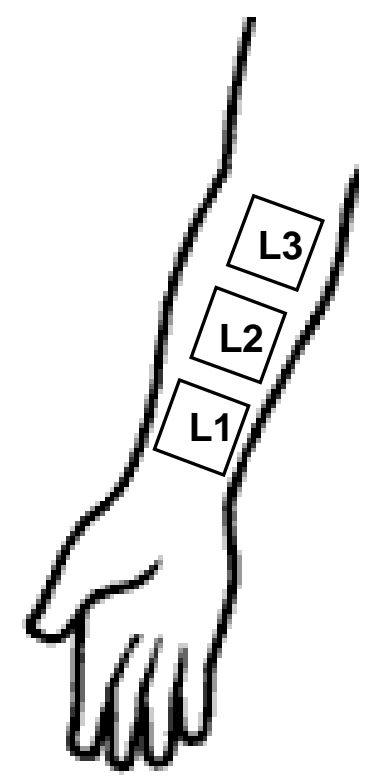

Braço Direito

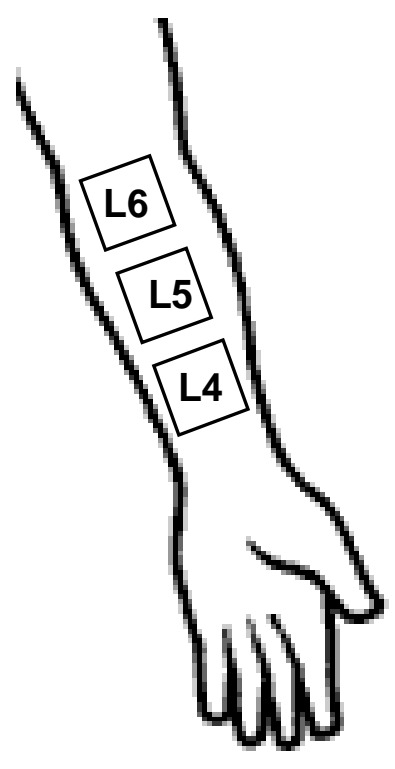

Braço Esquerdo

Legenda: Local de aplicação 1 (L1) - Braço direito / distal; Local de aplicação 2 (L2) - Braço direito / medial; Local de Aplicação 3 (L3) - Braço direito / proximal; Local de Aplicação 4 (L4) - Braço esquerdo / distal; Local de Aplicação 5 (L5) Braço esquerdo / medial; Local de Aplicação 6 (L6) - Braço esquerdo / proximal.

Figura 6. Locais de aplicação das formulações nos voluntários.

A quantidade de cada preparação aplicada e o modo de aplicação estão descritos na Tabela 8. Previamente ao teste clínico, os valores determinados para aplicação foram estabelecidos experimentalmente. Para as máscaras peel off, utilizaram-se quantidades que formavam filmes de aproximadamente $1 \mathrm{~mm}$ na superfície da pele. Para as emulsões, a quantidade determinada foi suficiente para cobrir a área delimitada do teste, não havendo resíduos visíveis da formulação após a aplicação. 
Tabela 8. Descrição da quantidade e modo de aplicação das preparações utilizadas no teste clínico.

\begin{tabular}{|c|c|c|}
\hline $\begin{array}{c}\text { Produto } \\
\text { codificado }\end{array}$ & Modo de Aplicação & $\begin{array}{c}\text { Quantidade } \\
\text { aplicada / } \\
\text { local de } \\
\text { aplicação }\end{array}$ \\
\hline $\mathrm{MC} / \mathrm{MS}$ & $\begin{array}{l}\text { Pesar a quantidade determinada em balança, utilizando } \\
\text { papel alumínio. Utilizar a dedeira para retira o produto do } \\
\text { papel alumínio e espalhar sobre a área demarcada, } \\
\text { distribuindo pela superfície da pele a quantidade } \\
\text { preconizada em forma de zigue-zague, formando uma } \\
\text { película homogênea, de espessura aproximada de } 1 \mathrm{~mm} \text {; } \\
\text { Após vinte minutos de contato com o produto (período de } \\
\text { secagem), retirar o filme formado sobre a pele, puxando } \\
\text { com força constante a partir de uma das bordas, que se } \\
\text { destacam após o período de secagem. }\end{array}$ & $500 \mathrm{mg}$ \\
\hline EC / ES & $\begin{array}{l}\text { Utilizar a seringa e distribuir gotas da formulação } \\
\text { uniformemente por toda a área de aplicação. Espalhar o } \\
\text { produto com a dedeira, da mesma maneira descrita para } \\
\text { as máscaras, até que nenhum resíduo do produto possa } \\
\text { ser detectado visualmente. }\end{array}$ & $50 \mathrm{mg}$ \\
\hline
\end{tabular}

Legenda:

MC - formulação de máscara facial peel off, contendo extrato de soja fermentado; MS base de máscara facial peel off; EC - emulsão óleo em água contendo extrato de soja fermentado; ES - base da emulsão óleo em água.

A definição das preparações que seriam aplicadas em cada local de aplicação foi realizada de modo que, no total de aplicações realizadas nos dez voluntários, foram utilizados 15 locais de aplicação para cada uma das preparações testadas, totalizando os 60 , necessários ao estudo. Os voluntários, os locais de aplicação de aplicação e as respectivas preparações aplicadas em cada local estão descritos na Tabela 9. 
Tabela 9. Descrição das preparações de acordo com os respectivos locais de aplicação, conforme aleatorização.

\begin{tabular}{ccccccccccc}
\hline Locais de & \multicolumn{10}{c}{ Voluntários } \\
\cline { 2 - 5 } & $\mathbf{1}$ & $\mathbf{2}$ & $\mathbf{3}$ & $\mathbf{4}$ & $\mathbf{5}$ & $\mathbf{6}$ & $\mathbf{7}$ & $\mathbf{8}$ & $\mathbf{9}$ & $\mathbf{1 0}$ \\
\hline L1 & EC & MC & EC & EC & MS & ES & MC & ES & ES & EC \\
\hline L2 & MS & EC & MS & MC & EC & EC & ES & MS & MS & ES \\
\hline L3 & MC & ES & MC & MS & MC & MS & MS & EC & MC & MS \\
\hline L4 & MS & MC & ES & MS & EC & ES & ES & MC & MC & MC \\
\hline L5 & ES & MS & MC & MC & ES & EC & MC & EC & ES & EC \\
\hline L6 & EC & ES & EC & ES & MC & MS & EC & MS & MS & ES \\
\hline
\end{tabular}

Legenda:

Local de aplicação 1 (L1) - Braço direito / distal; Local de aplicação 2 (L2) - Braço direito / medial; Local de Aplicação 3 (L3) - Braço direito / proximal; Local de Aplicação 4 (L4) Braço esquerdo / distal; Local de Aplicação 5 (L5) - Braço esquerdo / medial; Local de Aplicação 6 (L6) - Braço esquerdo / proximal.MC - formulação de máscara facial peel off, contendo extrato de soja fermentado; MS - base de máscara facial peel off; EC - emulsão óleo em água contendo extrato de soja fermentado; ES - base da emulsão óleo em água.

\subsubsection{Avaliação Instrumental}

A avaliação da eficácia instrumental foi realizada, para todos os equipamentos, por meio da cinética de avaliação, sendo que as medidas foram efetuadas imediatamente antes da aplicação das formulações e após a climatização dos voluntários (t0), quarenta e cinco minutos após a aplicação das formulações (t45), noventa minutos após a aplicação (t90) e, finalmente, cento e oitenta minutos após a aplicação (t180). Este procedimento foi realizado em dois dias, sendo cinco voluntários submetidos ao tratamento em cada dia.

\subsubsection{Efeito de hidratação das camadas superiores da pele}

Esta variável foi medida por meio dos valores de capacitância, conforme a cinética estabelecida para avaliação dos produtos, cuja variação está relacionada às 
mudanças da constante dielétrica da superfície da pele, dependente da hidratação do estrato córneo (BERARDESCA et al., 1995).

A medida foi determinada pelo Corneometer ${ }^{\circledR}$ CM 825 PC (Courage \& Khazaka), que fornece valores arbitrários e adimensionais, em uma escala de 0 a 120 (unidades corneométricas).

\subsubsection{Efeito da perda de água transepidérmica}

O efeito de barreira cutânea foi avaliado por meio da comparação da perda de água durante os períodos estabelecidos pelo experimento, comparando os produtos aplicados (BERARDESCA et al., 1995).

A medida foi determinada pelo Tewameter ${ }^{\circledR}$ TW210 (Courage \& Khazaka), que fornece valores absolutos expressos em $\mathrm{g} / \mathrm{m}^{2} / \mathrm{h}$ e posteriormente convertidos a unidades arbitrárias, pelo próprio instrumento. O equipamento possui uma sonda com par de sensores para temperatura e umidade.

\subsubsection{Efeito na elasticidade e na firmeza da pele}

Nesta avaliação, utilizou-se o Cutometer $^{\circledR}$ SEM 575 (Courage and Khazaka). Por meio de um estiramento vertical das camadas cutâneas superficiais, criado por meio de vácuo, determinou-se a resistência cutânea (BERARDESCA et al., 1995).

Durante a determinação da medida, as propriedades biomecânicas da pele foram codificadas para uma curva de deformação versus tempo, conforme representado na Figura 5. A partir dos registros do equipamento, obtiveram-se os valores de M1 (extensibilidade máxima) e M2 (deformação em comparação com +estado inicial). O efeito tensor, avaliado objetivamente em cada voluntário, considerou que, se M1 decresce, a firmeza cutânea aumenta, e vice-versa. De forma semelhante, se M2 decresce, a elasticidade cutânea aumenta, e vice-versa (BERARDESCA et al., 1995, adaptada). 


\subsubsection{Análise estatística dos dados}

Os resultados obtidos foram expressos individualmente por voluntários para, em seguida, compor a análise estatística. Esta análise utilizou o software SAS 9.1, obtido do SAS Institute, Cary, NC, sob sistema operacional Linux (SAS - BUSINESS INTELLIGENCE SOFTWARE AND PREDICTIVE ANALYTICS, 2008).

Para as três medidas experimentais realizadas - Efeito de hidratação nas camadas superiores da pele; Efeito da perda de água transepidérmica; e Efeito na elasticidade e na firmeza da pele - existia o interesse na verificação dos efeitos isolados dos produtos aplicados, do tempo de aplicação da presença ou ausência do extrato soja fermentado por Bifidobacterium animale. Estes mesmos efeitos foram cruzados a fim de verificar suas interações.

No caso das avaliações do efeito tempo, as medidas obtidas em T0 foram consideradas como covariável. Tal procedimento remove as interferências individuais de cada voluntário e permite a obtenção dos resultados para todo o grupo amostral. Os valores obtidos em T0 passam a ser valores basais, aos quais os valores de T45, T90 e T180 são comparados (STATISTIKA, 2007).

Os valores obtidos durante as avaliações foram classificados como variáveis quantitativas contínuas. Estas variáveis são classificadas desta forma porque pertencem a um intervalo de números reais e são resultantes da mensuração de valores como, por exemplo, a massa de um indivíduo. O modelo probabilístico utilizado para análise das variáveis foi a distribuição F de Snedecor. (MORETTIN \& BUSSAB, 2005). 


\section{Teste de Estabilidade Preliminar (EP)}

\subsection{Bases de máscaras faciais peel off}

\subsubsection{Características organolépticas e valor de pH}

Foram elaboradas 36 bases de máscara facial peel off, submetidas à avaliação organoléptica e determinação do valor de pH, antes e após a exposição às condições de estresse térmico e estufa $50,0 \pm 2,0^{\circ} \mathrm{C} / 72$ horas (BABY, 2005; AGÊNCIA NACIONAL DE VIGILÂNCIA SANITÁRIA, 2004; PINTO, 2005; TRAVERSA, 2003; ZAGUE, 2007).

Os resultados obtidos na avaliação das características organolépticas (cor, odor, aspecto e aplicação e toque) e na determinação dos valores de $\mathrm{pH}$, durante o Estudo de Estabilidade Preliminar para as bases de máscara facial peel off (1 a 36) foram descritos nas Tabelas 10 a 14. 
Tabela 10. Avaliação das características organolépticas e valor de $\mathrm{pH}$ das bases de máscara facial peel off (1 a 8) durante o Estudo de Estabilidade Preliminar.

\begin{tabular}{|c|c|c|c|c|c|c|c|c|}
\hline \multirow{3}{*}{ Bases } & \multicolumn{8}{|c|}{ Parâmetro avaliado } \\
\hline & \multirow{2}{*}{ Teste } & \multirow{2}{*}{ Aspecto } & \multirow{2}{*}{ Cor } & \multirow{2}{*}{ Odor } & \multirow{2}{*}{$\begin{array}{c}\text { Aplicação } \\
\text { /Toque }\end{array}$} & \multicolumn{2}{|c|}{$\mathrm{pH}$} & \multirow{2}{*}{$\begin{array}{c}\text { Variação } \\
\text { pH (\%) }\end{array}$} \\
\hline & & & & & & As. & Ds. & \\
\hline \multirow{3}{*}{1} & C & $\mathrm{N}$ & $\mathrm{N}$ & $\mathrm{N}$ & $A$ & $\mathrm{Na}$ & $\mathrm{Na}$ & 0 \\
\hline & $\mathrm{ET}$ & M & $\mathrm{N}$ & $M$ & $A$ & 5,5 & 6,9 & 25,5 \\
\hline & E 50 & M & $\mathrm{N}$ & $M$ & $A$ & 5,5 & 6,2 & 12,7 \\
\hline \multirow{3}{*}{2} & $\mathrm{C}$ & $\mathrm{N}$ & $\mathrm{N}$ & $\mathrm{N}$ & $A$ & $\mathrm{Na}$ & $\mathrm{Na}$ & 0 \\
\hline & $\mathrm{ET}$ & M & $\mathrm{N}$ & $M$ & $A$ & 6,9 & 7,0 & 1,45 \\
\hline & E 50 & M & $\mathrm{N}$ & $\mathrm{N}$ & $A$ & 6,9 & 5,6 & 18,8 \\
\hline \multirow{3}{*}{3} & $\mathrm{C}$ & $\mathrm{N}$ & $\mathrm{N}$ & $\mathrm{N}$ & MD & $\mathrm{Na}$ & $\mathrm{Na}$ & 0 \\
\hline & E T & M & $\mathrm{N}$ & M & MD & 7,1 & 6,9 & 2,8 \\
\hline & E 50 & $\mathrm{M}$ & $\mathrm{N}$ & $\mathrm{M}$ & MD & 7,1 & 6,5 & 8,5 \\
\hline \multirow{3}{*}{4} & $\mathrm{C}$ & $\mathrm{N}$ & $\mathrm{N}$ & $\mathrm{N}$ & $A$ & $\mathrm{Na}$ & $\mathrm{Na}$ & 0 \\
\hline & E T & $M$ & $\mathrm{~N}$ & $M$ & $A$ & 7,1 & 6,9 & 2,8 \\
\hline & E 50 & $\mathrm{~N}$ & $\mathrm{~N}$ & $\mathrm{~N}$ & A & 7,1 & 6,7 & 5,6 \\
\hline \multirow{3}{*}{5} & $\mathrm{C}$ & $\mathrm{N}$ & $\mathrm{N}$ & $\mathrm{N}$ & $\mathrm{D}$ & $\mathrm{Na}$ & $\mathrm{Na}$ & 0 \\
\hline & E T & $\mathrm{N}$ & $\mathrm{N}$ & $\mathrm{N}$ & $D$ & 7,1 & 6,9 & 2,8 \\
\hline & E 50 & $M$ & $\mathrm{~N}$ & $M$ & $A$ & 7,1 & 6,6 & 7,0 \\
\hline \multirow{3}{*}{6} & $\mathrm{C}$ & $\mathrm{N}$ & $\mathrm{N}$ & $\mathrm{N}$ & $A$ & $\mathrm{Na}$ & $\mathrm{Na}$ & 0 \\
\hline & E T & $\mathrm{N}$ & $\mathrm{N}$ & $\mathrm{N}$ & $A$ & 7,3 & 6,9 & 5,5 \\
\hline & E 50 & $\mathrm{~N}$ & $\mathrm{~N}$ & $M$ & A & 7,3 & 6,7 & 8,2 \\
\hline \multirow{3}{*}{7} & $\mathrm{C}$ & $\mathrm{N}$ & $\mathrm{N}$ & $\mathrm{N}$ & $A$ & $\mathrm{Na}$ & $\mathrm{Na}$ & 0 \\
\hline & $\mathrm{ET}$ & $\mathrm{M}$ & $\mathrm{N}$ & $M$ & $A$ & 7,1 & 6,8 & 4,2 \\
\hline & E 50 & $\mathrm{M}$ & $\mathrm{N}$ & $\mathrm{N}$ & $A$ & 7,1 & 6,5 & 8,5 \\
\hline \multirow{3}{*}{8} & $\mathrm{C}$ & $\mathrm{N}$ & $\mathrm{N}$ & $\mathrm{N}$ & $A$ & $\mathrm{Na}$ & $\mathrm{Na}$ & 0 \\
\hline & $\mathrm{ET}$ & $\mathrm{M}$ & $\mathrm{N}$ & $M$ & $A$ & 7,1 & 6,8 & 4,2 \\
\hline & E 50 & $\mathrm{~N}$ & $\mathrm{~N}$ & $M$ & A & 7,1 & 6,6 & 7,0 \\
\hline
\end{tabular}

\section{Legenda:}

Base: base de máscara facial peel off

Teste: C - Centrifugação; ET - Estresse térmico; E 50 - Estufa $50,0 \pm 2,0^{\circ} \mathrm{C} / 72$ horas

Aspecto: N - Normal; M - Modificado; IM - Intensamente modificado;

Cor: N - Normal; M - Modificado; IM - Intensamente modificado;

Odor: N - Normal; M - Modificado; IM - Intensamente modificado;

Aplicação e Toque: A - toque agradável, facilidade de aplicação na pele (espalhabilidade);

D - toque desagradável, pegajoso, relativa dificuldade de aplicação na pele (espalhabilidade); MD toque muito desagradável, muito pegajoso, comprometendo aplicação na pele;

pH: Na - não aplicável; As.: após 48 horas de preparo (t0); Ds.: após a condição do teste 
Tabela 11. Avaliação das características organolépticas e valor de $\mathrm{pH}$ das bases de máscara facial peel off (9 a 16) durante o Estudo de Estabilidade Preliminar.

\begin{tabular}{|c|c|c|c|c|c|c|c|c|}
\hline \multirow{3}{*}{ Bases } & \multicolumn{8}{|c|}{ Parâmetro avaliado } \\
\hline & \multirow{2}{*}{ Teste } & \multirow{2}{*}{ Aspecto } & \multirow{2}{*}{ Cor } & \multirow{2}{*}{ Odor } & \multirow{2}{*}{$\begin{array}{c}\text { Aplicação } \\
\text { /Toque }\end{array}$} & \multicolumn{2}{|c|}{$\mathrm{pH}$} & \multirow{2}{*}{$\begin{array}{c}\text { Variação } \\
\text { pH (\%) }\end{array}$} \\
\hline & & & & & & As. & Ds. & \\
\hline & C & $\mathrm{N}$ & $\mathrm{N}$ & $\mathrm{N}$ & $A$ & $\mathrm{Na}$ & $\mathrm{Na}$ & 0 \\
\hline \multirow[t]{3}{*}{9} & $\mathrm{ET}$ & $\mathrm{N}$ & $\mathrm{N}$ & $\mathrm{N}$ & $A$ & 7,3 & 6,9 & 5,5 \\
\hline & E 50 & $\mathrm{~N}$ & $\mathrm{~N}$ & $\mathrm{~N}$ & $A$ & 7,3 & 6,8 & 6,8 \\
\hline & $\mathrm{C}$ & $\mathrm{N}$ & $\mathrm{N}$ & $\mathrm{N}$ & MD & $\mathrm{Na}$ & $\mathrm{Na}$ & 0 \\
\hline \multirow[t]{3}{*}{10} & $\mathrm{ET}$ & $\mathrm{N}$ & $\mathrm{N}$ & $\mathrm{N}$ & MD & 7,4 & 6,8 & 6,8 \\
\hline & E 50 & $\mathrm{~N}$ & $\mathrm{~N}$ & $\mathrm{~N}$ & MD & 7,4 & 6,2 & 16,2 \\
\hline & $\mathrm{C}$ & $\mathrm{N}$ & $\mathrm{N}$ & $\mathrm{N}$ & MD & $\mathrm{Na}$ & $\mathrm{Na}$ & 0 \\
\hline \multirow[t]{3}{*}{11} & E T & $\mathrm{N}$ & $\mathrm{N}$ & $\mathrm{N}$ & MD & 7,3 & 6,8 & 6,8 \\
\hline & E 50 & M & $\mathrm{N}$ & $\mathrm{N}$ & MD & 7,3 & 6,3 & 13,7 \\
\hline & $\mathrm{C}$ & $\mathrm{N}$ & $\mathrm{N}$ & $\mathrm{N}$ & MD & $\mathrm{Na}$ & $\mathrm{Na}$ & 0 \\
\hline \multirow[t]{3}{*}{12} & $\mathrm{E} T$ & $\mathrm{~N}$ & $\mathrm{~N}$ & $\mathrm{~N}$ & MD & 7,5 & 6,9 & 8,0 \\
\hline & E 50 & $\mathrm{M}$ & $\mathrm{N}$ & $\mathrm{N}$ & MD & 7,5 & 6,3 & 16,0 \\
\hline & $\mathrm{C}$ & $\mathrm{N}$ & $\mathrm{N}$ & $\mathrm{N}$ & $A$ & $\mathrm{Na}$ & $\mathrm{Na}$ & 0 \\
\hline \multirow[t]{3}{*}{13} & $\mathrm{ET}$ & $\mathrm{N}$ & $\mathrm{N}$ & $\mathrm{N}$ & $A$ & 7,5 & 7,0 & 6,7 \\
\hline & E 50 & $M$ & $\mathrm{~N}$ & $\mathrm{~N}$ & $A$ & 7,5 & 6,4 & 14,7 \\
\hline & $\mathrm{C}$ & $\mathrm{N}$ & $\mathrm{N}$ & $\mathrm{N}$ & $A$ & $\mathrm{Na}$ & $\mathrm{Na}$ & 0 \\
\hline \multirow[t]{3}{*}{14} & $\mathrm{ET}$ & $\mathrm{N}$ & $\mathrm{N}$ & $\mathrm{N}$ & $A$ & 7,2 & 7,0 & 2,8 \\
\hline & E 50 & $\mathrm{~N}$ & $\mathrm{~N}$ & $M$ & A & 7,2 & 6,7 & 6,9 \\
\hline & $\mathrm{C}$ & $\mathrm{N}$ & $\mathrm{N}$ & $\mathrm{N}$ & $D$ & $\mathrm{Na}$ & $\mathrm{Na}$ & 0 \\
\hline \multirow[t]{3}{*}{15} & $\mathrm{ET}$ & $M$ & $\mathrm{~N}$ & $\mathrm{~N}$ & $D$ & 7,4 & 6,9 & 6,8 \\
\hline & E 50 & $\mathrm{M}$ & $\mathrm{N}$ & $\mathrm{N}$ & $D$ & 7,4 & 6,7 & 9,5 \\
\hline & $\mathrm{C}$ & $\mathrm{N}$ & $\mathrm{N}$ & $\mathrm{N}$ & MD & $\mathrm{Na}$ & $\mathrm{Na}$ & 0 \\
\hline \multirow[t]{2}{*}{16} & $\mathrm{ET}$ & $\mathrm{M}$ & $\mathrm{N}$ & $\mathrm{N}$ & MD & 7,5 & 7,0 & 6,7 \\
\hline & E 50 & $M$ & $\mathrm{~N}$ & $\mathrm{~N}$ & MD & 7,5 & 6,4 & 14,7 \\
\hline
\end{tabular}

Legenda:

Base: base de máscara facial peel off

Teste: C - Centrifugação; ET - Estresse térmico; E 50 - Estufa $50,0 \pm 2,0^{\circ} \mathrm{C} / 72$ horas

Aspecto: N - Normal; M - Modificado; IM - Intensamente modificado;

Cor: N - Normal; M - Modificado; IM - Intensamente modificado;

Odor: N - Normal; M - Modificado; IM - Intensamente modificado;

Aplicação e Toque: A - toque agradável, facilidade de aplicação na pele (espalhabilidade);

D - toque desagradável, pegajoso, relativa dificuldade de aplicação na pele (espalhabilidade); MD toque muito desagradável, muito pegajoso, comprometendo aplicação na pele;

pH: Na - não aplicável; As.: após 48 horas de preparo (t0); Ds.: após a condição do teste 
Tabela 12. Avaliação das características organolépticas e valor de $\mathrm{pH}$ das bases de máscara facial peel off (17 a 24) durante o Estudo de Estabilidade Preliminar.

\begin{tabular}{|c|c|c|c|c|c|c|c|c|}
\hline \multirow{3}{*}{ Bases } & \multicolumn{8}{|c|}{ Parâmetro avaliado } \\
\hline & \multirow{2}{*}{ Teste } & \multirow{2}{*}{ Aspecto } & \multirow{2}{*}{ Cor } & \multirow{2}{*}{ Odor } & \multirow{2}{*}{$\begin{array}{l}\text { Aplicação } \\
\text { /Toque }\end{array}$} & \multicolumn{2}{|c|}{$\mathrm{pH}$} & \multirow{2}{*}{$\begin{array}{c}\text { Variação } \\
\text { pH (\%) }\end{array}$} \\
\hline & & & & & & As. & Ds. & \\
\hline & C & $\mathrm{N}$ & $\mathrm{N}$ & $\mathrm{N}$ & MD & $\mathrm{Na}$ & $\mathrm{Na}$ & 0 \\
\hline \multirow[t]{3}{*}{17} & $\mathrm{ET}$ & $\mathrm{N}$ & $\mathrm{N}$ & $\mathrm{N}$ & MD & 7,6 & 7,1 & 6,6 \\
\hline & E 50 & M & $\mathrm{N}$ & $M$ & MD & 7,6 & 6,4 & 15,8 \\
\hline & $\mathrm{C}$ & $\mathrm{N}$ & $\mathrm{N}$ & $\mathrm{N}$ & $A$ & $\mathrm{Na}$ & $\mathrm{Na}$ & 0 \\
\hline \multirow[t]{3}{*}{18} & $\mathrm{ET}$ & M & $\mathrm{N}$ & $\mathrm{N}$ & $A$ & 7,4 & 6,9 & 6,8 \\
\hline & E 50 & $\mathrm{~N}$ & $\mathrm{~N}$ & M & A & 7,4 & 6,4 & 13,5 \\
\hline & $\mathrm{C}$ & $\mathrm{N}$ & $\mathrm{N}$ & $\mathrm{N}$ & $\mathrm{D}$ & $\mathrm{Na}$ & $\mathrm{Na}$ & 0 \\
\hline \multirow[t]{3}{*}{19} & E T & $\mathrm{N}$ & $\mathrm{N}$ & $\mathrm{N}$ & $\mathrm{D}$ & 7,3 & 5,6 & 23,3 \\
\hline & E 50 & $\mathrm{M}$ & $\mathrm{N}$ & $\mathrm{N}$ & $\mathrm{D}$ & 7,3 & 6,3 & 13,7 \\
\hline & $\mathrm{C}$ & $\mathrm{N}$ & $\mathrm{N}$ & $\mathrm{N}$ & $A$ & $\mathrm{Na}$ & $\mathrm{Na}$ & 0 \\
\hline \multirow[t]{3}{*}{20} & E T & $\mathrm{N}$ & $\mathrm{N}$ & $\mathrm{N}$ & $A$ & 6,7 & 6,8 & 1,5 \\
\hline & E 50 & $\mathrm{~N}$ & $\mathrm{~N}$ & $\mathrm{M}$ & A & 6,7 & 6,2 & 7,5 \\
\hline & $\mathrm{C}$ & $\mathrm{N}$ & $\mathrm{N}$ & $\mathrm{N}$ & $\mathrm{D}$ & $\mathrm{Na}$ & $\mathrm{Na}$ & 0 \\
\hline \multirow[t]{3}{*}{21} & E T & $\mathrm{N}$ & $\mathrm{N}$ & $\mathrm{N}$ & $D$ & 6,9 & 6,9 & 0 \\
\hline & E 50 & $M$ & $\mathrm{~N}$ & $\mathrm{M}$ & $D$ & 6,9 & 6,4 & 7,2 \\
\hline & $\mathrm{C}$ & $\mathrm{N}$ & $\mathrm{N}$ & $\mathrm{N}$ & $A$ & $\mathrm{Na}$ & $\mathrm{Na}$ & 0 \\
\hline \multirow[t]{3}{*}{22} & E T & $\mathrm{N}$ & $\mathrm{N}$ & $\mathrm{N}$ & $A$ & 6,8 & 6,9 & 1,5 \\
\hline & E 50 & $\mathrm{~N}$ & $\mathrm{~N}$ & $\mathrm{M}$ & A & 6,8 & 6,4 & 5,9 \\
\hline & $\mathrm{C}$ & $\mathrm{N}$ & $\mathrm{N}$ & $\mathrm{N}$ & $A$ & $\mathrm{Na}$ & $\mathrm{Na}$ & 0 \\
\hline \multirow[t]{3}{*}{23} & $\mathrm{ET}$ & $M$ & $\mathrm{~N}$ & $\mathrm{~N}$ & $A$ & 7,2 & 6,9 & 4,3 \\
\hline & E 50 & $\mathrm{~N}$ & $\mathrm{~N}$ & $\mathrm{M}$ & $A$ & 7,2 & 6,9 & 4,3 \\
\hline & $\mathrm{C}$ & $\mathrm{N}$ & $\mathrm{N}$ & $\mathrm{N}$ & $A$ & $\mathrm{Na}$ & $\mathrm{Na}$ & 0 \\
\hline \multirow[t]{2}{*}{24} & $\mathrm{ET}$ & $\mathrm{M}$ & $\mathrm{N}$ & $\mathrm{N}$ & $A$ & 7,4 & 7,0 & 0,7 \\
\hline & E 50 & $M$ & $\mathrm{~N}$ & $\mathrm{M}$ & $D$ & 7,4 & 6,6 & 10,8 \\
\hline
\end{tabular}

Legenda:

Base: base de máscara facial peel off

Teste: C - Centrifugação; ET - Estresse térmico; E 50 - Estufa $50,0 \pm 2,0^{\circ} \mathrm{C} / 72$ horas

Aspecto: N - Normal; M - Modificado; IM - Intensamente modificado;

Cor: N - Normal; M - Modificado; IM - Intensamente modificado;

Odor: N - Normal; M - Modificado; IM - Intensamente modificado;

Aplicação e Toque: A - toque agradável, facilidade de aplicação na pele (espalhabilidade);

D - toque desagradável, pegajoso, relativa dificuldade de aplicação na pele (espalhabilidade); MD toque muito desagradável, muito pegajoso, comprometendo aplicação na pele;

pH: Na - não aplicável; As.: após 48 horas de preparo (t0); Ds.: após a condição do teste 
Tabela 13. Avaliação das características organolépticas e valor de $\mathrm{pH}$ das bases de máscara facial peel off (25 a 32) durante o Estudo de Estabilidade Preliminar.

\begin{tabular}{|c|c|c|c|c|c|c|c|c|}
\hline \multirow{3}{*}{ Bases } & \multicolumn{8}{|c|}{ Parâmetro avaliado } \\
\hline & \multirow{2}{*}{ Teste } & \multirow{2}{*}{ Aspecto } & \multirow{2}{*}{ Cor } & \multirow{2}{*}{ Odor } & \multirow{2}{*}{$\begin{array}{c}\text { Aplicação } \\
\text { /Toque }\end{array}$} & \multicolumn{2}{|c|}{$\mathrm{pH}$} & \multirow{2}{*}{$\begin{array}{c}\text { Variação } \\
\text { pH (\%) }\end{array}$} \\
\hline & & & & & & As. & Ds. & \\
\hline & C & $\mathrm{N}$ & $\mathrm{N}$ & $\mathrm{N}$ & $A$ & $\mathrm{Na}$ & $\mathrm{Na}$ & 0 \\
\hline \multirow[t]{3}{*}{25} & $\mathrm{ET}$ & $\mathrm{N}$ & $\mathrm{N}$ & $\mathrm{N}$ & $A$ & 7,0 & 6,7 & 4,3 \\
\hline & E 50 & M & $\mathrm{N}$ & $M$ & $A$ & 7,0 & 6,2 & 11,4 \\
\hline & $\mathrm{C}$ & $\mathrm{N}$ & $\mathrm{N}$ & $\mathrm{N}$ & $A$ & $\mathrm{Na}$ & $\mathrm{Na}$ & 0 \\
\hline \multirow[t]{3}{*}{26} & $\mathrm{ET}$ & $\mathrm{N}$ & $\mathrm{N}$ & $\mathrm{N}$ & $A$ & 7,0 & 6,8 & 2,9 \\
\hline & E 50 & M & $\mathrm{N}$ & M & $A$ & 7,0 & 6,4 & 8,6 \\
\hline & $\mathrm{C}$ & $\mathrm{N}$ & $\mathrm{N}$ & $\mathrm{N}$ & $A$ & $\mathrm{Na}$ & $\mathrm{Na}$ & 0 \\
\hline \multirow[t]{3}{*}{27} & E T & $\mathrm{N}$ & $\mathrm{N}$ & $\mathrm{N}$ & $A$ & 7,3 & 7,2 & 1,4 \\
\hline & E 50 & $\mathrm{M}$ & $\mathrm{N}$ & $\mathrm{M}$ & $\mathrm{D}$ & 7,3 & 6,6 & 9,6 \\
\hline & $\mathrm{C}$ & $\mathrm{N}$ & $\mathrm{N}$ & $\mathrm{N}$ & $A$ & $\mathrm{Na}$ & $\mathrm{Na}$ & 0 \\
\hline \multirow[t]{3}{*}{28} & E T & $M$ & $\mathrm{~N}$ & $\mathrm{~N}$ & $A$ & 7,2 & 6,5 & 9,7 \\
\hline & E 50 & $\mathrm{~N}$ & $\mathrm{~N}$ & $\mathrm{~N}$ & $A$ & 7,2 & 6,2 & 13,9 \\
\hline & $\mathrm{C}$ & $\mathrm{N}$ & $\mathrm{N}$ & $\mathrm{N}$ & $A$ & $\mathrm{Na}$ & $\mathrm{Na}$ & 0 \\
\hline \multirow[t]{3}{*}{29} & $\mathrm{ET}$ & $\mathrm{M}$ & $\mathrm{N}$ & $\mathrm{N}$ & $A$ & 7,3 & 6,6 & 9,6 \\
\hline & E 50 & $\mathrm{~N}$ & $\mathrm{~N}$ & $\mathrm{~N}$ & $A$ & 7,3 & 6,3 & 13,7 \\
\hline & $\mathrm{C}$ & $\mathrm{N}$ & $\mathrm{N}$ & $\mathrm{N}$ & MD & $\mathrm{Na}$ & $\mathrm{Na}$ & 0 \\
\hline \multirow[t]{3}{*}{30} & E T & $M$ & $\mathrm{~N}$ & $\mathrm{~N}$ & $\mathrm{MD}$ & 7,2 & 6,5 & 9,7 \\
\hline & E 50 & $\mathrm{~N}$ & $\mathrm{~N}$ & $\mathrm{~N}$ & MD & 7,2 & 6,1 & 15,3 \\
\hline & $\mathrm{C}$ & $\mathrm{N}$ & $\mathrm{N}$ & $\mathrm{N}$ & $A$ & $\mathrm{Na}$ & $\mathrm{Na}$ & 0 \\
\hline \multirow[t]{3}{*}{31} & E T & $M$ & $\mathrm{~N}$ & $\mathrm{~N}$ & $A$ & 7,1 & 6,6 & 7,0 \\
\hline & E 50 & IM & $\mathrm{N}$ & $\mathrm{N}$ & $A$ & 7,1 & 6,2 & 12,7 \\
\hline & $\mathrm{C}$ & $\mathrm{N}$ & $\mathrm{N}$ & $\mathrm{N}$ & MD & $\mathrm{Na}$ & $\mathrm{Na}$ & 0 \\
\hline \multirow[t]{2}{*}{32} & $\mathrm{ET}$ & $\mathrm{M}$ & $\mathrm{N}$ & $\mathrm{N}$ & MD & 7,1 & 7,0 & 1,4 \\
\hline & E 50 & $M$ & $\mathrm{~N}$ & $M$ & MD & 7,1 & 6,5 & 8,5 \\
\hline
\end{tabular}

Legenda:

Base: base de máscara facial peel off

Teste: C - Centrifugação; ET - Estresse térmico; E 50 - Estufa 50,0 $\pm 2,0^{\circ} \mathrm{C} / 72$ horas

Aspecto: N - Normal; M - Modificado; IM - Intensamente modificado;

Cor: N - Normal; M - Modificado; IM - Intensamente modificado;

Odor: N - Normal; M - Modificado; IM - Intensamente modificado;

Aplicação e Toque: A - toque agradável, facilidade de aplicação na pele (espalhabilidade);

D - toque desagradável, pegajoso, relativa dificuldade de aplicação na pele (espalhabilidade); MD toque muito desagradável, muito pegajoso, comprometendo aplicação na pele;

pH: Na - não aplicável; As.: após 48 horas de preparo (t0); Ds.: após a condição do teste 
Tabela 14. Avaliação das características organolépticas e valor de $\mathrm{pH}$ das bases de máscara facial peel off (33 a 36) durante o Estudo de Estabilidade Preliminar.

\begin{tabular}{|c|c|c|c|c|c|c|c|c|}
\hline \multirow{3}{*}{ Bases } & \multicolumn{8}{|c|}{ Parâmetro avaliado } \\
\hline & \multirow{2}{*}{ Teste } & \multirow{2}{*}{ Aspecto } & \multirow{2}{*}{ Cor } & \multirow{2}{*}{ Odor } & \multirow{2}{*}{$\begin{array}{l}\text { Aplicação } \\
\text { /Toque }\end{array}$} & \multicolumn{2}{|c|}{ pH } & \multirow{2}{*}{$\begin{array}{c}\text { Variação } \\
\text { pH (\%) }\end{array}$} \\
\hline & & & & & & As. & Ds. & \\
\hline \multirow{3}{*}{33} & C & $\mathrm{N}$ & $\mathrm{N}$ & $\mathrm{N}$ & $\mathrm{D}$ & $\mathrm{Na}$ & $\mathrm{Na}$ & 0 \\
\hline & $\mathrm{ET}$ & $M$ & $\mathrm{~N}$ & $\mathrm{~N}$ & $\mathrm{D}$ & 7,2 & 7,2 & 0 \\
\hline & E 50 & $\mathrm{~N}$ & $\mathrm{~N}$ & $M$ & $\mathrm{D}$ & 7,2 & 6,6 & 8,3 \\
\hline \multirow{3}{*}{34} & $\mathrm{C}$ & $\mathrm{N}$ & $\mathrm{N}$ & $\mathrm{N}$ & $A$ & $\mathrm{Na}$ & $\mathrm{Na}$ & 0 \\
\hline & E T & $\mathrm{N}$ & $\mathrm{N}$ & $\mathrm{N}$ & $A$ & 7,4 & 6,9 & 6,8 \\
\hline & E 50 & $\mathrm{~N}$ & $\mathrm{~N}$ & $M$ & $A$ & 7,4 & 6,7 & 9,5 \\
\hline \multirow{3}{*}{35} & $\mathrm{C}$ & $\mathrm{N}$ & $\mathrm{N}$ & $\mathrm{N}$ & $A$ & $\mathrm{Na}$ & $\mathrm{Na}$ & 0 \\
\hline & E T & $\mathrm{N}$ & $\mathrm{N}$ & $\mathrm{N}$ & $A$ & 7,2 & 6,7 & 6,9 \\
\hline & E 50 & $\mathrm{~N}$ & $\mathrm{~N}$ & $\mathrm{~N}$ & $A$ & 7,2 & 6,8 & 5,6 \\
\hline \multirow{3}{*}{36} & $C$ & $\mathrm{~N}$ & $\mathrm{~N}$ & $\mathrm{~N}$ & $A$ & $\mathrm{Na}$ & $\mathrm{Na}$ & 0 \\
\hline & E T & $M$ & $\mathrm{~N}$ & $\mathrm{~N}$ & $A$ & 7,3 & 7,1 & 2,7 \\
\hline & E 50 & $M$ & $\mathrm{~N}$ & $M$ & $D$ & 7,3 & 6,5 & 11,0 \\
\hline
\end{tabular}

\section{Legenda:}

Base: base de máscara facial peel off

Teste: C - Centrifugação; ET - Estresse térmico; E 50 - Estufa 50,0 $\pm 2,0^{\circ} \mathrm{C} / 72$ horas

Aspecto: N - Normal; M - Modificado; IM - Intensamente modificado;

Cor: N - Normal; M - Modificado; IM - Intensamente modificado;

Odor: N - Normal; M - Modificado; IM - Intensamente modificado;

Aplicação e Toque: A - toque agradável, facilidade de aplicação na pele (espalhabilidade); D - toque desagradável, pegajoso, relativa dificuldade de aplicação na pele (espalhabilidade); MD toque muito desagradável, muito pegajoso, comprometendo aplicação na pele;

pH: Na - não aplicável; As.: após 48 horas de preparo (t0); Ds.: após a condição do teste

Os resultados referentes ao item Aspecto das Tabelas 10 a 14 indicaram que, das 28 bases elaboradas, cerca de $70 \%$ apresentaram uma modificação em comum, caracterizada pela presença de líquido sobrenadante após o teste de estresse térmico e estufa, identificada pela classificação $\mathbf{M} / \mathbf{I} \mathbf{M}$. Existem duas possibilidades para justificar o fato.

A primeira explicação atribui a presença de líquido sobrenadante à condensação de vapor de água da atmosfera. Durante a realização dos testes de estresse térmico e estufa, ocorreu aumento da temperatura da preparação e do 
material de acondicionamento. Com o posterior resfriamento, à temperatura ambiente, a água presente na atmosfera sob a forma de vapor, em contato com a superfície fria do material de embalagem primária, condensou-se e precipitou-se, acumulando-se sobre as preparações.

A segunda explicação sugere alterações decorrentes da instabilidade das preparações, possivelmente pela perda de água da própria formulação durante os testes. Este fato pode ter sido ocasionado pela baixa consistência das bases de máscara facial peel off e/ou pela concentração/miscibilidade reduzida dos umectantes, como glicerina, propilenoglicol e butilenoglicol.

Não foram observadas alterações na Cor das preparações, indicando estabilidade adequada (principalmente térmica) e compatibilidade do corante utilizado nas preparações elaboradas.

Os resultados de Odor indicaram manifestações de instabilidades nos testes de estresse térmico e de estufa $(50,0 \stackrel{\circ}{ } \mathrm{C})$ para as bases classificadas como $\mathbf{M}$ neste critério - 23 preparações, aproximadamente 64\% do total. Essas manifestações caracterizaram-se por diminuição da intensidade do odor da fragrância e aumento do odor de etanol, devido à evaporação. Não foram verificados outros odores.

A avaliação de Aplicação e Toque para as máscaras faciais peel off é determinante, pois elas precisam ter aderência à superfície da pele da face, mas o toque agradável é imprescindível para ocorrer a aceitação do consumidor (MARTINE et al., 1995). Bases contendo concentrações elevadas dos componentes que conferem aumento da viscosidade, como álcool polivinílico (15,0\% p/p), base autoemulsionante $(2,0 \% \mathrm{p} / \mathrm{p})$ e silicone de copolímero glicol $(2,0 \% \mathrm{p} / \mathrm{p})$, como as preparações $\mathbf{F 1 0}$ e F12, apresentaram resultados na avaliação de Aplicação e Toque semelhantes às bases com concentrações inferiores ou mesmo ausência da utilização dos mesmos componentes (12,0,0,0 e 0\% p/p, respectivamente), como na preparação F17. Da mesma maneira, dentre as preparações que foram classificadas como agradáveis ao toque e de fácil espalhabilidade, encontram-se aquelas com composições opostas quanto à concentração dos mesmos componentes, como F14, que possui 15,0\% p/p de PVA, 2,0\% p/p de base autoemulsonante e de silicone de copolímero glicol; e F9, que possui 12,0, 0,0 e 0,0\% dos componentes citados, respectivamente. Portanto, pode-se dizer que não foi observada uma relação direta entre a composição quali e quantitativa das bases de máscara facial peel off e a resposta de Aplicação e Toque. 
Com relação aos testes realizados, as bases F9, F13, F28, F29 e F35 apresentaram resultados satisfatórios na avaliação das características organolépticas do Estudo de Estabilidade Preliminar frente às outras preparações elaboradas. No entanto, as bases F13, F28 e F29, para sua utilização em estudos posteriores, deveriam ser reestruturadas quanto à composição, em virtude da formação de líquido sobrenadante durante os testes em temperaturas mais elevadas $\left(50,0^{\circ} \mathrm{C}\right)$. As alterações citadas anteriormente nas características organolépticas são aceitas no Estudo de Estabilidade Preliminar, considerando que foram condições drásticas às quais as formulações foram submetidas (AGÊNCIA NACIONAL DE VIGILÂNCIA SANITÁRIA, 2004). Mesmo assim, há formulações em que tais alterações não foram verificadas, em todos os testes realizados - F9 e F35 -, indicando sua maior estabilidade com relação às demais.

Observou-se que o valor de pH manteve uma variação abaixo de $15 \%$ para a maior parte das formulações, com exceção das bases F1, F2, F10, F12, F17, F19 e F30, que apresentaram resultados desfavoráveis, acima de 15\%.

Desta forma, as bases F9 e F35 foram identificadas como as preparações de melhor desempenho dentre as 36 bases de máscara facial peel off elaboradas, na avaliação organoléptica e determinação do valor de pH no Estudo de Estabilidade Preliminar. 


\subsubsection{Tempo de secagem e formação de filme}

As médias dos tempos de secagem (triplicata) para as bases de máscara facial peel off 1 a 36, estão representadas na Figura 7.

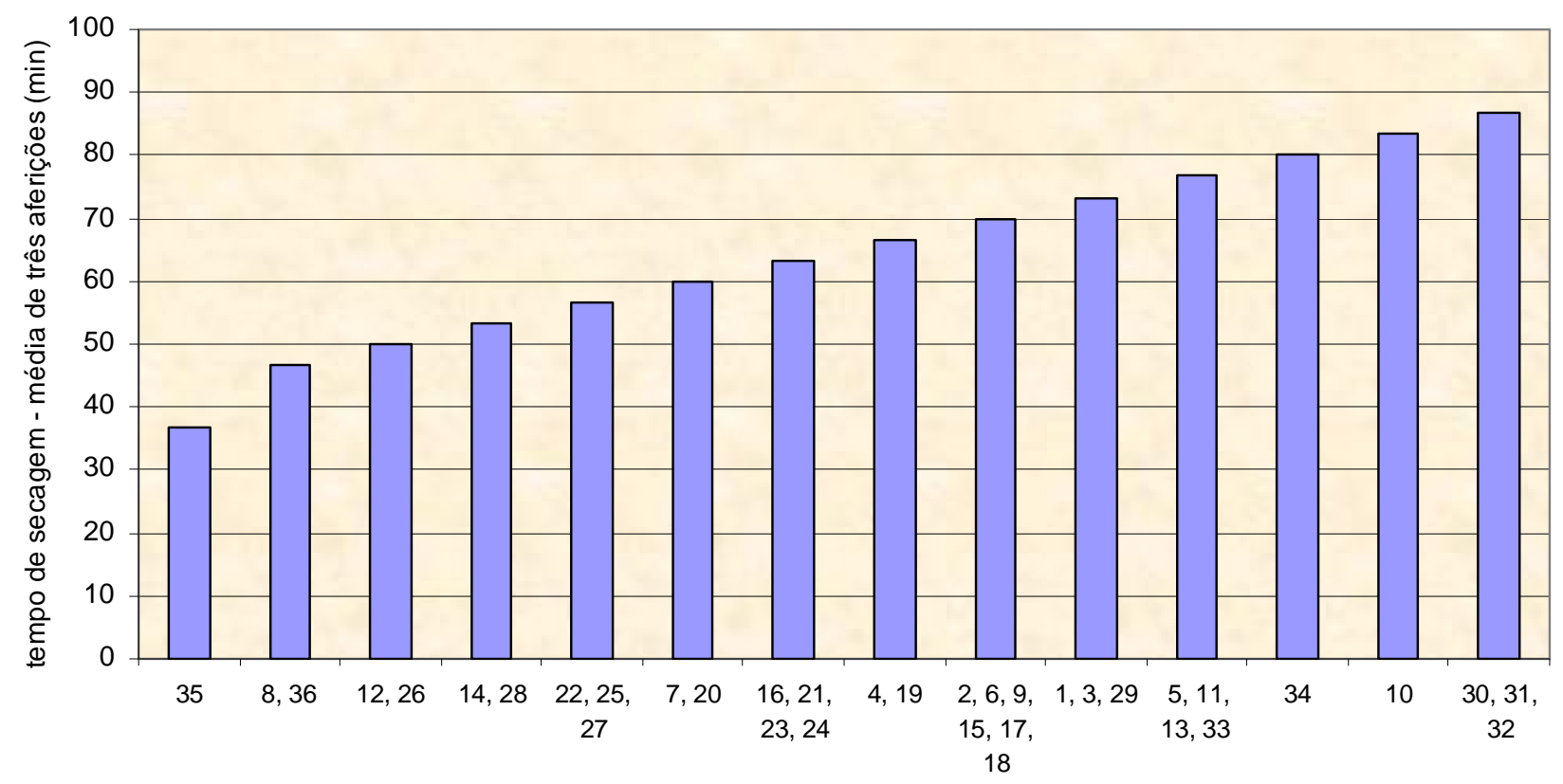

Pré-formulações

Figura 7. Tempo de secagem (min) das bases 1 a 36 (média da triplicata) em estufa (36,5 \pm $\left.1,0^{\circ} \mathrm{C}\right)$

Conforme a Figura 7, as bases de máscara facial peel off F8, F12, F26, F35 e F36 apresentaram melhor desempenho que as demais no teste do tempo de secagem, ou seja, formaram um filme resistente e de fácil retirada da lâmina em menor tempo, com os tempos de 46,7; $50 ; 50 ; 36,7$ e 46,7 min, respectivamente. Destas preparações, apenas a base $\mathbf{F 3 5}$, que apresentou o melhor desempenho no teste de secagem, não apresentou modificações significativas nos testes de avaliação das características organolépticas e variação do valor de $\mathrm{pH}$. A preparação $\mathbf{F 9}$, que juntamente com $\mathbf{F 3 5}$, foi a base de melhor desempenho na avaliação organoléptica e de valor de $\mathrm{pH}$, apresentou alto tempo de secagem (70 min), o que inviabiliza seu uso em comparação com as outras preparações.

Portanto, a base F35 foi selecionada como a preparação de melhor desempenho no Estudo de Estabilidade Preliminar. 
Apesar dos seus resultados satisfatórios, o tempo de secagem da base de máscara facial peel off F35 - 36,7 min - foi considerado elevado. Máscaras faciais peel off formam filmes no intervalo de tempo de 10 a 30 minutos, após sua aplicação (MARTINE et al., 1995, CHARLET, 1996). Um período de tempo prolongado de secagem inviabilizaria o uso cosmético da máscara facial peel off, refletindo na baixa aderência ao tratamento por parte dos consumidores (WILKINSON \& MOORE, 1982).

Com o intuito de contornar o problema, foram realizadas adaptações na base F35, com a subseqüente realização dos Estudos de Estabilidade Preliminar e Acelerada, visando diminuir seu tempo de secagem e minimizar a ocorrência de possíveis processos de instabilidade da preparação em estudos posteriores.

\subsection{Adequação da base F35 e Estudo de Estabilidade Preliminar}

A partir dos resultados obtidos no Estudo de Estabilidade Preliminar para as 36 bases de máscaras faciais peel off, foi selecionada a preparação F35. Ela foi submetida às adequações, como aumento na concentração de PVA e adição de Goma Guar (espessante), a fim de diminuir o tempo de secagem da base, melhorando seu desempenho na formação do filme. As preparações alteradas passaram a ser denominadas formulações.

\subsubsection{Características organolépticas e valor de pH}

Os resultados obtidos na avaliação das características organolépticas e valores de pH no Estudo de Estabilidade Preliminar estão descritos na Tabela 15.

Foram elaboradas oito formulações a partir da base F35, acrescidas do extrato de soja $5 \% \mathrm{p} / \mathrm{p}$, que posteriormente foram submetidas à avaliação das características organolépticas e determinação do valor de $\mathrm{pH}$, antes e após a exposição às condições de estresse térmico e estufa $50,0 \pm 2,0^{\circ} \mathrm{C} / 72 \mathrm{~h}$ (BABY, 2005; AGÊNCIA NACIONAL DE VIGILÂNCIA SANITÁRIA, 2004; PINTO, 2005; TRAVERSA, 2003; ZAGUE, 2007).

Os resultados do Aspecto indicaram que ocorreu formação de líquido sobrenadante nas preparações F35/15 e F35/17, além de percebida uma maior fluidez, durante o teste do estresse térmico, indicados pelos resultados M/IM. As 
demais modificações apresentadas nas bases adaptadas foram decorrentes do aumento da fluidez das preparações. Além disso, observou-se aumento da turbidez durante o teste do estresse térmico.

Não foi observada alteração na Cor em nenhuma das preparações, indicando estabilidade adequada (principalmente térmica) e compatibilidade do corante empregado.

Os resultados de Odor indicaram diminuição da intensidade da fragrância nos testes de estresse térmico para todas as bases adaptadas. Essas manifestações caracterizaram-se pela volatilização do componente, devido à temperatura elevada. Não foram verificadas outras alterações do odor.

A avaliação do Aplicação e Toque para as preparações demonstrou que aquelas que possuíam 20\% p/p de álcool polivinílico (F35/20 e F35/20G), a maior concentração do polímero, apresentaram consistência elevada e viscosidade comprometida, o que pode estar relacionado à proporção elevada do polímero na preparação. As formulações com melhor desempenho na avaliação do Aplicação e Toque foram aquelas com concentrações intermediárias de PVA (F35/17G e F35/18, 17 e $18 \%$ p/p de polímero, respectivamente).

Como descrito anteriormente, as alterações observadas nas características organolépticas para os testes de estresse térmico e estufa $\left(50^{\circ} \mathrm{O}\right.$ ) são aceitas no Estudo de Estabilidade Preliminar, considerando as condições drásticas a que as preparações foram submetidas (AGÊNCIA NACIONAL DE VIGILÂNCIA SANITÁRIA, 2004). 
Tabela 15. Avaliação das características organolépticas e valor de $\mathrm{pH}$ das formulações de máscara facial peel off (modificações da base F35) no Estudo de Estabilidade Preliminar.

\begin{tabular}{|c|c|c|c|c|c|c|c|c|}
\hline \multirow{3}{*}{ 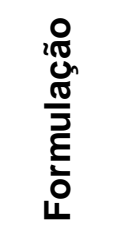 } & \multicolumn{8}{|c|}{ Parâmetro avaliado } \\
\hline & \multirow{2}{*}{ Teste } & \multirow{2}{*}{ Aspecto } & \multirow{2}{*}{ Cor } & \multirow{2}{*}{ Odor } & \multirow{2}{*}{$\begin{array}{c}\text { Aplicação } \\
\text { Toque }\end{array}$} & \multicolumn{2}{|c|}{$\mathrm{pH}$} & \multirow{2}{*}{$\begin{array}{c}\text { Variação } \\
\text { pH (\%) }\end{array}$} \\
\hline & & & & & & As. & Ds. & \\
\hline & $\mathrm{C}$ & $\mathrm{M}$ & $\mathrm{N}$ & $\mathrm{N}$ & $A$ & $\mathrm{Na}$ & $\mathrm{Na}$ & $\mathrm{Na}$ \\
\hline \multirow[t]{2}{*}{$35 / 15$} & $\mathrm{ET}$ & IM & $\mathrm{N}$ & $M$ & $A$ & 6,3 & 6,1 & 3,2 \\
\hline & E 50 & $\mathrm{~N}$ & $\mathrm{~N}$ & $\mathrm{~N}$ & $\mathrm{D}$ & 6,3 & 5,7 & 9,5 \\
\hline & $\mathrm{C}$ & $\mathrm{N}$ & $\mathrm{N}$ & $\mathrm{N}$ & $A$ & $\mathrm{Na}$ & $\mathrm{Na}$ & $\mathrm{Na}$ \\
\hline \multirow[t]{2}{*}{ 35/15G } & E T & $M$ & $\mathrm{~N}$ & $M$ & $A$ & 6,4 & 6,1 & 4,7 \\
\hline & E 50 & $\mathrm{~N}$ & $\mathrm{~N}$ & $\mathrm{~N}$ & $\mathrm{D}$ & 6,4 & 5,9 & 7,8 \\
\hline & $\mathrm{C}$ & $\mathrm{M}$ & $\mathrm{N}$ & $\mathrm{N}$ & $A$ & $\mathrm{Na}$ & $\mathrm{Na}$ & $\mathrm{Na}$ \\
\hline \multirow[t]{3}{*}{$35 / 17$} & E T & IM & $\mathrm{N}$ & $M$ & $A$ & 6,6 & 6,2 & 6,1 \\
\hline & E 50 & $\mathrm{~N}$ & $\mathrm{~N}$ & $\mathrm{~N}$ & $\mathrm{D}$ & 6,6 & 5,9 & 10,6 \\
\hline & $\mathrm{C}$ & $\mathrm{N}$ & $\mathrm{N}$ & $\mathrm{N}$ & $A$ & $\mathrm{Na}$ & $\mathrm{Na}$ & $\mathrm{Na}$ \\
\hline \multirow[t]{3}{*}{$35 / 17 G$} & E T & $M$ & $\mathrm{~N}$ & $\mathrm{M}$ & $A$ & 6,5 & 6,2 & 4,6 \\
\hline & E 50 & $\mathrm{~N}$ & $\mathrm{~N}$ & $\mathrm{~N}$ & $A$ & 6,5 & 5,8 & 10,8 \\
\hline & $\mathrm{C}$ & $\mathrm{N}$ & $\mathrm{N}$ & $\mathrm{N}$ & $A$ & $\mathrm{Na}$ & $\mathrm{Na}$ & $\mathrm{Na}$ \\
\hline \multirow[t]{3}{*}{$35 / 18$} & $\mathrm{ET}$ & $M$ & $\mathrm{~N}$ & $\mathrm{M}$ & $A$ & 6,6 & 6,1 & 7,6 \\
\hline & E 50 & $\mathrm{~N}$ & $\mathrm{~N}$ & $\mathrm{~N}$ & $A$ & 6,6 & 5,8 & 12,1 \\
\hline & $\mathrm{C}$ & $\mathrm{N}$ & $\mathrm{N}$ & $\mathrm{N}$ & $A$ & $\mathrm{Na}$ & $\mathrm{Na}$ & $\mathrm{Na}$ \\
\hline \multirow[t]{3}{*}{$35 / 18 G$} & $\mathrm{ET}$ & $M$ & $\mathrm{~N}$ & $\mathrm{M}$ & $A$ & 6,7 & 6,6 & 1,5 \\
\hline & E 50 & $\mathrm{~N}$ & $\mathrm{~N}$ & $\mathrm{~N}$ & $\mathrm{D}$ & 6,7 & 5,9 & 11,9 \\
\hline & $C$ & $\mathrm{~N}$ & $\mathrm{~N}$ & $\mathrm{~N}$ & MD & $\mathrm{Na}$ & $\mathrm{Na}$ & $\mathrm{Na}$ \\
\hline \multirow[t]{3}{*}{$35 / 20$} & $\mathrm{ET}$ & $M$ & $\mathrm{~N}$ & $M$ & MD & 6,6 & 6,2 & 6,1 \\
\hline & E 50 & $\mathrm{~N}$ & $\mathrm{~N}$ & $\mathrm{~N}$ & MD & 6,6 & 5,8 & 12,1 \\
\hline & $\mathrm{C}$ & $\mathrm{N}$ & $\mathrm{N}$ & $\mathrm{N}$ & MD & $\mathrm{Na}$ & $\mathrm{Na}$ & $\mathrm{Na}$ \\
\hline \multirow[t]{2}{*}{$35 / 20 G$} & $\mathrm{ET}$ & $M$ & $\mathrm{~N}$ & $\mathrm{M}$ & MD & 6,8 & 6,3 & 7,4 \\
\hline & E 50 & $\mathrm{~N}$ & $\mathrm{~N}$ & $\mathrm{~N}$ & MD & 6,8 & 5,9 & 13,2 \\
\hline
\end{tabular}

\section{Legenda:}

Formulação: preparações resultantes das alterações na base F35

Teste: C - Centrifugação; ET - Estresse térmico; E 50 - Estufa $50 \pm 2,0^{\circ} \mathrm{C} / 72$ horas

Aspecto: N - Normal; M - Modificado; IM - Intensamente modificado;

Cor: N - Normal; M - Modificado; IM - Intensamente modificado;

Odor: N - Normal; $\mathbf{M}$ - Modificado; IM - Intensamente modificado;

Aplicação e Toque: A - toque agradável, facilidade de aplicação na pele (espalhabilidade);

D - toque desagradável, pegajoso, relativa dificuldade de aplicação na pele (espalhabilidade); MD - toque muito desagradável, muito pegajoso, comprometendo aplicação na pele;

pH: Na - não aplicável; As.: após 48 horas de preparo (t0); Ds: após a condição do teste 
Observou-se que o valor de pH manteve uma variação abaixo de 15\% para a todas as bases adaptadas, sendo que as de maior concentração de álcool polivinílico (acima de 17\% p/p) apresentaram variação superior a 10\% para o teste em estufa $\left(50,0^{\circ} \mathrm{C}\right)$.

Diante dos resultados, as formulações F35/17G e F35/18 foram selecionadas como as de melhor desempenho na avaliação das características organolépticas.

\subsubsection{Tempo de secagem e formação de filme}

As médias dos tempos de secagem, obtidas com as leituras em triplicata para as formulações resultantes das modificações na base F35 estão representadas na Figura 8.

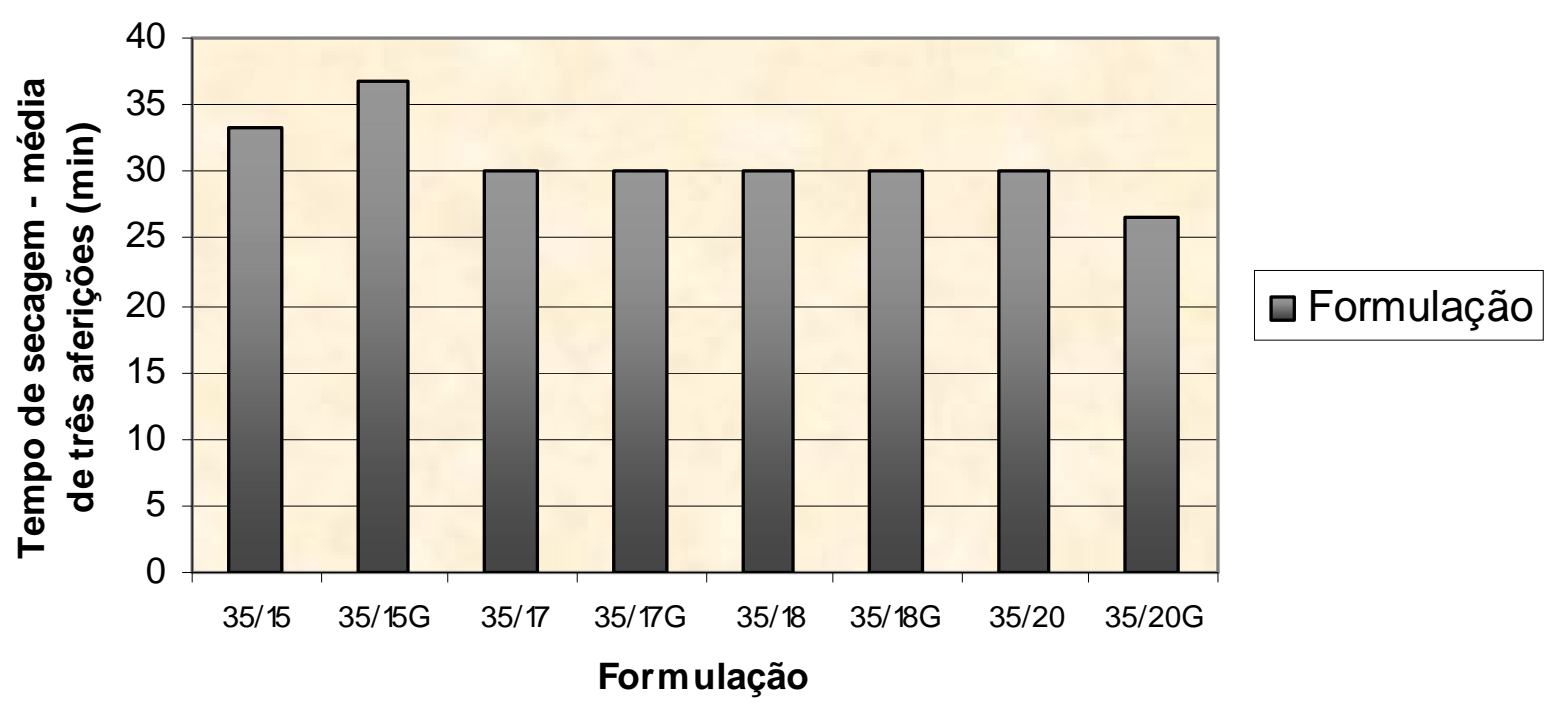

Figura 8. Tempo de secagem $(\mathrm{min})$ das formulações obtidas a partir das modificações na de máscara facial peel off F35 (média da triplicata), na condição de estufa $\left(36,5 \pm 1,0{ }^{\circ} \mathrm{C}\right)$

Conforme os resultados apresentados na Figura $\mathbf{8}$, as formulações $\mathbf{3 5 / 1 7}$, 35/17G, 35/18, 35/18G e 35/20 apresentaram o melhor desempenho no teste do tempo de secagem, ou seja, formaram um filme resistente e de fácil retirada da lâmina em um tempo máximo de 30,0 min, sendo que a formulação 35/20G apresentou valor menor (26,7 $\mathrm{min})$. O tempo de secagem reduzido é um critério de escolha da formulação, uma vez que é um pré-requisito imprescindível para máscaras peel off (WILKINSON \& MOORE, 1982), assim como características 
organolépticas, destacando-se entre elas a Aplicação e Toque, em virtude da importância da aderência da máscara no local de aplicação.

Aliado aos resultados da avaliação organoléptica e de valor de $\mathrm{pH}$, onde pequenas modificações foram aceitas nas condições drásticas de temperatura (estresse térmico e estufa a 50,0 $\pm 2,0{ }^{\circ} \mathrm{C} / 72$ horas), selecionaram-se as formulações 35/18 e 35/17G para ○ Estudo de Estabilidade Acelerada. As preparações 35/18, 35/20 e 35/20G foram excluídas, uma vez que apresentaram dificuldade na espalhabilidade na pele e lâmina, devido à consistência elevada, atribuída às concentrações maiores de PVA. A formulação 35/17 foi excluída em virtude da intensa modificação observada no estresse térmico, atribuída à formação de película de água sobre a formulação.

\subsection{Bases da emulsão óleo em água}

Os resultados obtidos na avaliação das características organolépticas (cor, odor, aspecto e aplicação e toque) e na determinação dos valores de pH no Estudo de Estabilidade Preliminar para as preparações da emulsão O/A, contendo (formulação) ou não (base) extrato de soja fermentado (EC e ES, respectivamente) estão descritos na Tabela 15 (AGÊNCIA NACIONAL DE VIGILÂNCIA SANITÁRIA, 2004; PINTO, 2005).

$\mathrm{Na}$ avaliação dos resultados da Tabela 16, a característica Aspecto demonstrou que a emulsão EC (formulação) tornou-se visualmente menos consistente nos testes de estresse térmico e estufa $\left(50,0 \pm 2,0^{\circ} \mathrm{C} / 72\right.$ horas), enquanto a emulsão ES (base) manifestou o mesmo comportamento apenas no teste da estufa. Não foi observada separação de fases em nenhuma amostra das formulações. As emulsões são, portanto, consideradas estáveis quanto ao aspecto.

Não ocorreram variações de Cor nas preparações, indicando estabilidade (principalmente térmica) do corante utilizado. Foi observada diminuição da intensidade do Odor, nos testes de estresse térmico e estufa, para a formulação ES, e no teste de estufa para a formulação EC. Estes resultados eram esperados diante das condições drásticas utilizadas para os testes.

As formulações apresentaram Aplicação e Toque agradável em todos os testes avaliados, com boa espalhabilidade e ausência de resíduos na pele após sua aplicação. 
As variações do valor de $\mathbf{p H}$, em todas as condições do estudo, foram inferiores a $15 \%$ (máximo de 3,5\%) para todas as amostras analisadas, indicando a estabilidade físico-química das preparações.

Tabela 16. Avaliação das características organolépticas e valor de pH das preparações de emulsão O/A sem extrato de soja fermentado (ES, base) e contendo extrato de soja fermentado (EC, formulação) durante o Estudo de Estabilidade Preliminar.

\begin{tabular}{|c|c|c|c|c|c|c|c|c|}
\hline \multirow{3}{*}{ 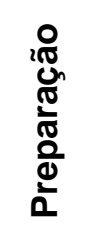 } & \multicolumn{8}{|c|}{ Parâmetro avaliado } \\
\hline & \multirow{2}{*}{ Teste } & \multirow{2}{*}{ Aspecto } & \multirow{2}{*}{ Cor } & \multirow{2}{*}{ Odor } & \multirow{2}{*}{$\begin{array}{c}\text { Aplicação } \\
\text { Toque }\end{array}$} & \multicolumn{2}{|c|}{$\mathrm{pH}$} & \multirow{2}{*}{$\begin{array}{r}\text { Variação } \\
-\quad \mathrm{pH}(\%)\end{array}$} \\
\hline & & & & & & As. & Ds. & \\
\hline \multirow{3}{*}{ ES } & C & $\mathrm{N}$ & $\mathrm{N}$ & $\mathrm{N}$ & A & $\mathrm{Na}$ & $\mathrm{Na}$ & $\mathrm{Na}$ \\
\hline & E T & $\mathrm{N}$ & $\mathrm{N}$ & M & A & 5,7 & 5,6 & 1,8 \\
\hline & E 50 & $M$ & $\mathrm{~N}$ & $M$ & A & 5,7 & 5,5 & 3,5 \\
\hline \multirow{3}{*}{$\mathrm{EC}$} & $\mathrm{C}$ & $\mathrm{N}$ & $\mathrm{N}$ & $\mathrm{N}$ & $A$ & $\mathrm{Na}$ & $\mathrm{Na}$ & $\mathrm{Na}$ \\
\hline & E T & $M$ & $\mathrm{~N}$ & $\mathrm{~N}$ & A & 6,4 & 6,3 & 1,6 \\
\hline & E 50 & $M$ & $\mathrm{~N}$ & $M$ & A & 6,4 & 6,3 & 1,6 \\
\hline
\end{tabular}

\section{Legenda:}

ES: emulsão sem extrato de soja fermentado (base)

EC: emulsão contendo extrato de soja fermentado (formulação)

Teste: C - Centrifugação; ET - Estresse térmico; E 50 - Estufa $50,0 \pm 2,0^{\circ} \mathrm{C} / 72$ horas

Aspecto: $\mathbf{N}$ - Normal; $\mathbf{M}$ - Modificado; IM - Intensamente modificado;

Cor: $\mathbf{N}$ - Normal; $\mathbf{M}$ - Modificado; IM - Intensamente modificado;

Odor: N - Normal; $\mathbf{M}$ - Modificado; IM - Intensamente modificado;

Aplicação e Toque: A - toque agradável, facilidade de aplicação na pele (espalhabilidade);

D - toque desagradável, pegajoso, relativa dificuldade de aplicação na pele (espalhabilidade); MD - toque muito desagradável, muito pegajoso, comprometendo aplicação na pele;

pH: Na - não aplicável; As.: após 48 horas de preparo (t0); Ds.: após a condição do teste

Os resultados demonstraram que a emulsão base, submetida aos Estudos de Estabilidade Preliminar, Acelerada e Normal de acordo com PINTO (2005), foi considerada adequada para este estudo, sendo adaptada e submetida novamente ao Estudo de Estabilidade Preliminar e estudos clínicos, com (EC) e sem (ES) a incorporação do extrato de soja fermentado por Bifidobacterium animale. 


\section{Estudo de Estabilidade Acelerada}

A partir dos resultados obtidos no Estudo de Estabilidade Preliminar, as formulações F35/17G e F35/18, que apresentaram desempenho satisfatório, e a formulação de emulsão contendo extrato de soja fermentado foram submetidas ao Estudo de Estabilidade Acelerada, conforme descrito no item 2.5 de Material e Métodos.

\subsection{Variáveis analisadas nas formulações $F 35 / 17 G$ e F35/18}

Os resultados obtidos na avaliação das características organolépticas, determinação do valor de $\mathrm{pH}$ e da viscosidade aparente no Estudo de Estabilidade Acelerada estão descritos na Tabela 17.

A partir desta, foram elaborados os gráficos representados nas Figuras 9 a 14, com resultados das variações, em porcentagem, dos valores de $\mathrm{pH}$ e de viscosidade para as formulações, ao término do Estudo de Estabilidade Acelerada, com relação aos resultados obtidos nas condições iniciais. 
Tabela 17. Avaliação das características organolépticas, pH e viscosidade aparente das formulações 35/17G e 35/18, no Estudo de Estabilidade Acelerada.

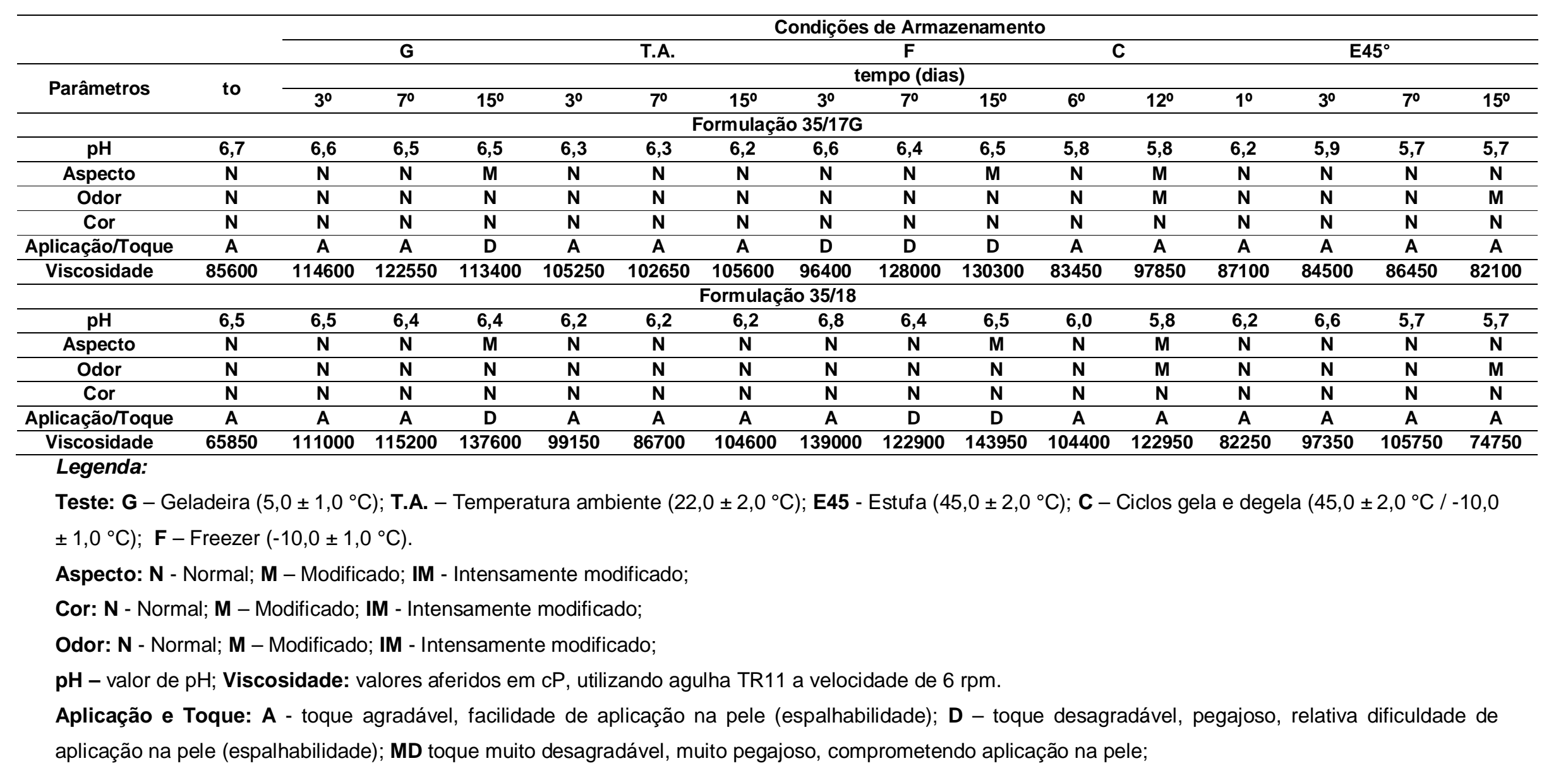




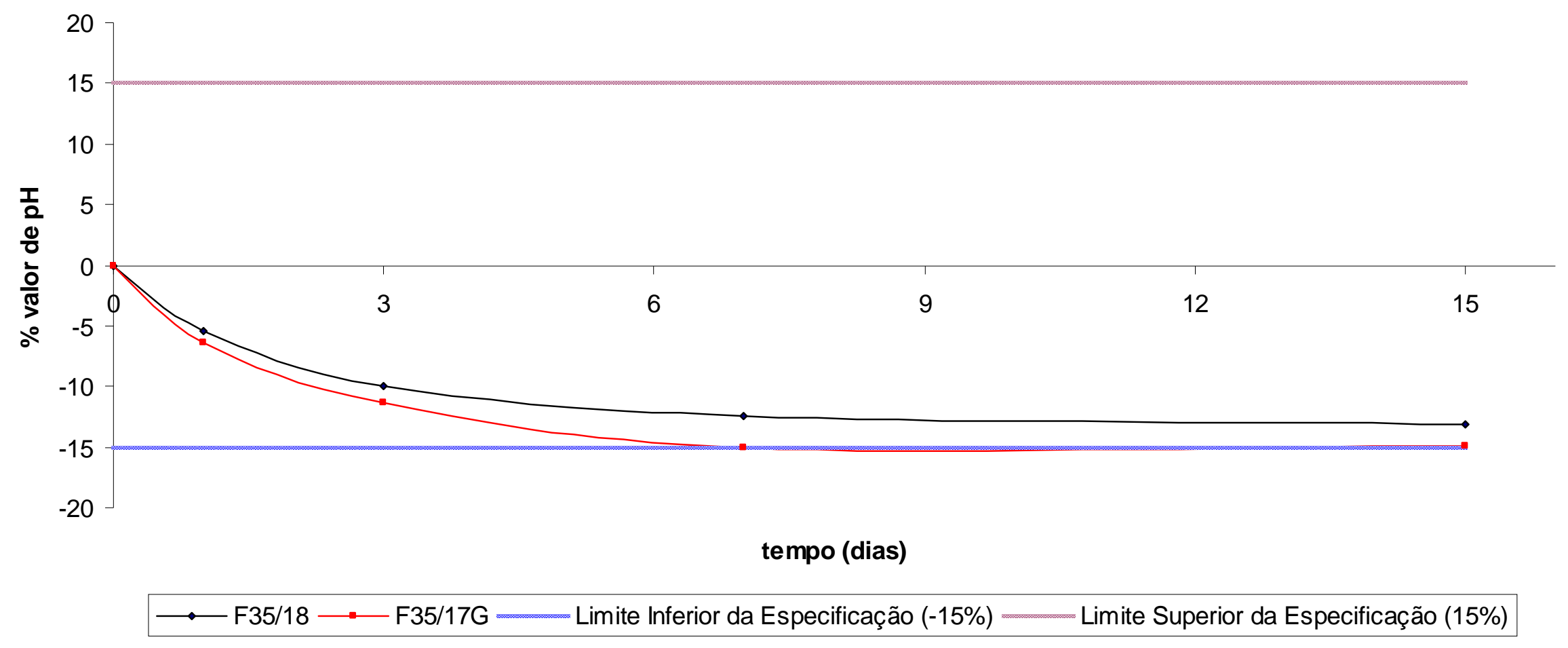

Figura 9. Variação percentual do valor de pH para as formulações F35/18 e F35/17G na condição de armazenamento em estufa (45,0 $\pm 2,0$ $\left.{ }^{\circ} \mathrm{C}\right)$, durante o Estudo de Estabilidade Acelerada. 


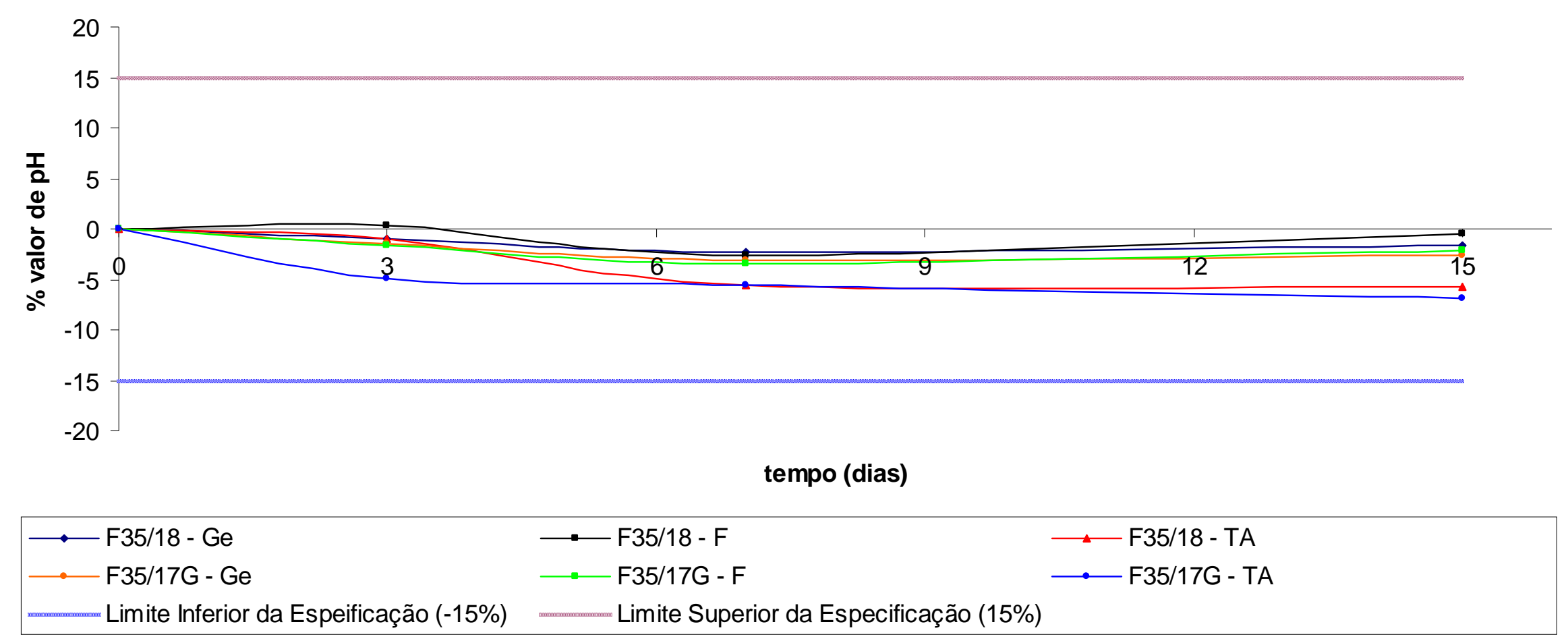

Figura 10. Variação percentual do valor de pH para as formulações F35/18 e F35/17G nas condições de armazenamento em Geladeira (Ge $\left.5,0 \pm 1,0^{\circ} \mathrm{C}\right)$, Freezer $\left(\mathrm{F}--10,0 \pm 1,0^{\circ} \mathrm{C}\right)$ e Temperatura Ambiente $\left(\mathrm{TA}-22,0 \pm 2,0^{\circ} \mathrm{C}\right)$ no Estudo de Estabilidade Acelerada. 


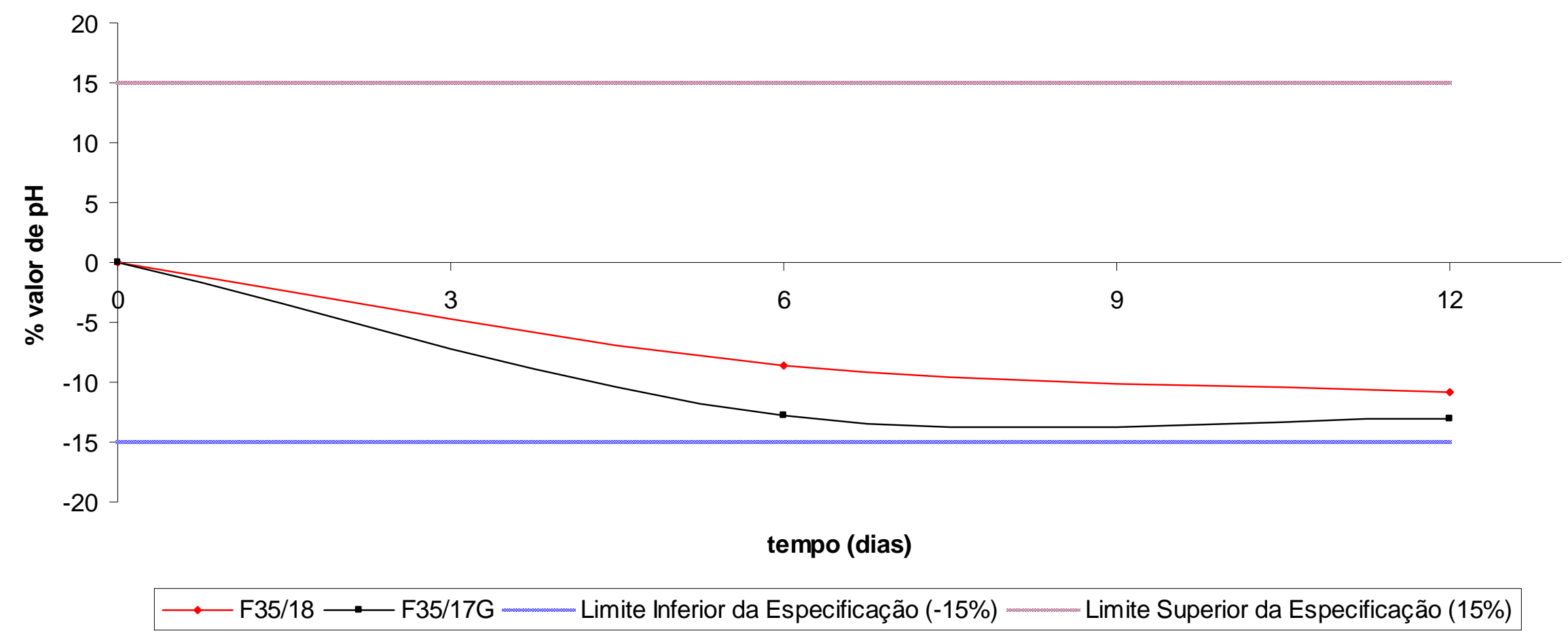

Figura 11. Variação percentual do valor de pH para as formulações-teste F35/18 e F35/17G na condição de armazenamento Ciclos gela e degela $\left(45,0 \pm 2,0{ }^{\circ} \mathrm{C} /-10,0 \pm 1,0{ }^{\circ} \mathrm{C}\right)$ no Estudo de Estabilidade Acelerada. 


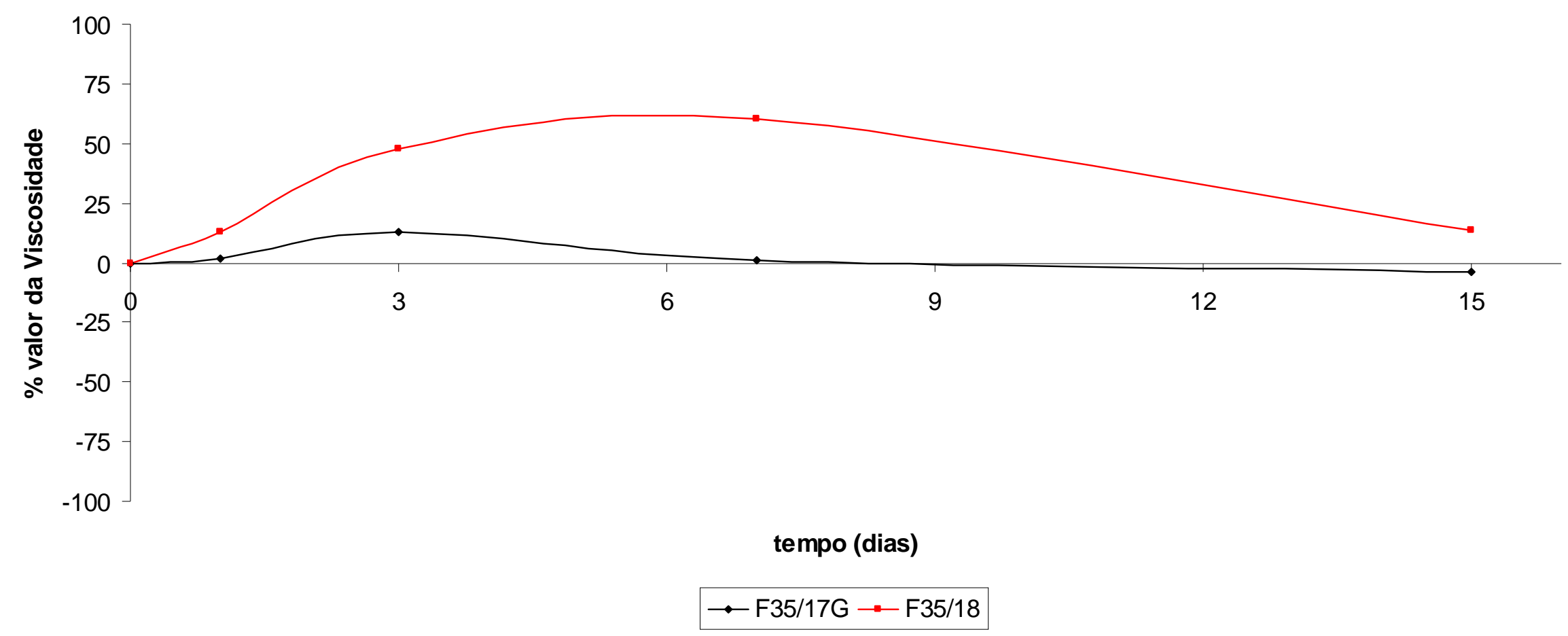

Figura 12. Variação percentual do valor de viscosidade para as formulações F35/18 e F35/17G na condição de armazenamento em estufa $(45,0 \pm 2,0 \stackrel{\circ}{ } \mathrm{C})$ no Estudo de Estabilidade Acelerada. 


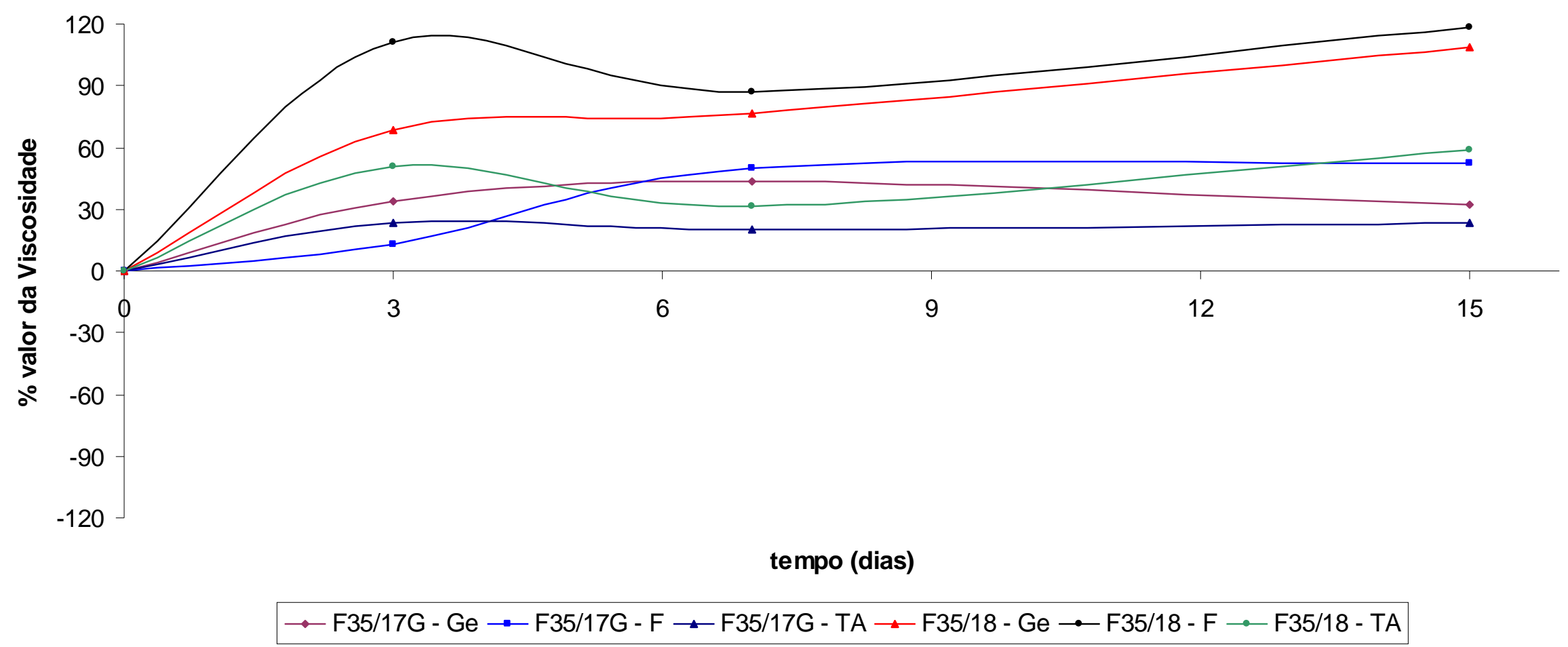

Figura 13. Variação percentual do valor de viscosidade para as formulações $F 35 / 18$ e $F 35 / 17 G$ nas condições de armazenamento em Geladeira $\left(\mathrm{Ge}-5,0 \pm 1,0^{\circ} \mathrm{C}\right)$, Freezer $\left(\mathrm{F}--10,0 \pm 1,0^{\circ} \mathrm{C}\right)$ e Temperatura Ambiente $\left(\mathrm{TA}-22,0 \pm 2,0^{\circ} \mathrm{C}\right)$ no Estudo de Estabilidade Acelerada. 


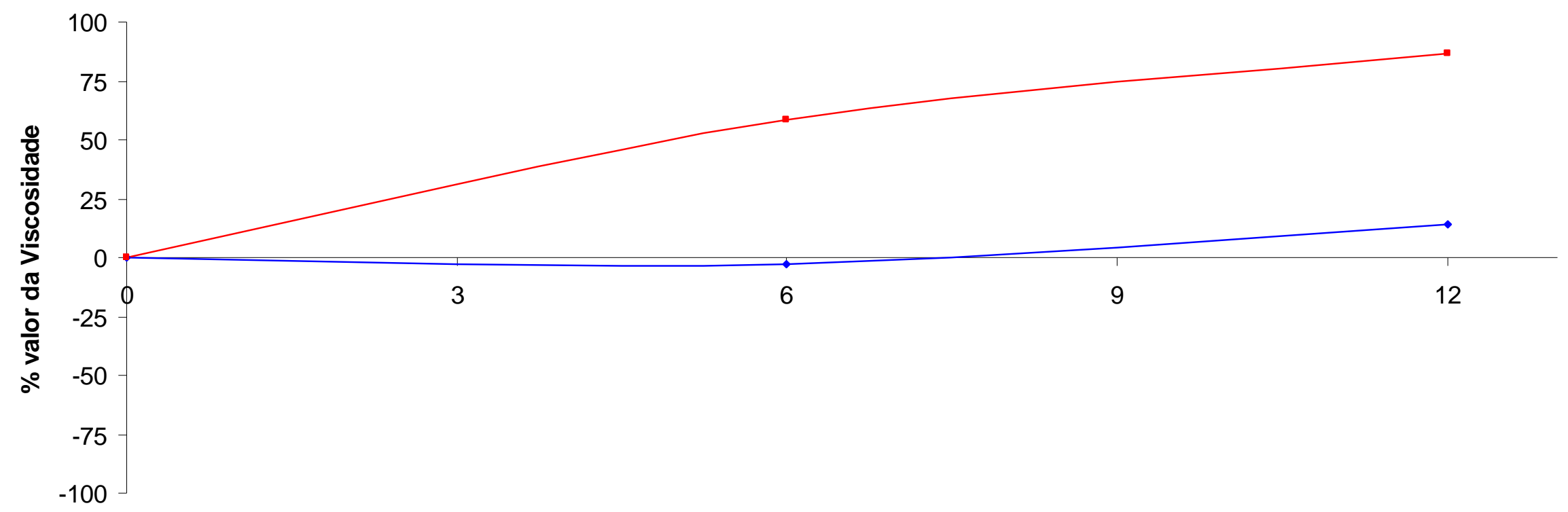

tempo (dias)

F35/17G $\rightarrow-F 35 / 18$

Figura 14. Variação percentual do valor de viscosidade para as formulações F35/18 e F35/17G na condição de armazenamento Ciclos gela e degela $\left(45,0 \pm 2,0{ }^{\circ} \mathrm{C} /-10,0 \pm 1,0 \stackrel{\circ}{ } \mathrm{C}\right)$ no Estudo de Estabilidade Acelerada. 


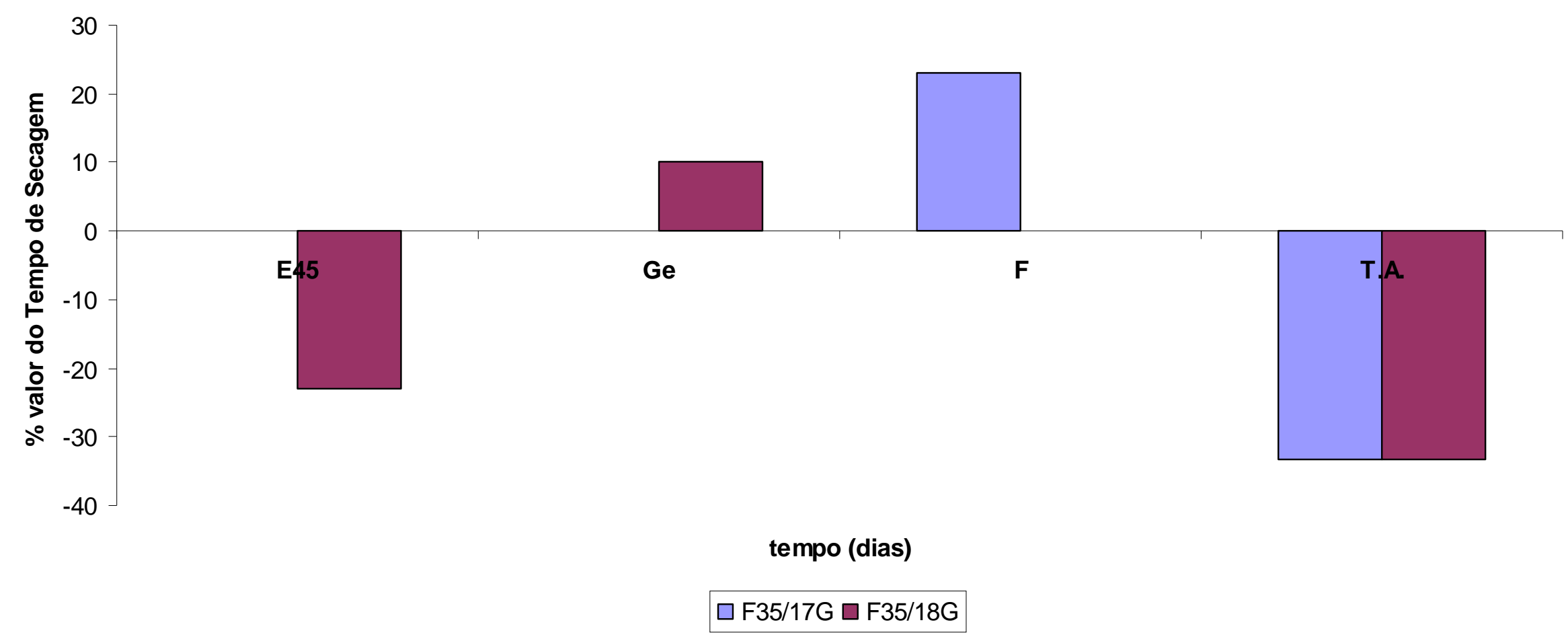

Figura 15. Variação percentual do tempo de secagem para as formulações-teste $F 35 / 18$ e $F 35 / 17 G$ na condição de armazenamento estufa $\left(45,0 \pm 2,0{ }^{\circ} \mathrm{C}\right)$, geladeira $\left(\mathrm{Ge}-5,0 \pm 1,0{ }^{\circ} \mathrm{C}\right)$, freezer $\left(\mathrm{F}--10,0 \pm 1,0{ }^{\circ} \mathrm{C}\right)$ e temperatura ambiente $\left(\mathrm{TA}-22,0 \pm 2,0{ }^{\circ} \mathrm{C}\right)$ no Estudo de Estabilidade Acelerada. As variações são decorrentes da diferença obtida do $15^{\circ}$ dia para t0, em todas as condições. 
A partir da observação da Tabela 17 e Figuras 9 a 14, os resultados de Aspecto demonstraram que a formulação F35/17G apresentou maior consistência no $15^{\circ}$ dia (observação visual) nas condições Geladeira e Freezer e $12^{\circ}$ dia na condição Ciclo. Isso foi confirmado pelo aumento da viscosidade aparente nestas condições, até $52 \%$ na condição Freezer. A formulação F35/18G também apresentou maior consistência no $15^{\circ}$ dia (observação visual) das condições Geladeira e Freezer e $12^{\circ}$ dia da condição Ciclo, também associadas às variações da viscosidade aparente, porém, com valores ainda maiores que os observados para a formulação F35/17G, chegando até $119 \%$ na condição Freezer.

Não foram observadas alterações na Cor das preparações, indicando estabilidade adequada (principalmente estabilidade térmica) e compatibilidade do corante utilizado.

Os resultados de Odor indicaram manifestações de instabilidades no $15^{\circ}$ dia das condições Estufa e Ciclo. Caracterizaram-se por diminuição da intensidade do odor da fragrância, não sendo perceptíveis outros odores. Alterações nas características físicas, químicas e físico-químicas foram descritas para preparações cosméticas em estudos de estabilidade, especialmente após exposição a temperaturas mais altas (BABY, 2007; MAIA, 2006). Portanto, a diminuição da intensidade do odor era esperada em virtude das condições drásticas de exposição das preparações.

A avaliação do Aplicação e Toque demonstrou que ambas formulações mantiveram o toque agradável, com boa aderência e espalhabilidade nas condições Estufa, Ciclo e Temperatura Ambiente, em todos os dias avaliados. Observou-se que as preparações tornaram-se mais pegajosas, em comparação ao to, na condição Freezer, em todos dias de avaliação, exceto a formulação F35/18, que não apresentou modificações no $3^{\circ}$ dia de teste. Ambas formulações apresentaram-se mais pegajosas e com a espalhabilidade dificultada em relação a to, no $15^{\circ}$ dia da condição de Geladeira.

Observou-se que o valor de pH manteve variações dentro da especificação determinada em todas as condições avaliadas - variações superiores e inferiores de até $15 \%$. Na Estufa, as preparações apresentaram tendência semelhante à diminuição do valor de $\mathrm{pH}$, sendo observados valores de até $-15 \%$ para a formulação F35/17G no $7^{\circ}$ e $15^{\circ}$ dias de avaliação. Estas variações para ambas preparações são aceitáveis em virtude da condição drástica $\left(45,0{ }^{\circ} \mathrm{C}\right)$ a que foram expostas 
(BABY, 2007; MAIA, 2006). Além disso, uma vez que o ponto isoelétrico das proteínas da soja encontra-se no valor de $\mathrm{pH}$ igual a 4,5, e apenas valores além da faixa de valor de $\mathrm{pH} 2$ a 10 causam degradação das proteínas e isoflavonas presentes no extrato de soja fermentado (GENOVESE et al., 2006), não era esperado o comprometimento da estabilidade química da preparação.

Foram verificadas variações no valor de $\mathbf{p H}$ inferiores a $5,0 \%$, para ambas as preparações, nas condições Geladeira e Freezer. Similarmente, na condição Temperatura Ambiente, os valores obtidos foram inferiores a $10 \%$, para ambas formulações, chegando ao máximo de -6\% para a formulação F35/18 e -7\% para F35/17G, no $15^{\circ}$ dia de avaliação. Considerando que, em valores de temperaturas mais elevadas foram observadas alterações mais significativas, este perfil também era esperado, observando-se menos modificações em temperaturas mais baixas (BABY, 2007; MAIA, 2006).

$\mathrm{Na}$ condição Ciclo, foi observada a mesma tendência de diminuição do valor de pH ao longo dos dias de avaliação, para ambas formulações, com a formulação F35/17G apresentando variações maiores, até $-13 \%$. Da mesma maneira que fora observado para a condição de Estufa, essas variações eram esperadas e aceitáveis, dentro da faixa de especificação, em virtude da condição drástica de armazenamento das preparações (BABY, 2007; MAIA, 2006).

Simultaneamente à determinação do valor de $\mathbf{p H}$, foi avaliado o valor da viscosidade aparente das formulações em todas as condições do Estudo de Estabilidade Acelerada. Na condição Estufa, observou-se que F35/18 apresentou variações de até $61 \%$ no valor da viscosidade, verificada no $7^{\circ}$ dia, enquanto F35/17G apresentou variação máxima de 13\%, no 3ำ dia de teste. Apesar de ser uma condição drástica, notou-se que as preparações não seguem uma mesma tendência de resposta à condição avaliada.

Esta diferença entre as preparações para a variação do valor de viscosidade foi observada em todas as condições. Na Geladeira, F35/18 ocorreram variações de 69 até 109\%, enquanto foram verificados valores entre 32 e 43\% para F35/17G. No Freezer, verificaram-se intervalos de 87 até $119 \%$ para a formulação F35/18, enquanto que F35/17G não apresentou valores superiores a $52 \%$. Na condição Ciclo, ocorreu um valor máximo de $87 \%$ de variação no $12^{\circ}$ dia de avaliação para F35/18, enquanto que, para F35/17G, foi de $14 \%$. Finalmente, na condição Temperatura Ambiente, nas qual as máscaras faciais peel off geralmente são 
comercializadas, verificou-se variação máxima de $59 \%$ no valor da viscosidade para a preparação $\mathbf{F 3 5 / 1 8}$, no $1^{\circ}$ dia de avaliação; para F35/17G, a variação máxima verificada na mesma condição foi $23 \%$, no 15ำ dia de avaliação.

Estudos comprovaram que a goma guar e outros hidrocolóides promovem estabilidade às dispersões coloidais, alterando as propriedades reológicas de preparações constituídas de polímeros hidrofílicos, como amido (SUPHANTHARIKA, 2005; PONGSAWATMANIT, 2008). O álcool polivinílico, principal componente das formulações de máscara facial, é um polímero constituído de cadeia carbônica substituída por hidroxilas (ARANHA \& LUCAS, 2001; CHIELLINI et al., 2003; MARTINDALE, 1989). Estas características, semelhantes às da goma guar (MERCK, 1996) e do amido (açúcares), sugerem que a formulação F35/17G apresentou menores variações nos valores de viscosidade que a formulação F35/18 no estudo de estabilidade pela formação de interações intermoleculares entre o álcool polivinílico e a goma guar, conferindo maior estabilidade à preparação.

Diante dos resultados da avaliação organoléptica, valor de $\mathrm{pH}$ e valor da viscosidade aparente para as formulações de máscara facial peel off no Estudo de Estabilidade Acelerada, pode-se afirmar que F35/17G apresentou melhores resultados que $\mathbf{F 3 5 / 1 8}$.

A avaliação do desempenho das formulações é realizada por meio da determinação do tempo de secagem das formulações in vitro. No Estudo de Estabilidade Acelerada, foram avaliadas as variações no tempo de secagem após a exposição das preparações às condições Estufa, Geladeira, Freezer e Temperatura Ambiente. As determinações dos valores foram realizadas no $15^{\circ}$ dia de cada uma das condições, determinando a variação, em porcentagem, a partir do valor obtido para as formulações em t0. A Figura 15 apresenta os resultados obtidos.

Não foram observadas variações no valor do tempo de secagem para F35/17G nas condições Estufa e Geladeira, em relação ao t0. Nestas mesmas condições, F35/18 apresentou variações de -23 e 10\%, respectivamente. A formulação F35/17G apresentou variação de 23\% no Freezer, enquanto nenhuma variação foi verificada para F35/18, na mesma condição. Ambas formulações apresentaram variação de $-33 \%$ à Temperatura Ambiente.

Associado aos resultados obtidos na avaliação organoléptica, valor de $\mathrm{pH}$ e de viscosidade, considerou-se que a formulação F35/17G apresentou maior 
estabilidade frente aos testes realizados, associados a pequenas variações no tempo de secagem in vitro, em comparação com F35/18. A formulação foi selecionada para a realização dos testes clínicos, devendo ser mantida em geladeira, para garantia da menor variação do tempo de secagem e das demais variáveis analisadas no Estudo de Estabilidade Acelerada.

\subsection{Variáveis analisadas na formulação de emulsão óleo em água contendo extrato de soja fermentado}

Os resultados obtidos na avaliação das características organolépticas, determinação do valor de $\mathrm{pH}$ e da viscosidade aparente no Estudo de Estabilidade Acelerada estão descritos na Tabela 18.

A partir desta, foram elaborados os gráficos representados nas Figuras 16 a 21, com resultados das variações, em porcentagem, dos valores de $\mathrm{pH}$ e de viscosidade para as formulações, ao término do Estudo de Estabilidade Acelerada, com relação aos resultados obtidos nas condições iniciais. 
Tabela 18. Avaliação das características organolépticas, pH e viscosidade aparente da formulação de emulsão contendo extrato de soja fermentado, no Estudo de Estabilidade Acelerada.

\begin{tabular}{|c|c|c|c|c|c|c|c|c|c|c|c|c|c|c|c|c|}
\hline \multirow{4}{*}{ Parâmetros } & \multirow{4}{*}{ To } & \multicolumn{15}{|c|}{ Condições de Armazenamento } \\
\hline & & \multicolumn{3}{|c|}{$\mathbf{G}$} & \multicolumn{3}{|c|}{ T.A. } & \multicolumn{3}{|c|}{$\mathbf{F}$} & \multicolumn{2}{|c|}{$\mathbf{C}$} & \multicolumn{4}{|c|}{$\mathrm{E} 45^{\circ}$} \\
\hline & & \multicolumn{15}{|c|}{ tempo (dias) } \\
\hline & & 3은 & $7^{\circ}-$ & $15^{\circ}$ & 30 & $7^{\circ}$ & $15^{\circ}$ & 3은 & $7^{\circ}$ & $15^{\circ}$ & 60 & $12^{\circ}$ & $1^{\circ}$ & 3은 & $7^{\circ}$ & $15^{\circ}$ \\
\hline \multicolumn{17}{|c|}{ Emulsão com Extrato de Soja } \\
\hline $\mathrm{pH}$ & 7,4 & 7,0 & 7,1 & 7,1 & 7,0 & 7,1 & 7,1 & 7,1 & 7,9 & 7,1 & 7,1 & 7,1 & 7,1 & 7,1 & 6,9 & 6,9 \\
\hline Aspecto & $\mathbf{N}$ & $\mathbf{N}$ & $\mathbf{N}$ & $\mathbf{N}$ & $\mathbf{N}$ & $\mathbf{N}$ & $\mathbf{N}$ & $\mathbf{N}$ & $\mathbf{N}$ & $\mathbf{N}$ & $\mathbf{M}$ & $\mathbf{M}$ & $\mathbf{N}$ & $\mathbf{N}$ & $\mathbf{N}$ & M \\
\hline Odor & $\mathbf{N}$ & $\mathbf{N}$ & $\mathbf{N}$ & $\mathbf{N}$ & $\mathbf{N}$ & $\mathbf{N}$ & $\mathbf{N}$ & $\mathbf{N}$ & $\mathbf{N}$ & $\mathbf{N}$ & $\mathbf{N}$ & IM & $\mathbf{N}$ & $\mathbf{N}$ & $\mathbf{M}$ & IM \\
\hline Cor & $\mathbf{N}$ & $\mathbf{N}$ & $\mathbf{N}$ & $\mathbf{N}$ & $\mathbf{N}$ & $\mathbf{N}$ & $\mathbf{N}$ & $\mathbf{N}$ & $\mathbf{N}$ & $\mathbf{N}$ & $\mathbf{N}$ & $\mathbf{N}$ & $\mathbf{N}$ & $\mathbf{N}$ & $\mathbf{N}$ & $\mathbf{N}$ \\
\hline Aplicação/toque & A & A & A & $\mathbf{A}$ & A & $\mathbf{A}$ & $\mathbf{A}$ & $\mathbf{A}$ & $\mathbf{A}$ & $\mathbf{A}$ & A & D & $\mathbf{A}$ & $\mathbf{A}$ & $\mathbf{A}$ & D \\
\hline Viscosidade & 40200 & 38600 & 36500 & 38750 & 39400 & 36650 & 37700 & 41250 & 36750 & 38600 & 83450 & 97850 & 32550 & 42600 & 30950 & 31500 \\
\hline
\end{tabular}

\section{Legenda:}

Teste: G - Geladeira $\left(5,0 \pm 1,0{ }^{\circ} \mathrm{C}\right) ;$ T.A. - Temperatura ambiente $\left(22,0 \pm 2,0^{\circ} \mathrm{C}\right) ; \mathbf{E} 45$ - Estufa $\left(45,0 \pm 2,0{ }^{\circ} \mathrm{C}\right) ; \mathbf{C}-$ Ciclos gela e degela $\left(45,0 \pm 2,0{ }^{\circ} \mathrm{C} /-10,0\right.$ $\left.\pm 1,0^{\circ} \mathrm{C}\right) ; \mathbf{F}-$ Freezer $\left(-10,0 \pm 1,0^{\circ} \mathrm{C}\right)$.

Aspecto: N - Normal; $\mathbf{M}$ - Modificado; IM - Intensamente modificado;

Cor: $\mathbf{N}$ - Normal; $\mathbf{M}$ - Modificado; IM - Intensamente modificado;

Odor: N - Normal; M - Modificado; IM - Intensamente modificado;

pH - valor de pH; Viscosidade: valores aferidos em cP, utilizando agulha TR11 a velocidade de $12 \mathrm{rpm}$.

Aplicação e Toque: A - toque agradável, facilidade de aplicação na pele (espalhabilidade); D - toque desagradável, pegajoso, relativa dificuldade de aplicação na pele (espalhabilidade); MD toque muito desagradável, muito pegajoso, comprometendo aplicação na pele; 


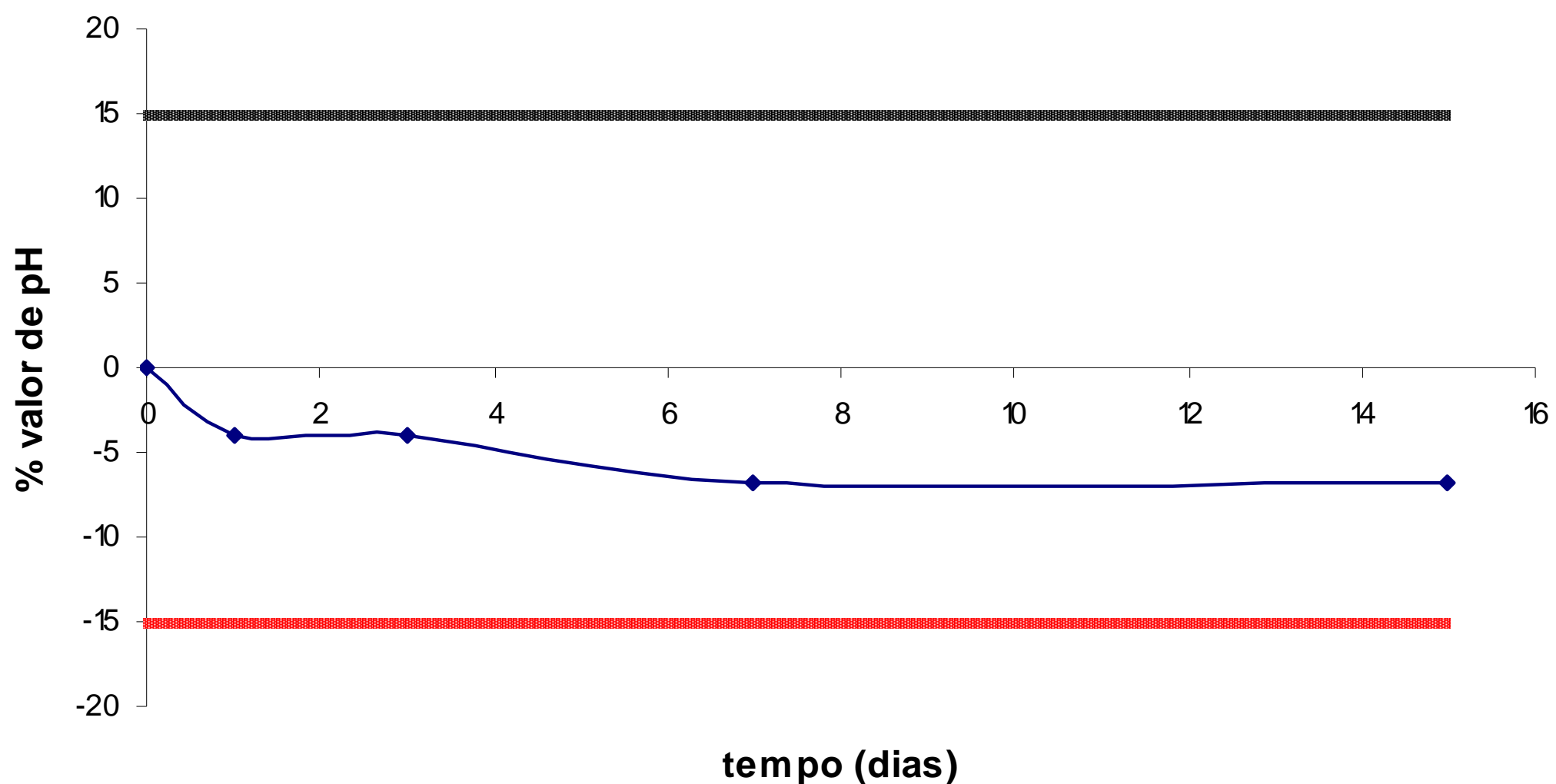

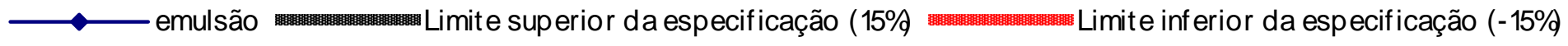

Figura 16. Variação percentual do valor de pH para a formulação de emulsão contendo extrato de soja fermentado por Bifidobacterium animale na condição de armazenamento em estufa $(45,0 \pm 2,0 \stackrel{\circ}{ } \mathrm{C})$, durante o Estudo de Estabilidade Acelerada. 


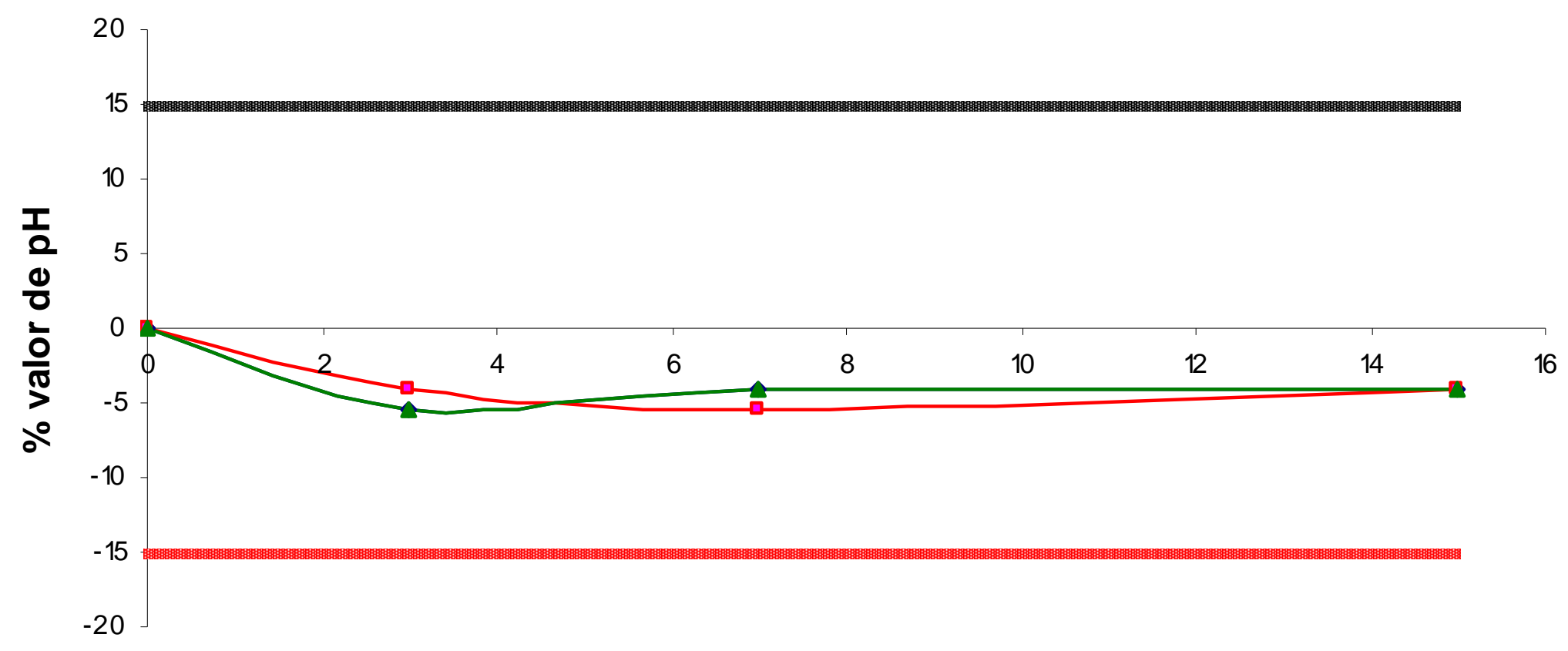

tem po (dias)

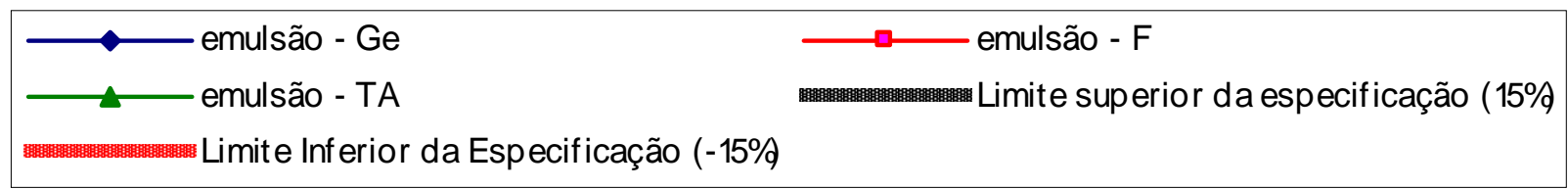

Figura 17. Variação percentual do valor de pH para a formulação de emulsão contendo extrato de soja fermentado por Bifidobacterium animale nas condições de armazenamento em Geladeira $\left(\mathrm{Ge}-5,0 \pm 1,0^{\circ} \mathrm{C}\right)$, Freezer $\left(\mathrm{F}--10,0 \pm 1,0^{\circ} \mathrm{C}\right)$ e Temperatura Ambiente $(\mathrm{TA}-22,0$ $\pm 2,0^{\circ} \mathrm{C}$ ) no Estudo de Estabilidade Acelerada. 


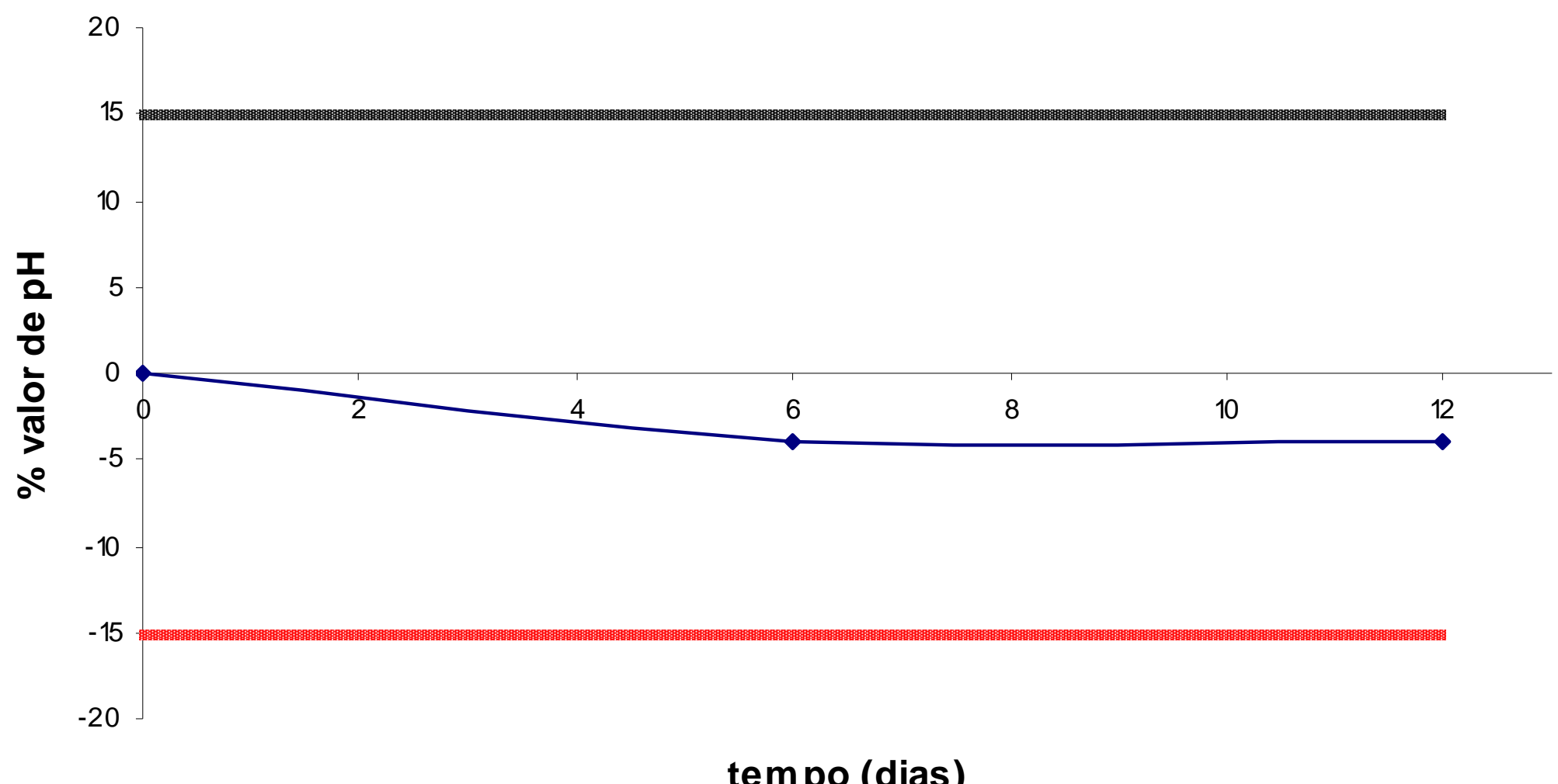

\section{tem po (dias)}

emulsão

Figura 18. Variação percentual do valor de pH para a formulação de emulsão contendo extrato de soja fermentado por Bifidobacterium animale na condição de armazenamento Ciclos gela e degela $\left(45,0 \pm 2,0{ }^{\circ} \mathrm{C} /-10,0 \pm 1,0{ }^{\circ} \mathrm{C}\right)$ no Estudo de Estabilidade Acelerada. 


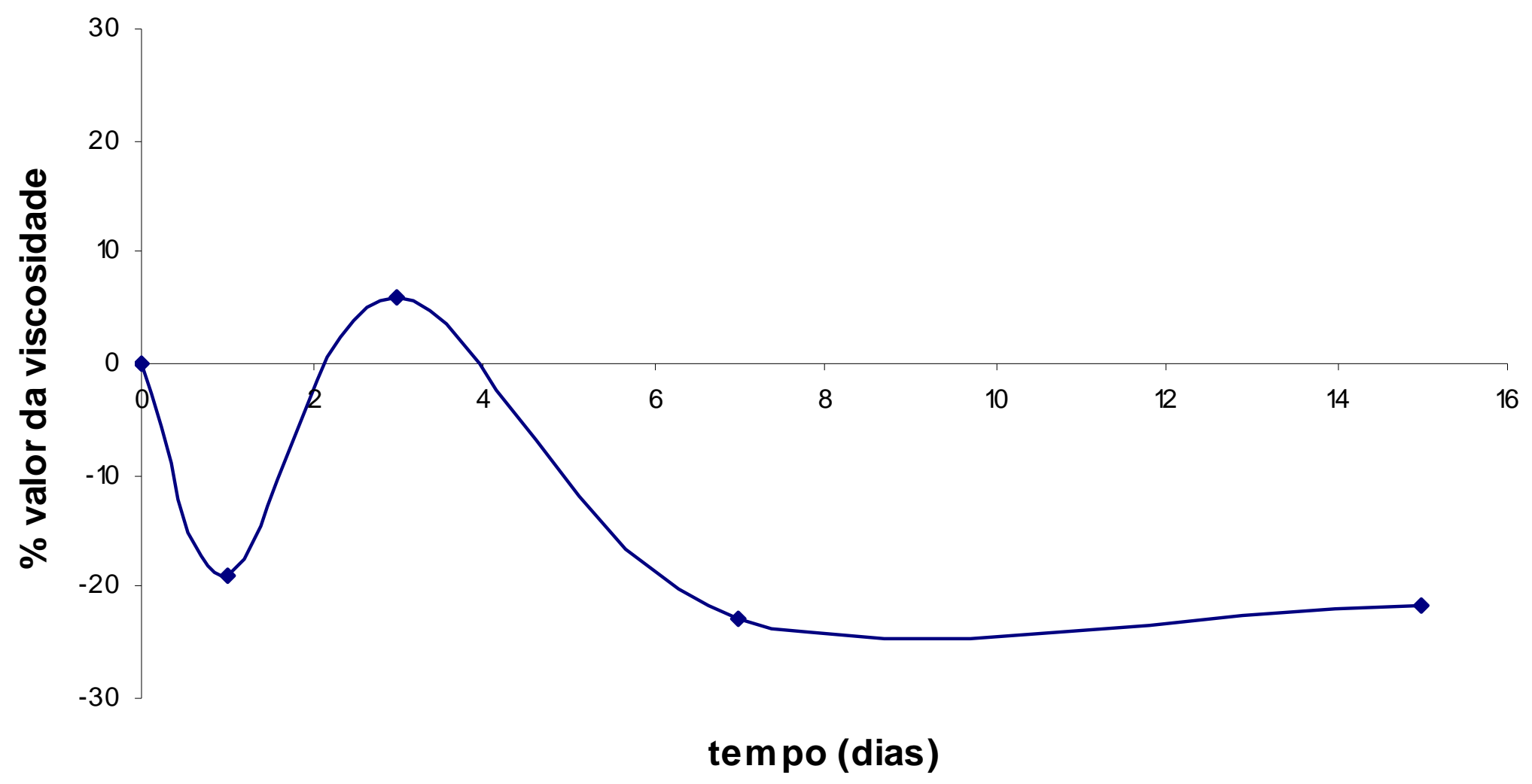

\section{$\longrightarrow$ emulsão}

Figura 19. Variação percentual do valor de viscosidade para a formulação de emulsão contendo extrato de soja fermentado por Bifidobacterium animale na condição de armazenamento em estufa $(45,0 \pm 2,0 \stackrel{\circ}{ } \mathrm{C})$ no Estudo de Estabilidade Acelerada. 


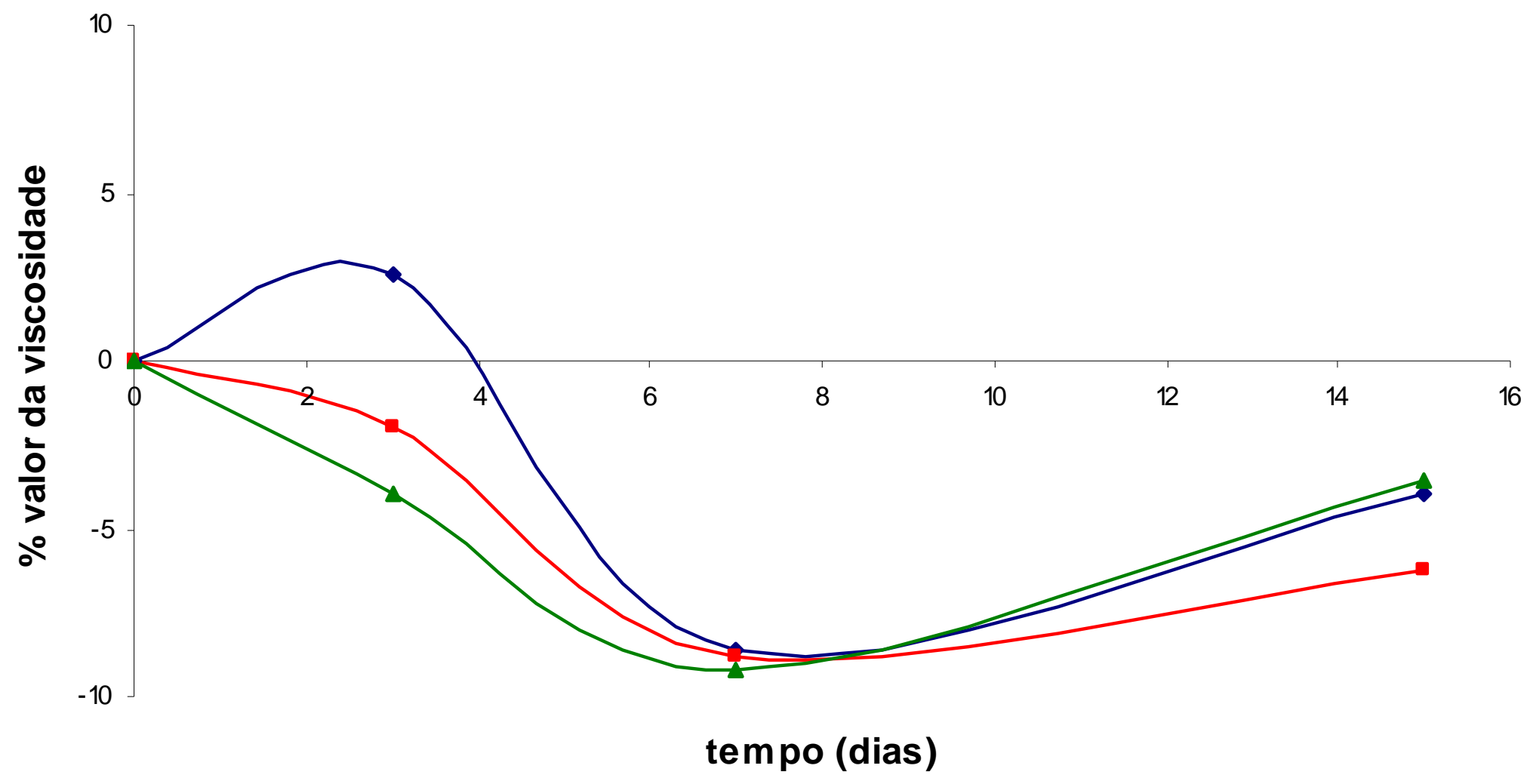

$\longrightarrow$ emulsão - F emulsão - TA $\longrightarrow$ emulsão - Ge

Figura 20. Variação percentual do valor de viscosidade para a formulação de emulsão contendo extrato de soja fermentado por Bifidobacterium animale nas condições de armazenamento em Geladeira ( $\left.\mathrm{Ge}-5,0 \pm 1,0{ }^{\circ} \mathrm{C}\right)$, Freezer $\left(\mathrm{F}--10,0 \pm 1,0{ }^{\circ} \mathrm{C}\right)$ e Temperatura Ambiente $\left(\mathrm{TA}-22,0 \pm 2,0^{\circ} \mathrm{C}\right)$ no Estudo de Estabilidade Acelerada. 


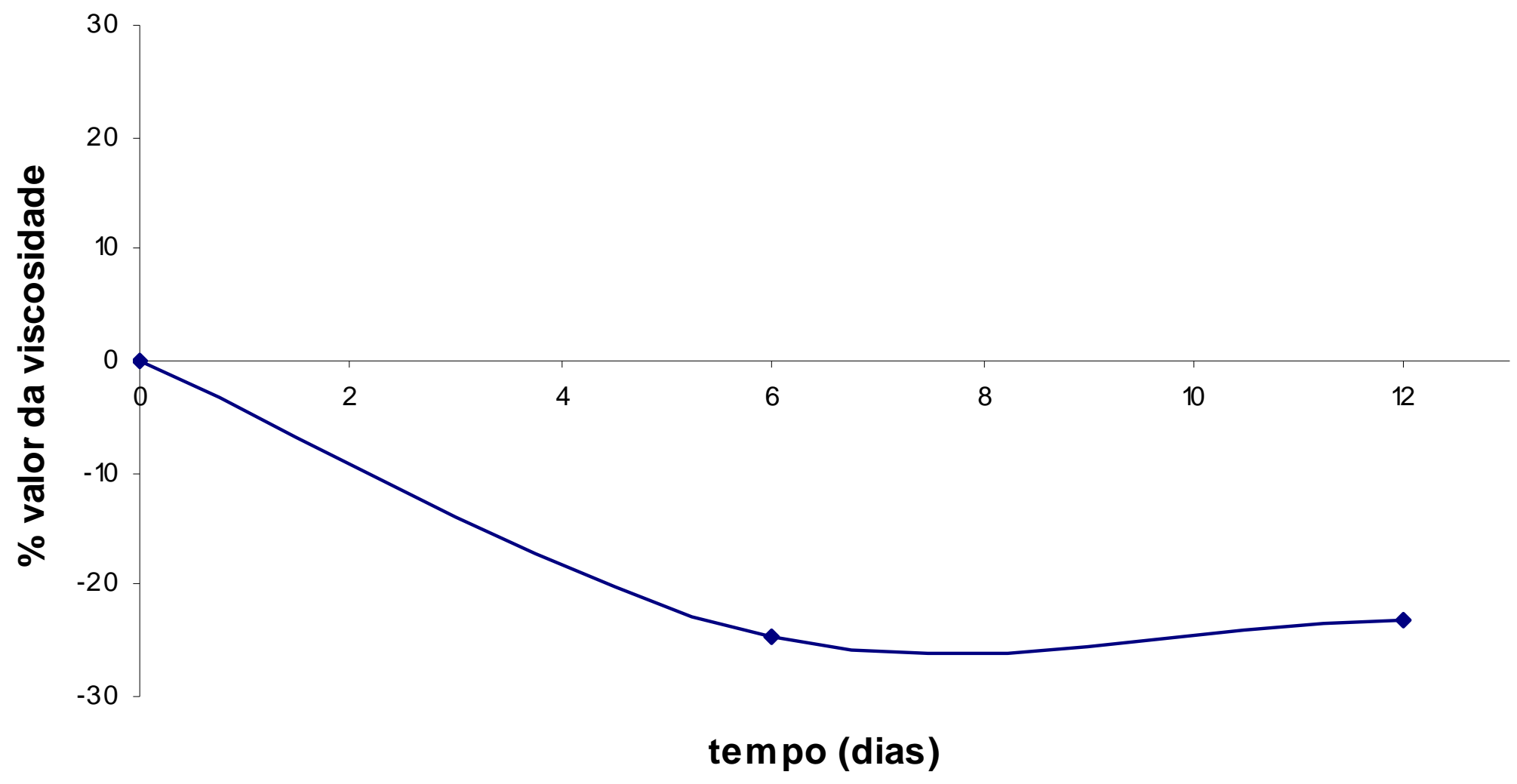
Figura 21. Variação percentual do valor de viscosidade para a formulação de emulsão contendo extrato de soja fermentado por
Bifidobacterium animale na condição de armazenamento Ciclos gela e degela $(45,0 \pm 2,0 \stackrel{\circ}{\circ} / /-10,0 \pm 1,0 \stackrel{\circ}{\circ})$ no Estudo de Estabilidade
Acelerada. 
A partir da observação da Tabela 18 e Figuras 16 a $\mathbf{2 1}$, os resultados de Aspecto demonstraram que a emulsão apresentou menor consistência no $15^{\circ}$ dia (observação visual) na condição Geladeira e Freezer e $6^{\circ}$ e $12^{\circ}$ dias na condição Ciclo. Isso foi confirmado pela diminuição da viscosidade aparente nestas condições, até $25 \%$ na condição Freezer.

Não foram observadas alterações na Cor da emulsão, indicando estabilidade adequada, principalmente estabilidade térmica.

Os resultados de Odor indicaram manifestações de instabilidades nos $7^{\circ} \mathrm{e}$ $15^{\circ}$ dias da condição Estufa e $12^{\circ}$ dia da condição Ciclo. Caracterizaram-se por diminuição da intensidade ou perda do odor da fragrância, não sendo perceptíveis outros odores. Esta manifestação era esperada em virtude das condições drásticas de exposição da emulsão (BABY, 2007; MAIA, 2006).

A avaliação do Aplicação e Toque demonstrou que ambas formulações mantiveram o toque agradável e espalhabilidade nas condições Geladeira, Freezer e Temperatura Ambiente, em todos os dias avaliados. Observou-se que as preparações tornaram-se mais pegajosas (sensação de oleosidade), em comparação ao to, na condição Ciclo, no $12^{\circ}$ dia, e na condição Estufa, no $15^{\circ}$ dia.

Observou-se que o valor de pH manteve variações dentro da especificação determinada em todas as condições avaliadas - variações superiores e inferiores de até $15 \%$. Com variações máximas de $7 \%$, na condição Estufa, pode-se dizer que a formulação de emulsão incorporada do extrato de soja fermentado não propicia a degradação dos componentes do extrato (GENOVESE et al., 2006), não comprometendo a estabilidade química da preparação ou as prováveis ações atribuídas aos componentes da soja.

Simultaneamente à determinação do valor de $\mathrm{pH}$, foi avaliado o valor da viscosidade aparente da emulsão contendo o extrato de soja fermentado em todas as condições do Estudo de Estabilidade Acelerada. Foram verificadas variações inferiores a $30 \%$ para todas as condições avaliadas. Na condição Temperatura Ambiente, na qual formulações como a emulsão, geralmente, são utilizadas e comercializadas, verificou-se variação máxima de $9 \%$.

Diante dos resultados da avaliação organoléptica, valor de $\mathrm{pH}$ e valor da viscosidade aparente para a formulação de emulsão contendo o extrato de soja fermentado no Estudo de Estabilidade Acelerada, afirmou-se que a preparação 
estava apta à sua utilização nos estudos clínicos, como formulação utilizada na comparação ao desempenho das formulações de máscara facial peel off.

\section{Testes Clínicos}

\subsection{Dados obtidos das medidas instrumentais}

Os resultados dos testes clínicos estão representados nas Tabelas 19 a 26. A aleatorização, ou seja, a aplicação das formulações, conforme os locais definidos nos voluntários, foi definida estatisticamente e está descrita detalhadamente em MATERIAL E MÉTODOS, no item 2.6.7. 
Tabela 19. Avaliação clínica da hidratação $(C W)$ e perda de água transepidérmica (TEWL) para a amostra MS - base cosmética de máscara facial peel off (sem extrato de soja fermentado por Bifidobacterium animale).

\begin{tabular}{|c|c|c|c|c|c|c|c|c|c|}
\hline \multirow{2}{*}{ VOL. } & \multirow{2}{*}{ L. } & \multicolumn{4}{|c|}{ MEDIDAS CW } & \multicolumn{4}{|c|}{ MEDIDAS TEWL } \\
\hline & & to & $t 45$ & t90 & $t 180$ & to & T45 & t90 & t180 \\
\hline 2 & 5 & 35,7 & 48,7 & 38,7 & 43,3 & 8,52 & 10,2 & 8,55 & 6,65 \\
\hline 3 & 2 & 29,0 & 43,3 & 38,7 & 34,7 & 7,58 & 8,12 & 8,47 & 8,20 \\
\hline 4 & 3 & 31,0 & 42,7 & 48,7 & 43,7 & 8,88 & 7,57 & 12,55 & 6,03 \\
\hline 4 & 4 & 34,3 & 42,7 & 39,7 & 39,0 & 8,90 & 6,11 & 13,31 & 5,47 \\
\hline 5 & 1 & 41,0 & 51,3 & 50,3 & 42,7 & 6,72 & 10,7 & 14,44 & 9,86 \\
\hline 6 & 3 & 33,0 & 62,7 & 56,7 & 65,3 & 6,86 & 8,05 & 9,96 & 9,57 \\
\hline 6 & 6 & 32,3 & 59,0 & 53,0 & 58,0 & 6,81 & 8,58 & 5,47 & 9,06 \\
\hline 7 & 3 & 36,7 & 43,0 & 46,3 & 45,7 & 4,45 & 6,89 & 7,29 & 7,27 \\
\hline 8 & 2 & 38,3 & 37,0 & 46,0 & 42,7 & 4,93 & 6,84 & 7,59 & 7,39 \\
\hline 8 & 6 & 33,7 & 37,0 & 43,3 & 36,3 & 6,36 & 5,81 & 6,67 & 7,26 \\
\hline 9 & 2 & 46,0 & 63,7 & 55,7 & 63,7 & 7,78 & 8,68 & 9,89 & 8,60 \\
\hline 9 & 6 & 42,7 & 64,7 & 58,7 & 55,7 & 9,45 & 9,78 & 8,45 & 9,15 \\
\hline 10 & 3 & 31,7 & 39,0 & 38,3 & 36,7 & 5,63 & 8,94 & 7,81 & 7,41 \\
\hline 12 & 2 & 37,0 & 49,7 & 47,0 & 47,3 & 7,77 & 6,83 & 7,13 & 8,48 \\
\hline 12 & 4 & 40,7 & 51,7 & 49,3 & 50,7 & 5,58 & 5,81 & 5,87 & 6,78 \\
\hline
\end{tabular}

Legenda:

VOL.: voluntário

L.: local de aplicação, conforme aleatorização

CW: hidratação obtidas com o Corneometer ${ }^{\circledR}$ (UA - unidades arbitrárias)

TEWL: perda de água transepidérmica obtida com o Tewameter $^{\circledR}$ (UA - unidades arbitrárias).

t0: tempo zero, anterior à aplicação da amostra

t45, t90 e t180: medidas obtidas 45, 90 e 180 minutos transcorridos após a aplicação da amostra, respectivamente. 
Tabela 20. Avaliação clínica da hidratação (CW) e perda de água transepidérmica (TEWL) para a amostra MC - base cosmética de máscara facial peel off (com extrato de soja fermentado por Bifidobacterium animale).

\begin{tabular}{|c|c|c|c|c|c|c|c|c|c|}
\hline \multirow{2}{*}{ VOL. } & \multirow{2}{*}{ L. } & \multicolumn{4}{|c|}{ MEDIDAS CW } & \multicolumn{4}{|c|}{ MEDIDAS TEWL } \\
\hline & & to & t45 & t90 & $t 180$ & to & T45 & t90 & t180 \\
\hline 2 & 1 & 37,3 & 48,7 & 48,7 & 53,0 & 9,71 & 10,09 & 10,25 & 8,18 \\
\hline 2 & 4 & 36,7 & 43,3 & 45,3 & 44,3 & 6,69 & 9,56 & 8,48 & 7,20 \\
\hline 3 & 3 & 28,7 & 28,0 & 26,3 & 26,3 & 8,30 & 8,74 & 7,43 & 6,37 \\
\hline 3 & 5 & 25,7 & 36,7 & 28,7 & 30,3 & 8,96 & 9,22 & 9,16 & 8,17 \\
\hline 4 & 2 & 34,0 & 40,3 & 44,7 & 42,0 & 5,90 & 8,57 & 11,22 & 5,72 \\
\hline 4 & 5 & 34,0 & 44,7 & 45,0 & 44,7 & 8,34 & 6,48 & 13,03 & 6,58 \\
\hline 5 & 3 & 31,3 & 51,0 & 44,3 & 41,0 & 6,70 & 8,28 & 9,03 & 7,75 \\
\hline 5 & 6 & 32,7 & 48,7 & 42,7 & 40,0 & 6,48 & 9,78 & 7,21 & 7,78 \\
\hline 7 & 1 & 28,7 & 32,7 & 36,3 & 37,3 & 7,46 & 7,81 & 9,43 & 9,41 \\
\hline 7 & 5 & 36,3 & 47,3 & 39,7 & 42,0 & 4,41 & 8,39 & 8,86 & 10,79 \\
\hline 8 & 4 & 41,0 & 53,7 & 45,3 & 44,3 & 3,72 & 3,35 & 4,28 & 4,49 \\
\hline 9 & 3 & 38,3 & 58,3 & 47,7 & 48,7 & 7,54 & 9,37 & 7,44 & 6,50 \\
\hline 9 & 4 & 33,7 & 53,7 & 40,0 & 42,7 & 5,35 & 10,10 & 8,98 & 6,33 \\
\hline 10 & 4 & 36,7 & 43,3 & 39,3 & 40,7 & 5,45 & 8,75 & 8,82 & 7,82 \\
\hline 12 & 3 & 34,0 & 43,3 & 43,3 & 47,3 & 5,47 & 7,07 & 7,16 & 8,11 \\
\hline
\end{tabular}

Legenda:

VOL.: voluntário

L.: local de aplicação, conforme aleatorização

CW: hidratação obtidas com o Corneometer ${ }^{\circledR}$ (UA - unidades arbitrárias)

TEWL: perda de água transepidérmal obtida com o Tewameter $^{\circledR}$ (UA - unidades arbitrárias).

t0: tempo zero, anterior à aplicação da amostra

t45, t90 e t180: medidas obtidas 45, 90 e 180 minutos transcorridos após a aplicação da amostra, respectivamente. 
Tabela 21. Avaliação clínica da hidratação (CW) e perda de água transepidérmica (TEWL) para a amostra ES - emulsão sem extrato de soja fermentado por Bifidobacterium animale.

\begin{tabular}{|c|c|c|c|c|c|c|c|c|c|}
\hline \multirow{2}{*}{ VOL. } & \multirow{2}{*}{ L. } & \multicolumn{4}{|c|}{ MEDIDAS CW } & \multicolumn{4}{|c|}{ MEDIDAS TEWL } \\
\hline & & to & $\mathrm{t} 45$ & t90 & $t 180$ & to & T45 & t90 & t180 \\
\hline 2 & 3 & 31,3 & 38,7 & 40,3 & 38,3 & 7,44 & 9,45 & 9,35 & 7,00 \\
\hline 2 & 6 & 30,3 & 40,7 & 38,0 & 38,3 & 7,30 & 10,03 & 10,55 & 9,54 \\
\hline 3 & 4 & 26,3 & 39,0 & 33,0 & 33,3 & 6,91 & 5,91 & 5,63 & 5,56 \\
\hline 4 & 6 & 29,0 & 34,0 & 37,7 & 37,7 & 10,73 & 7,06 & 12,42 & 6,53 \\
\hline 5 & 5 & 29,3 & 27,3 & 35,3 & 36,3 & 8,02 & 8,93 & 8,23 & 7,04 \\
\hline 6 & 1 & 29,7 & 35,3 & 31,3 & 32,7 & 9,13 & 9,60 & 12,35 & 10,42 \\
\hline 6 & 4 & 29,3 & 43,3 & 41,3 & 50,7 & 11,43 & 10,30 & 10,90 & 10,42 \\
\hline 7 & 2 & 36,0 & 41,3 & 37,7 & 39,0 & 6,90 & 8,11 & 10,02 & 9,36 \\
\hline 7 & 4 & 33,0 & 37,3 & 35,0 & 36,3 & 5,23 & 7,72 & 7,40 & 9,95 \\
\hline 8 & 1 & 33,0 & 36,7 & 33,0 & 34,7 & 4,82 & 5,61 & 9,66 & 7,30 \\
\hline 9 & 1 & 36,3 & 36,7 & 32,3 & 36,3 & 10,03 & 8,09 & 10,54 & 6,78 \\
\hline 9 & 5 & 42,3 & 44,7 & 37,7 & 38,7 & 7,89 & 8,83 & 9,49 & 9,19 \\
\hline 10 & 2 & 38,3 & 31,0 & 32,3 & 39,0 & 5,16 & 5,77 & 8,62 & 8,74 \\
\hline 10 & 6 & 37,7 & 34,3 & 33,7 & 39,0 & 6,66 & 7,80 & 6,98 & 9,01 \\
\hline 12 & 5 & 40,7 & 44,7 & 42,7 & 42,7 & 5,61 & 5,78 & 8,15 & 8,57 \\
\hline
\end{tabular}

Legenda:

VOL.: voluntário

L.: local de aplicação, conforme aleatorização

CW: hidratação obtidas com o Corneometer ${ }^{\circledR}$ (UA - unidades arbitrárias)

TEWL: perda de água transepidérmal obtida com o Tewameter $^{\circledR}$ (UA - unidades arbitrárias).

t0: tempo zero, anterior à aplicação da amostra

t45, t90 e t180: medidas obtidas 45, 90 e 180 minutos transcorridos após a aplicação da amostra, respectivamente. 
Tabela 22. Avaliação clínica da hidratação (CW) e perda de água transepidérmica (TEWL) para a amostra EC - emulsão com extrato de soja fermentado por Bifidobacterium animale.

\begin{tabular}{|c|c|c|c|c|c|c|c|c|c|}
\hline \multirow{2}{*}{ VOL. } & $\mathbf{L}$. & \multicolumn{4}{c}{ MEDIDAS CW } & \multicolumn{5}{c|}{ MEDIDAS TEWL } \\
\hline & & $\mathbf{t 0}$ & $\mathbf{t 4 5}$ & $\mathbf{t 9 0}$ & $\mathbf{t 1 8 0}$ & $\mathbf{t 0}$ & $\mathbf{T 4 5}$ & $\mathbf{t 9 0}$ & $\mathbf{t 1 8 0}$ \\
\hline $\mathbf{2}$ & 2 & 37,7 & 47,3 & 41,7 & 33,0 & 7,59 & 8,41 & 9,24 & 7,51 \\
\hline 3 & 1 & 25,3 & 34,0 & 30,7 & 26,3 & 8,28 & 8,27 & 9,29 & 8,13 \\
\hline 3 & 6 & 24,3 & 32,7 & 25,7 & 26,7 & 7,08 & 9,02 & 9,38 & 7,36 \\
\hline 4 & 1 & 35,0 & 30,3 & 37,7 & 35,3 & 9,71 & 9,33 & 14,41 & 7,26 \\
\hline 5 & 2 & 32,7 & 30,3 & 42,3 & 37,0 & 6,31 & 8,06 & 9,73 & 7,94 \\
\hline 5 & 4 & 31,7 & 34,3 & 40,7 & 37,7 & 10,61 & 8,80 & 8,87 & 10,00 \\
\hline 6 & 2 & 30,7 & 42,0 & 43,7 & 46,3 & 8,83 & 9,02 & 12,12 & 9,89 \\
\hline 6 & 5 & 30,7 & 42,7 & 42,3 & 46,0 & 9,31 & 11,75 & 7,50 & 10,05 \\
\hline 7 & 6 & 31,7 & 36,7 & 33,0 & 35,7 & 4,80 & 7,83 & 10,02 & 10,39 \\
\hline 8 & 3 & 35,3 & 33,7 & 34,0 & 32,3 & 5,51 & 6,87 & 7,81 & 8,55 \\
\hline 8 & 5 & 34,3 & 42,3 & 38,0 & 33,0 & 4,33 & 5,98 & 4,27 & 7,01 \\
\hline 10 & 1 & 35,0 & 31,3 & 30,7 & 35,3 & 5,20 & 6,92 & 8,89 & 7,99 \\
\hline 10 & 5 & 39,0 & 41,0 & 40,3 & 42,7 & 6,14 & 7,67 & 8,12 & 7,36 \\
\hline 12 & 1 & 31,3 & 35,7 & 35,0 & 35,7 & 7,67 & 5,20 & 6,90 & 6,35 \\
\hline 12 & 6 & 40,0 & 46,7 & 39,7 & 40,3 & 6,14 & 7,52 & 8,45 & 7,87 \\
\hline
\end{tabular}

Legenda:

VOL.: voluntário

L.: local de aplicação, conforme aleatorização

CW: hidratação obtidas com o Corneometer ${ }^{\circledR}$ (UA - unidades arbitrárias)

TEWL: perda de água transepidérmal obtida com o Tewameter $^{\circledR}$ (UA - unidades arbitrárias).

t0: tempo zero, anterior à aplicação da amostra

t45, t90 e t180: medidas obtidas 45, 90 e 180 minutos transcorridos após a aplicação da amostra, respectivamente. 
Tabela 23. Avaliação clínica da elasticidade e firmeza da pele (CUTO) para a amostra MS base cosmética de máscara facial peel off (sem extrato de soja fermentado por Bifidobacterium animale).

\begin{tabular}{|c|c|c|c|c|c|c|c|c|c|}
\hline \multirow{2}{*}{ VOL. } & \multirow{2}{*}{ L. } & \multicolumn{4}{|c|}{ CUTO - M1 } & \multicolumn{4}{|c|}{ CUTO - M2 } \\
\hline & & to & t45 & t90 & $t 180$ & to & T45 & t90 & t180 \\
\hline 2 & 5 & 0,405 & 0,385 & 0,345 & 0,315 & 0,080 & 0,075 & 0,075 & 0,065 \\
\hline 3 & 2 & 0,365 & 0,385 & 0,385 & 0,410 & 0,090 & 0,060 & 0,050 & 0,060 \\
\hline 4 & 3 & 0,405 & 0,475 & 0,390 & 0,450 & 0,085 & 0,065 & 0,040 & 0,045 \\
\hline 4 & 4 & 0,315 & 0,265 & 0,360 & 0,345 & 0,065 & 0,025 & 0,080 & 0,065 \\
\hline 5 & 1 & 0,430 & 0,425 & 0,425 & 0,325 & 0,065 & 0,055 & 0,025 & 0,045 \\
\hline 6 & 3 & 0,450 & 0,405 & 0,465 & 0,445 & 0,040 & 0,030 & 0,025 & 0,045 \\
\hline 6 & 6 & 0,450 & 0,385 & 0,440 & 0,475 & 0,045 & 0,025 & 0,020 & 0,050 \\
\hline 7 & 3 & 0,465 & 0,475 & 0,510 & 0,435 & 0,050 & 0,080 & 0,080 & 0,065 \\
\hline 8 & 2 & 0,365 & 0,330 & 0,325 & 0,280 & 0,165 & 0,100 & 0,080 & 0,075 \\
\hline 8 & 6 & 0,400 & 0,380 & 0,365 & 0,455 & 0,140 & 0,090 & 0,075 & 0,180 \\
\hline 9 & 2 & 0,365 & 0,365 & 0,350 & 0,395 & 0,100 & 0,045 & 0,065 & 0,065 \\
\hline 9 & 6 & 0,380 & 0,375 & 0,440 & 0,370 & 0,060 & 0,040 & 0,080 & 0,060 \\
\hline 10 & 3 & 0,440 & 0,455 & 0,315 & 0,385 & 0,065 & 0,075 & 0,020 & 0,045 \\
\hline 12 & 2 & 0,455 & 0,585 & 0,590 & 0,465 & 0,050 & 0,085 & 0,055 & 0,045 \\
\hline 12 & 4 & 0,640 & 0,445 & 0,665 & 0,555 & 0,100 & 0,050 & 0,100 & 0,050 \\
\hline
\end{tabular}

\section{Legenda:}

VOL.: voluntário

L.: local de aplicação, conforme aleatorização

CUTO M1: deformação final ou extensibilidade máxima (UA - unidades arbitrárias)

CUTO M2: deformação resultante em comparação com o valor inicial (UA - unidades arbitrárias).

t0: tempo zero, anterior à aplicação da amostra t45, t90 e t180: medidas obtidas 45, 90 e 180 minutos transcorridos após a aplicação da amostra, respectivamente. 
Tabela 24. Avaliação clínica da elasticidade e firmeza da pele (CUTO) para a amostra MC base cosmética de máscara facial peel off (com extrato de soja fermentado por Bifidobacterium animale).

\begin{tabular}{|c|c|c|c|c|c|c|c|c|c|}
\hline \multirow{2}{*}{ VOL. } & \multirow{2}{*}{ L. } & \multicolumn{4}{|c|}{ CUTO - M1 } & \multicolumn{4}{|c|}{ CUTO - M2 } \\
\hline & & to & t45 & t90 & $t 180$ & to & T45 & t90 & t180 \\
\hline 2 & 1 & 0,565 & 0,320 & 0,360 & 0,305 & 0,125 & 0,080 & 0,115 & 0,075 \\
\hline 2 & 4 & 0,345 & 0,320 & 0,350 & 0,325 & 0,035 & 0,055 & 0,095 & 0,055 \\
\hline 3 & 3 & 0,575 & 0,445 & 0,510 & 0,485 & 0,095 & 0,075 & 0,080 & 0,065 \\
\hline 3 & 5 & 0,435 & NA & 0,465 & 0,420 & 0,075 & NA & 0,070 & 0,110 \\
\hline 4 & 2 & 0,325 & 0,380 & 0,355 & 0,325 & 0,060 & 0,070 & 0,055 & 0,050 \\
\hline 4 & 5 & 0,355 & 0,330 & 0,350 & 0,360 & 0,045 & 0,055 & 0,070 & 0,075 \\
\hline 5 & 3 & 0,420 & 0,475 & 0,455 & 0,415 & 0,055 & 0,050 & 0,035 & 0,025 \\
\hline 5 & 6 & 0,415 & 0,495 & 0,435 & 0,485 & 0,030 & 0,030 & 0,020 & 0,040 \\
\hline 7 & 1 & 0,640 & 0,460 & 0,385 & 0,375 & 0,090 & 0,085 & 0,065 & 0,085 \\
\hline 7 & 5 & 0,455 & 0,480 & 0,415 & 0,435 & 0,100 & 0,075 & 0,080 & 0,075 \\
\hline 8 & 4 & 0,410 & 0,460 & 0,290 & 0,390 & 0,160 & 0,150 & 0,085 & 0,150 \\
\hline 9 & 3 & 0,440 & 0,410 & 0,410 & 0,390 & 0,065 & 0,065 & 0,070 & 0,070 \\
\hline 9 & 4 & 0,390 & 0,395 & 0,415 & 0,375 & 0,075 & 0,080 & 0,110 & 0,095 \\
\hline 10 & 4 & 0,410 & 0,450 & 0,400 & 0,435 & 0,065 & 0,065 & 0,060 & 0,065 \\
\hline 12 & 3 & 0,640 & 0,655 & 0,620 & 0,515 & 0,100 & 0,025 & 0,065 & 0,045 \\
\hline
\end{tabular}

\section{Legenda:}

VOL.: voluntário

L.: local de aplicação, conforme aleatorização

CUTO M1: deformação final ou extensibilidade máxima (UA - unidades arbitrárias)

CUTO M2: deformação resultante em comparação com o valor inicial (UA - unidades arbitrárias).

t0: tempo zero, anterior à aplicação da amostra t45, t90 e t180: medidas obtidas 45, 90 e 180 minutos transcorridos após a aplicação da amostra, respectivamente. 
Tabela 25. Avaliação clínica da elasticidade e firmeza da pele (CUTO) para a amostra ES emulsão sem extrato de soja fermentado por Bifidobacterium animale.

\begin{tabular}{|c|c|c|c|c|c|c|c|c|c|}
\hline \multirow{2}{*}{ VOL. } & \multirow{2}{*}{ L. } & \multicolumn{4}{|c|}{ CUTO - M1 } & \multicolumn{4}{|c|}{ CUTO - M2 } \\
\hline & & to & t45 & t90 & $t 180$ & to & T45 & t90 & $t 180$ \\
\hline 2 & 3 & 0,395 & 0,400 & 0,405 & 0,450 & 0,050 & 0,060 & 0,090 & 0,045 \\
\hline 2 & 6 & 0,425 & 0,415 & 0,425 & 0,380 & 0,075 & 0,100 & 0,090 & 0,065 \\
\hline 3 & 4 & 0,445 & 0,465 & 0,425 & 0,425 & 0,115 & 0,070 & 0,065 & 0,045 \\
\hline 4 & 6 & 0,395 & 0,380 & 0,455 & 0,400 & 0,075 & 0,095 & 0,055 & 0,050 \\
\hline 5 & 5 & 0,395 & 0,410 & 0,445 & 0,395 & 0,035 & 0,055 & 0,070 & 0,045 \\
\hline 6 & 1 & 0,255 & 0,465 & 0,270 & 0,285 & 0,030 & 0,075 & 0,070 & 0,045 \\
\hline 6 & 4 & 0,305 & 0,505 & 0,310 & 0,305 & 0,060 & 0,045 & 0,040 & 0,045 \\
\hline 7 & 2 & 0,615 & 0,355 & 0,410 & 0,365 & 0,095 & 0,070 & 0,080 & 0,055 \\
\hline 7 & 4 & 0,420 & 0,450 & 0,410 & 0,420 & 0,110 & 0,130 & 0,090 & 0,080 \\
\hline 8 & 1 & 0,320 & 0,310 & 0,305 & 0,280 & 0,125 & 0,100 & 0,115 & 0,095 \\
\hline 9 & 1 & 0,370 & 0,375 & 0,380 & 0,295 & 0,065 & 0,050 & 0,085 & 0,050 \\
\hline 9 & 5 & 0,390 & 0,335 & 0,370 & 0,380 & 0,075 & 0,075 & 0,095 & 0,060 \\
\hline 10 & 2 & 0,375 & 0,360 & 0,345 & 0,345 & 0,050 & 0,050 & 0,045 & 0,055 \\
\hline 10 & 6 & 0,455 & 0,415 & 0,390 & 0,400 & 0,035 & 0,050 & 0,035 & 0,060 \\
\hline 12 & 5 & 0,545 & 0,535 & 0,500 & 0,470 & 0,100 & 0,050 & 0,035 & 0,065 \\
\hline
\end{tabular}

Legenda:

VOL.: voluntário

L.: local de aplicação, conforme aleatorização

CUTO M1: deformação final ou extensibilidade máxima (UA - unidades arbitrárias)

CUTO M2: deformação resultante em comparação com o valor inicial (UA - unidades arbitrárias).

t0: tempo zero, anterior à aplicação da amostra t45, t90 e t180: medidas obtidas 45, 90 e 180 minutos transcorridos após a aplicação da amostra, respectivamente. 
Tabela 26. Avaliação clínica da elasticidade e firmeza da pele (CUTO) para a amostra EC emulsão com extrato de soja fermentado por Bifidobacterium animale.

\begin{tabular}{|c|c|c|c|c|c|c|c|c|c|}
\hline \multirow{2}{*}{ VOL. } & \multirow{2}{*}{ L. } & \multicolumn{4}{|c|}{ CUTO - M1 } & \multicolumn{4}{|c|}{ CUTO - M2 } \\
\hline & & to & t45 & t90 & t180 & to & T45 & t90 & t180 \\
\hline 2 & 2 & 0,615 & 0,365 & 0,335 & 0,345 & 0,170 & 0,080 & 0,065 & 0,040 \\
\hline 3 & 1 & 0,405 & 0,375 & 0,335 & 0,350 & 0,085 & 0,075 & 0,055 & 0,075 \\
\hline 3 & 6 & 0,585 & 0,505 & 0,475 & 0,515 & 0,070 & 0,110 & 0,045 & 0,095 \\
\hline 4 & 1 & 0,345 & 0,305 & 0,295 & 0,325 & 0,075 & 0,085 & 0,055 & 0,070 \\
\hline 5 & 2 & 0,340 & 0,335 & 0,400 & 0,340 & 0,035 & 0,040 & 0,050 & 0,040 \\
\hline 5 & 4 & 0,415 & 0,505 & 0,470 & 0,475 & 0,035 & 0,050 & 0,040 & 0,025 \\
\hline 6 & 2 & 0,295 & 0,380 & 0,355 & 0,315 & 0,020 & 0,035 & 0,040 & 0,025 \\
\hline 6 & 5 & 0,345 & 0,375 & 0,395 & 0,400 & 0,045 & 0,040 & 0,065 & 0,055 \\
\hline 7 & 6 & 0,385 & 0,485 & 0,475 & 0,475 & 0,050 & 0,065 & 0,075 & 0,080 \\
\hline 8 & 3 & 0,360 & 0,430 & 0,335 & 0,330 & 0,120 & 0,145 & 0,100 & 0,100 \\
\hline 8 & 5 & 0,350 & 0,340 & 0,370 & 0,310 & 0,110 & 0,095 & 0,135 & 0,080 \\
\hline 10 & 1 & 0,355 & 0,395 & 0,380 & 0,375 & 0,035 & 0,075 & 0,055 & 0,035 \\
\hline 10 & 5 & 0,405 & 0,345 & 0,390 & 0,365 & 0,045 & 0,035 & 0,055 & 0,055 \\
\hline 12 & 1 & 0,625 & 0,555 & 0,570 & 0,485 & 0,105 & 0,040 & 0,100 & 0,040 \\
\hline 12 & 6 & 0,515 & 0,555 & 0,590 & 0,475 & 0,045 & 0,040 & 0,065 & 0,030 \\
\hline
\end{tabular}

Legenda:

VOL.: voluntário

L.: local de aplicação, conforme aleatorização

CUTO M1: deformação final ou extensibilidade máxima (UA - unidades arbitrárias)

CUTO M2: deformação resultante em comparação com o valor inicial (UA - unidades arbitrárias).

t0: tempo zero, anterior à aplicação da amostra t45, t90 e t180: medidas obtidas 45, 90 e 180 minutos transcorridos após a aplicação da amostra, respectivamente. 
Considerando os resultados obtidos a partir das aplicações nos locais descritos nas Tabelas 19 a 26, observou-se que dois voluntários, denominados 1 e 11, foram excluídos do estudo, sendo substituídos pelo voluntário 12, pois apresentaram dermatite atópica após a retirada da máscara facial peel off dos locais de aplicação e foram substituídos para que as manifestações não causassem interferência nas avaliações instrumentais. As Figuras 22 e 23 apresentam as imagens das reações dos voluntários à máscara facial, contendo ou não extrato de soja fermentado.

A manifestação foi mais intensa, em ambos os voluntários, nos locais de aplicação da base cosmética de máscara facial peel off, sem extrato de soja fermentado e foi ausente quando do uso da emulsão. Esta resposta indicou que o provável causador da reação foi um componente da base de máscara facial peel off, e não do extrato de soja fermentado ou da emulsão. Considerando que todos os componentes têm seu uso autorizado pela Agência Nacional de Vigilância Sanitária e as matérias-primas apresentavam-se dentro do prazo de validade, atribui-se o fato ao conservante que possui iodo em sua formulação, uma vez que existem relatos na literatura de reações adversas ao usos tópico de substâncias derivadas do iodo (OISO et al., 2006; TOMINAGA et al., 2000; WEINBERG et al., 2003). Esta reação foi isolada, uma vez que, mesmo possuindo iodo em sua composição, o conservante é autorizado pela ANVISA para utilização em cosméticos e sua concentração na base de máscara facial peel off estava cerca de três vezes abaixo do limite máximo permitido legalmente (AGÊNCIA NACIONAL DE VIGILÂNCIA SANITÁRIA, 2000; AGÊNCIA NACIONAL DE VIGILÂNCIA SANITÁRIA, 2001).

É importante a realização de um estudo sobre os componentes da formulação de máscara facial peel off que poderiam causar a resposta de reação de hipersensibilidade registrada no ensaio clínico, realizando testes de segurança, a fim de garantir a segurança de uso do produto Somente após a conclusão destes testes é que a formulação poderá ser disponibilizada para comercialização e uso. 

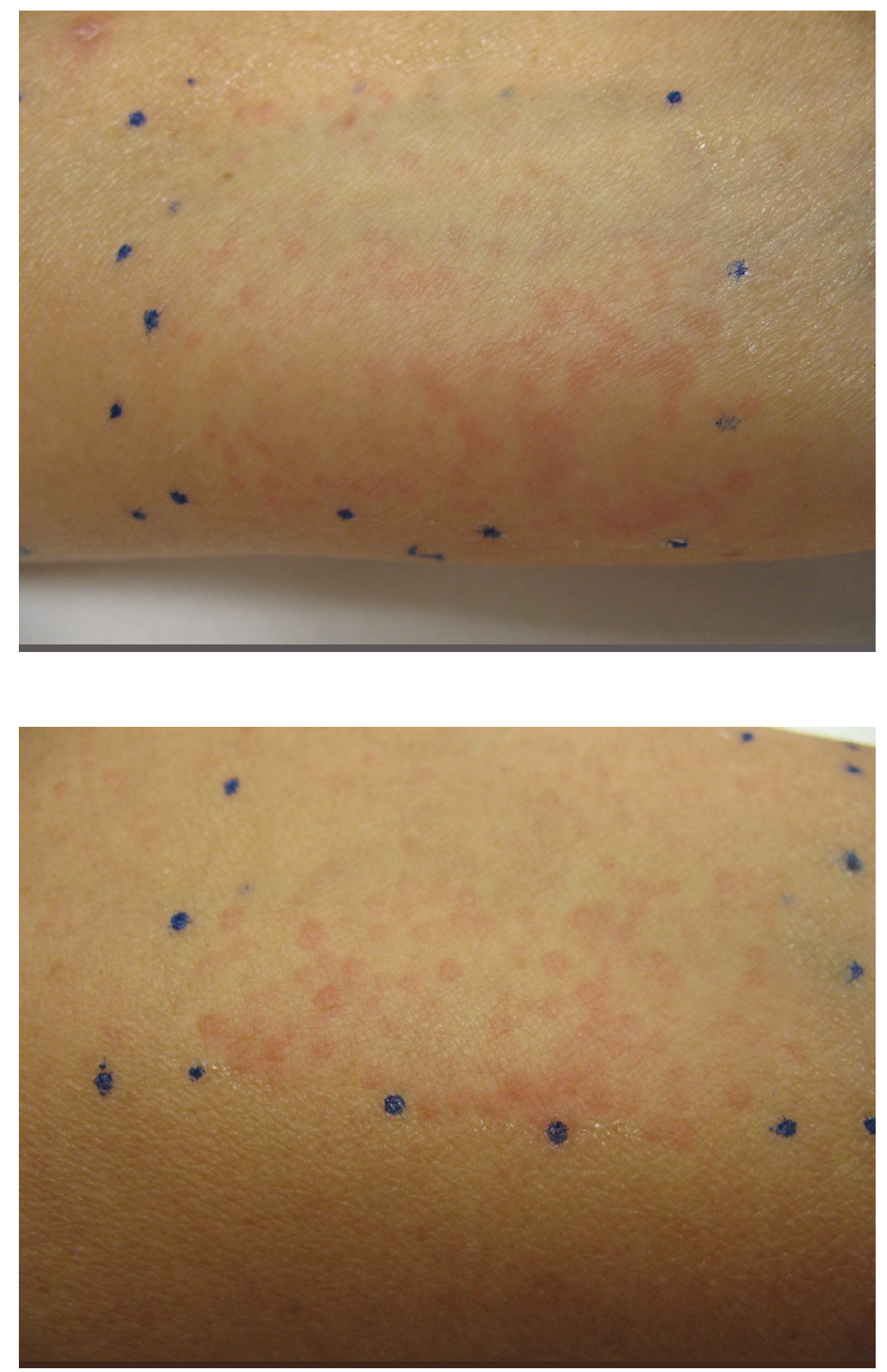

Figura 22. Fotografias das manifestações (dermatite atópica) dos voluntários após aplicação e retirada da formulação de máscara facial peel off sem extrato de soja fermentado por Bifidobacterium animale. Os pontos azuis delimitam a área de aplicação do produto. 

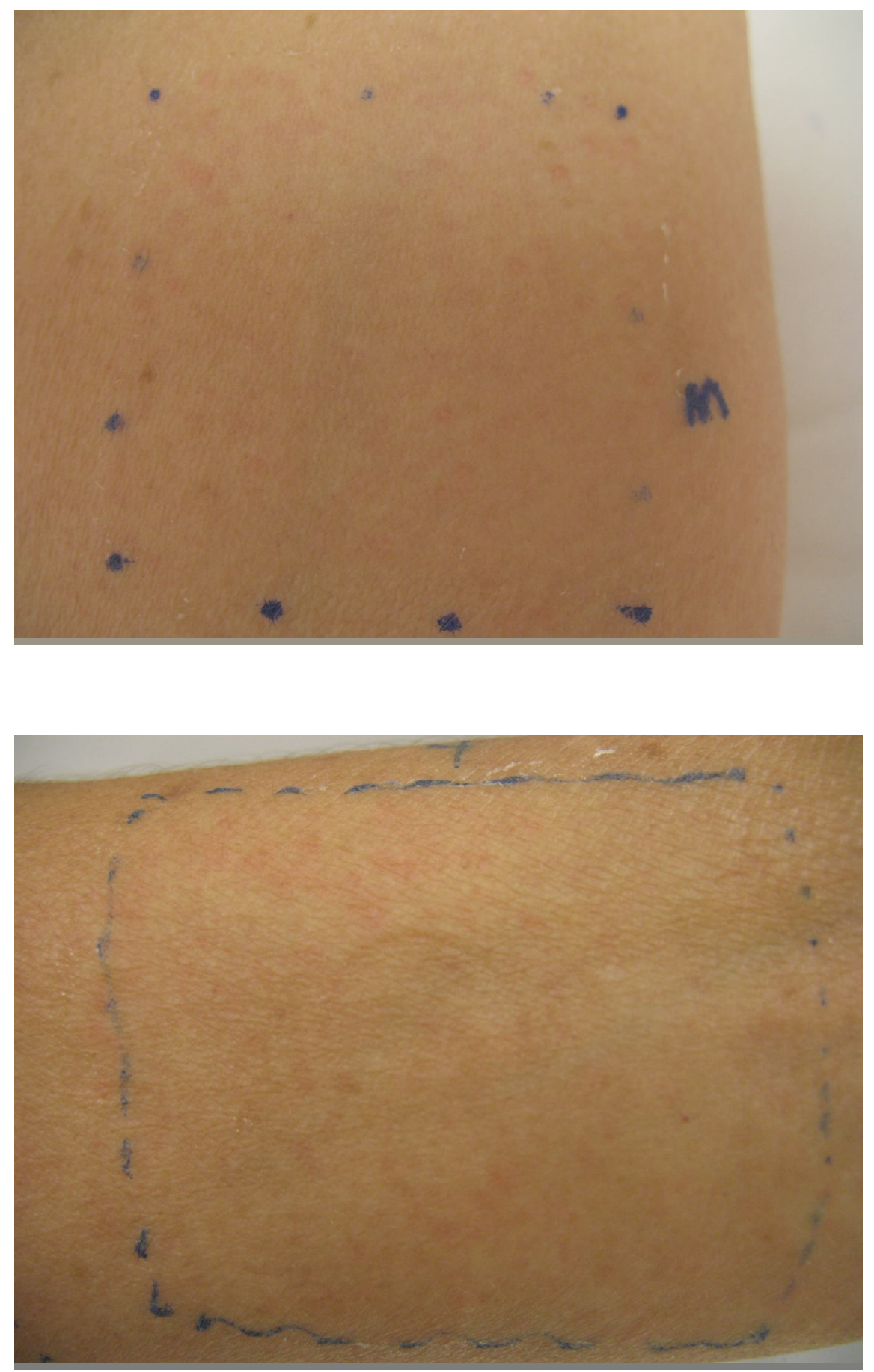

Figura 23. Fotografias das manifestações (dermatite atópica) dos voluntários após aplicação e retirada da formulação de máscara facial peel off com extrato de soja fermentado por Bifidobacterium animale. Os pontos azuis delimitam a área de aplicação do produto. 


\subsection{Análise estatística dos dados}

Os valores obtidos nos testes clínicos para a avaliação instrumental foram avaliados estatisticamente e, em seguida, interpretados.

As Tabelas 27 a 35 apresentam os resultados estatísticos obtidos a partir das variáveis extrato, tempo e produto. A variável extrato avaliou o impacto da presença ou ausência do extrato de soja fermentado por Bifidobacterium animale nas medidas instrumentais; os valores referentes ao tempo avaliaram a influência do tempo, em um estudo cinético, nas medidas realizadas; e a variável produto referiuse aos valores obtidos para MS (base de máscara facial peel off), MC (máscara facial peel off contendo extrato de soja fermentado por Bifidobacterium animale), ES (base cosmética da emulsão óleo em água) e EC (emulsão óleo em água contendo extrato de soja fermentado por Bifidobacterium animale), isoladamente. Todas as variáveis foram avaliadas separadamente e, também, por cruzamentos, como das variáveis extrato $\mathbf{x}$ tempo, por exemplo, avaliou-se a influência nas medidas instrumentais na presença ou ausência do extrato de soja, nos diferentes períodos de tempo avaliados neste estudo cinético, não importando qual tipo de formulação, se máscara peel-off ou emulsão.

As Figuras 24 a 31 apresentam os gráficos obtidos após o tratamento estatístico para as medidas realizadas, conforme os tempos definidos para a coleta dos dados $(0,45,90$ e 180 minutos).

\subsubsection{Efeito na firmeza e elasticidade da pele}

O tratamento dos dados estatísticos para $\mathbf{M 1}$ (deformação final ou extensibilidade máxima) está descrito na Tabela 27. 
Tabela 27. Tratamento estatístico obtido dos valores mensurados para M1 (deformação final ou extensibilidade máxima).

\begin{tabular}{|c|c|c|c|}
\hline Efeito & $\begin{array}{l}\text { Graus de } \\
\text { liberdade }\end{array}$ & Valor F & $P>F$ \\
\hline Extrato & 1 & 0,20 & 0,6550 \\
\hline Tempo & 2 & 4,60 & 0,0113 \\
\hline Interação Extrato / Tempo & 2 & 0,18 & 0,8393 \\
\hline Produto & 1 & 0,28 & 0,5965 \\
\hline Interação Extrato / Produto & 1 & 3,61 & 0,0591 \\
\hline Interação Produto / Tempo & 2 & 0,47 & 0,6259 \\
\hline Interação Extrato/ Produto/ Tempo & 2 & 1,36 & 0,2598 \\
\hline
\end{tabular}

Conforme observado na Tabela 27, foi obtido um valor de $\mathbf{P}>\mathbf{F}$ inferior a 0,05 para o efeito do tempo, indicando uma significância ao nível de 5\% (ou a um nível de confiança de 95\%). Associado à diminuição dos valores de M1 de acordo com o decorrer do tempo em relação a t0 (início), evidenciada nos gráficos das Figuras 24 e 25, este resultado indicou um aumento da firmeza cutânea, em função do tempo, para todas as formulações avaliadas (bases cosméticas da emulsão óleo em água e máscara facial e formulações de emulsão e máscara facial contendo extrato de soja fermentado). No entanto, considerando que os demais efeitos foram superiores a 0,05, não foi observada uma diferença significativa no aumento da firmeza cutânea quando comparado ao uso da máscara facial ou da emulsão, assim como não houve diferença significativa no uso de formulações contendo extrato de soja fermentado para aquelas onde o extrato não está presente.

Adicionalmente aos efeitos obtidos com o tratamento estatístico, foi realizada a comparação do nível de significância entre os diferentes valores de tempo. Conforme os resultados apresentados na Tabela 28, observou-se que ocorreu diferença significativa (menor que 0.05) entre os tempos T45 e T180, demonstrado pelo valor $\mathbf{0 , 0 0 9}$. Os resultados sugeriram que o aumento da firmeza é dependente do tempo, sendo menor logo após a aplicação. Este resultado e válido para as quatro preparações avaliadas. Da mesma forma, esta diferença não foi significativa considerando os efeitos produto e extrato. 


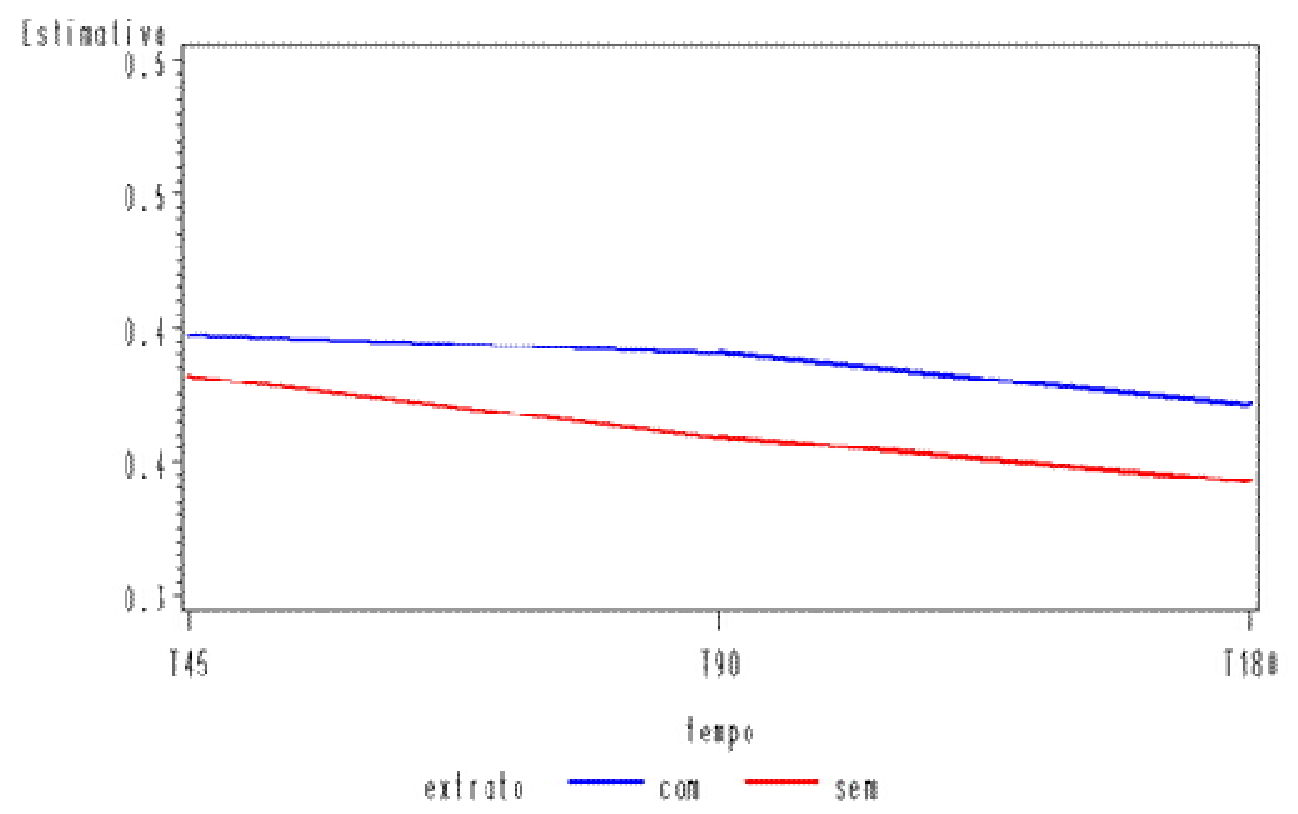

Figura 24. Variação da estimativa - após tratamento estatístico dos dados brutos - do valor de M1 (deformação final ou extensibilidade máxima) em relação ao tempo para as formulações de emulsão, contendo ou não extrato de soja fermentado por Bifidobacterium animale (com e sem, respectivamente).

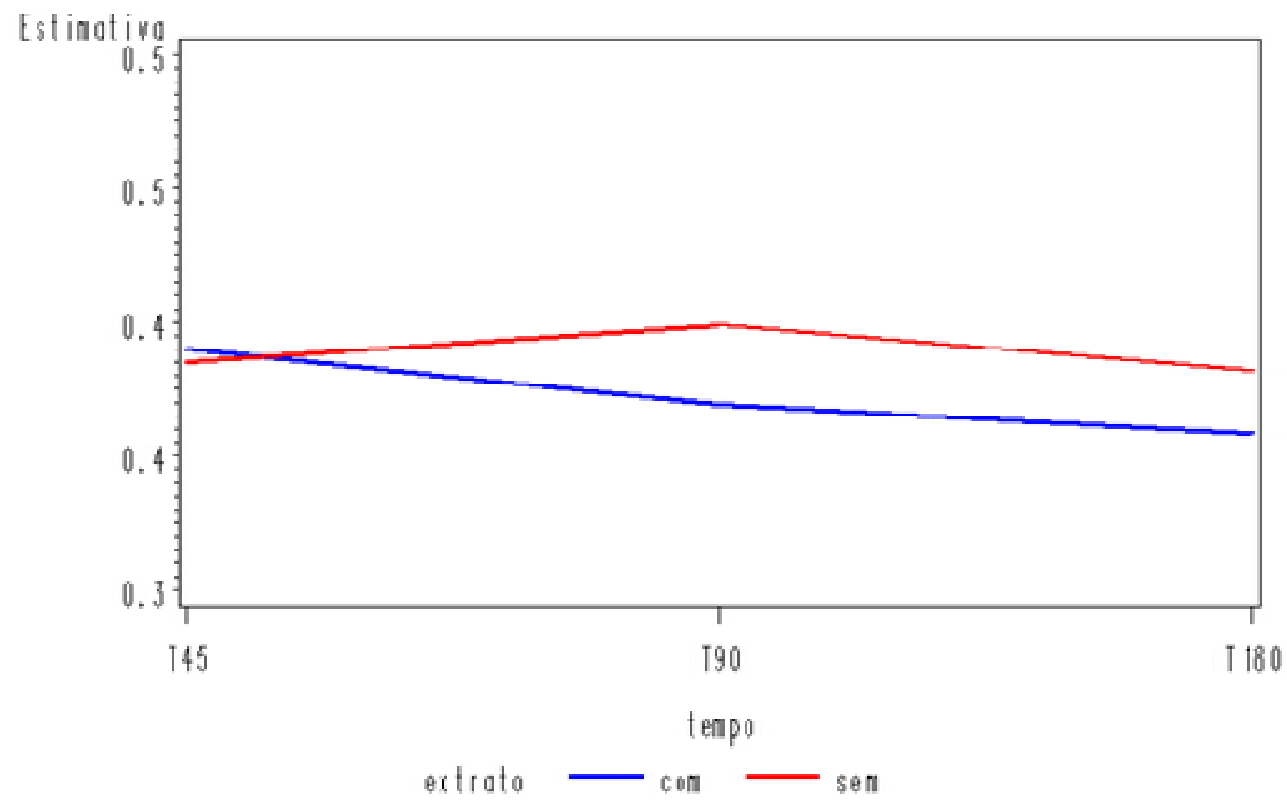

Figura 25. Variação da estimativa - após tratamento estatístico dos dados brutos - do valor de M1 (deformação final ou extensibilidade máxima) em relação ao tempo para as formulações de máscara facial contendo ou não extrato de soja fermentado por Bifidobacterium animale (com e sem, respectivamente). 
Tabela 28. Comparação entre os tempos de aplicação e avaliação das preparações produtos para M1, com os respectivos níveis de significância (deformação final ou extensibilidade máxima).

\begin{tabular}{|cc|}
\hline Tempos & Nível de significância \\
\hline T45 X T90 & 0,521 \\
\hline T45 X T180 & 0,009 \\
\hline T90 X T180 & 0,138 \\
\hline
\end{tabular}

Os gráficos apresentados nas Figuras 24 e 25 permitiram afirmar que ocorreu a tendência de diminuição do valor de $\mathbf{M} 1$ com o decorrer do tempo, para todas as preparações cosméticas avaliadas e, conseqüentemente, a tendência de aumento da firmeza cutânea. Como no estudo cinético os valores obtidos do tratamento estatístico não apresentaram uma diferença significativa para dar suporte a tal afirmação, a realização de um posterior estudo a longa duração poderá comprovar se a tendência observada nos gráficos é realmente significativa.

O tratamento estatístico dos dados para M2 (deformação resultante em comparação com o valor inicial) está descrito na Tabela 29.

Tabela 29. Tratamento estatístico obtido dos valores mensurados para M2 (deformação resultante em comparação com o valor inicial).

\begin{tabular}{|c|c|c|c|}
\hline Efeito & $\begin{array}{c}\text { Graus de } \\
\text { liberdade }\end{array}$ & Valor F & $\mathbf{P}>\mathbf{F}$ \\
\hline Extrato & 1 & 1,28 & $\mathbf{0 , 2 6 0 4}$ \\
\hline Tempo & 2 & 0,79 & $\mathbf{0 , 4 5 4 9}$ \\
\hline Interação Extrato / Tempo & 2 & 0,09 & $\mathbf{0 , 9 1 2 7}$ \\
\hline Produto & 1 & 0,05 & $\mathbf{0 , 8 2 3 5}$ \\
\hline Interação Extrato / Produto & 1 & 1,60 & $\mathbf{0 , 2 0 7 7}$ \\
\hline Interação Produto / Tempo & 2 & 3,67 & $\mathbf{0 , 0 2 7 5}$ \\
\hline Interação Extrato/ Produto/ Tempo & 2 & 0,15 & $\mathbf{0 , 8 6 0 4}$ \\
\hline
\end{tabular}


Conforme observado na Tabela 29, foi obtido um valor de $\mathbf{P}>\mathbf{F}$ inferior a 0,05 para o efeito produto $\mathbf{X}$ tempo, indicando uma significância ao nível de 5\% (ou a um nível de confiança de 95\%). Associado à diminuição dos valores de M2 de acordo com tempo em relação a t0 (início), evidenciada nos gráficos das Figuras 26 e 27, os resultados obtidos indicaram um aumento da elasticidade para as formulações de emulsão, com ou sem extrato de soja fermentado por Bifidobacterium animale. No entanto, observou-se que, apesar da diferença detectada para os valores da emulsão ser estatisticamente significativa em relação aos valores observados para a máscara, não houve diferença absoluta significativa entre os valores da estimativa, evidenciada pela pequena variação dentro da escala numérica no eixo y (estimativa).

Em função dos resultados obtidos, pode-se afirmar que não ocorreu diferença significativa entre as formulações quanto à capacidade de promoção do aumento da elasticidade da pele.

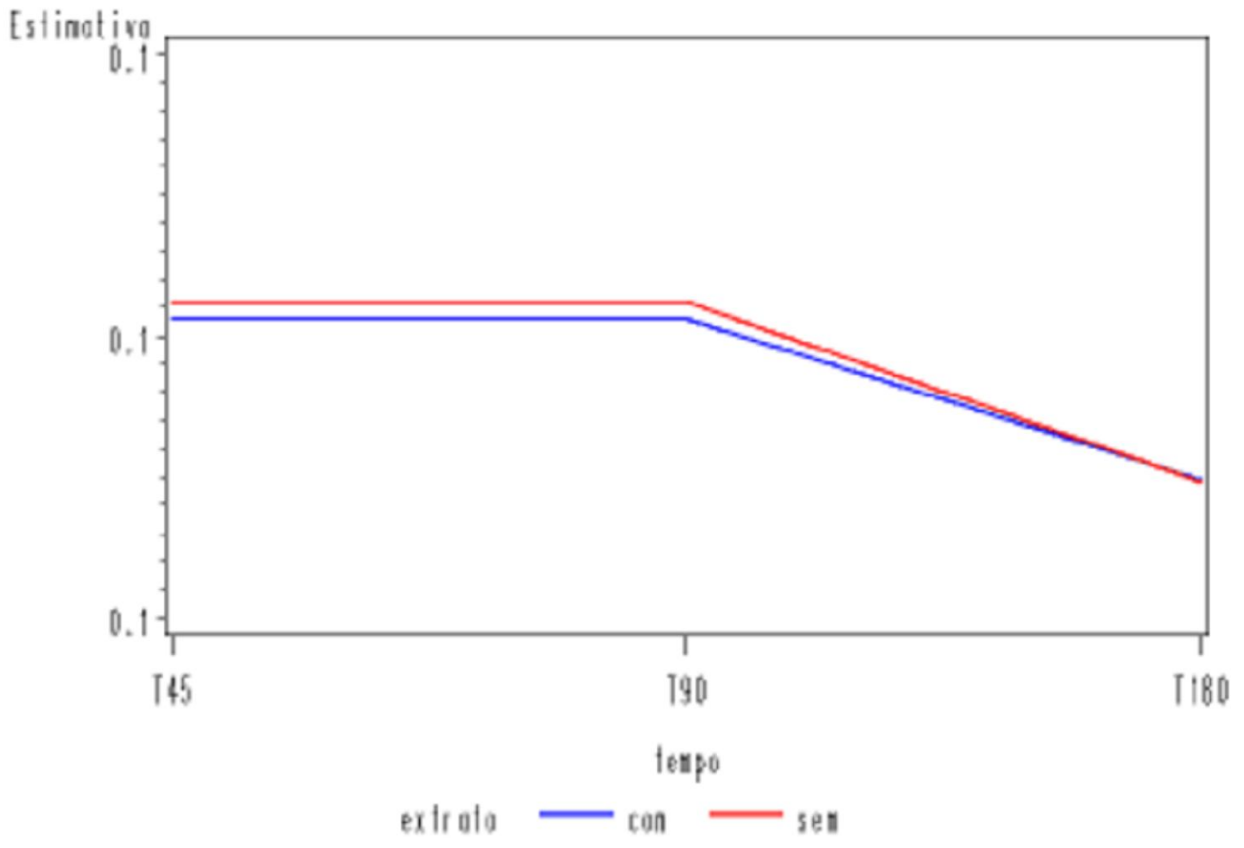

Figura 26. Variação da estimativa - após tratamento estatístico dos dados brutos - do valor de M2 (deformação resultante em comparação com o valor inicial) em relação ao tempo para as formulações de emulsão contendo ou não extrato de soja fermentado por Bifidobacterium animale (com e sem, respectivamente). 


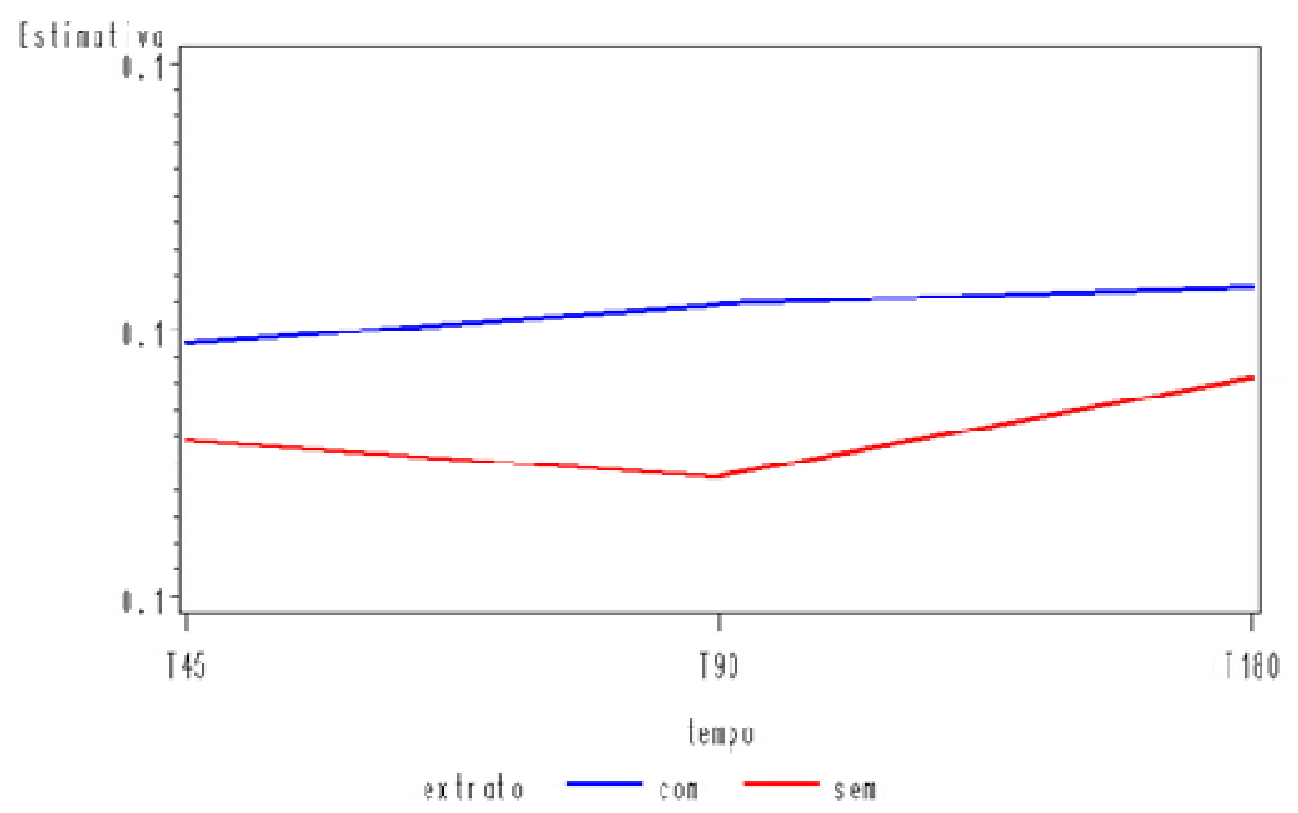

Figura 27. Variação da estimativa - após tratamento estatístico dos dados brutos - do valor de M2 (deformação resultante em comparação com o valor inicial) em relação ao tempo para as formulações de máscara facial contendo ou não extrato de soja fermentado por Bifidobacterium animale (com e sem, respectivamente).

Como fora discutido anteriormente para os valores de M1, os gráficos apresentados nas Figuras 26 e 27 permitiram afirmar que ocorreu a tendência de diminuição do valor de M2 com o decorrer do tempo para as preparações de emulsão e, consequentemente, a tendência de aumento da elasticidade cutânea.

De acordo com a literatura, análises do aumento da elasticidade e firmeza da pele induzida por produtos tópicos, incluindo substâncias ativas (BARBA et al., 2008), indicaram alterações nas propriedades mecânicas da pele. Por outro lado, resultados da avaliação de emulsões óleo em água contendo ou não nanopartículas lipídicas demonstraram que não houve diferença estatisticamente significativa entre as formulações no aumento da elasticidade e firmeza da pele (MÜLLER et al., 2003). Considerando os diferentes resultados obtidos em estudos da literatura e que, no estudo cinético realizado nesta pesquisa, os valores obtidos a partir do tratamento estatístico não apresentaram diferença significativa. Seria recomendável a realização de um estudo posterior, a longo prazo, para comprovar se a tendência observada nos gráficos é realmente significativa, ou seja, se as preparações de emulsão testadas são mais eficazes na promoção do aumento da elasticidade cutânea que as formulações de máscara facial peel off avaliadas. 


\subsubsection{Efeito da perda de água transepidérmica}

O tratamento dos dados estatísticos para TEWL (perda de água transepidérmica) está descrito na Tabela $\mathbf{3 0}$.

Tabela 30. Tratamento estatístico obtido dos valores mensurados para TEWL (perda de água transepidérmica).

\begin{tabular}{|c|c|c|c|}
\hline Efeito & $\begin{array}{c}\text { Graus de } \\
\text { liberdade }\end{array}$ & Valor $\mathbf{F}$ & $\mathbf{P}>\mathbf{F}$ \\
\hline Extrato & 1 & 0,21 & $\mathbf{0 , 6 4 9 0}$ \\
\hline Tempo & 2 & 8,50 & $\mathbf{0 , 0 0 0 3}$ \\
\hline Interação Extrato / Tempo & 2 & 0,64 & $\mathbf{0 , 5 3 6 1}$ \\
\hline Produto & 1 & 0,30 & $\mathbf{0 , 5 8 4 7}$ \\
\hline Interação Extrato / Produto & 1 & 0,00 & $\mathbf{0 , 9 4 5 7}$ \\
\hline Interação Produto / Tempo & 2 & 1,20 & $\mathbf{0 , 3 0 2 9}$ \\
\hline Interação Extrato/ Produto/ Tempo & 2 & 0,17 & $\mathbf{0 , 8 4 3 2}$ \\
\hline
\end{tabular}

Conforme observado na Tabela $\mathbf{3 0}$, obteve-se um valor de $\mathbf{P}>\mathbf{F}$ inferior a 0,05 para o Efeito Tempo, indicando uma significância ao nível de 5\% (ou a um nível de confiança de 95\%). Associado à diminuição dos valores de TEWL de acordo com tempo em relação a T0, evidenciada nos gráficos da Figura 28 e 29, este resultado indicou uma diminuição da perda de água transepidérmica, para todas as formulações. No entanto, considerando que os demais efeitos foram superiores a 0,05; não foi observada uma diferença significativa no aumento da perda de água transepidérmica quando comparado o uso da máscara facial ou da emulsão, assim como não houve diferença significativa no uso de formulações contendo extrato de soja fermentado para aquelas onde o extrato não está presente.

Adicionalmente aos efeitos obtidos com o tratamento estatístico, foi realizada a comparação do nível de significância entre os diferentes tempos. Conforme os resultados apresentados na Tabela 31, observando-se que houve diferenças significativas (menor que 5\%) entre os tempos T45 e T90 e entre os tempos T90 e $\mathrm{T} 180$, demonstrados pelos valores $\mathbf{0 , 0 0 3}$ e $\mathbf{0 , 0 0 1}$. Os valores sugerem, portanto, que 
a diminuição da perda de água transepidérmica é dependente do tempo, sendo maior no período intermediário ä aplicação (T90) e menor nos períodos iniciais e finais ä aplicação (T45 e T180). Da mesma forma, esta diferença não é significativa considerando os Efeitos Produto e Extrato.

Tanto na formulação da emulsão óleo em água quanto na formulação de máscara facial peel off são encontrados componentes que alteram a estrutura do estrato córneo, como glicerol e propilenoglicol, penetrando na epiderme (BRINKMANN et al., 2005). Sabe-se, também que os polióis são altamente higroscópicos, uma vez que formam ligações de hidrogênio com a água (COHEN et al., 1993), promovendo aumento da concentração de água na pele (SAGIV et al., 2003), além de maciez e emoliência (BETTINGER et al., 1999). Desta forma, era esperado uma diminuição da perda de água transepidérmica pelo aumento da quantidade de água na pele devido à presença de polióis em ambas formulações.

FLUHR et al. (1999) descreveram a função do glicerol, um dos componentes da máscara facial, em agir não somente como umectante, mas também como promotor de reorganização do estrato córneo após a indução da escamação da pele por meio de processos físicos ou químicos. Os resultados apontaram para a diminuição da perda de água transepidérmica ocasionada pela reorganização do estrato córneo, cerca de 72 horas após aplicações repetidas de glicerol, seguida de oclusão por meio de filmes de polipropileno, sistema semelhante ao da máscara facial peel off.

BATT et al. (1986) descreveram a diminuição da perda de água transepidérmica utilizando filmes de polietileno sobre a pele, como supressores da perda de água para o ambiente. Efeito semelhante seria observado na máscara facial peel off, ocasionado pela formação do filme de álcool polivinílico após a secagem da preparação. No entanto, pela provável oclusão provocada pela máscara facial peel off (BABY et al., 2004; DeNAVERRE, 1975), era esperada uma diferença significativa entre os efeitos provocados pela máscara facial e pela emulsão. Uma vez que foi observada a diminuição na perda de água transepidérmica para todas as preparações, mas não foi observada uma diferença entre formulações, supõe-se que o efeito de oclusão da máscara não foi capaz provocar diminuição da perda de água transepidérmica de forma significativa, quando comparada a emulsão óleo em água, em um estudo cinético, de curta duração - inferior a 24 horas. 
Da mesma forma, a ausência de diferença significativa da perda de água transepidérmica entre as formulações contendo o extrato de soja para suas respectivas bases cosméticas indicou ausência da ação dos componentes do extrato, associados às preparações em diminuir a perda de água transepidérmica em um estudo cinético de curta duração.

Tabela 31. Comparação entre os tempos de aplicação e avaliação dos produtos para TEWL (perda de água transepidérmica), com os respectivos níveis de significância.

\begin{tabular}{|c|c|}
\hline Tempos & Nível de significância \\
\hline T45 X T90 & 0,003 \\
\hline T45 X T180 & 0,917 \\
\hline T90 X T180 & 0,001 \\
\hline
\end{tabular}

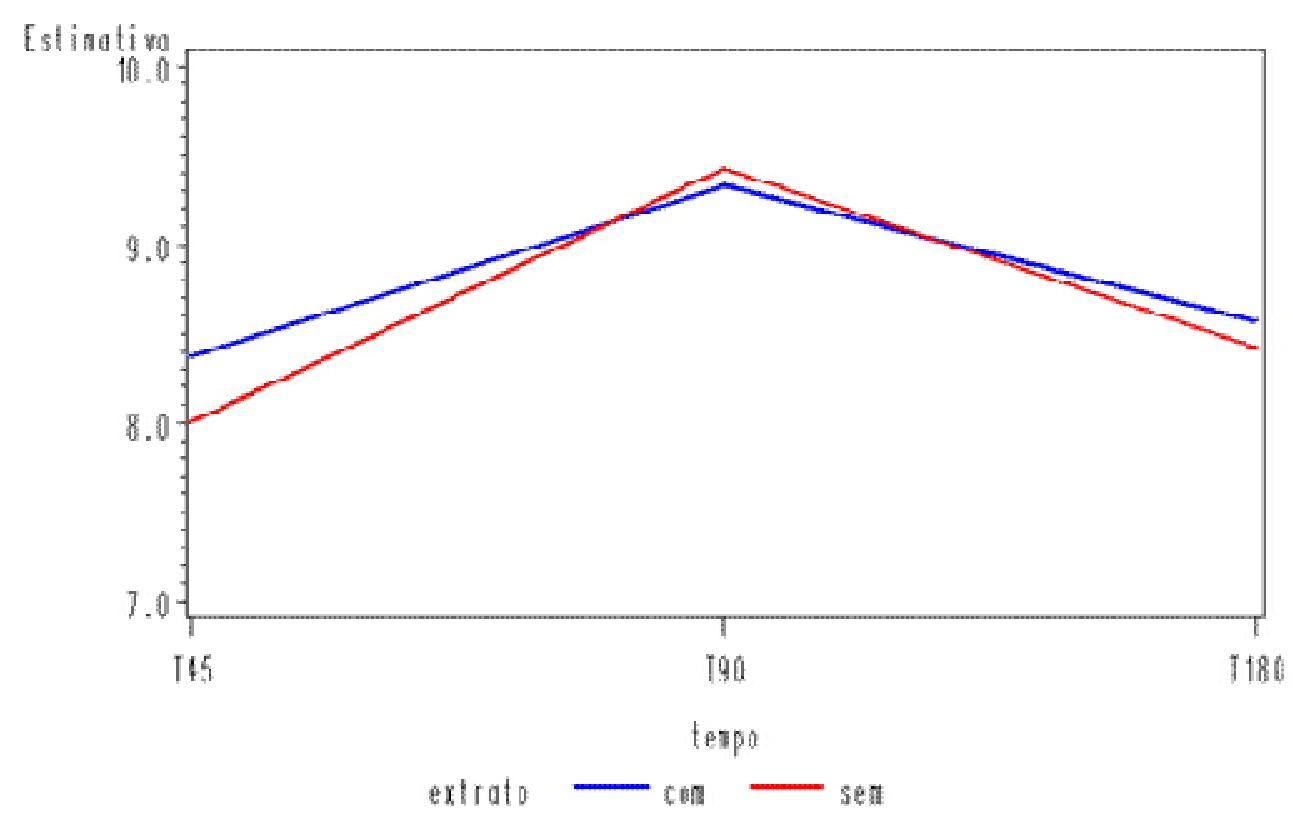

Figura 28. Variação da estimativa - após tratamento estatístico dos dados brutos - do valor de TEWL (perda de água transepidérmica) em relação ao tempo para as formulações de emulsão contendo ou não extrato de soja fermentado por Bifidobacterium animale (com e sem, respectivamente). 


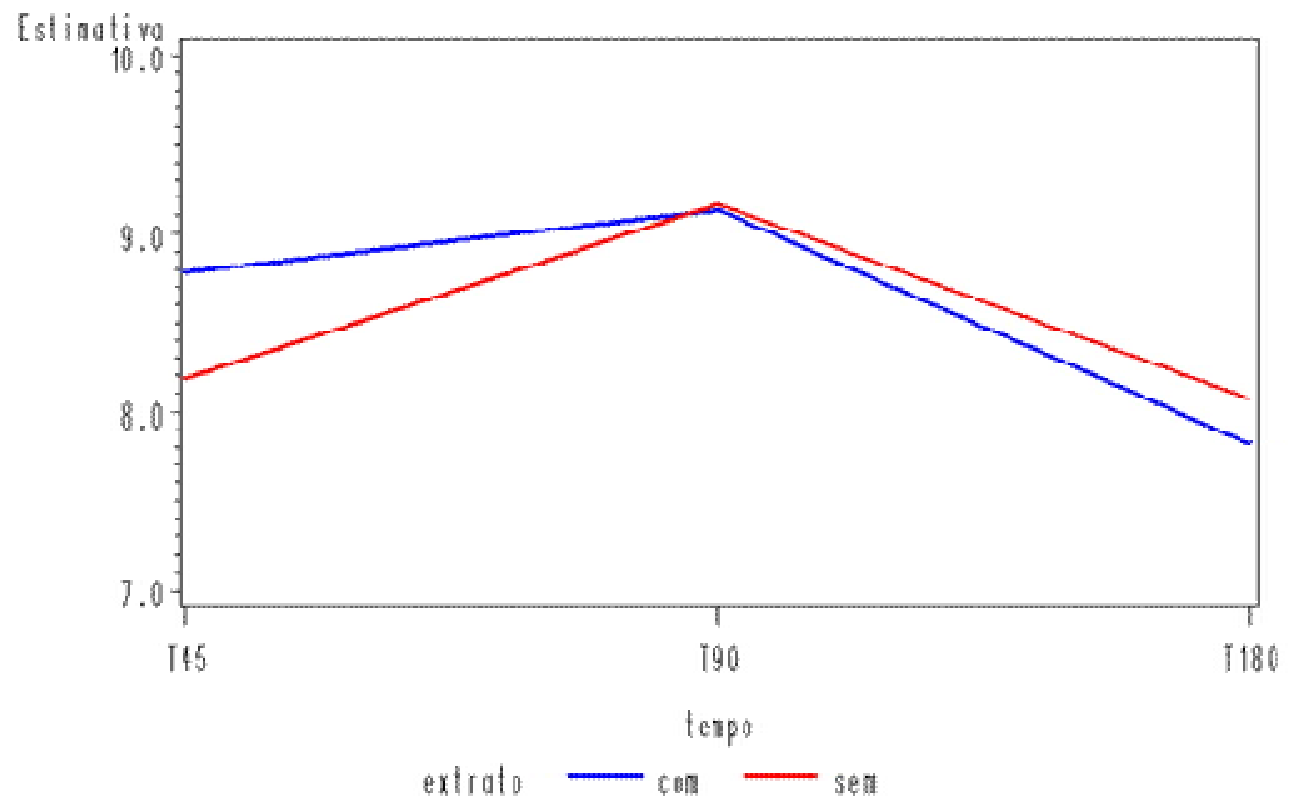

Figura 29. Variação da estimativa - após tratamento estatístico dos dados brutos - do valor de TEWL (perda de água transepidérmica) em relação ao tempo para as formulações de máscara facial contendo ou não extrato de soja fermentado por Bifidobacterium animale (com e sem, respectivamente).

\subsubsection{Efeito do aumento da hidratação das camadas superiores da pele}

O tratamento dos dados estatísticos para CW (hidratação das camadas superiores da pele) está descrito na Tabela 32. 
Tabela 32. Tratamento estatístico obtido dos valores mensurados para CW (hidratação das camadas superiores da pele).

\begin{tabular}{|c|c|c|c|}
\hline Efeito & $\begin{array}{c}\text { Graus de } \\
\text { liberdade }\end{array}$ & Valor F & $\mathbf{P}>\mathbf{F}$ \\
\hline Extrato & $\mathbf{1}$ & $\mathbf{2 , 7 8}$ & $\mathbf{0 , 0 9 7 5}$ \\
\hline Tempo & $\mathbf{2}$ & $\mathbf{5 , 0 4}$ & $\mathbf{0 , 0 0 7 5}$ \\
\hline Interação Extrato / Tempo & $\mathbf{2}$ & $\mathbf{0 , 7 5}$ & $\mathbf{0 , 4 7 4 4}$ \\
\hline Produto & $\mathbf{1}$ & $\mathbf{2 7 , 1 5}$ & $<\mathbf{0 , 0 0 0 1}$ \\
\hline Interação Extrato / Produto & $\mathbf{1}$ & $\mathbf{0 , 2 6}$ & $\mathbf{0 , 6 0 9 9}$ \\
\hline Interação Produto / Tempo & 2 & 1,93 & 0,1477 \\
\hline Interação Extrato/ Produto/ Tempo & $\mathbf{2}$ & $\mathbf{1 , 3 5}$ & $\mathbf{0 , 2 6 2 8}$ \\
\hline
\end{tabular}

Conforme observado na Tabela 32, foram obtidos valores de $\mathbf{P}>\mathbf{F}$ inferior a 0,05 para os Efeitos Tempo e Produto, indicando uma significância ao nível de 5\% (ou a um nível de confiança de 95\%). Foi observado um aumento estatisticamente mais significativo na hidratação das camadas superiores da pele para as formulações de máscara facial que os valores obtidos para as formulações de emulsão, como pode ser visto na Tabela 33 e nas Figuras 30 e 31 . A presença ou ausência do extrato de soja fermentado não foram identificadas como fatores determinantes nas alterações das medidas obtidas pela Corneometria.

Adicionalmente aos efeitos obtidos com o tratamento estatístico, foi realizada a comparação do nível de significância entre os diferentes tempos. Conforme os resultados apresentados na Tabela 33, e observou-se que houve diferença significativa (maior que 95\%) entre os tempos T45 e T90 e entre T45 e T180, demonstradas pelo valores 0,009 e 0,045. O valor sugere, portanto, que o aumento da hidratação das camadas superiores da pele é significativamente maior imediatamente após a aplicação dos produtos (T45), sendo maior para as formulações de máscara facial.

A diferença entre a hidratação promovida pelos produtos, além de evidenciada visualmente pelos gráficos apresentados nas Figuras 30 e 31, pode ser 
verificada de acordo com os dados da Tabela 34, onde as estimativas para as preparações de emulsão são significativamente inferiores às da máscara facial.

Tabela 33. Comparação entre os tempos de aplicação e avaliação dos produtos para $\mathrm{CW}$ (hidratação das camadas superiores da pele), com os respectivos níveis de significância.

\begin{tabular}{|c|c|}
\hline Tempos & Nível de significância \\
\hline T45 X T90 & 0,009 \\
\hline T45 X T180 & 0,045 \\
\hline T90 X T180 & 0,826 \\
\hline
\end{tabular}

Tabela 34. Comparação entre os tempos de aplicação e avaliação dos produtos para $\mathrm{CW}$ (hidratação das camadas superiores da pele).

\begin{tabular}{|c|c|}
\hline Produto & Estimativa \\
\hline Emulsão com Extrato & 37.168 \\
\hline Emulsão sem Extrato & 35.898 \\
\hline Máscara com Extrato & 41.388 \\
\hline Máscara sem Extrato & 43.207 \\
\hline
\end{tabular}

Associado aos resultados obtidos para a mensuração da perda de água transepidérimica, aqueles obtidos com o aumento da hidratação das camadas superiores da pele, empregando o Corneometer $^{\circledR}$, demonstraram que, a curto prazo, a máscara facial peel off provocou o aumento da hidratação da pele pelo efeito oclusivo, sendo o único efeito responsável pelo aumento da concentração de água na epiderme causador da diferença observada, uma vez que o extrato de soja fermentado, presente em ambas formulações, não propiciou este aumento. 


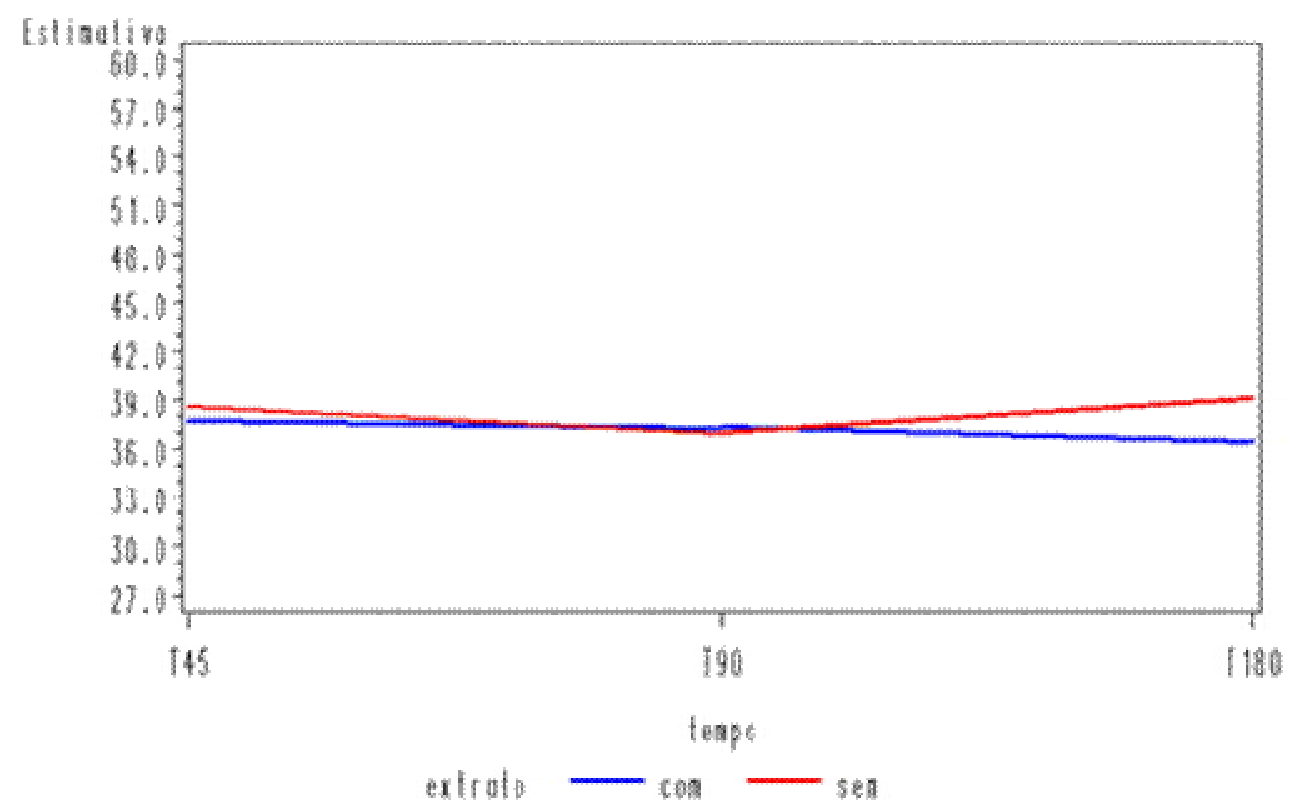

Figura 30. Variação da estimativa - após tratamento estatístico dos dados brutos - do valor de CW (hidratação das camadas superiores da pele) em relação ao tempo para as formulações de emulsão contendo ou não extrato de soja fermentado por Bifidobacterium animale (com e sem, respectivamente).

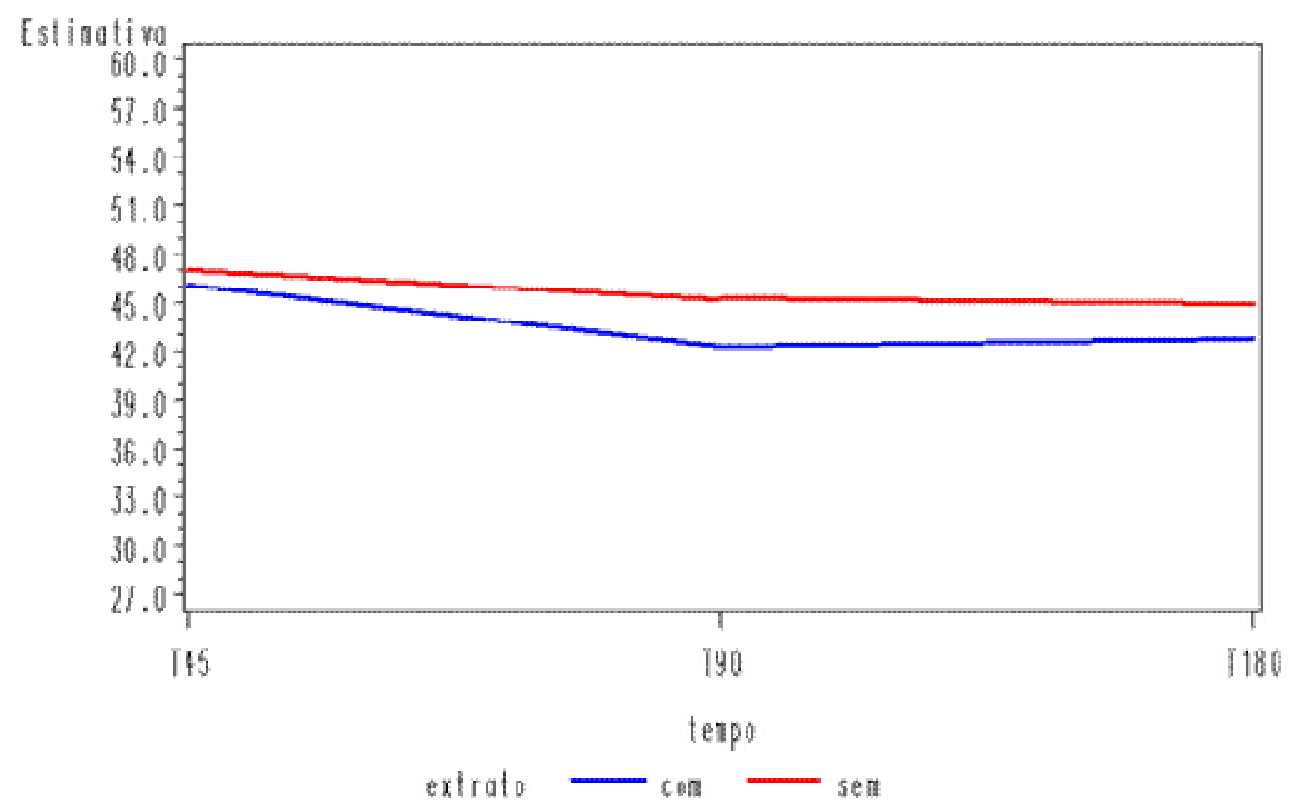

Figura 31. Variação da estimativa - após tratamento estatístico dos dados brutos - do valor de CW (hidratação das camadas superiores da pele) em relação ao tempo para as formulações de máscara facial contendo ou não extrato de soja fermentado por Bifidobacterium animale (com e sem, respectivamente). 
MAIBACH et al. (1998) investigaram a variação de parâmetros como pH da superfície epitelial, perda de água transepidérmica, temperatura e hidratação do estrato córneo. A determinação da perda de água transepidérmica e da hidratação do estrato córneo foram determinados por meio de medidas instrumentas, utilizando o Tewameter $^{\circledR}$ TM 210 e o Coneometer ${ }^{\circledR}$ CM 820, respectivamente. Os resultados indicaram que a perda de água através da pele segue uma variação circadiana, sofrendo variações ao longo do dia. Por outro lado, em um intervalo de 24 horas, não foi verificada variação significativa da hidratação da pele. Tais resultados suportam a observação do aumento significativo de hidratação da pele provocado pelas preparações de máscara facial peel off, em detrimento das formulações de emulsão, ao mesmo tempo que justificaram a ausência de diferença significativa entre os resultados de perda de água transepidérmica das formulações durante um estudo de curta duração.

CAMPOS et al. (2006) avaliaram a capacidade de formulações de bases autoemulsionantes contendo ou não extrato de Aloe vera promoverem o aumento do teor de água nas camadas superficiais da pele, avaliada por medida da corneometria. O estudo demonstrou que houve aumento significativo do teor de água no estrato córneo após estudos de curto e longo-prazo. Este resultado, associado aos resultados de hidratação produzida por oclusão com filmes poliméricos (FLUHR et al., 1999), reforçaram o efeito hidratante promovido pela oclusão das máscaras faciais peel off em relação às formulações de emulsão em estudos a curto prazo, associado à presença de glicerol, um agente umectante.

A presença ou ausência do extrato de soja fermentado nas formulações não provocou um aumento significativo na hidratação da pele, indicando ineficácia dos constituintes do extrato de promover hidratação da pele em um estudo de curta duração.

Devem ser realizados estudos a longo prazo com a finalidade de confirmar as tendências de aumento da elasticidade da pele, firmeza cutânea e perda de água transepidérrmica e para verificar se o efeitos de hidratação das camadas superiores da pele são mantidos em períodos maiores que aqueles avaliados no estudo cinético. Além disso, o estudo a longo prazo teria a finalidade de comprovar se há ação do extrato de soja fermentado por Bifidobacterium animale nas variáveis analisadas em períodos de maior contato do extrato com a pele e/ou maior freqüência de uso, o que não fora observado no estudo cinético. 
Finalmente, em relação à pesquisa realizada neste projeto, são ressaltadas as constatações a seguir sumarizadas, as quais poderão conduzir a novas perspectivas no estudo:

- A formulação F35/17G de máscara facial peel off contendo extrato de soja fermentado por Bifidobacterium animale, caracterizada basicamente por conter $17 \%$ $\mathrm{p} / \mathrm{p}$ de álcool polivinílico e 0,5\% p/p de goma guar e selecionada a partir das 36 bases, apresentou-se estável quanto às suas características organolépticas, valor de $\mathrm{pH}$ e de viscosidade durante os Estudos de Estabilidade Preliminar e Acelerada, sendo selecionada para a realização dos ensaios clínicos.

- Foi desenvolvido e padronizado um novo método para determinação do tempo de secagem in vitro de formulações de máscaras faciais peel off. A formulação F35/17G apresentou desempenho satisfatório, com tempo de secagem igual ou inferior a 30 minutos e superior a 10 minutos, considerado ideal para tais formulações.

- A emulsão contendo ou não extrato de soja fermentado também apresentou resultados satisfatórios durante os Estudos de Estabilidade Preliminar e Acelerada, demonstrando ser uma formulação apta à utilização nos testes clínicos para comparação de seus efeitos aos da máscara facial peel off.

- Os resultados dos testes de firmeza da pele comprovaram que todas as formulações testadas de máscara facial peel off e emulsão apresentaram desempenho satisfatório no aumento da firmeza cutânea, confirmado pelo tratamento estatístico dos dados referentes aos valores de M1, não permitindo inferir um efeito significativo relacionado especificamente à aplicação da máscara ou da emulsão ou à presença/ausência do extrato de soja fermentado no estudo cinético realizado.

- Na determinação da elasticidade da pele, a análise estatística do valor de M2 comprovou que nenhuma das formulações testadas apresentou efeito significativo sobre a elasticidade cutânea. Portanto, a utilização da máscara em detrimento da emulsão, contendo ou não extrato de soja fermentado, não possui vantagens no 
uso, considerando-se os efeitos na elasticidade e firmeza cutânea obtidos no estudo cinético realizado.

- Os resultados dos testes de perda de água transepidérmica comprovaram que todas as formulações testadas apresentaram desempenho similar. Portanto, a utilização da máscara em detrimento da emulsão, contendo ou não extrato de soja fermentado, não possui vantagens no uso, considerando-se os efeitos na perda de água transepidérmica neste estudo cinético.

- Os resultados da avaliação do efeito das formulações na hidratação das camadas superiores da pele comprovaram que a máscara facial é um promotor de hidratação da pele mais eficiente que a emulsão. Esta eficiência não está relacionada ao extrato de soja fermentado, e sim à base, uma vez que os resultados para as formulações contendo ou não o extrato são estatisticamente similares. Portanto, por meio deste estudo, comprovou-se, a curto prazo, que as máscaras faciais exercem aumento na hidratação da pele, provavelmente relacionado ao efeito oclusivo. 
VI CONCLUSÕES 
- Foram desenvolvidas formulações de máscaras faciais peel off e emulsões óleo em água contendo extrato de soja fermentado pelo Bifidobacterium animale, sendo que as de melhor desempenho nos estudos de estabilidade foram submetidas à avaliação instrumental para determinar sua influência no efeito hidratante, tensor e na perda de água transepidérmica das camadas superiores da pele.

- O método de determinação do tempo de secagem in vitro de máscaras faciais peel off permitiu avaliar as formulações de melhor desempenho.

- Os Estudos de Estabilidade Preliminar e Estabilidade Acelerada das bases cosméticas e formulações permitiram, aliados ao método de determinação do tempo de secagem, selecionar a formulação F35/17G de máscara facial como a de melhor desempenho para os ensaios clínicos, assim como a formulação de emulsão desenvolvida.

- Diante dos resultados da avaliação do efeito hidratante, tensor e na perda de água transepidérmica das bases de máscara facial peel off e emulsão óleo em água sem adição do extrato de soja fermentado e adicionado deste componente ativo, comprova-se que a máscara facial peel-off desenvolvida e testada é um promotor de hidratação mais eficiente que a formulação de emulsão. 
VII REFERÊNCIAS BIBLIOGRÁFICAS 
ÁBACO VITAL. Matérias Primas. Materias Grasas. Emolientes. Decyl Oleate. Disponível em: http://www.abacovital.com/fichastecnicas/grasas/emolientes/decyloleate.htm. Acesso em: 20 out. 2007.

ABOISSA: ÓlEOS VEGETAIS. Palmitato de isopropila. Disponível em: http://www.aboissa.com.br/informativos/espec/hcc/palmitatoisopropila.htm. Acesso em: 23 nov. 2007.

AGÊNCIA NACIONAL DE VIGILÂNCIA SANITÁRIA. Guia de estabilidade de produtos cosméticos. Brasília: Ministério da Saúde, 2004. v.1, 45p. (Séries Temáticas: Cosméticos) (Série Qualidade, 1). Disponível em: http://www.anvisa.gov.br/divulga/public/series/cosmeticos.pdf. Acesso em: 13 mar. 2006.

AGÊNCIA NACIONAL DE VIGILÂNCIA SANITÁRIA. Legislação. VisaLegis. Resolução n.196, de 10 de outubro de 1996. Estabelece os requisitos para realização de pesquisa clínica de produtos para saúde utilizando seres humanos. Disponível em: http://elegis.anvisa.gov.br/leisref/public/showAct.php?id=663\&word=. Acesso em: 20 dez. 2007.

AGÊNCIA NACIONAL DE VIGILÂNCIA SANITÁRIA. Legislação. VisaLegis. Resolução n.162, de 11 de Setembro de 2001. A Agência Nacional de Vigilância Sanitária estabelece a lista de substâncias de ação conservante para produtos de higiene pessoal, cosméticos e perfumes. Disponível em: http://elegis.anvisa.gov.br/leisref/public/showAct.php?id=265\&word=. Acesso em: 20 fev. 2008.

NOTA: as referências bibliográficas estão de acordo com a norma NBR 6023/2002 preconizada pela Associação Brasileira de Normas Técnicas (ABNT). 
AGÊNCIA NACIONAL DE VIGILÂNCIA SANITÁRIA. Legislação. VisaLegis.

Resolução n.79, de 28 de Agosto de 2000. A Agência Nacional de Vigilância Sanitária estabelece a definição e classificação de produtos de higiene pessoal, cosméticos e perfumes e outros, aprova normas de rotulagem de produtos, atualiza lista de conservantes, corantes, filtros UV permitidos e lista restritiva e lista de substâncias de uso proibido. Disponível em: http://elegis.anvisa.gov.br/leisref/public/showAct.php?id=18300\&word=. Acesso em: 20 fev. 2008.

ANSEL, H.C.; POPOVICH, N.G.; ALLEN Jr., L.V. Farmacotécnica: formas farmacêuticas e sistemas de liberação de fármacos. São Paulo: Premier, 2000. p.304-307.

ARANHA, I.; LUCAS, E. Poli (álcool vinílico) modificado com cadeias hidrocarbônicas: avaliação do balanço hidrófilo/lipófilo. Polímeros: Ciência e Tecnologia, v.11, n.4, p.174-181, 2001.

AUBIN, G. Experimentação biológica dos produtos cosméticos. In: PRUNIÉRAS, M., dir. Manual de cosmetologia dermatológica. 2.ed. São Paulo: Organização Andrei, 1994. p.233-243, 238-303.

BABY, A.R. Desenvolvimento e avaliação da estabilidade de formulações cosméticas anticelulíticas contendo o extrato comercial de Trichilia catigua Adr. Juss (e) Ptychopetalum olacoides Bentham, padronizado em flavonóides totais. São Paulo, 2005. 159p. Dissertação de Mestrado Faculdade de Ciências Farmacêuticas - Universidade de São Paulo.

BABY, A.R.; MIGLIATO, K.F.; MACIEL, C.P. M.; ZAGUE, V.; PINTO, C.A.S.O.; SALGADO, H. R. N.; KANEKO, T. M.; VELASCO, M. V. R. Accelerated chemical stability data of $\mathrm{O} / \mathrm{W}$ fluid emulsions containig the extract of Trichilia catigua Adr. Juss. (and) Ptychopetalum olacoides Bentham. Revista Brasileira de Ciências Farmacêuticas, v.43, n.3, p.405-412, 2007. 
BABY, A.R.; ZAGUE, V.; MACIEL, C.P.M.; KANEKO, T.M.; CONSIGLIERI, V.O.; VELASCO, M.V.R. Development of cosmetic mask formulations. Revista Brasileira de Ciências Farmacêuticas, v.40, n.1, p.159-161, 2004.

BARBA, C.; MÉNDEZ, S.; RODDICK-LANZILOTTA, A.; KELLY, R.; PARRA, J.L.; CODERCH, L.; Cosmetic effectiveness of topically applied hydrolised keratin peptides and lipids derived from wool. Skin Research and Technology, v.14, n.2, p.243-248, 2008.

BAREL, A.O.; CLARYS, P. Measurement of epidermal capacitance. In: SERUP, J.; JEMEC, B.E., eds. Handbook of non-invasive methods and the skin. Boca Raton, London: CRC Press, 1995. p.165-170.

BAREL, A.O.; PAYE, M.; MAIBACH, H.I., eds. Handbook of cosmetic science and technology. New York: Marcel Dekker, 2001. p.19-27.

BATT, M.D.; FAIRHURST, E. Hydration of the stratum corneum. International Journal of Cosmetic Science, v.8, n.6, p.253-264, 1986.

BAUMANN, L.S.; LAZARUS, M.C. The use of cosmeceuticals moisturizers. Dermatologic Therapy, v.14, n.3, p.200-207, 2001.

BERARDESCA, E.; ELSNER, P.; WILHELM, K.P.; MAIBACH, H.I., eds. Bioengineering of the skin: methods and instrumentation. Boca Raton: CRC Press, 1995. 141p. (CRC Series in Dermatology).

BETTINGER, J.; GLOOR, M.; VOLLERT, A.; KLEESZ, P.; FLUHR, J.; GEHRING, W. Comparison of different non-invasive test methods with respect to the different moisturizers on skin. Skin Research and Technology, v.5, n.1, p.21-27, 1999.

BONADEO, I. Cosmética: ciência y tecnologia. Madri: Editorial Ciência, 1982. p.8689. 
BRANDÃO, L. Índex ABC: Ingredientes para a indústria de produtos de higiene pessoal, cosméticos e perfumes. 2.ed. São Paulo: Associação Brasileira de Cosmetologia, 2000. 1071p.

BRASIL. Ministério Público Federal. Procuradoria Geral da República. Secretarias. Serviços Integrados à Saúde. Secretaria de Serviços Integrados à Saúde. Informações de Saúde. Atlas do Corpo Humano. Os sentidos: tato. Disponível em: http://www.pgr.mpf.gov.br/pgr/saude/sa/tato.htm. Acesso em: 5 jan. 2008.

BRINKMANN, I.; MULLER-GOYMANN, C.C. An attempt to clarify the influence of glycerol, propylene glycol, isopropyl myristate an a combination of propylene glycol and isopropyle myristate on human stratum corneum. Pharmazie, v.60, n.3, p.215-220, 2005.

CAMPOS, P.M.B.G.M.; DAL' BELO, S.E.; GASPAR, L.R. Moisturizing effect of cosmetic formulations containing Aloe vera extract in different concentrations assessed by skin bioengineering techniques. Skin Research and Technology, v. 12, n.4, p. 241-246, 2006.

CHARLET, E. Cosmética para farmacêuticos: ciência y tecnologia. Zaragoza: Acribia, 1996. p.86-88.

CHEMYUNION. Matérias-Primas: Cosmética. Excipientes. Agentes de Consistência: Uniox C. Disponível em: http://www.chemyunion.com.br/site/html/produtos/produto.aspx?Pais=17\&Lang=1 $\& \mathrm{M}=$ Produtos $\& \mathrm{D}=1500 \& \mathrm{~F}=10 \& \mathrm{~S}=5000 \&$ Prod $=4948$. Acesso em: 20 out. 2007.

CHEMYUNION. Matérias-Primas: Cosmética. Excipientes. Agentes de Consistência: Lactato de Miristila. Disponível em: http://www.chemyunion.com.br/site/html/produtos/produto.aspx?Pais=17\&Lang=1 $\& M=$ Produtos $\& D=1500 \& F=10 \& S=5026 \& P r o d=4931$. Acesso em: 20 out. 2007. 
CHIELLINI, E.; CORTI, A.; D'ANTONE, S.; SOLARO, R. Biodegradation of poly (vinyl alcohol) based materials. Progress in Polymer Science, v.28, n.6, p.963-1014, 2003.

CHIEN, H.L.; HUANG, H.Y.; CHOU, C.C. Transformation of isoflavone phytoestrogens during the fermentation of soymilk with lactic acid bacteria and bifidobacteria. Food Microbiology, v.23, n.8, p.772-778, 2006.

CLARIANT. Ficha técnica de produto. Disponível em: http://fun.clariant.com/fun/internet.nsf/. Acesso em: 20 fev. 2006.

CLARIANT. Ficha técnica de produto. Disponível em: http://fun.clariant.com/C125691A003596E5/vwLookupDownloads/Taking care of your Sensory Innovations Aristoflex 2005.pdf/\$FILE/Taking care of your Se nsory Innovations Aristoflex 2005.pdf. Acesso em: 08 set. 2007.

COHEN, S.; MARCUS, Y.; MIGRON, Y.; DIKSTEIN, S.; SHAFRAN, A. Waer sorption, binding and solubility of polyols. Journal of the Chemical Society, v.89, p.3271-3275, 1993.

COLIPA - THE EUROPEAN COSMETIC TOILETRY AND PERFUMARY ASSOCIATION. Estrutura de Formulações Cosméticas Disponível em: http://www.colipa.com/site/index.cfm?SID=15588\&OBJ=28453\&back=1. Acesso em: 20 fev. 2008.

CONTRERAS, M.J.F.; SORIANO, M.M.J.; FLORES, E.S. Development of a cream from a self-emulsifying base and moisturizing actives. Farmaco, v.56, n.5/7, p.513-522, 2001.

COUTEAU, C.; COIFFARD, L.J.M.; SEBILLE-RIVAIN, V. Influence of excipients on moisturizing effect of urea. Drug Development and Industrial Pharmacy, v.32, n.2, p.239-242, 2006. 
CRODA. Ficha técnica de produtos. Disponível em: http://www.croda.com.br/. Acesso em: 20 fev. 2006.

CRODA. Ficha técnica de produtos. Disponível em: http://www.croda.com.br/. Acesso em: 22 out. 2007.

CUA, A.B.; WILHELM, K.P.; MAIBACH, H.I. Elastic properties of human skin: relation to age, sex and anatomical region. Archives of Dermatological Research, v.282, n.5, p.283-288, 1990.

DAVIS, H.M. Analysis of creams and lotions. In: NEWBURGER, S.H.; SENZEL, A.J. Manual of cosmetic analysis. 2.ed. Washington: Association of Official Analytical Chemists, 1977. p.32.

DeNAVERRE, M.G. Face masks. In: The chemistry and manufacture of cosmetics. 2.ed. Orlando: Continental Press, 1975. v.3, p.421-441.

DOW CORNING. Ficha técnica do silicone de copolímero glicol. Disponível em: http://www.dowcorning.com/applications/search/default.aspx?R=5502EN. Acesso em: 20 fev. 2006.

DOW CORNING. Products: Product Finder. 5225C. Dow Corning ${ }^{\circledR}$ 5225C Formulation AID. Disponível em: http://www.dowcorning.com/applications/search/default.aspx?R=1145EN\&DCCS F=291EN. Acesso em: 20 out. 2007.

DRAELOS, Z.D. Cosméticos em dermatologia. Rio de Janeiro: Revinter, 1999. p.224-226.

EMBRAPA SOJA. Soja na alimentação. Disponível em: http://www.cnpso.embrapa.br/soja alimentacao/index.php?pagina=23\#5. Acesso em: 12 dez. 2007. 
FAZENDA, J.M.R. Tintas e vernizes: ciência e tecnologia. 2.ed. São Paulo: ABRAFATI, 1993. v.1, p.665.

FITZPATRICK, T.B.; PATHAR, M.; PARRISH, J.A. Protection of human skin against the effects of the sunburn ultraviolet (290-320 nm). In: FITZPATRICK, T.B., ed. Sunlight and man, normal and abnormal photobiological responses. Tokyo: Etials, 1974.p.751-765.

FLUHR, J.W.; AKENGIN, A.; BORNKESSEL, A.; FUCHS, S.; PRAESSLER, J.; NORGAUER, J.; GRIESHABER, R.; KLEESZ, P.; ELSNER, P. Additive impairment or the barrier function by mechanical irritation, occlusion and sodium lauryl sulphate in vivo. British Journal of Dermatology, v.153, n.1, p.125-131, 2005.

FLUHR, J.W.; GLOOR, M.; LEHMANN, L.; LAZZERINI, S.; DISTANTE, F.; BERARDESCA, E. Glycerol accelerates recovery of barrier function in vivo. Acta Demato-Venereologica, v.79, n.6, p.418-421, 1999.

GARTNER, L.P.; HIATT, J.L. Tegumento. In: Tratado de histologia em cores. Rio de Janeiro: Guanabara Koogan, 1999. p.253-266.

GENOVESE, M.I.; LAJOLO, F.M.; BARBOSA, A.C.L. Influence of temperature, pH and ionic strength on the production of isoflavone rich-soy protein isolates. Food Chemistry, v.98, n.4, p.757-766, 2006.

HADGRAFT, J. Skin, the final frontier. International Journal of Pharmaceutics, v.224, n.1/2, p.1-18, 2001.

IPIRANGA. Ipiranga Química. Química Humana. Ficha técnica do álcool polivinílico 224. Disponível em: http://www.ipirangaquimica.com.br/icq2008/arquivos.php?tem=sim\&nitem=64320 005\&chave=FISPQ Acesso em: 20 fev. 2006. 
JUNQUEIRA, L.C.U.; CARNEIRO, J. Histologia básica: texto e atlas. 10.ed. Rio de Janeiro: Guanabara Koogan, 2004. p.359-370.

KUMAR, T.M.P.; UMESH, H.M.; SHIVAKUMAR, H.G.; RAVI, V.; SIDDARAMAIAH. Feasibility of polyvinyl alcohol as a transdermal drug delivery system for terbutaline sulphate. Journal of Macromolecular Science, Part A: Pure and Applied Chemistry, v.44, n.6, p.583-589, 2007.

LCW. Ficha técnica de produtos. Disponível em: www.lcwbrasil.com.br. Acesso em: 20 fev. 2006.

LIU, J., HOFFMANN, H.; Hydrogels in aqueous phases of polyvinylalcohol (PVA), surfactans and clay minerals. Colloid and Polymer Science, v.283, v.1, p.24-32, 2004.

LONZA. Ficha técnica de produtos. Disponível em: http://www.lonza.com.br/pdf/GlydantPlusLiquid.pdf. Acesso em: 10 abr. 2006.

LUPO, M.P. Antioxidants and vitamins in cosmetics. Clinics in Dermatology, v.19, n. 4, p.467-473, 2001.

LYOO, W.S.; SEO, S.I.; YEUM, J.H.; YOON, W.S.; JI, B.C.; KIM, B.S.; LEE, S.S.; $\mathrm{KIM}$, B.C. Effect of degree of saponificationon the rheological properties of syndiotactic Poly (vinyl alcohol)/ water solution. Journal of Applied Polymer Science, v.86, n.2, p.463-467, 2002.

MAIA, A. M.; BABY, A. R.; PINTO, C. A. S. O.; YASAKA, W. J.; SUENAGA, T. M.; KANEKO, T. M., VELASCO, M. V. R. Influence of sodium metabisulfite and glutathione on the syability of vitamin $\mathrm{C}$ in $\mathrm{O} / \mathrm{W}$ emulsion and extemporaneous aqueous gel. International Journal of Pharmaceutics, v.322, n.2, p.130-135, 2006. 
MAIA, A.M. Desenvolvimento e avaliação da estabilidade de formulações cosméticas contendo ácido ascórbico. São Paulo, 2002. 117p. Dissertação de Mestrado - Faculdade de Ciências Farmacêuticas - Universidade de São Paulo.

MAGALHÃES, J. Cosmetologia. Rio de Janeiro: Rubio, 2000. p.82-159.

MAJMUDAR, G.; SMITH, M. Técnicas de screening in vitro em dermatologia. Cosmetics \& Toiletries, Ed. Português, v.10, n.3, p.44-49, 1998.

MARTINDALE: the extra pharmacopoeia. London: The Pharmaceutical Press, 1989. p.1247.

MARTINE, M.C.; CHIVOT, M.; PEYREFITTE, G. Cosmetología. Barcelona: Masson, 1995. p.81-85.

MERCK index. 12.ed. Whitehouse Station, 1996. p. 4600.

MORETTIN, P.A.; BUSSAB, W.O. Estatística básica. 5.ed. São Paulo: Saraiva, 2005. p.190-191.

MÜLLER, R. H.; WISSING, S. A. The influence of solid nanoparticles on skin hydration and viscoelasticity - an in vivo study. European Journal of Pharmaceutics and Biopharmaceutics, v.56, n.1, p.67-72, 2003.

MIYAZAKI, K.; HANAMIZU, T.; LIZUKA, R.; CHIBA, K. Genistein and daidzein stimulate hyaluronic acid production in transformed human keratinocyte culture and hairless mouse skin. Skin Pharmacology and Applied Skin Physiology, v.15, n.3, p.175-183, 2002.

NOKHODCHI, A.; JELVEHGARI, M.; SIAHI-SHADBAD, M.R.; AZARMI, S.; MARTIN, G.P. The microsponge delivery system of benzoyl peroxide: preparation, characterization and release studies. International Journal of Pharmaceutics, v.308, n.1/2, p.124-132, 2006. 
$\mathrm{OH}$, C.H.; YOON, H.S.; BAIK, S.H. Quantitative measurement of desquamation and skin elasticity in diabetic patients. Skin Research and Technology, v.8, n.4, p.250-254, 2002.

OISO, N.; FUKAI, K.; ISHII, M. Allergic contact dermatitis from iodine in a topical ointment. Contact Dermatitis, v.54, n.6, p.347-348, 2006.

ORIENTI, I.; Di PIETRA, A.; LUPPI, B.; ZECCHI, V. Crosslinked polyvinylalcohol hydrogels as vehicles for hydrophilic drugs. Archiv der Pharmazie, v.333, n.12, p.421-424, 2000.

OTIENO, D.O.; ASHTON, J.F.; SHAH, N.P. Evaluation of enzymic potential for biotransformation of isoflavone phytoestrogen in soymilk by Bifidobacterium animalis, Lactobacillus acidophilus and Lactobacillus casei. Food Research International, v.39, n.4, p.394-407, 2006.

PARIS. CLUB DES CRATEURS DE BEAUTÉ. Figura de máscara facial Disponível em:

http://www.ccbparis.fr/ fr/ fr/skincare/index prod.aspx?prdcode=P10652\&CatCo de=G0 01\%5EG1 $01 \quad 50 \% 5 E G 2 \quad 01 \quad 50 \quad 50$. Acesso em: 05 jan. 2008.

PEYREFITTE, G.; MARTINE, M.C.; CHIVOT, M. Estética-cosmética: cosmetologia, biologia geral, biologia da pele. São Paulo: Organização Andrei, 1998. 507p.

PINTO, C.A.S.O. Estudo comparativo da estabilidade de formulações cosméticas contendo papaína livre e modificada. São Paulo, 2005. 128p. Dissertação de Mestrado - Faculdade de Ciências Farmacêuticas - Universidade de São Paulo.

PONGSAWATMANIT, R.; SRIJUNTHONGSIRI, S. Influence of xanthan gum on rheological properties and freeze-thaw stability of tapioca starch. Journal of Food Engineering. v.88, n.1, p.137-143, 2008. 
POUCHER, W.A.; JOUHAR, A.J. Poucher's perfumes, cosmetics and soaps. 9.ed. London, New York: Chapman and Hall, 1991. 751 p.

PRISTA, L.N.; ALVES, A.C.; MORGADO, R.M.R. Técnica farmacêutica e farmácia galénica. Porto: Fundação Calouste Gulbenkian, 1992. p.998-1001.

PRAKASH, D.; UPADHYAY, G.; SINGH, B.N.; SINGH, H.B. Antioxidant and free radical-scavenging activities of seeds and agri-wastes of some varieties of soybean (Glycine max). Food Chemistry, v.104, n.2, p.783-790, 2007.

RAWLINGS, A.V.; HARDING, C.R. Moisturization and skin barrier function. Dermatologic Therapy, v.17, suppl.1, p.43-48, 2004.

SAGIV, A.; MARCUS, Y. The connection between in vitro water up-take and in vivo skin moisturization. Skin Research and Technology, v.9, n.4, p.306-311, 2003.

SAS - BUSINESS INTELLIGENCE SOFTWARE AND PREDICTIVE ANALYTICS. Descrição do SAS/STAT ${ }^{\circledR}$ Disponível em: http://www.sas.com/technologies/analytics/statistics/stat/index.html. Acesso em: 20 mar. 2008.

SCOTTI, L.; VELASCO, M.V.R. Envelhecimento cutâneo à luz da cosmetologia: estudo do envelhecimento cutâneo e da eficácia das substâncias ativas empregadas na prevenção. São Paulo: Tecnopress, 2003. 115p.

SERUP, J.; O'GOSHI, K. Inter-instrumental variation of skin capacitance measured with the Corneometer ${ }^{\circledast}$. Skin Research and Technology, v.11, n.2, p.107-109, 2005.

SHAH, V.P.; MAIBACH, H.I., eds. Topical drug bioavailability, bioequivalence and penetration. New York, London: Plenum Press, 1993. 453p. 
SHIMIZU, H.; TOMITA, Y.; AKAYAMA, M. Stratum corneum hydration and flexibility are useful parameters to indicate clinical severity of congenital ichthyosis. Experimental Dermatology, v.14, n.8, p.619-624, 2005.

SOUZA, M.S.M. Análise moderna de cosméticos comprova eficácia. Química \& Derivados, v.379, p.42-51, 2000.

SPECIAL CHEM: INNOVATIONS \& SOLUTIONS IN COSMETICS. Ficha técnica de produto. Disponível em: http://www.specialchem4cosmetics.com/common/cos/services/ingredients/display product.aspx?or=docindex\&menu=true\&id=2081. Acesso em: 20 dez. 2007.

STATISTIKA. Relatório de análise de resultados: avaliação objetiva dos efeitos na elasticidade/firmeza, na barreira cutânea e na hidratação da pele de quatro produtos cosméticos em comparação sob condições normais de uso. Campinas: Statistika Consultoria, 2007. 14p.

SUPHANTHARIKA, M.; CHAISAWANG, M. Effects of guar gum and xantham gum additions on physical and rheological of cationic tapioca starch. Carbohydrate Polymers. v.61, n.3, p.288-295, 2005.

TOMINAGA, K.; NISHIOKA, K.; SEGUCHI, T.; YASUNO, H.; YAMAMOTO, T. The results of ingredient patch testing in contact dermatitis elicited by povidone-iodine preparations. Contact Dermatitis v.42, n.2, p.90-94, 2000.

TRAVERSA, E. Desenvolvimento de formulações cosméticas contendo papaína e avaliação da sua eficácia depilatória sobre o folículo piloso. São Paulo, 2003. 160p. Dissertação de Mestrado - Faculdade de Ciências Farmacêuticas Universidade de São Paulo.

UNIVERSIDADE DE SÃO PAULO. Faculdade de Odontologia de Ribeirão Preto. Camadas da epiderme. Disponível em: http://www.forp.usp.br/mef/embriologia/Fotos/anexos/fig01.jpg. Acesso em: 5 dez. 2007. 
YOSIPOVITCH, G.; XIONG, G.L.; HAUS, E.; SACKETT-LUNDEEN,L.; ASHKENAZI, I.; MAIBACH, H. Time-dependent variations of the skin barrier function in humans: transepidermal water loss, stratum corneum hydration, skin surface $\mathrm{pH}$, and skin temperature. Journal of Investigative Dermatology v.110, n.1, p.2024, 1998.

WEI, H. Photoprotective action of isoflavone genistein: models, mechanims, and relevance to clinical dermatology. Journal of American Academy of Dermatology, v.39, n.2, p.271-272, 1998.

WEINBERG, J. M.; TAYLOR, S. C,; SPANN, C. T.; Topical antimicrobial agents in dermatology. Clinics in Dermatology. v.21, n.1, p.70-77, 2003.

WILKINSON, J.B.; MOORE, R.J. Face packs and masks. In: WILKINSON, J.B., MOORE, R.J. Harry's cosmetology. 7.ed. London: Longman Group, 1982. p.276-284.

YAKULT COSMETICS. Extrato de soja fermentado. São Paulo, 2007. 1p. [Catálogo].

ZAGUE, V. Desenvolvimento e avaliação da estabilidade física e físico-química de máscaras faciais argilosas. São Paulo, 2007. 160p. Dissertação de Mestrado - Faculdade de Ciências Farmacêuticas - Universidade de São Paulo. 


\section{ANEXOS}

